\title{
Development and verification of a laboratory for the emissions testing of locomotive engines
}

\author{
Michael R. Shahan \\ West Virginia University
}

Follow this and additional works at: https://researchrepository.wvu.edu/etd

\section{Recommended Citation}

Shahan, Michael R., "Development and verification of a laboratory for the emissions testing of locomotive engines" (2008). Graduate Theses, Dissertations, and Problem Reports. 1988.

https://researchrepository.wvu.edu/etd/1988

This Thesis is protected by copyright and/or related rights. It has been brought to you by the The Research Repository @ WVU with permission from the rights-holder(s). You are free to use this Thesis in any way that is permitted by the copyright and related rights legislation that applies to your use. For other uses you must obtain permission from the rights-holder(s) directly, unless additional rights are indicated by a Creative Commons license in the record and/ or on the work itself. This Thesis has been accepted for inclusion in WVU Graduate Theses, Dissertations, and Problem Reports collection by an authorized administrator of The Research Repository @ WVU. For more information, please contact researchrepository@mail.wvu.edu. 


\title{
Development and Verification of a Laboratory for the Emissions Testing of Locomotive Engines
}

\author{
Michael R. Shahan
}

\author{
Thesis submitted to the \\ College of Engineering and Mineral Resources \\ At West Virginia University \\ In partial fulfillment of the requirements \\ for the degree of \\ Master of Science \\ in \\ Mechanical Engineering \\ W. Scott Wayne, Ph.D., Chair \\ Nigel Clark, Ph.D. \\ Benjamin Shade, Ph.D.
}

Department of Mechanical and Aerospace Engineering

Morgantown, West Virginia

2008

Keywords: In-use emissions, Locomotive engines, Emissions measurement techniques 


\section{Abstract \\ Development and Verification of a Laboratory for the Emissions Testing of Locomotive Engines}

\section{Michael R. Shahan}

West Virginia University (WVU) currently has a Transportable Emissions Laboratory capable of measuring the exhaust constituents produced by a heavy duty diesel engine. The laboratory has the capability of measuring the exhaust constituents from a partial exhaust stream of a locomotive diesel engine. As the field of locomotive engine emissions testing broadens, it has become desirable for WVU to develop a laboratory that is capable of sampling the gaseous exhaust constituents produced by a locomotive engine from a raw, undiluted gas stream, in tandem with a partial flow dilution tunnel system for particulate matter. This document provides the design philosophy behind such a laboratory, as well as laboratory studies to verify the proper functionality of such system. Results from the study include the comparison of gaseous emissions between WVU's Engines and Emissions Laboratory (EERL) full exhaust dilution tunnel system resulting in laboratory percentage differences of $3.4 \%, 3.57 \%, 0.33 \%$, and $2.93 \%$ for hydrocarbons, oxides of nitrogen, carbon dioxide, and carbon monoxide, respectively. The partial flow dilution tunnel system was tested on a locomotive engine. The results from that study produced an overall system percentage difference of $4.8 \%$ for the line-haul mode of the first engine, $5.69 \%$ and $8.2 \%$ for the line-haul and switch mode, respectively for the second engine. 


\section{ACKNOWLEDGEMENTS}

I am grateful to have been given the opportunity to further my education, while simultaneously gaining work experience in a professional laboratory setting. I feel that this experience broadened my engineering skills and gave me memories that will last a lifetime. Coming into all of this, my knowledge of engines and emissions was quite limited. Several courses I was involved with, as well as work experience, greatly expanded my knowledge and perception of the functionality of the internal combustion engine.

First I would like to thank Dr. Scott Wayne for giving me the chance to pursue an advanced degree in engineering. Without your continuing help and support this feat and accomplishment would not have been possible. Second, I would like to thank Dr. Nigel Clark and Dr. Ben Shade for accepting the committee member position. Dr. Clark, I respect you greatly for your knowledge of engines and really enjoyed your I.C. engines course. I look forward to gaining experience from your insights. I would also like to thank Dr. Andrew Nix for his help with the locomotive testing and PM verification. Dr. Nix provided a great amount of support for this project. I wish him the best of luck for the emissions testing programs that he will be involved with in the future.

Last but not least I would like to thank the following people:

Brad Ralston, Dan Carder, Yuebin Wu, Chris Rowe, Jason England, all the students and employees I have encountered throughout the Engines and Emissions Research Center. Most importantly I would like to thank my family for motivating me to finish my degrees. 


\section{Table of Contents}

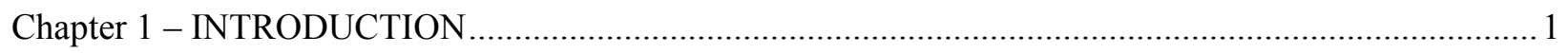

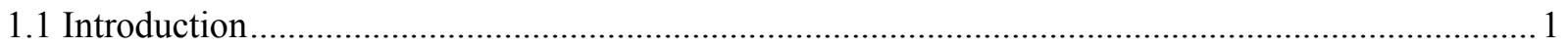

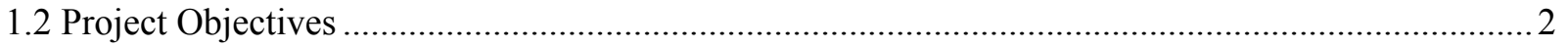

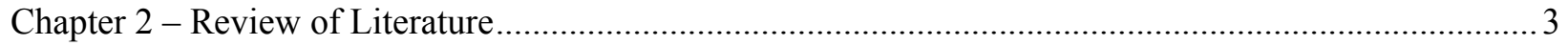

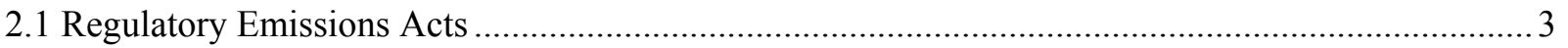

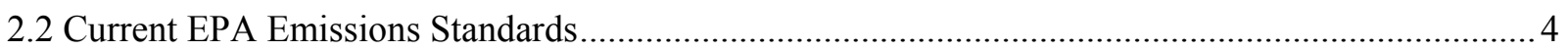

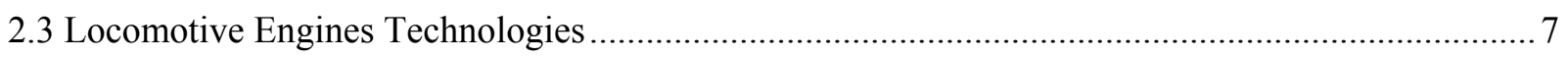

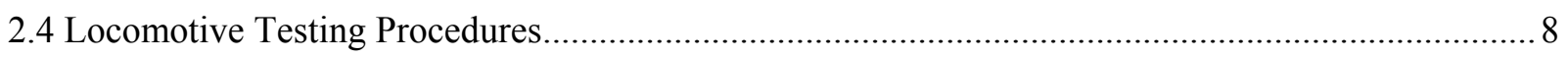

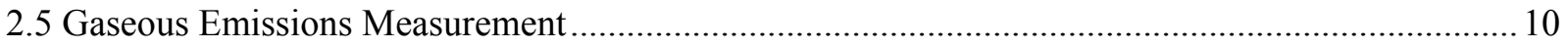

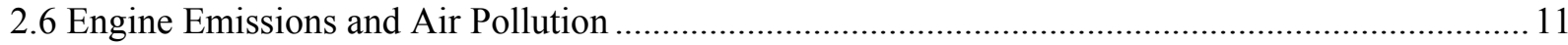

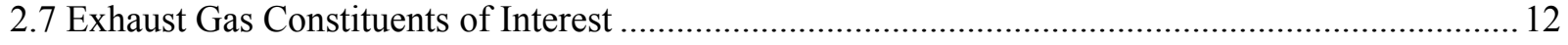

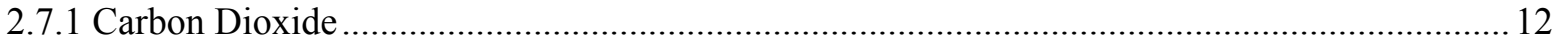

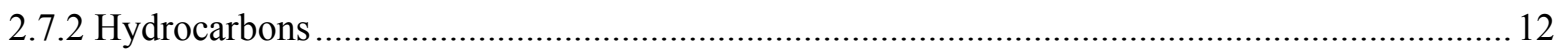

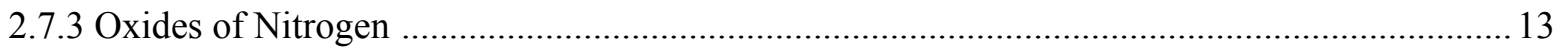

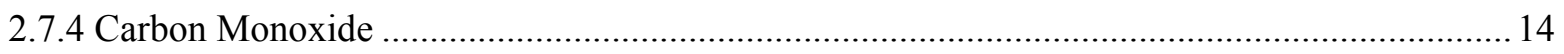

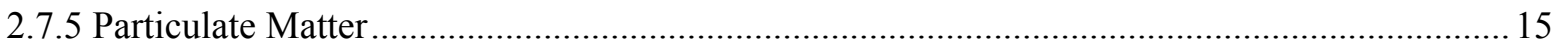

2.8 Exhaust Constituents Measurement Techniques........................................................................... 15

2.8.1 Carbon Monoxide/ Carbon Dioxide Measurement ................................................................... 16

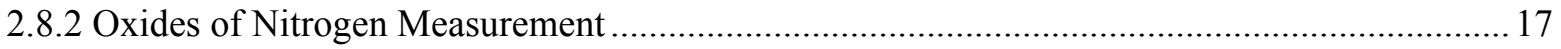

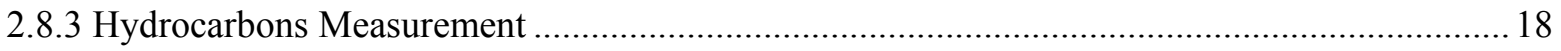

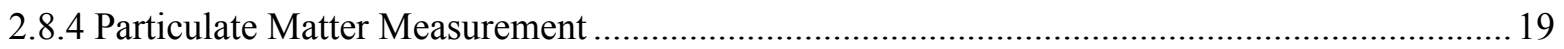

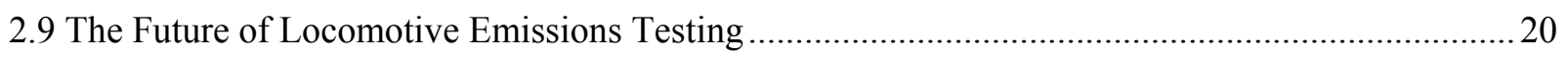

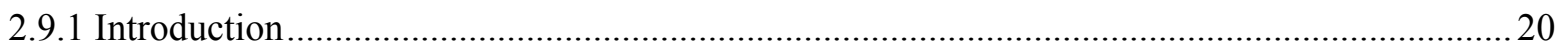

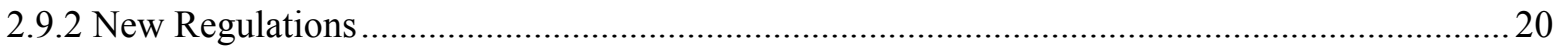

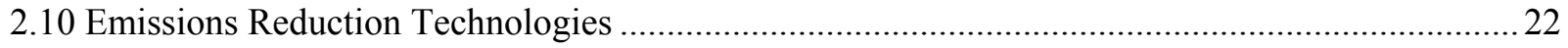

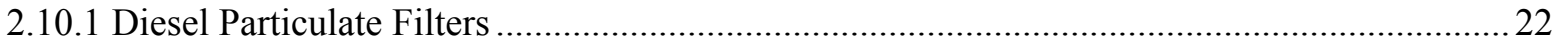

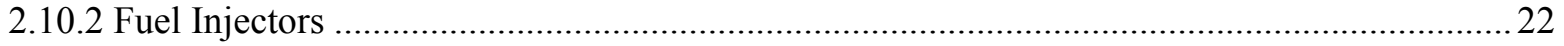

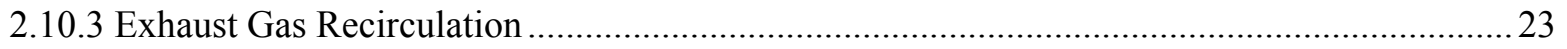

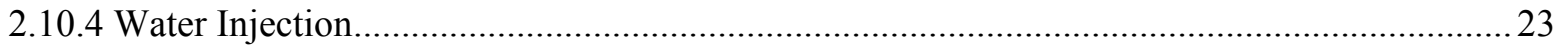

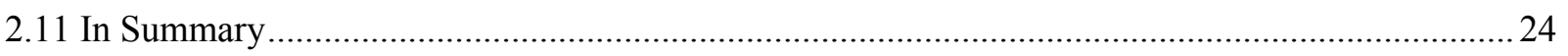

Chapter 3 - Gaseous Emissions Measurement Equipment Design .....................................................25

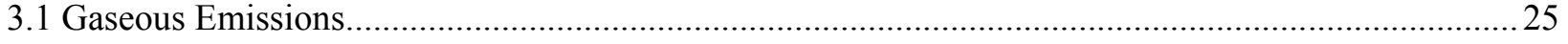




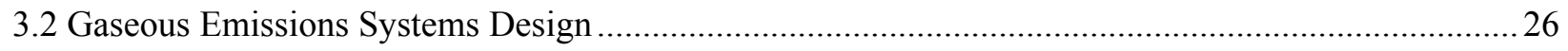

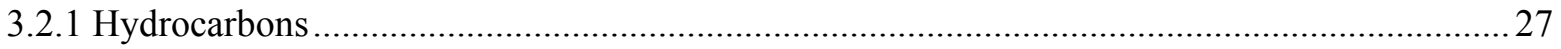

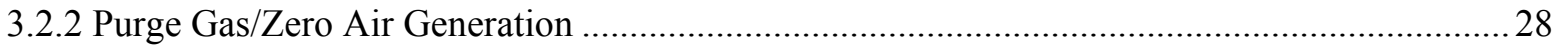

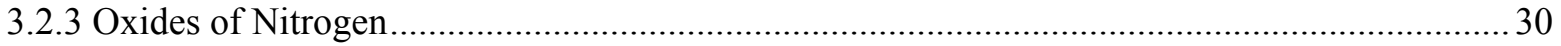

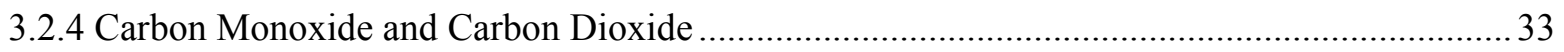

Chapter 4 - Gaseous Emissions Equipment Verification …............................................................... 35

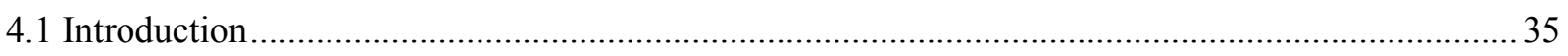

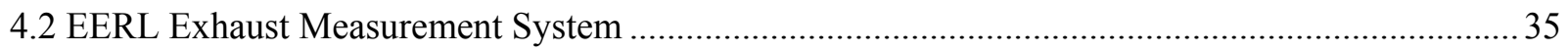

4.2.1 Full-Flow Exhaust Dilution Tunnel ……........................................................................ 35

4.2.2 EERL Dilute Gaseous Emissions Sampling System............................................................. 37

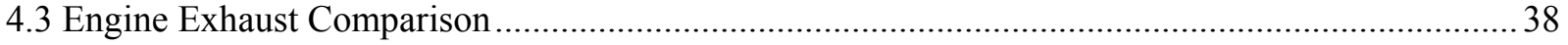

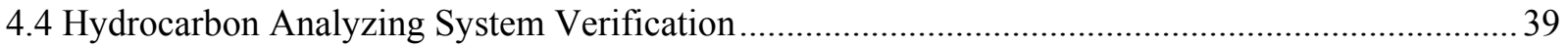

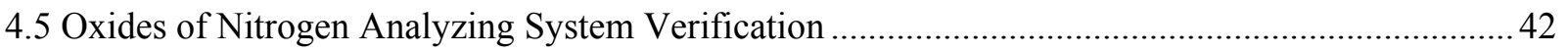

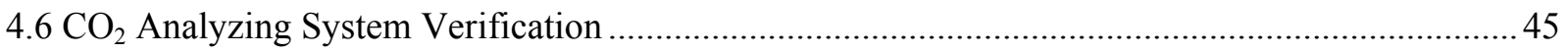

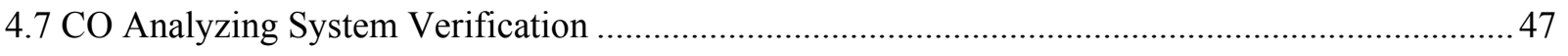

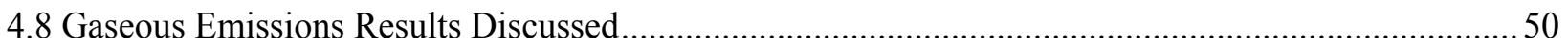

Chapter 5 - Particulate Matter Measurement System Design ...............................................................53

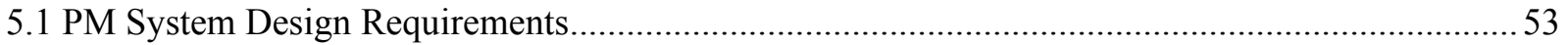

5.2 Particulate Matter Filter Flow Requirements ................................................................................. 55

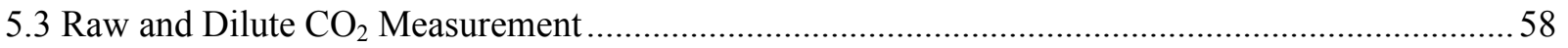

5.4 Calculations Involved in Determining PM Mass Emission Rates .................................................59

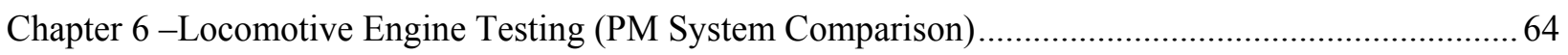

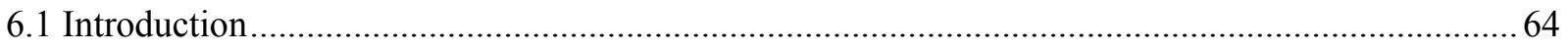

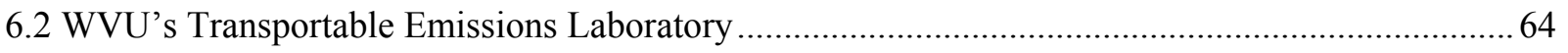

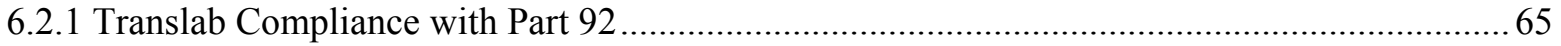

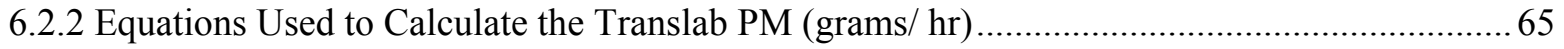

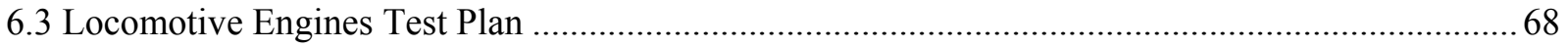

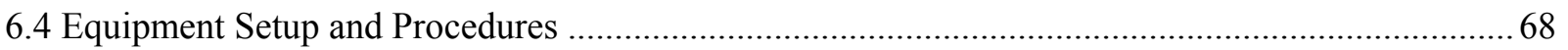

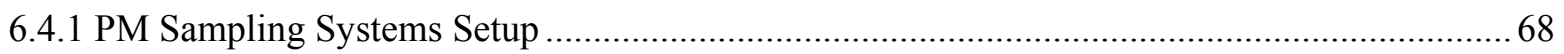

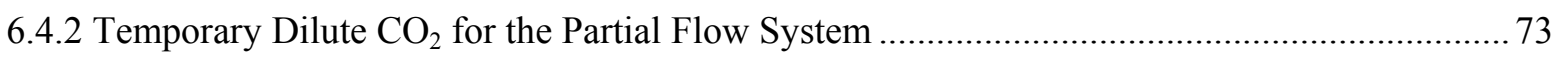

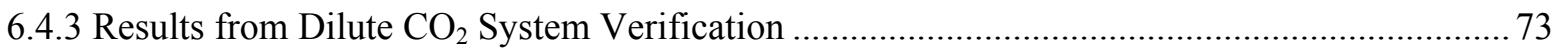

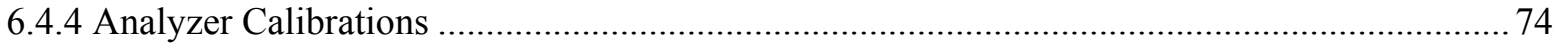

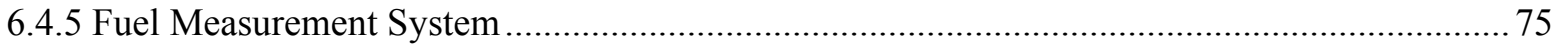




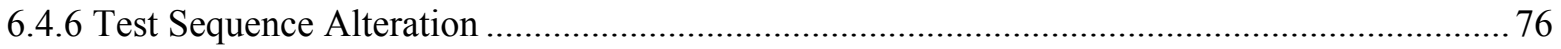

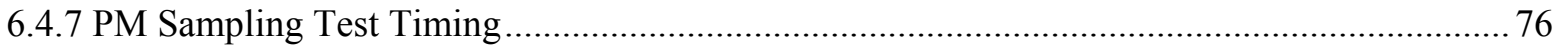

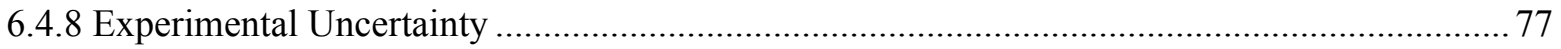

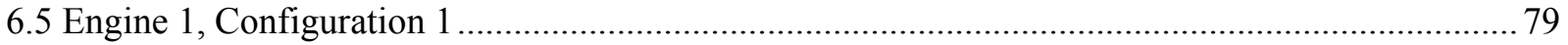

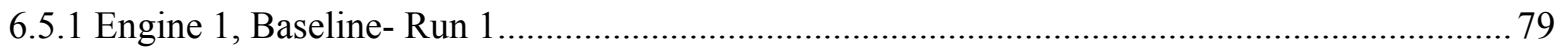

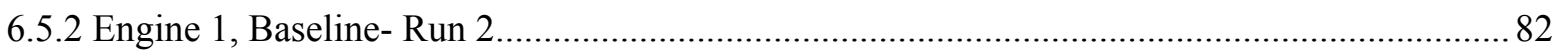

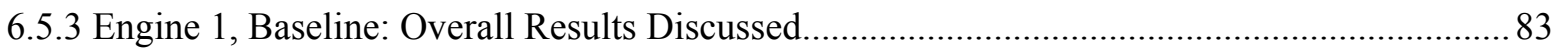

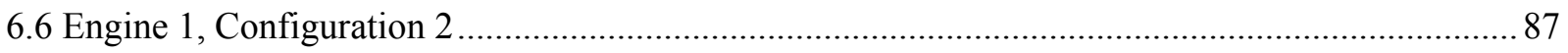

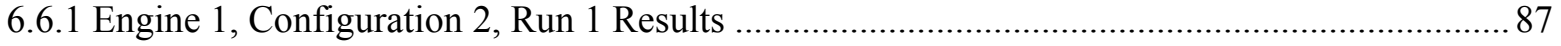

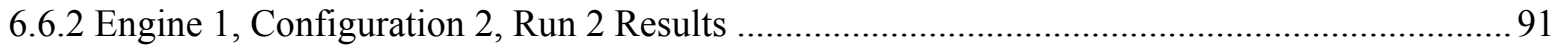

6.6.3 Engine 1, Configuration 2: Overall Results Discussed ........................................................ 93

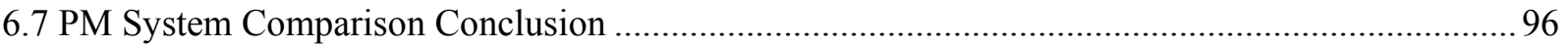

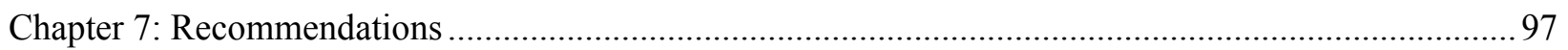

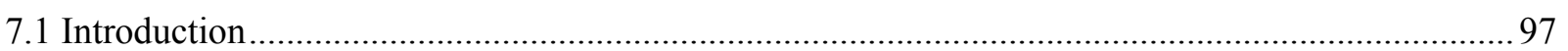

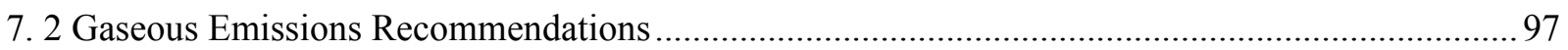

7.2.1 Hydrocarbon System Requirements for 1033 Compliance ................................................... 97

7.2.2 $\mathrm{NO}_{\mathrm{x}}$ System Requirements for 1033 Compliance ................................................................... 98

7.2.3 CO/ $/ \mathrm{CO}_{2}$ System Requirements for 1033 Compliance ......................................................... 99

7.3 Particulate Matter Sampling System Recommendations ................................................................ 100

7.3.1 Particulate Matter Sampling System, Title 40 Part 1033 Compliance................................... 100

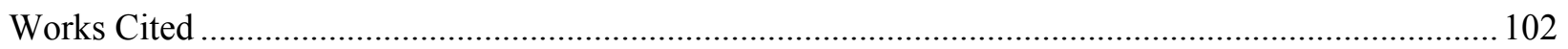

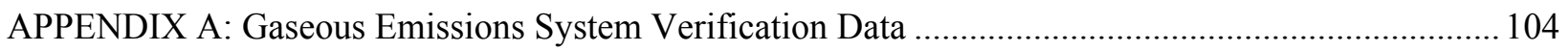




\section{LIST OF TABLES}

Table 1: Exhaust Emissions Standards for Locomotives [2] …............................................................. 5

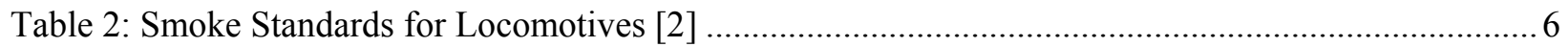

Table 3: Typical Power Distribution of Locomotive Notches [1] f........................................................... 7

Table 4: Locomotive Engine Test Sequence [2] ............................................................................ 9

Table 5: Weighting Factors for Calculating Emission Rates [2] ........................................................ 10

Table 6: 1033.101 Line-Haul Locomotive Emission Standards [3] .................................................. 21

Table 7: 1033.101 Switch Locomotive Emission Standards [3] ..........................................................2

Table 8: 1033.101 Smoke Standards for Locomotives (Percent Opacity) [3] ........................................21

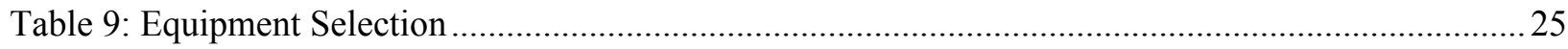

Table 10: HC Emissions Measurement System List of Components .......................................................28

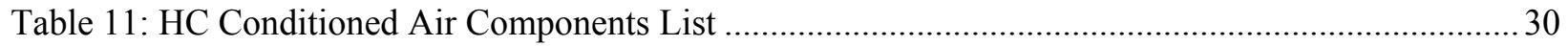

Table 12: $\mathrm{NO}_{\mathrm{x}}$ Emissions Measurement System List of Components ...................................................... 32

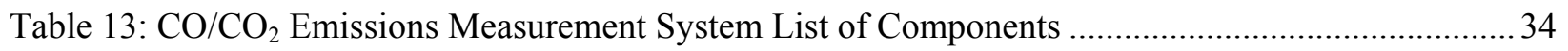

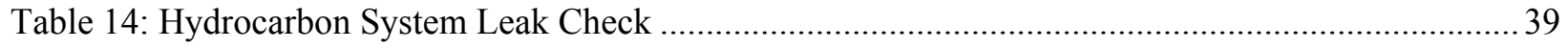

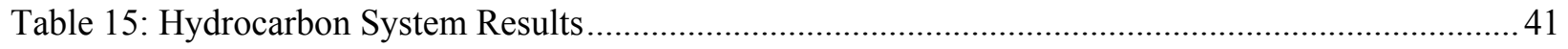

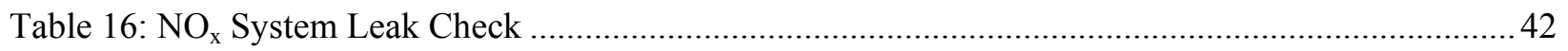

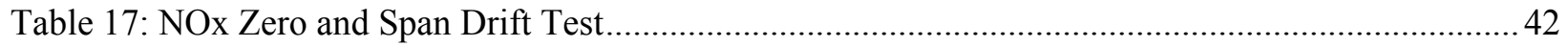

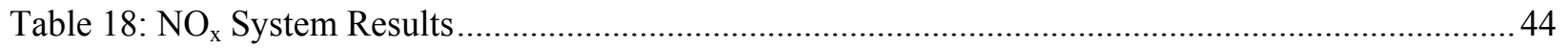

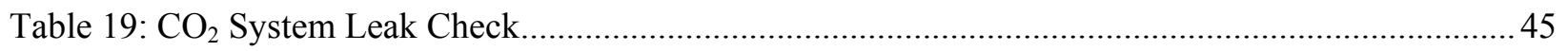

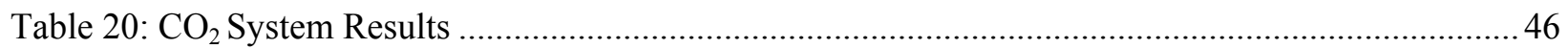

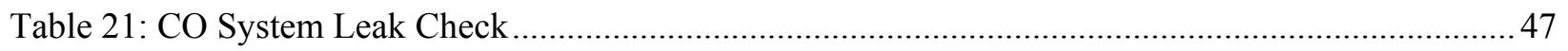

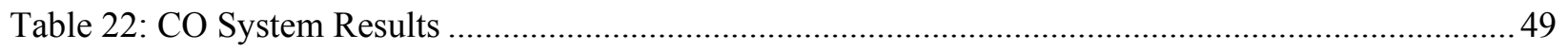

Table 23: Results Summary of Gaseous Emissions System Comparison............................................... 50

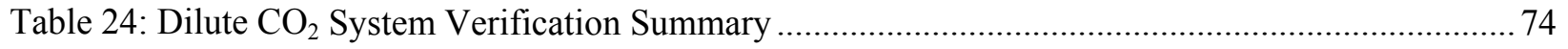

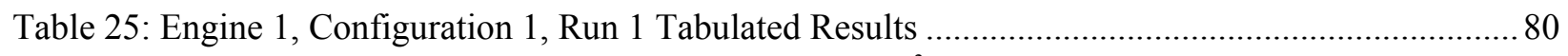

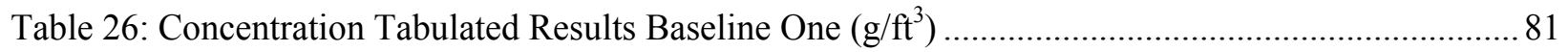

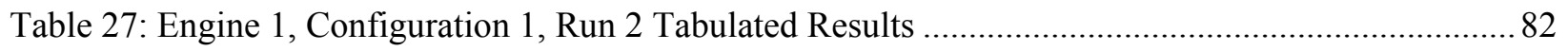

Table 28: Concentration Tabulated Results, Baseline Engine: Run Two $\left(\mathrm{g} / \mathrm{ft}^{3}\right)$................................... 83

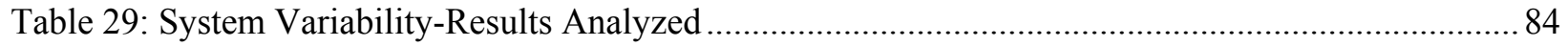

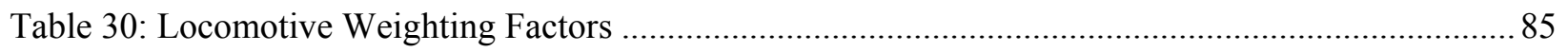

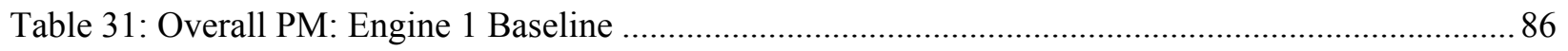

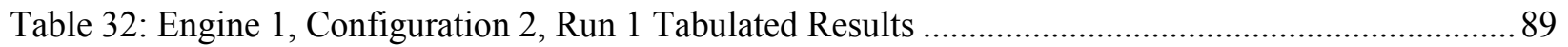

Table 33: Concentration Tabulated Results, Modified Engine: Run $1\left(\mathrm{~g} / \mathrm{ft}^{3}\right)$...................................... 90

Table 34: Engine 1, Configuration 2, Run 2 Tabulated Results ...........................................................92

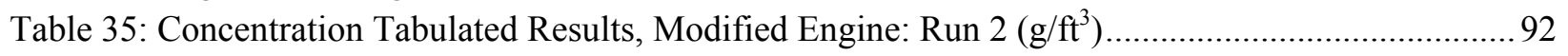

Table 36: System Variability-Results Analyzed, Configuration 2 ....................................................... 93

Table 37: Weighting Factors for Locomotive Testing ........................................................................ 94

Table 38: Modified Engine: Weighted PM (g/bhp-hr) for the Line Haul Duty Cycle..............................99

Table 39: Modified Engine: Weighted PM (g/bhp-hr) for the Switch Duty Cycle...................................95

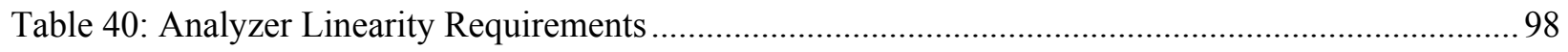




\section{LIST OF FIGURES}

Figure 1: Smoke Meter Optical System [2] ………………........................................................ 6

Figure 2: Exhaust Gas Sampling and Analytical Train [2] ...................................................................... 11

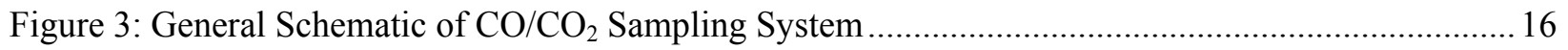

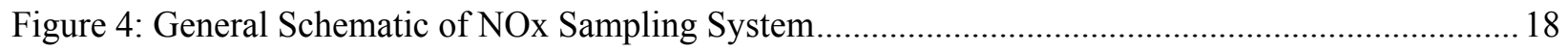

Figure 5: General Schematic of Hydrocarbon Sampling System ………............................................... 18

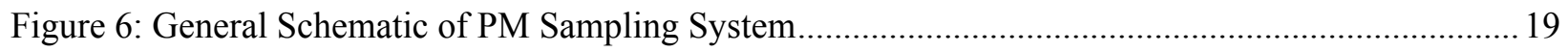

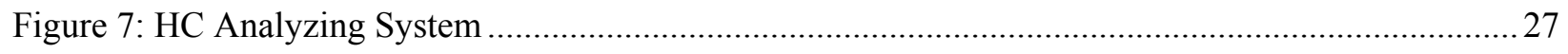

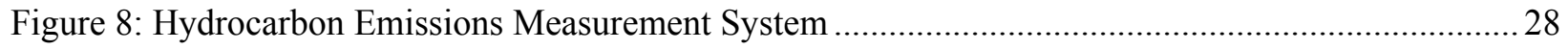

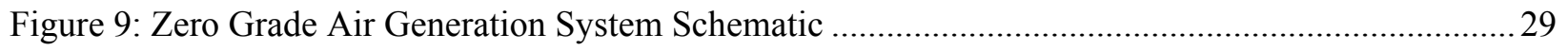

Figure 10: Zero Grade Air Generation System .......................................................................... 29

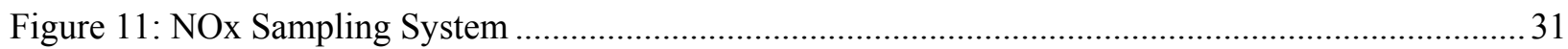

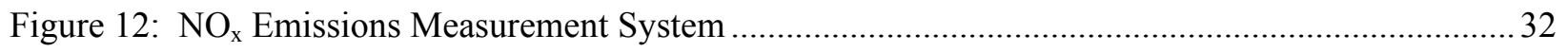

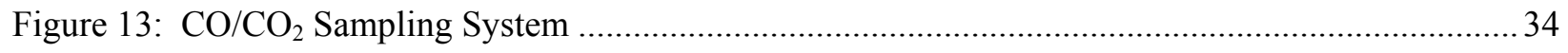

Figure 14: $\mathrm{CO} / \mathrm{CO}_{2}$ Emissions Measurement System........................................................................ 34

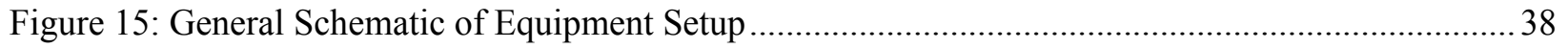

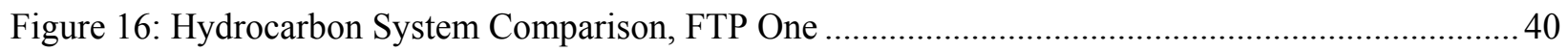

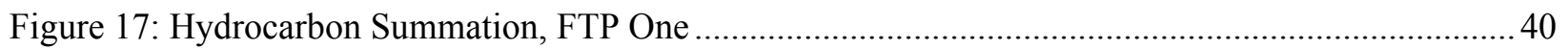

Figure 18: $\mathrm{NO}_{\mathrm{x}}$ System Comparison versus Bench EcoPhysics, FTP One ............................................. 43

Figure 19: $\mathrm{NO}_{\mathrm{x}}$ Summation versus Bench Ecophysics, FTP One........................................................... 43

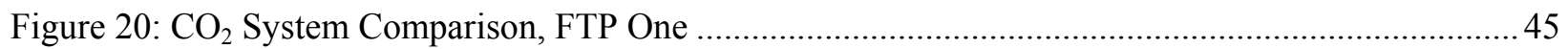

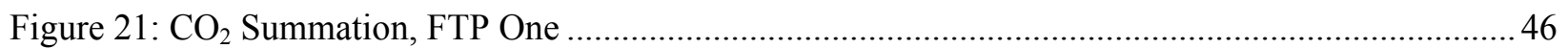

Figure 22: CO System Comparison FTP One ........................................................................... 48

Figure 23: CO Summation, FTP One

Figure 24: Raw Emissions Manifold System................................................................................ 51

Figure 25: Photograph of the Raw Emissions Sampling System as a Unit...............................................5 52

Figure 26: Partial Flow PM Dilution Tunnel System ..........................................................................5

Figure 27: Mass Flow Controller Calibration Curve …………………………………………….... 57

Figure 28: PM Mass Flow Controller System ……………………………………………….... 57

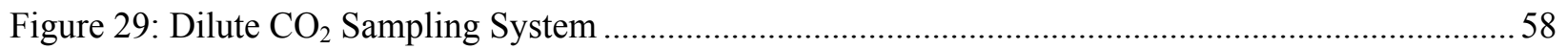

Figure 30: Sampling Probes Located within the Locomotive Stack ………………………….................69

Figure 31: PM System Comparison Experimental Setup …………………………………............... 70

Figure 32: Partial Flow Dilution Tunnel Sample Pump and Exhaust Manifold atop the Translab ............. 71

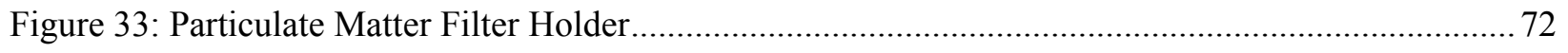

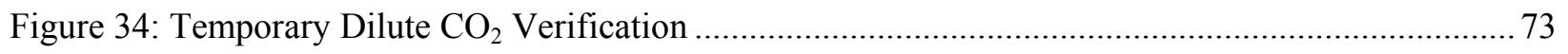

Figure 35: Integrated $\mathrm{CO}_{2}$ versus Time ………………….......................................................

Figure 36: PM Filter Flow Rate Vs. Time: Illustration of the Timing between Both Systems ...................77

Figure 37: Engine 1, Configuration 1, Run 1 Result.......................................................................... 79

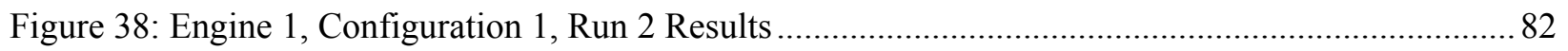

Figure 39: Brake Specific PM Mass Emissions, Baseline Run ............................................................... 86

Figure 40: Engine 1, Configuration 2 Run 1 Results (Notch 8 - Notch 1).................................................. 87

Figure 41: Engine 1, Configuration 2, Run 1 Results (Dynamic Brake - Low Idle).................................. 88

Figure 42: Engine 1, Configuration 2, Run 2 Results (Notch 8 - Notch 1)................................................. 91 
Figure 43: Engine 1, Configuration 2, Run 2 Results (Dynamic Brake - Low Idle) ............................... 91

Figure 44: Modified Engine: Weighted PM (g/bhp-hr) for the Line Haul Duty Cycle ............................ 95

Figure 45: Modified Engine: Weighted PM (g/bhp-hr) for the Switch Duty Cycle ................................. 95

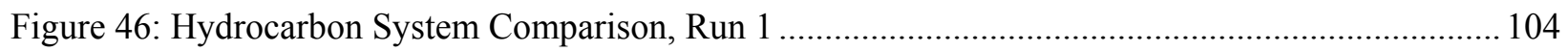

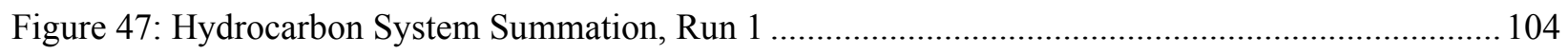

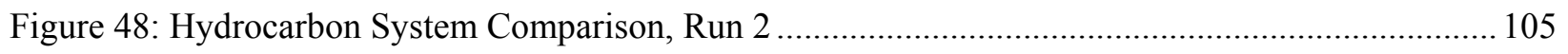

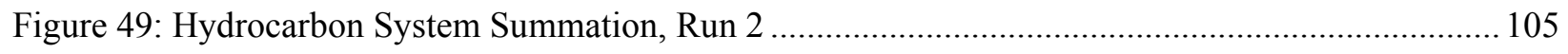

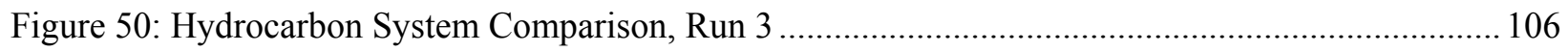

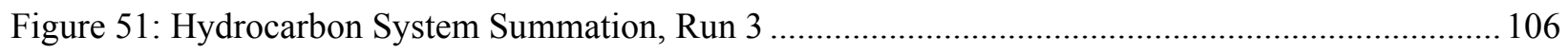

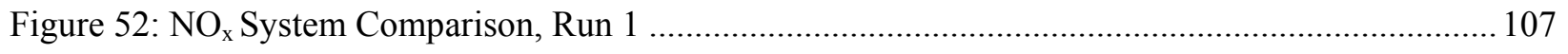

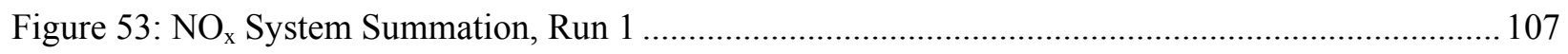

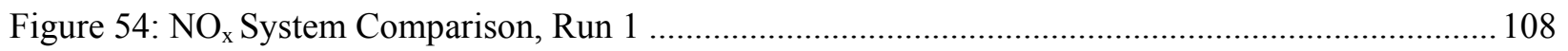

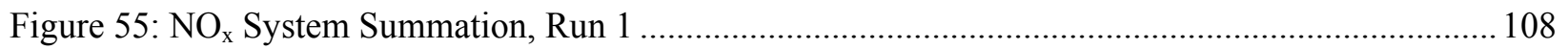

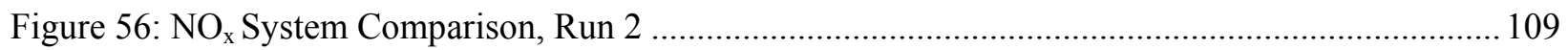

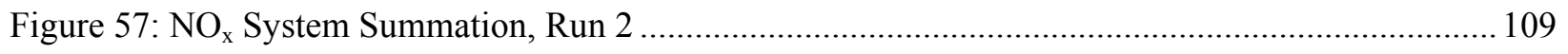

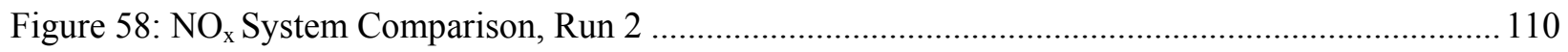

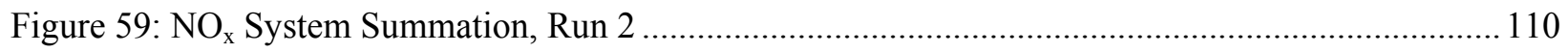

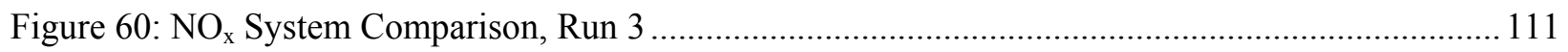

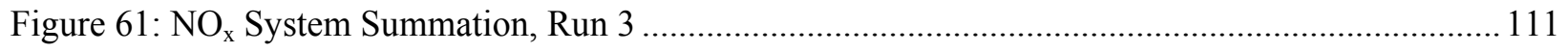

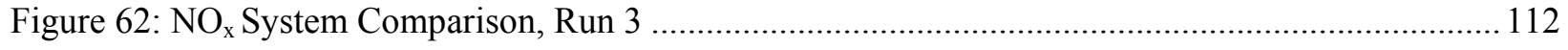

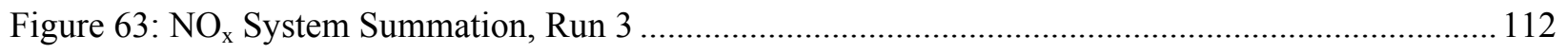

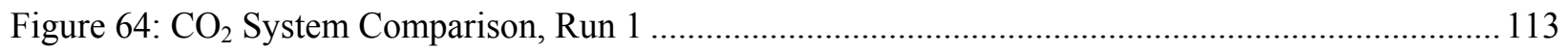

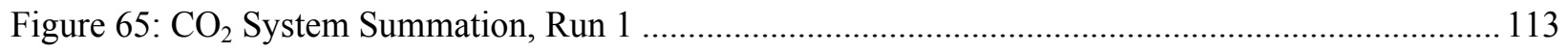

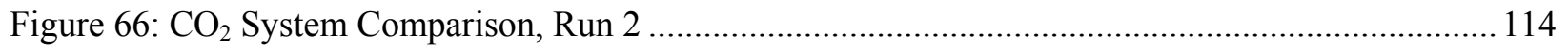

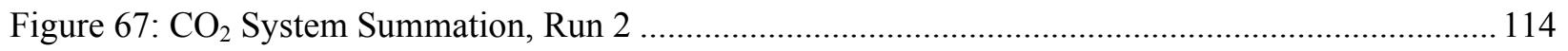

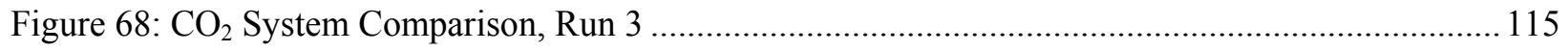

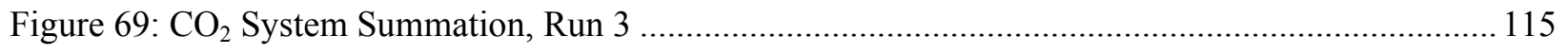

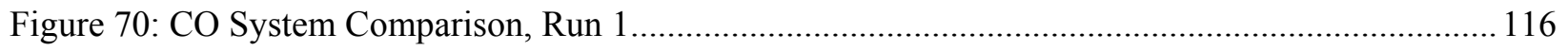

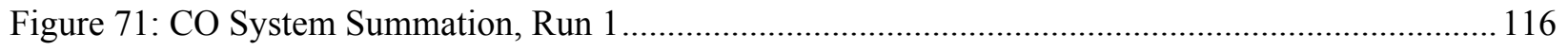

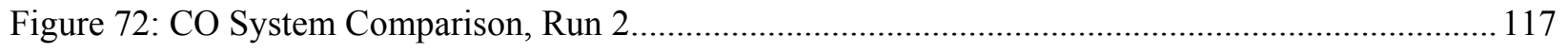

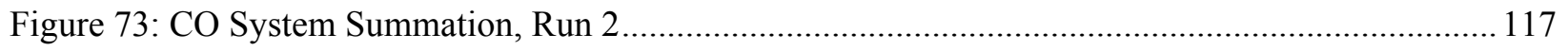

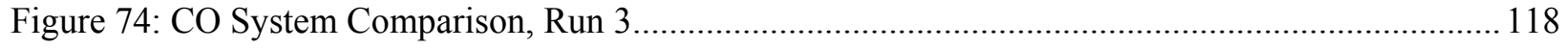

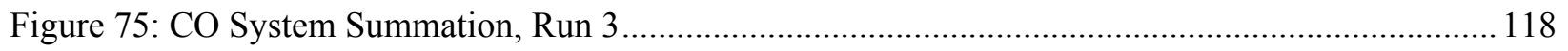




\section{NOMENCLATURE}
$\mathrm{ADC}$ - analog to digital conversion
DB - dynamic brake

CAFEE - Center for Alternative Fuels, Engines, and Emissions

CFM - cubic feet per minute

CFR - Code of Federal Regulations

$\mathrm{CO}$ - carbon monoxide

$\mathrm{CO}_{2}-$ carbon dioxide

EERL - Engines and Emissions Laboratory

EGR - exhaust gas recirculation

EPA - Environmental Protection Agency

$\mathrm{HC}$ - hydrocarbons

HFID - heated flame ionization detector

LFE - laminar flow element

NAAQS- National Ambient Air Quality Standards

NDIR- non-dispersive infrared technology

NMHC - non-methane hydrocarbons

$\mathrm{NO}_{\mathrm{x}}-$ oxides of nitrogen

PFT- partial flow dilution tunnel system

PM - particulate matter

ppm - parts per million

psi -pounds per square inch

psig - pounds per square inch gauge pressure

SCFM- standard cubic feet per minute

SOF - soluble organic fractions

SRM - standard reference material

THC - total hydrocarbons 
$\mathrm{WCO}_{2}$ - wet raw carbon dioxide concentration (\%)

$\mathrm{WCO}_{2 \mathrm{D}}$ - wet background carbon dioxide concentration (\%)

$\mathrm{WCO}_{2 \mathrm{E}}$ - wet dilute carbon dioxide concentration (\%)

WVU - West Virginia University 


\section{Chapter 1 - INTRODUCTION}

\subsection{Introduction}

West Virginia University's Center for Alternative Fuels, Engines, and Emissions Laboratory (CAFEE) was established to conduct emissions and fuel economy research to provide information that can aide in the development and improvement of engines and vehicles. The main goal of the research is to analyze ways to reduce harmful pollutants, while maintaining efficient engine power and/or increasing fuel economy. WVU currently has two engine testing laboratories. One facility, located on WVU's Evansdale campus, utilizes an engine dynamometer system capable of measuring the emissions produced by a heavy duty diesel engine. The other facility, located in Westover, WV, is WVU's Transportable Emissions Laboratory. The Transportable Emissions Laboratory makes use of a chassis dynamometer allowing for the testing of medium to heavy duty vehicles.

It was determined that the need for a laboratory capable of measuring the emissions of locomotive engines be designed and fabricated to measure gaseous exhaust constituents from a raw exhaust stream, in tandem with a partial flow dilution tunnel system for particulate matter, while meeting the specifications outlined in the Code of Federal Regulations (CFR), Title 40 Part 92 -Control of Air Pollution from Locomotives and Locomotive Engines [2]. The development of such a laboratory would expand WVU's capability to conduct research on locomotive engines, providing useful information to locomotive and engine manufacturers.

The overall design of the laboratory had to meet the specifications outlined in the CFR, as well as meet the demands set forth by WVU's CAFEE. It was requested that a laboratory be built in a fashion that would allow for it to have ease of mobility. To do so, the laboratory's 
measurement systems were designed to fit inside of $2 \mathrm{ft}$ cubic toolboxes. Each toolbox housed the components for the individual systems of the laboratory. For instance, one unit was designed to house the components of the $\mathrm{NO}_{\mathrm{x}}$ measurement system. Toolboxes were modified to allow the equipment to be maneuvered by two workers who could transfer and place the equipment on the test site. Maneuverability of this equipment would allow for WVU's CAFFE to potentially measure emissions from various engines in other applications; for instance marine vessels.

\subsection{Project Objectives}

The objectives of this study were to build emissions systems, then compare brake specific mass emission rates of the "raw laboratory system" versus already in use laboratories located at WVU. The systems were constructed in house at the Westover, WV laboratory. Verification was done by running collocated and simultaneous testing of the raw laboratory system versus the other systems available at WVU. Once the systems proved to function properly, they were commissioned for in-field testing of locomotive engines. Though all the equipment met the specifications mandated by the CFR, Part 92, as a quality check and quality assurance procedure, WVU chose to test all the equipment prior to in-field testing to diagnose any equipment complications or unforeseen problems and document quality control procedures. The testing of the individual laboratory systems was completed upon each system's availability. Ideally the laboratory would have been tested as a full functioning raw gaseous emissions and partial flow dilution tunnel PM system laboratory, but the components were not made available simultaneously due to their involvement upon completion of their build in other laboratory studies conducted at the CAFEE. 


\section{Chapter 2 - Review of Literature}

Locomotives are and have been an essential building block to the economic growth of the United States. The railroads are one of the important elements responsible for the successful growth of the United States as a world leader in trade and commerce. Millions of goods are shipped throughout the country by rail to their commercial destination. Large quantities of items shipped by rail at vast distances can be sent to their destination at costs that are much lower than items sent by plane or truck. One drawback with the locomotive, as with any vehicle operating from an internal combustion engine, is the pollution emitted from its exhaust plume. As the attitude moves towards going "green," emissions regulations, including those of locomotives are becoming much more stringent.

\subsection{Regulatory Emissions Acts}

Growing concern has developed to reduce the harmful pollutants that are produced by the combustion of petroleum based fuels. To combat the harmful effects that the internal combustion engine produces, the Environmental Protection Agency (EPA) has created strict guidelines for the manufacturers of locomotive engines to meet specifications for the amount of pollutants emitted by engines. In 1990, the Clean Air Act was passed by the EPA regulating the emissions produced by locomotive engines. At the time it was estimated that locomotives were one of the largest unregulated producers of oxides of nitrogen $\left(\mathrm{NO}_{\mathrm{x}}\right)[1,18]$. As a result the manufacturers of locomotive engines have had to invest in the development and research of engines that meet the EPA regulations. This chapter will discuss the procedures and methods employed to test and regulate the emissions produced by locomotive engines. The chapter will also focus on the individual pollutant constituents, as well as the methods of their detection. 


\subsection{Current EPA Emissions Standards}

Regulated emissions include hydrocarbons (HC); also referred to as total hydrocarbons (THC), carbon monoxide $(\mathrm{CO})$, oxides of nitrogen $\left(\mathrm{NO}_{\mathrm{x}}\right)$ and particulate matter $(\mathrm{PM})$ [2]. These exhaust gas constituents are regulated by the mass emitted per unit work done in the units of grams per brake horse power hour (g/bhp-hr) for heavy duty engines, off-road engines, and locomotive engines. Emissions are regulated in this manner to normalize exhaust constituent productions to a unit of work.

Regulations for locomotives are broken up into different classes known as tiers. These tiers are regulations for locomotives falling within certain ranges of manufacturing dates. Tier 0 standards apply for locomotives manufactured from 1973 - 2001. Tier 0 also includes new production locomotives manufactured in 2001 as well as remanufactured freight locomotives from 1994 - 2001. Tier 1 standards apply to locomotives manufactured from $2002-2004$. Tier 2 locomotive standards apply to engines produced in 2005 and after. Tier regulations are further divided into two categories relating to the type of locomotive being tested for emissions $[2,18]$. The two categories are switch and line - haul locomotives. Switch locomotives are smaller locomotives that are used in a switchyard to assemble and disassemble trains. Line - haul locomotives refer to locomotives that are responsible for moving lines of train cars over vast distances.

Setting the regulations of emissions in this manner allowed for locomotive manufacturers to plan and research technologies that would make achieving the emissions standards possible [1]. This allowed for the standards to be introduced into the industry gradually without causing an immediate infliction for locomotive engine manufacturers. Below in Table 1 are the emissions standards for locomotives, subdivided into tiers and type of duty cycle. 
Table 1: Exhaust Emissions Standards for Locomotives [2]

\begin{tabular}{|l|c|c|c|c|}
\hline \multirow{2}{*}{ Tier and Duty-cycle } & \multicolumn{5}{|c|}{ Gaseous and Particulate Emissions (g/bhp-hr) } \\
\cline { 2 - 5 } & HC* & CO & NOx & PM \\
\hline Tier O line-haul duty-cycle & 1.00 & 5.00 & 9.50 & 0.60 \\
\hline Tier 0 switch duty-cycle & 2.10 & 8.00 & 14.00 & 0.72 \\
\hline Tier 1 line-haul duty-cycle & 0.55 & 2.20 & 7.40 & 0.45 \\
\hline Tier 1 switch duty-cycle & 1.20 & 2.50 & 11.00 & 0.54 \\
\hline Tier 2 line-haul duty-cycle & 0.30 & 1.50 & 5.50 & 0.20 \\
\hline Tier 2 switch duty-cycle & 0.60 & 2.40 & 8.10 & 0.24 \\
\hline
\end{tabular}

* HC standards are in the form of THC for diesel, biodiesel, or any combination of fuels with diesel as the primary fuel; Methane emissions although a hydrocarbon are not regulated by the EPA because it is not photo-chemically reactive.

Smoke opacity standards have also been established for locomotive engines. The smoke opacity is measured by shining a light source through the exhaust plume of the locomotive. The amount of light traversing the plume is then measured using an opacity meter. The distance between the light source and receiver is specified to be one meter. For varying distances a correction is made to yield data that is representative of the one meter smoke opacity distance. Figure 1 below shows a generalized diagram for the smoke opacity measurement. It is acceptable practice to collect opacity data separate from gaseous emissions and particulate matter data as long as the testing is done immediately following the emissions testing. Opacity is measured not only in the engine's operating steady state mode, but also in the transitional period from one notch setting to another. Similar to when a truck changes gears, an increase in smoke opacity can be seen when the locomotive changes from one notch to another. The reason for the bellows is due to the transient turbocharger behavior. Smoke opacity regulations prevent large bellows of smoke reaching residential areas where it may create health risks [1, 18]. Large amounts of smoke are also unsightly and cause aesthetic problems. 


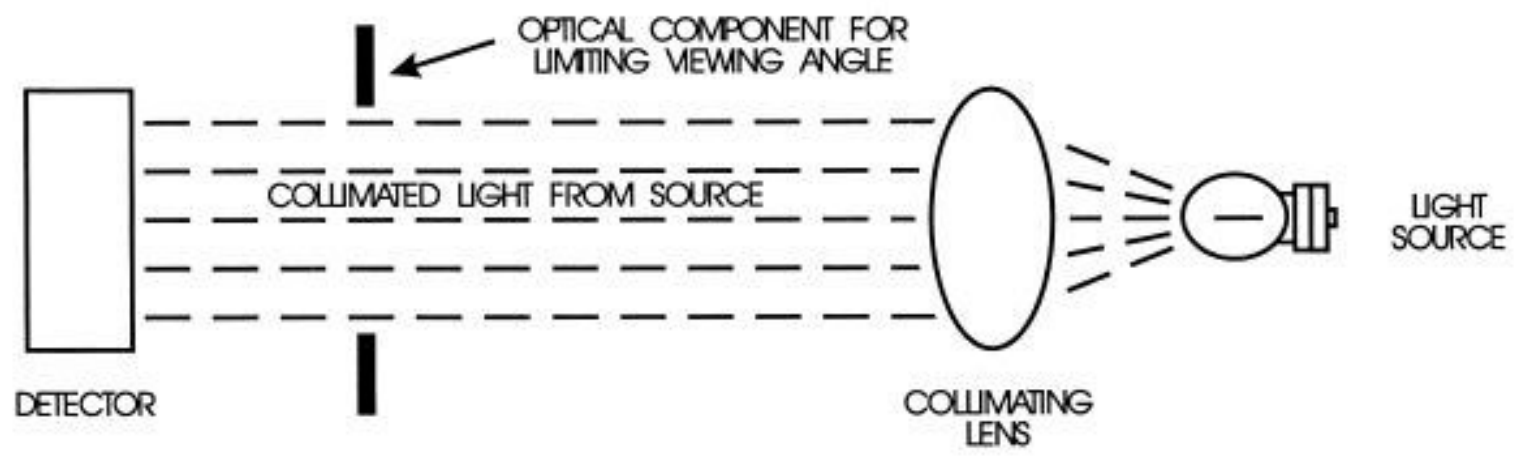

Figure 1: Smoke Meter Optical System [2]

Similar to exhaust gas emissions, the regulations for smoke opacity standards of locomotives are divided into tier classes. Table 2 below summarizes the current regulations set forth by the EPA. Both line - haul and switch locomotives must meet the opacity regulations under their specified tier class.

Table 2: Smoke Standards for Locomotives [2]

\begin{tabular}{|c|c|c|c|}
\hline \multicolumn{4}{|c|}{ Smoke Standards for Locomotives (Percent Opacity - Normalized) } \\
\hline & Steady-state peak & 30 -sec peak & 3-sec peak \\
\hline Tier 0 & 30 & 40 & 50 \\
\hline Tier 1 & 25 & 40 & 50 \\
\hline Tier 2 & 20 & 40 & 50 \\
\hline
\end{tabular}

Steady-state peak refers to the opacity of the smoke measured when the locomotive engine has established a steady mode of operation. The 30 second peak measures the opacity over a 30 second window, capturing the average opacity within this time frame. The 3 second peak captures the average opacity within a 3 second window. 


\subsection{Locomotive Engines Technologies}

Almost all locomotives used in the U.S. are powered by petroleum fueled diesel engines. These engines operate on diesel electric technology. Diesel engines convert rectilinear motion into rotational energy that drives an alternator or generator that then provides electricity to the locomotive's electrical motors, which send power to the wheels moving the train forward. A mechanical transmission would not be practical at that large of a scale. In order to get the desired gearing ratios a mechanical transmission would be extremely large and impractical. This design also enables the locomotives to incorporate steady state modes of operation with set power ratings and loads. These steady state modes, set by discrete "notches" provide electrical power to the locomotive [1]. A steady state engine is also beneficial for locomotive engine manufacturers to meet the EPA emissions standards, when compared to engines operating in a transient manner. The engine manufacturers can establish emissions control techniques achievable with steady state engine operations that could not be achieved with an engine operating in a transient cycle [1].

Table 3: Typical Power Distribution of Locomotive Notches [1]

\begin{tabular}{|c|c|c|c|c|c|c|c|c|}
\hline $\begin{array}{c}\text { Throttle } \\
\text { Notch }\end{array}$ & 1 & 2 & 3 & 4 & 5 & 6 & 7 & 8 \\
\hline $\begin{array}{c}\text { Percent of } \\
\text { Rated } \\
\text { Power }\end{array}$ & 4.5 & 11.5 & 23.5 & 35 & 48.5 & 64 & 85 & 100 \\
\hline
\end{tabular}




\subsection{Locomotive Testing Procedures}

A set of procedures for locomotive emissions testing has been developed by the EPA. Each locomotive is tested under the provisions set forth by the Code of Federal Regulations, Title 40, Part 92 [2]. In Part 92 all the details associated with emissions testing of locomotives engines are discussed. This includes the emissions test cycles and test equipment specifications. Part 92 was strictly followed when developing the equipment that would be used to test locomotive exhaust constituents. Locomotives are designed to operate in specific steady state engine settings referred to as notches. The highest notch, notch 8 , represents the locomotive's peak horsepower producing notch. Many locomotives employ a notch setting referred to as dynamic brake, which is designed to slow the locomotive. Traction motors and dynamic brake grids provide the locomotive's braking effort. One emissions strategy technique is to utilize a low idle as well as a normal idle notch setting. Alternative testing techniques have been developed for engines that do and do not contain these specific notch settings [3]. The regulated brake specific emissions in Table 1 are found using the following testing procedures. 
Table 4: Locomotive Engine Test Sequence [2]

\begin{tabular}{|c|c|c|c|}
\hline Mode No. & Notch Setting & Time in Notch & $\begin{array}{l}\text { Emissions } \\
\text { Measured }\end{array}$ \\
\hline Warm-up & Notch 8 & $\begin{array}{c}5+-1 \\
\text { minimum }\end{array}$ & NONE \\
\hline Warm-up & Lowest Idle & $\begin{array}{l}15 \text { minutes } \\
\text { maximum }\end{array}$ & NONE \\
\hline $1 a$ & Low Idle & $\begin{array}{l}6 \text { minutes } \\
\text { minimum }\end{array}$ & ALL \\
\hline 1 & Normal Idle & $\begin{array}{l}6 \text { minutes } \\
\text { minimum }\end{array}$ & ALL \\
\hline 2 & Dynamic Brake & $\begin{array}{l}6 \text { minutes } \\
\text { minimum }\end{array}$ & ALL \\
\hline 3 & Notch 1 & $\begin{array}{l}6 \text { minutes } \\
\text { minimum }\end{array}$ & ALL \\
\hline 4 & Notch 2 & $\begin{array}{l}6 \text { minutes } \\
\text { minimum }\end{array}$ & ALL \\
\hline 5 & Notch 3 & $\begin{array}{l}6 \text { minutes } \\
\text { minimum }\end{array}$ & ALL \\
\hline 6 & Notch 4 & $\begin{array}{l}6 \text { minutes } \\
\text { minimum }\end{array}$ & ALL \\
\hline 7 & Notch 5 & $\begin{array}{l}6 \text { minutes } \\
\text { minimum }\end{array}$ & ALL \\
\hline 8 & Notch 6 & $\begin{array}{l}6 \text { minutes } \\
\text { minimum }\end{array}$ & ALL \\
\hline 9 & Notch 7 & $\begin{array}{l}6 \text { minutes } \\
\text { minimum }\end{array}$ & ALL \\
\hline 10 & Notch 8 & $\begin{array}{l}15 \text { minutes } \\
\text { minimum }\end{array}$ & ALL \\
\hline
\end{tabular}

The EPA has developed weighting factor procedures to analyze the results of the emissions test. Weighting factors for each notch were determined based on the overall operation of a locomotive in its lifetime. This gives each locomotive one number in grams/brake horsepower- hour for each exhaust constituent measured. For instance, the mass emissions rate for each notch is determined in grams per seconds. This mass emissions rate is then multiplied by the corresponding weighting factor. This calculation is performed for the mass emission rates for each notch. These values are then summed to give a duty-cycle emissions rate for the 
locomotive in grams/brake horsepower-hour. Table 5 displays the weighting factors for each notch. Some locomotives are not equipped with multiple idle notches; therefore weighting factors were developed for both types of locomotives.

Table 5: Weighting Factors for Calculating Emission Rates [2]

\begin{tabular}{|l|r|c|c|c|c|}
\hline \multirow{2}{*}{$\begin{array}{c}\text { Throttle Notch } \\
\text { Setting }\end{array}$} & \multirow{2}{*}{ Test Mode } & \multicolumn{2}{c|}{$\begin{array}{c}\text { Locomotive not equipped with } \\
\text { multiple idle notches }\end{array}$} & $\begin{array}{c}\text { Locomotive equipped with } \\
\text { multiple idle notches }\end{array}$ \\
\cline { 3 - 6 } & & Line Haul & Switch & Line-haul & Switch \\
\hline Low Idle & $1 \mathrm{a}$ & NA & NA & 0.190 & 0.299 \\
\hline Normal Idle & 1 & 0.380 & 0.598 & 0.190 & 0.299 \\
\hline Dynamic Brake & 2 & 0.125 & 0.000 & 0.125 & 0.000 \\
\hline Notch 1 & 3 & 0.065 & 0.124 & 0.065 & 0.124 \\
\hline Notch 2 & 4 & 0.065 & 0.123 & 0.065 & 0.123 \\
\hline Notch 3 & 5 & 0.052 & 0.058 & 0.052 & 0.058 \\
\hline Notch 4 & 6 & 0.044 & 0.036 & 0.044 & 0.036 \\
\hline Notch 5 & 7 & 0.038 & 0.036 & 0.038 & 0.036 \\
\hline Notch 6 & 8 & 0.039 & 0.015 & 0.039 & 0.015 \\
\hline Notch 7 & 9 & 0.030 & 0.002 & 0.030 & 0.002 \\
\hline Notch 8 & 10 & 0.162 & 0.008 & 0.162 & 0.008 \\
\hline
\end{tabular}

\subsection{Gaseous Emissions Measurement}

Locomotive engines operate under steady state modes. These modes, termed notch settings have a predefined power and load setting as determined by the manufacturer. Since each mode of a locomotive engine is in steady state, emissions produced by the engine can be measured accurately with a slip stream sampling technique. An entire sample to be measured in a dilution tunnel is not needed, rather the emissions can be measured raw or undiluted from a partial sample extracted through an exhaust slip stream. This is beneficial because the equipment needed to collect an entire locomotive exhaust flow would be costly and large. The gaseous emissions produced by heavy duty truck diesel engines are measured in a full-exhaust dilution tunnel system, where the entire exhaust stream flows into a dilution tunnel and is mixed with 
dilution air. Heavy duty diesel truck engines are subjected to transient test modes, so a fullexhaust dilution tunnel is needed to be able to achieve proportional sampling. The gaseous emissions sampling system as proposed by the EPA can be found in Figure 2.

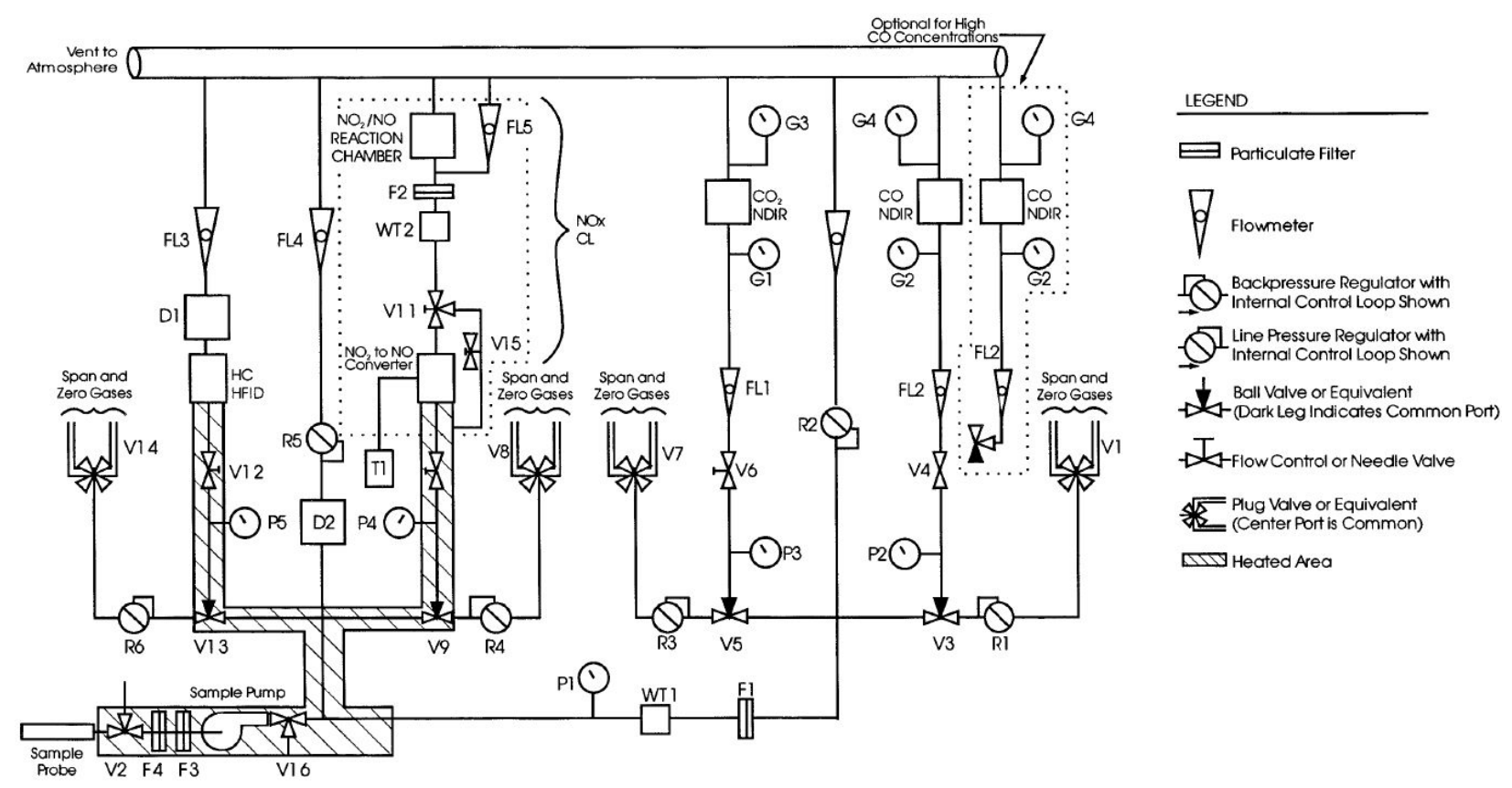

Figure 2: Partial Flow, Raw Exhaust Gas Sampling and Analytical Train [2]

Exhaust gases are drawn from the same sampling probe which is located in the stack of the locomotive. It can be seen that the system consists of heated lines and heated filters. The design of the actual system constructed will be discussed in further detail in Chapter 3 of this document.

\subsection{Engine Emissions and Air Pollution}

Exhaust produced by the internal combustion engine accounts for a major source of the world's air pollution problems. The reactions that take place in the internal combustion engine produce exhaust constituents that have been found to be harmful to both the environment and human population. Internal combustion engines produce several types of pollutants. An established understanding of the exhaust constituents formed must first be made, to develop 
techniques and procedures to reduce the amount of harmful constituents produced by engines in the future.

\subsection{Exhaust Gas Constituents of Interest}

\subsubsection{Carbon Dioxide}

Though not regulated, carbon dioxide is a major product of the combustion process. In a truly stoichiometric chemical reaction the following equation would result:

$$
\text { Fuel }+\mathrm{O}_{2}+3.76 \mathrm{~N}_{2} \stackrel{\text { yields }}{\longrightarrow} \mathrm{CO}_{2}+\mathrm{H}_{2} \mathrm{O}+3.76 \mathrm{~N}_{2} \quad \text { Equation } 1
$$

The previous equation was not balanced, however was generalized to show the basic products of the combustion process. In an ideal world the combustion process would only yield $\mathrm{CO}_{2}$, water and atmospheric nitrogen [4]. Carbon dioxide is known to be a major contributor leading to the green house effect. Green house gases trap the sun's radiation and heat into the earth's atmosphere prohibiting its escape. Effectively, greenhouse gases will eventually cause a rise in the earth's overall temperature. The fear developing with this is the possibility of the earth's ice caps melting with an increase in the earth's temperature. The water level of the earth would raise causing tremendous problems with flooding. The idea is theoretical but highly viewed as a threat.

\subsubsection{Hydrocarbons}

Hydrocarbons are one of the byproducts of the combustion of diesel fuel in an internal combustion engine. A large portion of the hydrocarbons emitted by an engine are the result of incomplete combustion. In fact $40 \%$ of the hydrocarbons emitted by an engine are unburned fuel components [4]. The other $60 \%$ of hydrocarbon emissions are partially reacted fuel components. These are small reactive molecules that were formed when large fuel molecules broke up during combustion. Another form of hydrocarbon emissions occurs due to engine blow by [4]. The combustion reaction that takes place can force some of the exhaust into the crankcase, 
pressurizing the crankcase. The oil in the crankcase can be exhausted into the atmosphere through the crankcase vent due to this pressurization. Likewise, deposited films of oil can accrue on the cylinder walls and be exhausted out of the engine as well. As an engine ages the amount of oil deposited on the engine's walls will increase in relation to the wear of the piston rings. The piston rings are what create a seal between the combustion chamber and the crankcase. Hydrocarbons pose a concern for several reasons. First, hydrocarbons give off an unpleasant odor. The smell usually associated with diesel engines is mainly the odor produced by hydrocarbons. Second, hydrocarbons are believed to be carcinogenic. The inhalation of the exhaust fumes over an extended period of time has been proven to develop certain forms of cancer. Hydrocarbons are also a key element in the formation of photochemical smog [4].

\subsubsection{Oxides of Nitrogen}

Oxides of nitrogen are another product of the combustion reaction that takes place in an internal combustion engine. $\mathrm{NO}_{\mathrm{x}}$ includes $\mathrm{NO}$ and $\mathrm{NO}_{2}$. The majority of oxides of nitrogen found in combustion gases are in the form of $\mathrm{NO}$ [4]. Ninety percent of the oxides of nitrogen formed by the combustion of air and fuel in an internal combustion engine is $\mathrm{NO}$ while $\mathrm{NO}_{2}$ makes up the remainder [1]. With newer engine technologies being developed, such as diesel particulate filters, $\mathrm{NO}_{2}$ can be a much higher percentage of $\mathrm{NOx}$, upwards of $35 \%$ [5]. Thermal $\mathrm{NO}_{\mathrm{x}}$ is produced by the high combustion temperatures. The combustion of a mixture of air and fuel produces combustion temperatures high enough to create endothermic reactions between nitrogen and oxygen forming various oxides of nitrogen. Diatomic nitrogen $\left(\mathrm{N}_{2}\right)$ splits apart into monatomic nitrogen $(\mathrm{N})$ at these high temperatures [6]. $\mathrm{N}_{2}$ is mainly inert; however monatomic nitrogen is highly reactive. The following chemical equations are likely reasons for the creation of $\mathrm{NO}_{\mathrm{x}}$ at high combustion temperatures [4]. 


$$
\begin{array}{cc}
\mathrm{N}_{2}+\mathrm{O} \stackrel{\text { yields }}{\longrightarrow} \mathrm{NO}+\mathrm{N} & \text { Equation } 2 \\
\mathrm{~N}+\mathrm{O}_{2} \stackrel{\text { yields }}{\longrightarrow} \mathrm{NO}+\mathrm{O} & \text { Equation } 3 \\
\mathrm{~N}+\mathrm{OH} \stackrel{\text { yields }}{\longrightarrow} \mathrm{NO}+\mathrm{H} & \text { Equation } 4
\end{array}
$$

Oxides of nitrogen are harmful to the environment because in the atmosphere these oxides form ozone and photochemical smog [4].

$$
\mathrm{NO}_{2}+\text { Sunlight } \stackrel{\text { yields }}{\longrightarrow} \mathrm{NO}+\mathrm{O}+\operatorname{smog} \text { Equation } 5
$$

Photochemical smog has become a growing problem in the major cities across the United States. Smog at the ground level can cause health problems when inhaled. It has also been known to damage crops and other forms of vegetation [6].

\subsubsection{Carbon Monoxide}

Carbon monoxide is a deadly, odorless byproduct of the combustion of petroleum based fuels. If inhaled, the gas will attack the heart and nervous system of the victim. Carbon monoxide is formed with a fuel rich equivalence ratio [4]. The equivalence ratio is defined as the actual ratio of fuel to air per fuel to air ratio stoichiometric.

$$
\text { Equivalence Ratio }=\frac{(F A)_{a c t}}{(F A) \text { stoich }} \quad \text { Equation } 6
$$

One instance where carbon monoxide is formed is when the above ratio is greater than 1 . Carbon monoxide is an undesirable exhaust constituent because its formation is the result of unburned fuel not reacting with $\mathrm{O}_{2}$. Therefore, its formation represents potential fuel energy that has been lost. Carbon monoxide is also believed to be a contributor to the greenhouse gases. 


\subsubsection{Particulate Matter}

Particulate matter refers to the particles found in the exhaust stream. PM is composed of solid or liquid particles suspended in gas [5]. The PM soot is composed of clusters of carbon atoms. Similar to the formation of carbon monoxide, particulate matter is formed in fuel rich equivalence ratios [4]. In a fuel rich state of combustion, there is not enough oxygen to react with the fuel to completely convert all fuel molecules to carbon dioxide. This leaves excess carbon atoms, which in turn form carbon spheres or soot. Another source of particulate matter formation comes from the lubricating systems of the engine. Oil that enters the combustion chamber can react to form clusters of soot, which are exhausted out of the engine. Particulate matter is one of the exhaust constituents of greatest concern. The effects PM on human health due to inhalation have been proven to be extremely negative [4]. Larger particulates inhaled by humans are filtered out through the nose and throat. The smaller particles (smaller than 10 micrometers) make it past the upper respiratory system, settling into the lungs. It is here where PM has been known to cause respiratory damage [4]. A controversy over the way in which PM is measured and regulated has developed. PM emissions are regulated on a mass basis. The problem with this is that the smaller PM particles are the ones that cause the majority of health risks for people. An engine may pass the PM mass emissions regulations, but in turn may be producing larger quantities of smaller PM particles.

\subsection{Exhaust Constituents Measurement Techniques}

It is understood that reducing the pollutants produced by diesel engines is an important engineering task. To make improvements in technology, the manufacturers and engineers must have tools to measure the exhaust constituents produced by the engine accurately. This section will discuss some of the technologies used to analyze the exhaust streams of diesel engines. 


\subsubsection{Carbon Monoxidel Carbon Dioxide Measurement}

Carbon dioxide and carbon monoxide concentrations are measured using non-dispersive infrared detection (NDIR). The principle of infrared light absorption is the fundamental backbone of the NDIR's functionality [8]. The governing principle behind a NDIR's operation is the fact that a particular concentration of gas will absorb a certain wavelength of infrared light. The other spectrums of light (those out of the infrared spectrum) will transmit through the gas concentration. An infrared light source is directed through the sample cell containing the gas to be analyzed. On the other side of the sample cell there is a chopper motor and an infrared light detector. The beam of light passing through the sample cell will lose some of its intensity based on the amount of infrared light absorbed by the gas concentration. The infrared light detector is split into two cells. On one side of the cell the sample gas is allowed to pass through. On the other side of the cell is a reference cell which is filled with a non-absorbing gas. The infrared detector will measure the difference between the sample cell and the reference cell [8]. This difference can determine the $\mathrm{CO}$ or $\mathrm{CO}_{2}$ gas concentration found in the sample stream. NDIR systems are maintained at temperatures above dew point, prior to the chiller units to prevent condensation from entering the analyzers. Water vapor absorbs a wavelength of light similar to $\mathrm{CO}$ and $\mathrm{CO}_{2}$, which could cause erroneous measurements. Water vapor will also damage the analyzers.

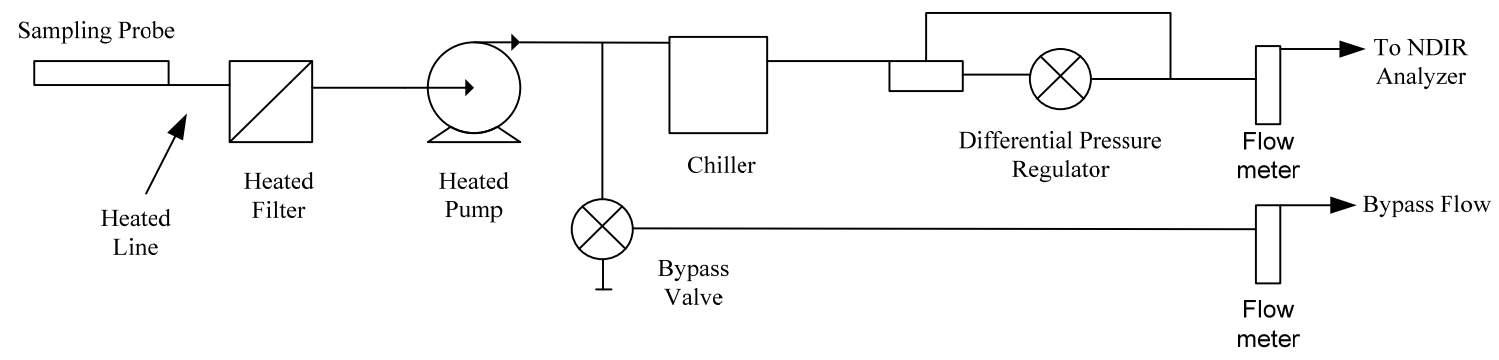

Figure 3: General Schematic of $\mathrm{CO} / \mathrm{CO}_{2}$ Sampling System 


\subsubsection{Oxides of Nitrogen Measurement}

$\mathrm{NO}_{\mathrm{x}}$ emissions are measured using chemiluminescent detection technology.

Chemiluminescent detection measures the concentration of NO present in the sample. The NO in the sample is converted into $\mathrm{NO}_{2}$ by gas-phase oxidation with molecular ozone $\left(\mathrm{O}_{3}\right)$. About $10 \%$ of the $\mathrm{NO}_{2}$ becomes electrically excited, followed by an immediate return to the non-excited state accompanied by the release of a photon during this reaction. A photon detector is then used to measure the photon emission quantity. This quantity is proportional to the amount of NO present in the sample $[11,19]$. Prior to reaching the analyzer the sample stream's concentration of $\mathrm{NO}_{2}$ must be converted into $\mathrm{NO}$ in order to take advantage of the above-mentioned reaction. This allows for the complete analysis of $\mathrm{NO}_{\mathrm{x}}\left(\mathrm{NO}+\mathrm{NO}_{2}\right) . \mathrm{NO}_{2}$ can be converted to $\mathrm{NO}$ by using a $\mathrm{NO}_{2}$ to $\mathrm{NO}$ converter in line with the analyzer and sample stream. The converter consists of a bed of activated carbon maintained at a temperature above $205^{\circ} \mathrm{C}$. The $\mathrm{NO}_{2}-\mathrm{NO}$ converter must have a $90 \%$ or greater conversion efficiency [19]. $\mathrm{NO}_{2}$ is soluble in water. To prevent losses of $\mathrm{NO}_{2}$ in water, the system must be maintained at a temperature above the dew point, $110-120^{\circ} \mathrm{C}$, to prevent condensation from forming resulting in a loss of $\mathrm{NO}_{2}$ [2]. To maintain this temperature a heated line is used from the sampling probe to the sample inlet of the $\mathrm{NO}_{\mathrm{x}}$ measurement box. Within the box the stainless steel lines are insulated to prevent heat loss. The components of the system such as the filter, pump and solenoid valve are heated to prevent cold spots within the system resulting in the formation of condensation. A basic design layout of the $\mathrm{NO}_{\mathrm{x}}$ measurement system can be found in Figure 4: 


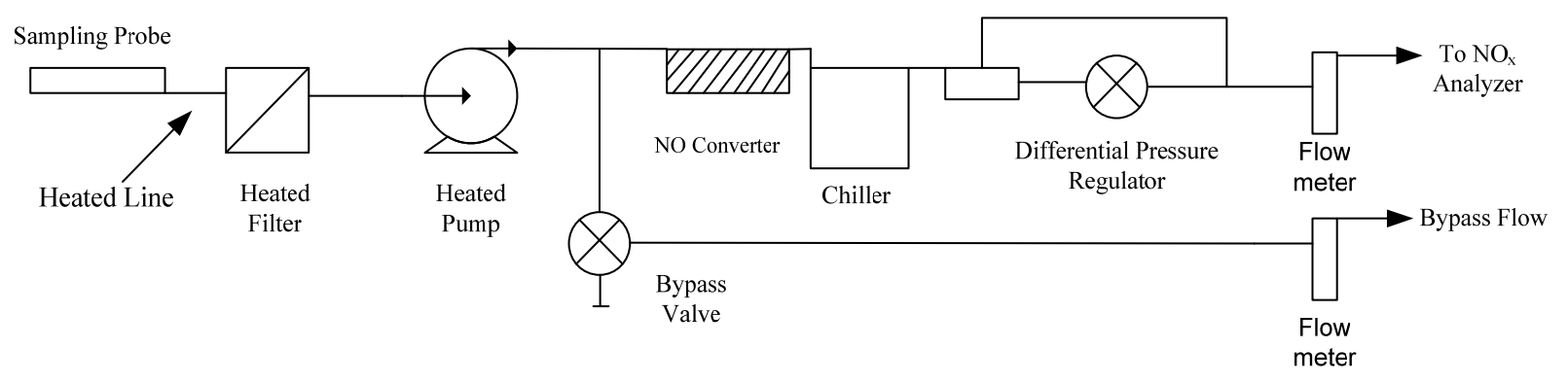

Figure 4: General Schematic of NOx Sampling System

\subsubsection{Hydrocarbons Measurement}

Hydrocarbons are measured using a heated flame ionization detector (HFID). The hydrocarbon analyzer contains a heated oven maintained at $190{ }^{\circ} \mathrm{C}$ [2]. A flame is inside of the heated oven, is sustained by the combustion of a regulated flow of air and a 40/60 ratio of hydrogen/helium fuel. The flame is elevated between two electrodes that establish an electrostatic field. The exhaust sample stream flows through the flame of the detector. As the sample flows through the flame, the hydrocarbons in the sample stream become ionized resulting in a small current being produced between the polarized electrodes of the analyzer. The current produced is directly proportional to the hydrocarbons that are present in the sample stream [19]. Exhaust streams prior to the HFID are maintained at temperatures above $375^{\circ} \mathrm{F}$ to prevent hydrocarbons from condensing.

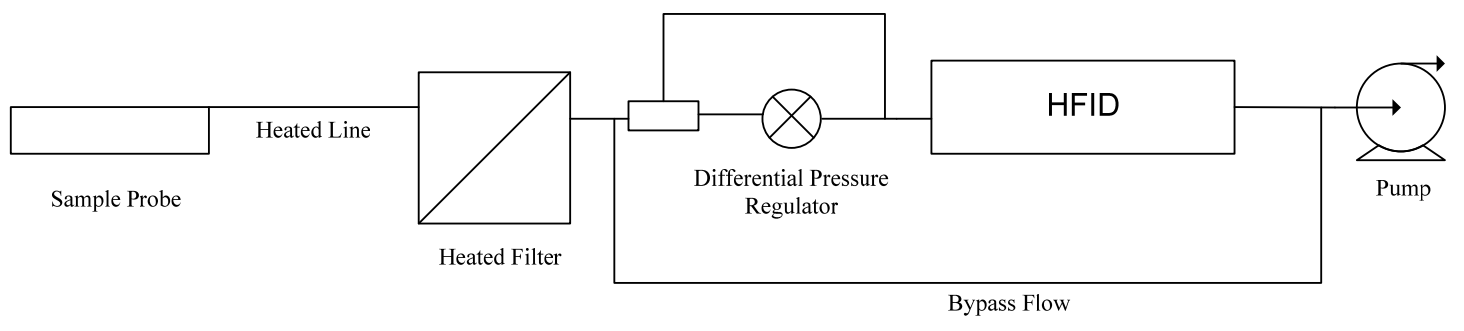

Figure 5: General Schematic of Hydrocarbon Sampling System 


\subsubsection{Particulate Matter Measurement}

PM is measured gravimetrically by collecting it on fluorocarbon-coated glass fiber filters. The process to do so requires a portion of exhaust stream to be diluted with air to maintain a temperature below $125^{\circ} \mathrm{F}$ [2]. This temperature is such, to prevent the loss of soluble organic fraction (SOF) of PM which evaporates at temperatures above [1]. PM formation is also influenced by the dilution process. The measurement technique is designed to simulate the formation process of raw exhaust mixing and diluting with ambient air as it does exiting the tail pipe of a vehicle. The process usually involves the sample entering a dilution tunnel where a slip stream system takes a portion of the total tunnel flow and passes a known volume of sample through a set of particulate filters. The filters are then weighed and the amount of PM deposited is determined. A relation is then made to the total exhaust PM concentration.

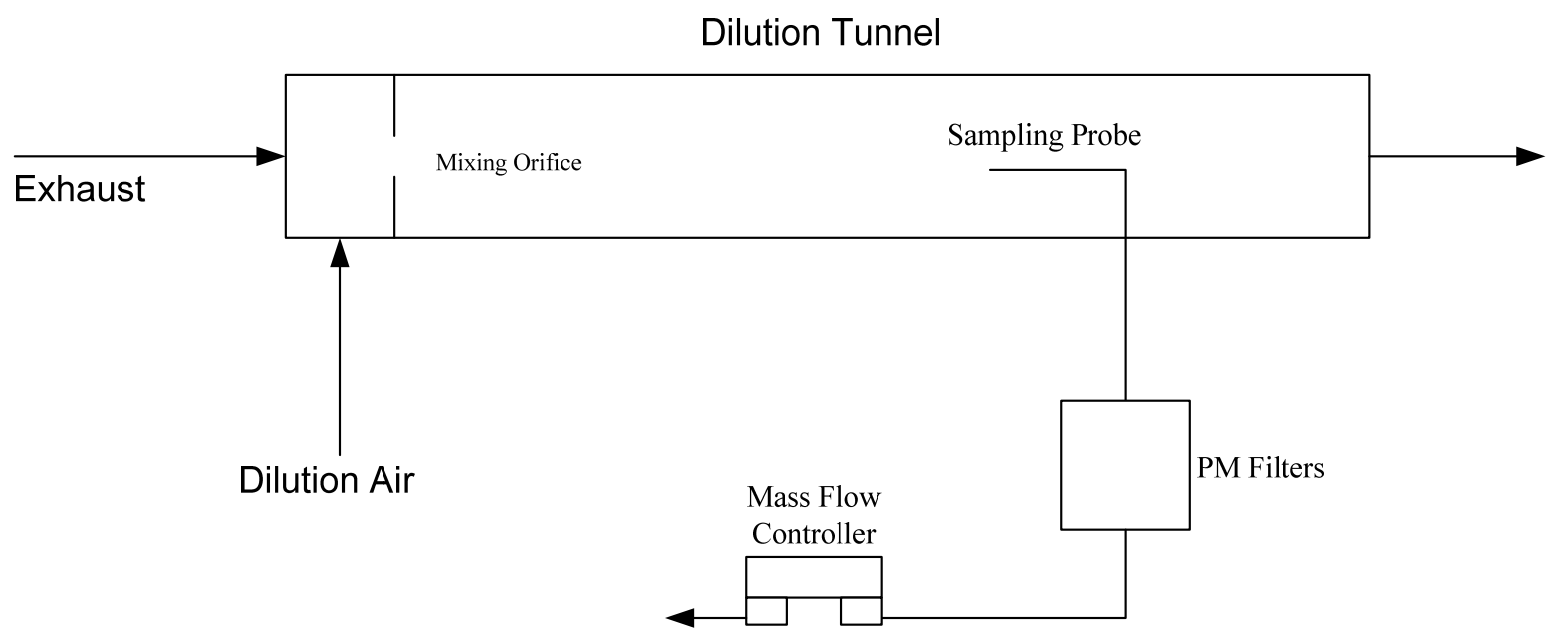

Figure 6: General Schematic of PM Sampling System 


\subsection{The Future of Locomotive Emissions Testing}

\subsubsection{Introduction}

The regulated mass emission rates produced by a locomotive are being reduced. To accurately measure the increasingly lower emissions, measurement techniques, testing procedures and emissions testing equipment must be updated. In March 2008, EPA finalized a three part program that will dramatically reduce emissions from diesel locomotives of all types; line-haul, switch, and passenger rail. The legislation will reduce PM emissions from these engines by as much as 90 percent and $\mathrm{NO}_{\mathrm{x}}$ emissions by as much as 80 percent when fully implemented [9]. Rather than continuously update Part 92 of the CFR, the EPA introduced another section, Part 1033 which refers to Part 1065 to address future locomotive emissions requirements and testing procedures [3].

\subsubsection{New Regulations}

Standards are determined by the original manufacture date of the locomotive. This is the date which the assembly of the locomotive was completed for the first time. An example would be locomotives originally manufactured in 2002, 2003, and 2004 are subject to the Tier 1 emissions standards for the duration of their useful life [3]. New standards are found in Tables 6, 7 , and 8 .

A long term strategy has been deployed to introduce advanced aftertreatment high efficiency catalytic technologies setting Tier 4 emissions for newly built locomotives to increasingly lower numbers. These standards are set to be phased in by 2015 . The updates that need to be completed to the raw gaseous emissions, partial flow dilution tunnel system are discussed later in this document under the recommendations section in order to comply with the provisions of Part 1033 and 1065. 
Table 6: 1033.101 Line-Haul Locomotive Emission Standards [3]

\begin{tabular}{|l|c|c|c|c|c|}
\hline \multirow{2}{*}{ Year of Original Manufacture } & \multirow{2}{*}{ Tier of Standards } & \multicolumn{4}{|c|}{ Standards (g/bhp-hr) } \\
\cline { 3 - 6 } & & NOx & PM & HC & CO \\
\hline $1973-1992$ & 0 & 8 & 0.22 & 1 & 5 \\
\hline $1993-2004$ & 1 & 7.4 & 0.22 & 0.55 & 2.2 \\
\hline $2005-2011$ & 2 & 5.5 & 0.1 & 0.3 & 1.5 \\
\hline $2012-2014$ & 3 & 5.5 & 0.1 & 0.3 & 1.5 \\
\hline 2015 or Later & 4 & 1.3 & 0.03 & 0.14 & 1.5 \\
\hline
\end{tabular}

Table 7: 1033.101 Switch Locomotive Emission Standards [3]

\begin{tabular}{|l|c|c|c|c|c|}
\hline \multirow{2}{*}{ Year of Original Manufacture } & \multicolumn{2}{|l|}{$\begin{array}{l}\text { Tier of } \\
\text { Standards }\end{array}$} & \multicolumn{4}{|c|}{ Standards (g/bhp-hr) } \\
\cline { 2 - 6 } & 0 & NOx & PM & HC & CO \\
\hline $1973-1992$ & 1 & 11.8 & 0.26 & 2.1 & 8 \\
\hline $1993-2004$ & 2 & 8.1 & 0.13 & 0.6 & 2.4 \\
\hline $2005-2011$ & 3 & 5 & 0.1 & 0.6 & 2.4 \\
\hline $2012-2014$ & 4 & 1.3 & 0.03 & 0.14 & 2.4 \\
\hline 2015 or Later & & & & & 2.5 \\
\hline
\end{tabular}

Table 8: 1033.101 Smoke Standards for Locomotives (Percent Opacity) [3]

\begin{tabular}{|c|c|c|c|}
\hline Tier & Steady State & 30 Sec. Peak & 3 Sec. Peak \\
\hline 0 & 30 & 40 & 50 \\
\hline 1 & 25 & 40 & 50 \\
\hline 2 and later & 20 & 40 & 50 \\
\hline
\end{tabular}




\subsection{Emissions Reduction Technologies}

With the new regulations taking soon effect, locomotive engine manufacturers have to combat the lower mass emission rates with technologies designed to reduce emission levels. An engine manufacturer's primary goal is to cost effectively reduce and meet the brake specific emissions regulations, while maintaining fuel consumption and engine power. Some of the available technologies are briefly discussed.

\subsubsection{Diesel Particulate Filters}

Diesel particulate filters are an aftertreatment device designed to reduce the PM emissions produced by an engine. Engine exhaust is routed through a filter which collects particulate matter on its surface. Filters reduce the opacity of the exhaust stream greatly [4]. Many filters are designed to burn off the PM collected on the filter after a certain period of time in a process referred to as filter regeneration [5]. The purpose of filter regeneration is to increase the operational life of the PM filter. Several techniques exist to regenerate the diesel particulate filters. This is a promising technology which has been proven to greatly reduce PM emissions.

\subsubsection{Fuel Injectors}

Fuel injectors influence the emissions produced by an engine. The amount of fuel injected as well as the timing when it is injected and how it is injected will affect the emission production. Slightly retarding the fuel injection is a way to decrease the levels of $\mathrm{NO}_{\mathrm{x}}$ while increasing the levels of PM [5]. Fuel injector techniques coupled with diesel particulate filters may get the emissions quantities of an engine to compliant levels. The number of injectors and their location in the cylinder can also affect the emission production rates. Injection swirls will reduce $\mathrm{CO}$ and $\mathrm{HC}$ emissions allowing for complete combustion [4]. The type of fuel injector will also present possible emissions reduction strategy techniques. Moving from mechanical fuel injectors to electronic fuel injectors gives the engine manufacturer the ability to control the 
timing of the fuel injection as well as the amount of fuel injected [4]. The spray pattern of a injector has been proven to develop near complete combustion of the air and fuel mixture.

\subsubsection{Exhaust Gas Recirculation}

Exhaust Gas Recirculation (EGR) is another promising technology available for locomotive engine manufacturers. A portion of the exhaust stream is recirculated in the place of the intake air on the intake port of the engine. The recirculated gases decrease the maximum combustion temperature of the cylinder by absorbing some of the energy produced by combustion, thus reducing the $\mathrm{NO}_{\mathrm{x}}$ production of the engine. The expected $\mathrm{NO}_{\mathrm{x}}$ reduction of an EGR system is on the order of 50 to 60 percent [11]. The benefit of such a system is the fact that the exhaust emissions used for the dilution of the intake air are already there, preventing the need for an external source of intake air dilution. Strategic EGR techniques can be developed to reduce brake specific emissions while maintaining efficient engine speed and torque. Under certain loading requirements the engine can be designed to increase or decrease the exhaust gases being recirculated back into the intake air.

\subsubsection{Water Injection}

Water injection, like an EGR system, is a form of intake air dilution. Water injected into the intake will absorb some of the energy produced by combustion, thus reducing the $\mathrm{NO}_{\mathrm{x}}$ production of the engine. The benefit of water injection over an EGR system is the fact that water is introduced as a liquid and doesn't displace as much volume as a recirculated gas. The

levels of $\mathrm{NO}_{\mathrm{x}}$ can be decreased while maintaining peak engine performance [1]. EGR systems have a tendency to decrease emissions levels but also decrease the engines peak performance substantially. The downside to water injection is an increase in PM and smoke levels. Water injected may also create problems with engine corrosion [1]. The other downfall to this system is the fact that the locomotive would have to carry an extra water supply as well as the fuel supply. 


\subsection{In Summary}

The purpose of this literature review was to discuss the emissions requirements imposed by the EPA for the locomotive engine manufacturers, as well as to discuss measurement techniques, and to discuss methods for manufacturers to meet these regulations. It is an engine manufacturer's responsibility to produce cleaner engines technologies to aide in the reduction of environmental and human hazards. The EPA has issued new regulations for locomotive engines soon taking effect. The measurement techniques and testing procedures for an engine must be updated to accurately measure the emissions production. Improvements in engines technologies will be beneficial to the atmospheric emissions levels. The EPA chose to phase in the regulations gradually to prevent tremendous financial demands on the engine manufacturers. Regulating and reducing the emissions of locomotive engines will create a significant step forward in the overall emissions levels of the United States. 


\section{Chapter 3 - Gaseous Emissions Measurement Equipment Design}

\subsection{Gaseous Emissions}

The EPA has mandated that emissions are measured using laboratory grade analyzers with certain addressable capabilities. These capabilities include precision, response, and drift. The precision of the analyzers used must be \pm 1 percent of full-scale concentration for each range that is used above $155 \mathrm{ppm}$. Ranges below $155 \mathrm{ppm}$ require an analyzer precision of \pm 2 percent. The analyzers used must also comply with the condition of a response time of $95 \%$ of a step value within six seconds or less of all ranges used. The zero drift for the analyzer in a one hour time period shall be less than $2 \%$ of full scale on the lowest range used. The zero-response is defined as the mean response including noise to a zero-gas during a 30-second time interval [2]. Analyzers meeting these specifications were chosen to be incorporated in the raw emissions laboratory, found in Table 9.

Table 9: Equipment Selection

\begin{tabular}{|c|c|c|}
\hline $\begin{array}{c}\text { Exhaust } \\
\text { Constituent }\end{array}$ & $\begin{array}{c}\text { Analyzer } \\
\text { Manufacturer }\end{array}$ & Model \# \\
\hline $\mathrm{NO}_{\mathrm{x}}$ & EcoPhysics & CLD 822 CMH \\
\hline $\mathrm{CO} / \mathrm{CO}_{2}$ & Horiba & AIA 220 \\
\hline $\mathrm{HC}$ & Horiba & FIA 236 \\
\hline
\end{tabular}

Each analyzing system was designed around the analyzers; allowing for a proper conditioned supply of sample gas, delivered for analysis. 


\subsection{Gaseous Emissions Systems Design}

Equipment for the raw emissions laboratory was designed for both form and function. The systems were designed to function under the specifications outlined by the Code of Federal Regulations. This includes the analyzer specifications mentioned prior, as well as the sample conditioning systems as mentioned in the literature review section of this document. The system's form was designed for ease of mobility. Each of the individual equipment systems are capable of being carried to the test site of interest by two persons. This allows the testing equipment to be set up in an area where a laboratory trailer would not easily fit, thus opening the opportunity to test various engine test site configurations.

To do so, each system was designed to fit inside of a Weather Guard $2 \mathrm{ft}$ cube toolbox. The toolboxes were retrofitted with steel handles, which allows workers to carry the equipment to a test site without the aid of machinery. Each box contains the individual components of a sampling system. Each sampling system consists of plumbing, filters, heaters, flow meters, chillers, regulators and so forth. The systems that make up the laboratory consists of HC analyzing system, zero grade air system, two $\mathrm{CO} / \mathrm{CO}_{2}$ sampling systems, $\mathrm{NO}_{\mathrm{x}}$ sampling system, and a PM filter mass flow control system. A computer system was designed to collect the data from the analyzers with the aid of data acquisition modules that were installed in each sampling unit; communicating through an Ethernet connection. The modules also contain thermocouple inputs and digital outputs that control the heated components of each system. 


\subsubsection{Hydrocarbons}

Hydrocarbons were measured using heated flame ionization detectors or HFIDs. The sample conditioning system consists of a heated pump, bypass manifold, and heated lines as shown in Figure 7.

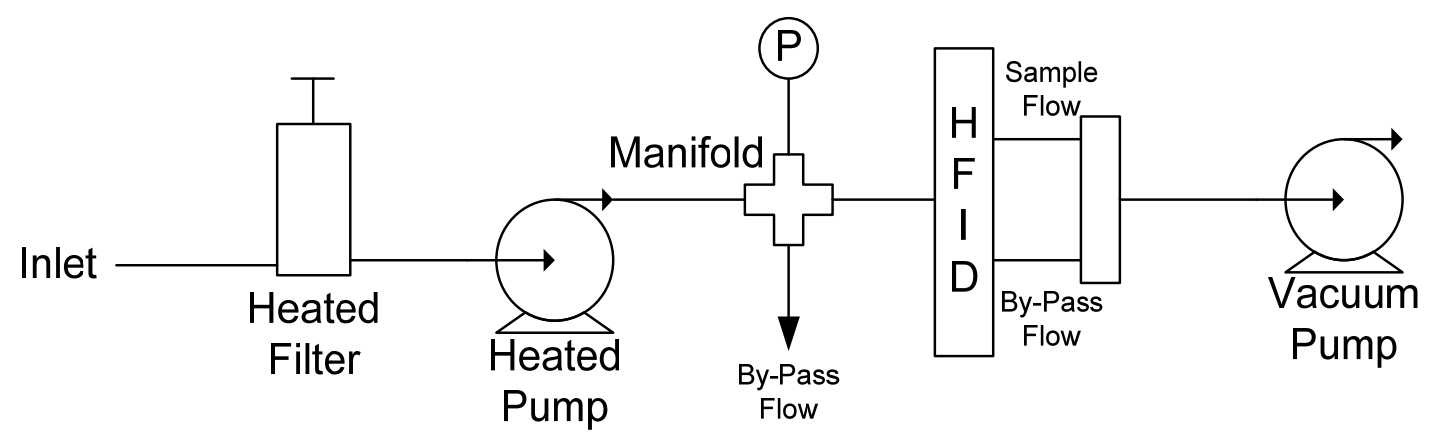

Figure 7: HC Analyzing System

The completed system is shown in Figure 8 below. All of the components were designed for ease of maintenance. The analyzer chosen for the system was a Horiba FIA 236. The system was designed to contain a module that would output a signal to a computer station via Ethernet connection. Data acquisition software was developed to collect the analog signals produced by the analyzer. The analog to digital converter was capable of measure analog inputs of $0-5$ volts. 


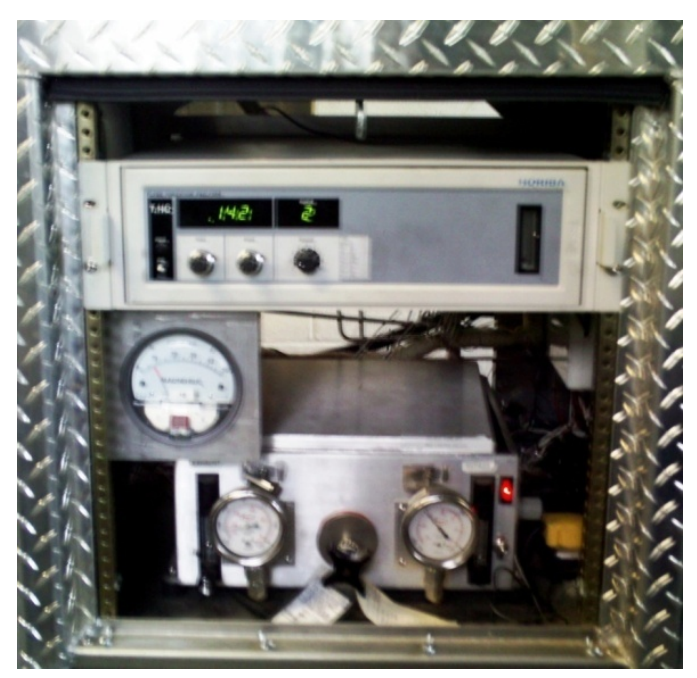

Figure 8: Hydrocarbon Emissions Measurement System

Table 10: HC Emissions Measurement System List of Components

\begin{tabular}{|c|c|c|}
\hline Component & Manufacturer & Comments \\
\hline Dual Head Heated Pump & Air Dynamics & 11 liters/min \\
\hline Internal Lines & Stainless Steel Tubing & Swagelok fittings \\
\hline Manifold Pressure & Magnehelic & Inches of Water \\
\hline Heated Filter & Unique Heated Products & Replaceable elements \\
\hline
\end{tabular}

\subsubsection{Purge Gas/Zero Air Generation}

A Parker-Balston FT-IR Purge gas generator followed by a zero air generator and air tanks provide the zero air for the hydrocarbon analysis system. The FT-IR purge gas generator provides a purified purge gas and air bearing gas from compressed air. The purge gas generator provides dry carbon dioxide free air. The zero air generator then removes the hydrocarbons from the air. The system can provide the hydrocarbon analyzer with the appropriate ultra pure zero grade air. Figure 9 presents a piping diagram of the zero grade air generation system. 


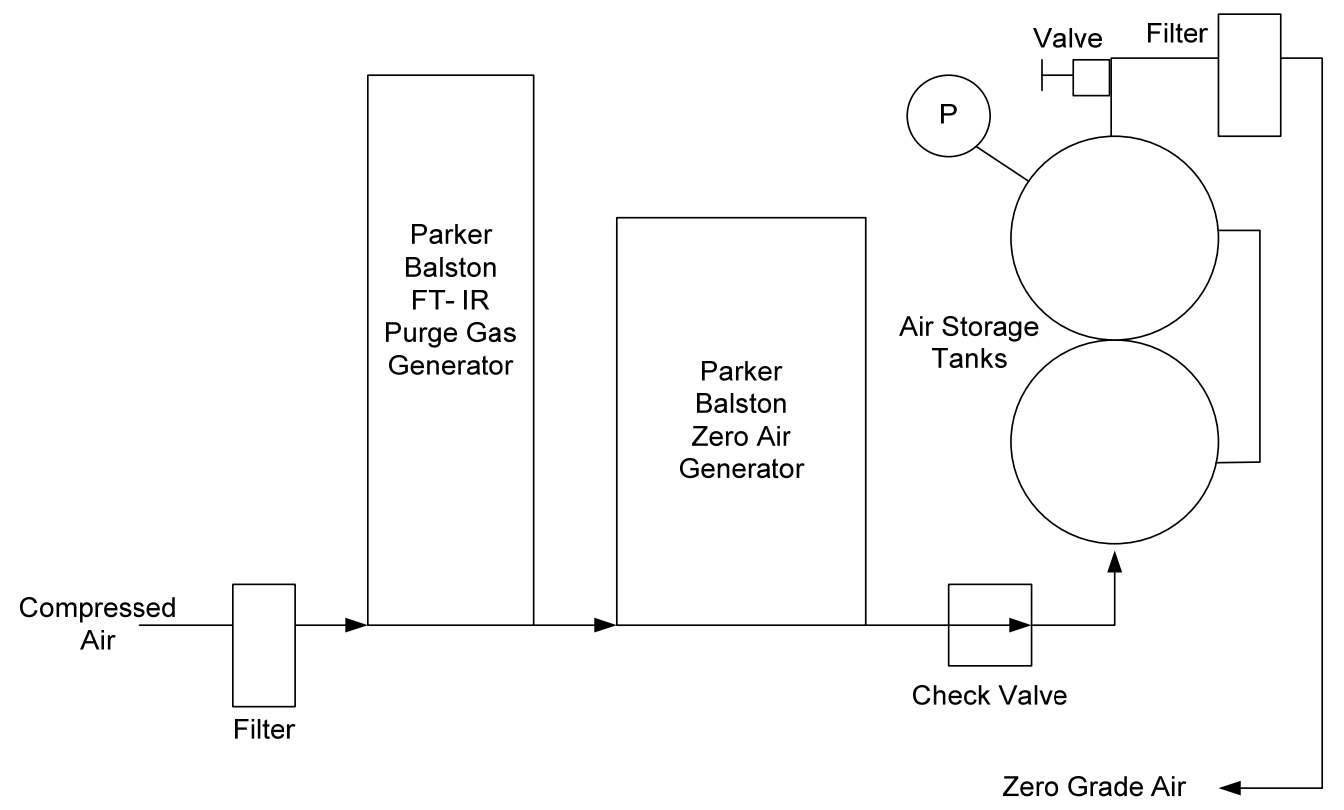

Figure 9: Zero Grade Air Generation System Schematic

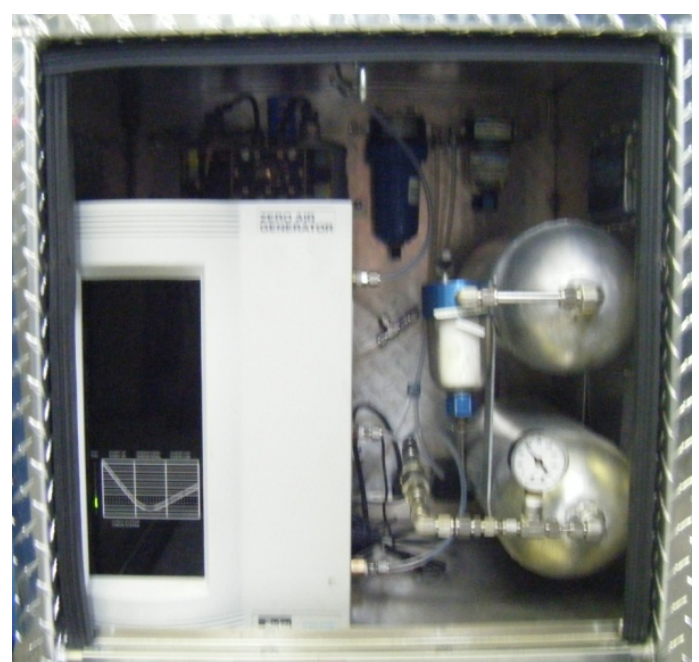

Figure 10: Zero Grade Air Generation System

Figure 10 is a photograph of the completed system. The system was designed so that the operator could see the notification panel located on the front of the zero air generator. The system also contained several filters to remove any unwanted particulate matter from the air. The piping was configured in such a way that the system was easily accessible for repair. 
Table 11: HC Conditioned Air Components List

\begin{tabular}{|c|c|c|}
\hline Component & Manufacturer & Comments \\
\hline Purge Gas Generator & Parker- Balston & Located behind the zero air generator \\
\hline Zero Air Generator & Parker- Balston & Located in the front for visual display \\
\hline Internal Plumbing & Swagelok & Stainless and Teflon tubing \\
\hline Air tanks & WVU & Aluminum storage tanks \\
\hline Filters & Various & Remove any particles in the system \\
\hline
\end{tabular}

Table 11 lists the components used in the system. All components in the system were leak checked post build to verify the system piping.

\subsubsection{Oxides of Nitrogen}

Oxides of nitrogen are measured using a chemiluminescent analyzer. Prior to reaching the analyzer the sample must first go through a $\mathrm{NO}_{2}$ to $\mathrm{NO}$ converter that has conversion efficiency greater than $90 \%$ [2]. The $\mathrm{NO}_{2}$ to $\mathrm{NO}$ converter serves as a catalytic reactor transforming the $\mathrm{NO}_{2}$ portion of a sample into NO. The purpose of this reactor is to reduce and or eliminate the losses of $\mathrm{NO}_{2}$ due to its solubility in water [2]. For this system a $\mathrm{NO}_{2}$ to $\mathrm{NO}$ converter manufactured by Horiba was incorporated into the system prior to a M\&C dual cell chiller. The chiller removed water present in the exhaust sample to prevent analyzer damage and misreading. The $\mathrm{NO}_{\mathrm{x}}$ sampling system contained a three-way valve for the option of bypassing the $\mathrm{NO}_{2}$ to $\mathrm{NO}$ converter. This bypass would allow for the sample to be analyzed by the EcoPhysics analyzer which houses an internal $\mathrm{NO}_{2}$ to $\mathrm{NO}$ converter allowing for the measurement of $\mathrm{NO}$ and $\mathrm{NO}_{2}$. To do so, the system first measures the concentration of $\mathrm{NO}$ in the sample prior to reaching its $\mathrm{NO}_{2}$ to $\mathrm{NO}$ converter. The sample is then passed through the converter and a new value of NO is read. The difference between the first and the second reading is the amount of $\mathrm{NO}_{2}$ present in the sample stream. The internal EcoPhysics $\mathrm{NO}_{2}$ to $\mathrm{NO}$ converter would not be capable of handling the $\mathrm{NO}_{2}$ concentration in a raw sample, particularly 
if a diesel particulate filter was being used. A schematic of the plumbing system contained in the $\mathrm{NO}_{\mathrm{x}}$ sampling system can be found in Figure 11:

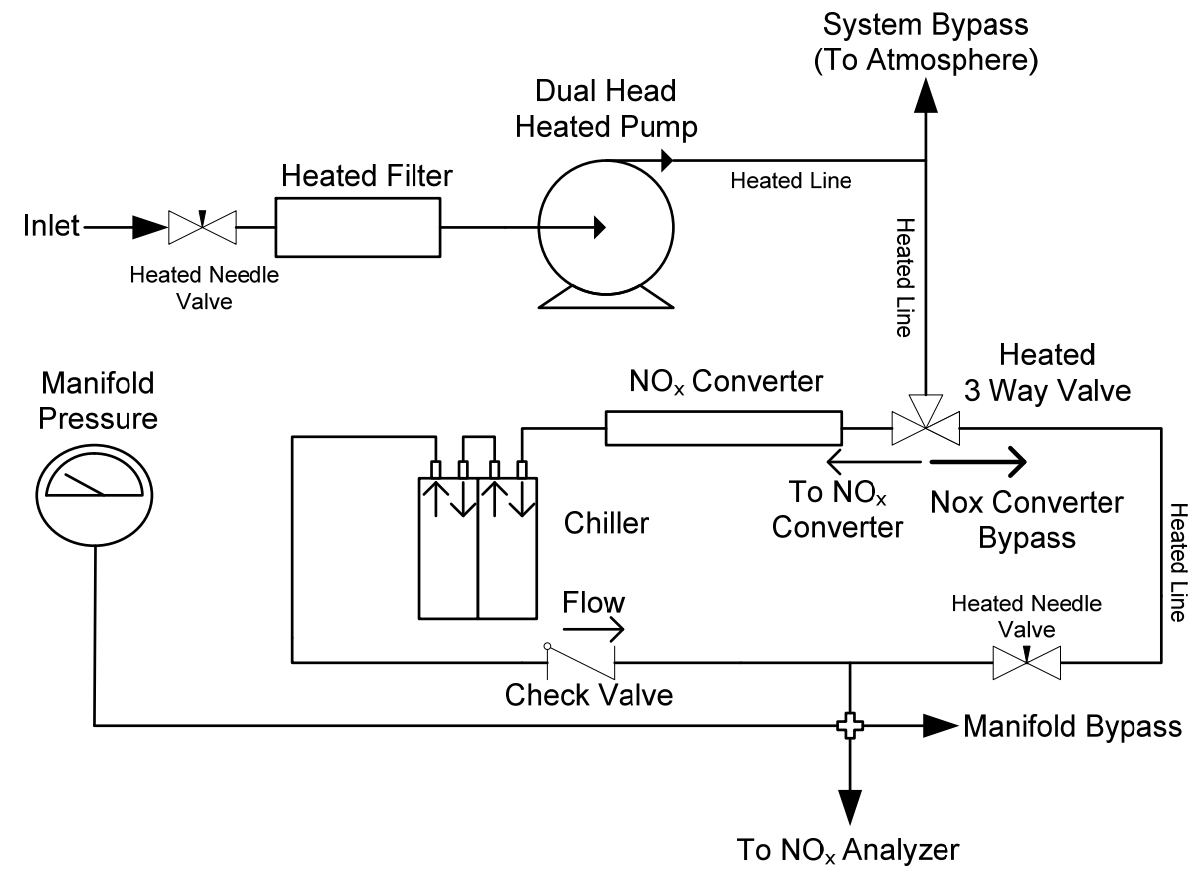

Figure 11: NOx Sampling System

The peltier chiller located inside of the system is a dual cell unit which is plumbed in series. This was designed to give enough chilling capacity to handle the amount of water found in a raw exhaust stream. The EcoPhysics analyzer contained an internal pump which drew a sample from the exhaust manifold through the analyzer for measurement. Having the manifold increased the velocity of the sample traveling through the system decreasing the time to travel from the exhaust source to the analyzer. Figure 12 shows the completed system. 


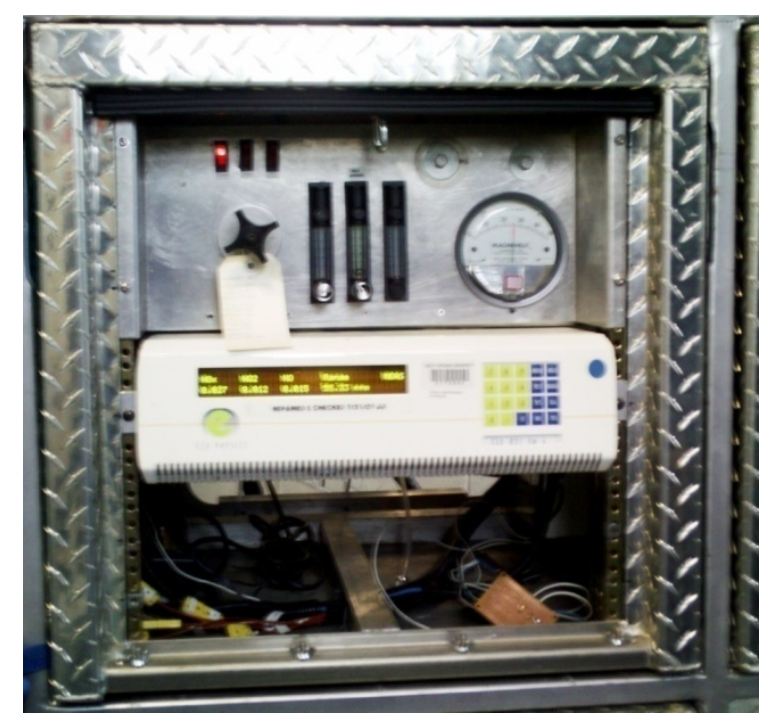

Figure 12: $\mathrm{NO}_{\mathrm{x}}$ Emissions Measurement System

\section{Table 12: $\mathrm{NO}_{\mathrm{x}}$ Emissions Measurement System List of Components}

\begin{tabular}{|c|c|c|}
\hline Component & Manufacturer & Comments \\
\hline Dual Head Heated Pump & Air Dynamics & $11 \mathrm{lpm}$ \\
\hline Heated Filter & Unique Heated Products & Replaceable elements \\
\hline Chiller & M\&C Coolers & Dual cell peltier chiller \\
\hline NOx Converter & COM-11 HRB & External Converter \\
\hline Check Valve & Swagelok & One direction of flow \\
\hline Internal Heated Lines & Omega & Heat Wrap then Exhaust Wrap \\
\hline 3 Way Heated Valve & Swagelok & Heat Wrap then Exhaust Wrap \\
\hline Manifold Pressure & Magnehelic & Inches of Water \\
\hline Internal Lines & Swagelok & Stainless Steel Tubing \\
\hline
\end{tabular}

Table 12 is a list of all of the components used in the $\mathrm{NO}_{\mathrm{x}}$ system design. All components were insulated with exhaust manifold wrap. This allowed for the temperature of the system to be controlled at a steady $235^{\circ} \mathrm{F}$ with the internal temperature controllers. 


\subsubsection{Carbon Monoxide and Carbon Dioxide}

Another two units were designed to house the $\mathrm{CO} / \mathrm{CO}_{2}$ sampling systems. Carbon dioxide and carbon monoxide concentrations are measured using non-dispersive infrared detection (NDIR). The sample entered the unit and passed through a heated filter maintained at a temperature above $235^{\circ} \mathrm{F}$. Then the sample was drawn through a heated head pump and sent to a M\&C cooler which removed the water from the sample stream. After the pump, the stream split to allow for a bypass flow. The bypass flow essentially reduced the time the sample stream would travel from the heated line located at the exhaust sampling point to the inlet of the $\mathrm{CO} / \mathrm{CO}_{2}$ sampling system. This allowed for faster response times. Once the sample passed through the chiller it was split and sent to two flow meters, one for $\mathrm{CO}$ and one for $\mathrm{CO}_{2}$. After the flow meters, a differential pressure regulator was installed to maintain a constant flow rate throughout the sampling system. The sample then entered the $\mathrm{CO} / \mathrm{CO}_{2}$ analyzer where the concentrations of $\mathrm{CO}$ in parts per million and $\mathrm{CO}_{2}$ in percent were measured. Two systems were built to measure $\mathrm{CO} / \mathrm{CO}_{2}$. One system was used to measure the exhaust constituents in the raw exhaust located at the exit of the engine's exhaust system. The other system was used to measure the $\mathrm{CO}_{2}$ concentrations found in the partial flow dilution tunnel system. This system, though only utilizing the $\mathrm{CO}_{2}$ part of the analyzer was made identical for the possibility of analyzer changeability and also leading for the opportunity for the system to be removed from the raw laboratory system and utilized in other projects where $\mathrm{CO}$ and $\mathrm{CO}_{2}$ were to be measured. Figure 13 shows the piping and instrumentation diagram for the $\mathrm{CO} / \mathrm{CO}_{2}$ system. Figure 14 shows one of the completed $\mathrm{CO} / \mathrm{CO}_{2}$ systems. Table 13 shows the components used in the system design. 


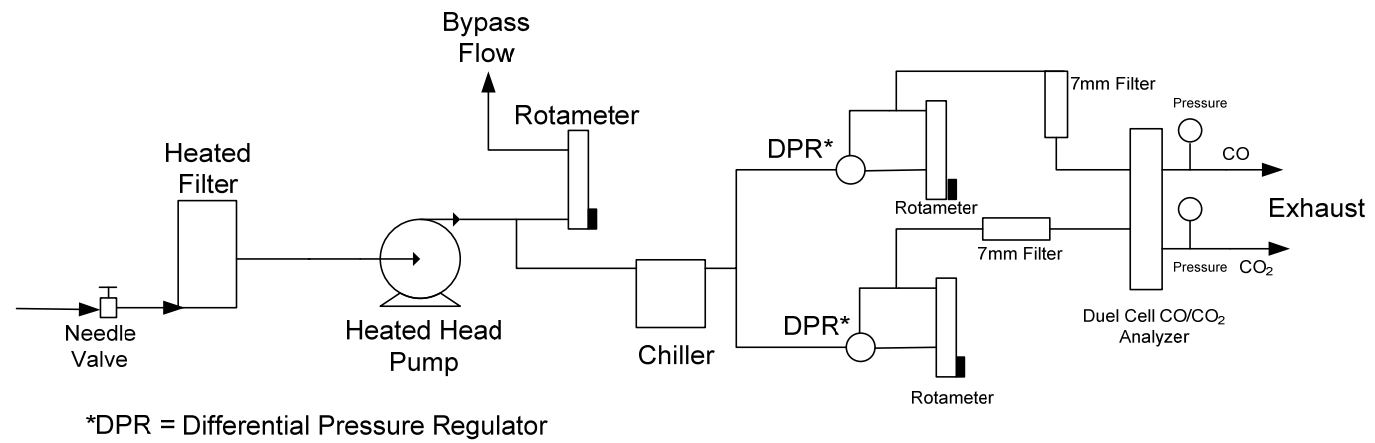

Figure 13: $\mathrm{CO} / \mathrm{CO}_{2}$ Sampling System

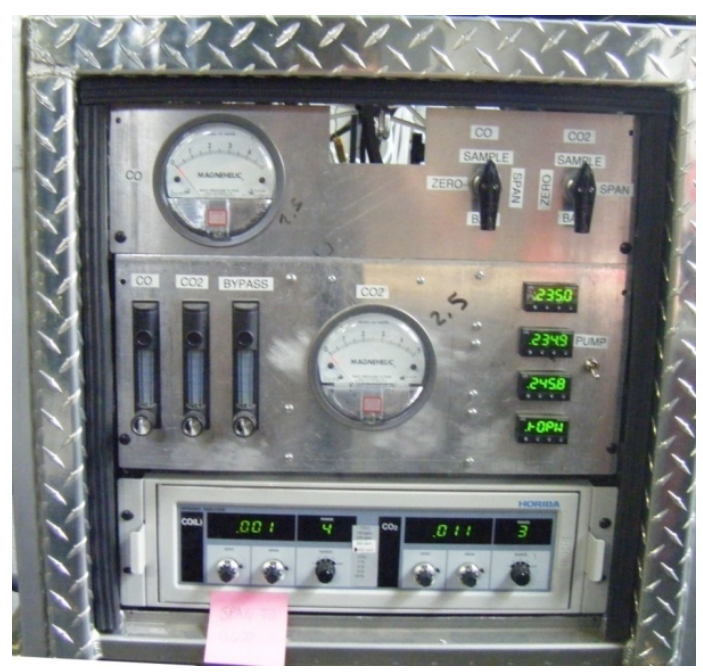

Figure 14: $\mathrm{CO} / \mathrm{CO}_{2}$ Emissions Measurement System

Table 13: $\mathrm{CO} / \mathrm{CO}_{2}$ Emissions Measurement System List of Components

\begin{tabular}{|c|c|c|}
\hline Component & Manufacturer & Comments \\
\hline Dual Head Heated Pump & Air Dynamics & $11 \mathrm{lpm}$ \\
\hline Heated Filter & Unique Heated Products & PM filter \\
\hline Chiller & M\&C Coolers & dual cell peltier chiller \\
\hline Post Analyzer Pressure & Magnehelic & inches of water \\
\hline Internal Lines & Stainless Steel Tubing & Swagelok fittings \\
\hline Internal Heated Lines & Omega & heat wrap then exhaust wrap \\
\hline 7 mm Filters & Swagelok & filters right before the analyzers \\
\hline
\end{tabular}




\section{Chapter 4 - Gaseous Emissions Equipment Verification}

\subsection{Introduction}

Once the individual systems were built their operation was tested versus a creditable exhaust constituent measurement system. To do so, the gaseous emissions sampling systems were transported to West Virginia University's Engine and Emissions Research Laboratory (EERL) for validation. The EERL featured a laboratory that operates under the restrictions and guidelines set forth by the Code of Federal Regulations 40, Part 86, Subpart N [13]. The objective of the study was to verify that the newly developed raw emissions measurement systems produced analogous data when compared to the EERL laboratory system, when measuring the emission constituents of a diesel engine. The following describes the equipment setup and procedures for this validation.

\subsection{EERL Exhaust Measurement System}

The Engines and Emissions Research Laboratory is a facility housing emissions measurement equipment meeting the minimum requirements set forth by the Environmental Protection Agency's Code of Federal Regulations Title 40, part 86, Subpart N which mandates the equipment specifications for laboratories capable of issuing heavy duty diesel engine certification [13]. The laboratory utilizes engine dynamometers to develop and execute engine testing protocols to simulate engine operations similar to the conditions an engine may be subjected to in its useful life. This gives the laboratory the ability to execute federal test protocols to certify diesel engines and fuels.

\subsubsection{Full-Flow Exhaust Dilution Tunnel}

Engine exhaust was measured within a full-flow exhaust dilution tunnel at the EERL. The entire exhaust sample was routed from the engine into a stainless steel dilution tunnel where it was mixed with conditioned dilution air. The tunnel entrance utilized a mixing orifice to further 
enhance the stream turbulence allowing for a complete homogenous exhaust/air mixture. The full-scale tunnel simulated the mixing of exhaust with ambient air; an event that occurs under normal engine operation. Another benefit to the air dilution was it lowered the sample dew point, preventing condensation from entering the analyzing systems. The effects of water on emissions measurement leads to inconsistencies and potential analyzer damage. Certain gas constituents, such as $\mathrm{NO}_{2}$ are soluble in water. The presence of water would lead to inaccurate measurements of $\mathrm{NO}_{\mathrm{x}}$. The analyzers are also sensitive to condensation. For instance non-dispersive infrared analyzers, which measure the concentrations of $\mathrm{CO}$ and $\mathrm{CO}_{2}$, can be damaged due to the presence of condensation. The NDIR analyzer may also produces erroneous measured values due to the possibility of interference from water due to its similar infrared wavelength absorption compared to $\mathrm{CO}$ and $\mathrm{CO}_{2}$.

The dilution tunnel operated on a constant volume sampling system / critical flow venturi system. A critical flow venturi at the tunnel exit in series with a blower system was used to control the total tunnel flow rate. Under choked flow the total tunnel flow rate was determined from the following equation [13].

$$
Q=\frac{K_{v}}{\sqrt{T}} P
$$

\section{Equation 7}

Where:

$\mathrm{Q} \rightarrow \mathrm{SCFM}$ (flow rate at standard conditions)

$\mathrm{K}_{\mathrm{v}} \rightarrow$ calibration coefficient determined by the manufacturer 
$\mathrm{P} \rightarrow$ absolute pressure at venturi inlet (in $\mathrm{Hg}$ )

$\mathrm{T} \rightarrow$ absolute temperature at venturi inlet $\left({ }^{\mathrm{o}} \mathrm{R}\right)$

This value was used to determine the total volume of flow through the tunnel during an exhaust analysis $\left(\mathrm{V}_{\text {mix }}\right)$. This was an important value for determining the mass emissions rates of exhaust constituents.

\subsubsection{EERL Dilute Gaseous Emissions Sampling System}

A sample was drawn from the dilution tunnel by a stainless steel sample probe. The probe was located at a distance downstream of the tunnel where the flow of the exhaust was well mixed with the dilution air. The flow rate in the tunnel was turbulent with a Reynolds number greater than 4000. This represented a turbulent flow that was beyond the bounds of the transitional turbulent zone. This value ensured that the sample being analyzed was completely mixed with the dilution air [1]. From the sample probe the dilute exhaust stream entered a heated line where it was transferred to the analyzing systems. The dilution tunnel contained a probe specifically designed for hydrocarbons and probes for $\mathrm{NO}_{\mathrm{x}}, \mathrm{CO}$, and $\mathrm{CO}_{2}$. The hydrocarbon probe was connected to a stainless steel $1 / 4^{\prime \prime}$ heated line that was maintained at a temperature of $375^{\circ} \mathrm{F}$. This value was specified by the CFR to prevent hydrocarbons from condensing. The $\mathrm{NO}_{\mathrm{x}}, \mathrm{CO}$, and $\mathrm{CO}_{2}$ probes were connected to Teflon heated lines maintained at a temperature of $235^{\circ} \mathrm{F}$. The exhaust samples then traveled throughout the individual sampling systems. Each system contained a heated filter to remove any particulate from the sample stream prior to reaching the analyzers. The systems also contained a heated head pump. Any equipment that came in contact with the sample stream was made out of stainless steel or an inert material (i.e. Teflon). All exhaust gas constituents were measured in parts per million or ppm. 


\subsection{Engine Exhaust Comparison}

Each system was tested versus the existing analyzing system located at the EERL. The majority of the testing took place by "piggy backing" off an existing test. The objective of the study was to review the exhaust concentrations determined by the engine laboratory's analysis system and compare those numbers to the raw emissions systems. To do so, the individual systems first underwent various quality assurance procedures to verify that they met passable checks. The systems were then connected to a sampling probe which would draw a sample from the full-scale dilution tunnel system. This allowed the individual systems to be tested and compared to the results produced by the EERL's gaseous emissions system.

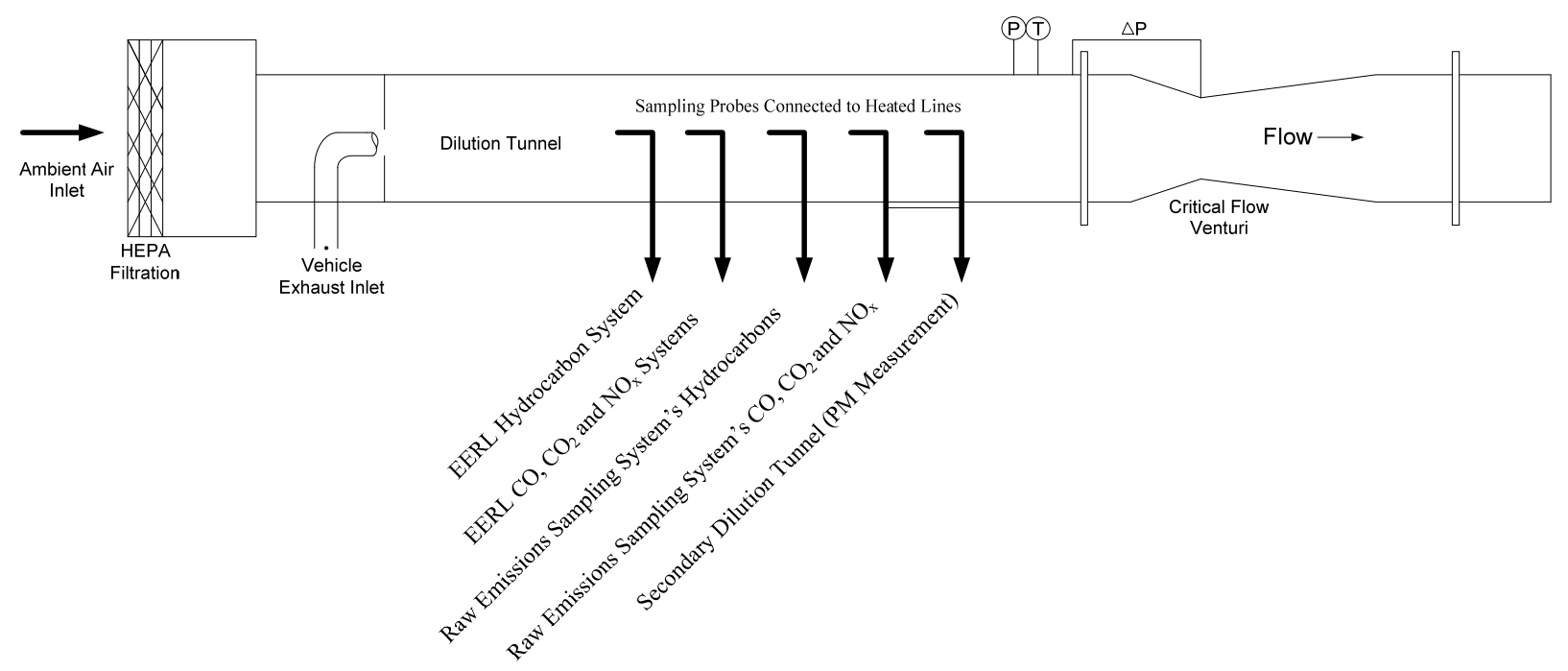

Figure 15: General Schematic of Equipment Setup (Not to Scale)

Figure 15 illustrates the basic testing set up. 


\subsection{Hydrocarbon Analyzing System Verification}

Initially the hydrocarbon system was leak checked, to verify the internal piping system. The piping system was pressurized to $\sim 5.3 \mathrm{psig}$. The system was left to stand for one minute and the pressure within the lines was monitored. To be considered passing, the pressure difference before and after could not vary by more than $0.5 \%$. The results from the leak check are found in Table 14. The analyzers were also drift checked. The system was zeroed and spanned and then allowed one hour for stabilization. The zero and span was rechecked and considered a passing test if the analyzer had not drifted more than $2 \%$ of full scale. Once the quality assurance procedures were completed, the hydrocarbon system was connected to the full scale dilution tunnel via $1 / 4 "$ stainless steel heated line, which was maintained at a temperature of $375^{\circ} \mathrm{F}$. Preserving this temperature prevented water and hydrocarbons from condensing in the line which would have resulted in an inaccuracy of hydrocarbon analysis. The engine was operated following a federal engine testing procedure. The engine used for this study was a Cummins ISM 370 diesel engine.

Table 14: Hydrocarbon System Leak Check

\begin{tabular}{|c|c|c|}
\hline Initial Pressure (psig) & Final Line Pressure (psig) & Percent Difference \\
\hline 5.312 & 5.308 & $0.08 \%$ \\
\hline 5.265 & 5.259 & $0.11 \%$ \\
\hline
\end{tabular}

An example of the data collected during the FTP tests is found in Figure 16 and Figure 17.

Figure 16 displays the hydrocarbon mass emissions rate recorded over the twenty minute test time. Figure 17 represents the accumulative hydrocarbons based on a $1 \mathrm{~Hz}$ sampling frequency. The final sum was used to calculate the percent difference between the two systems, which ultimately was the determining factor for system verification. 


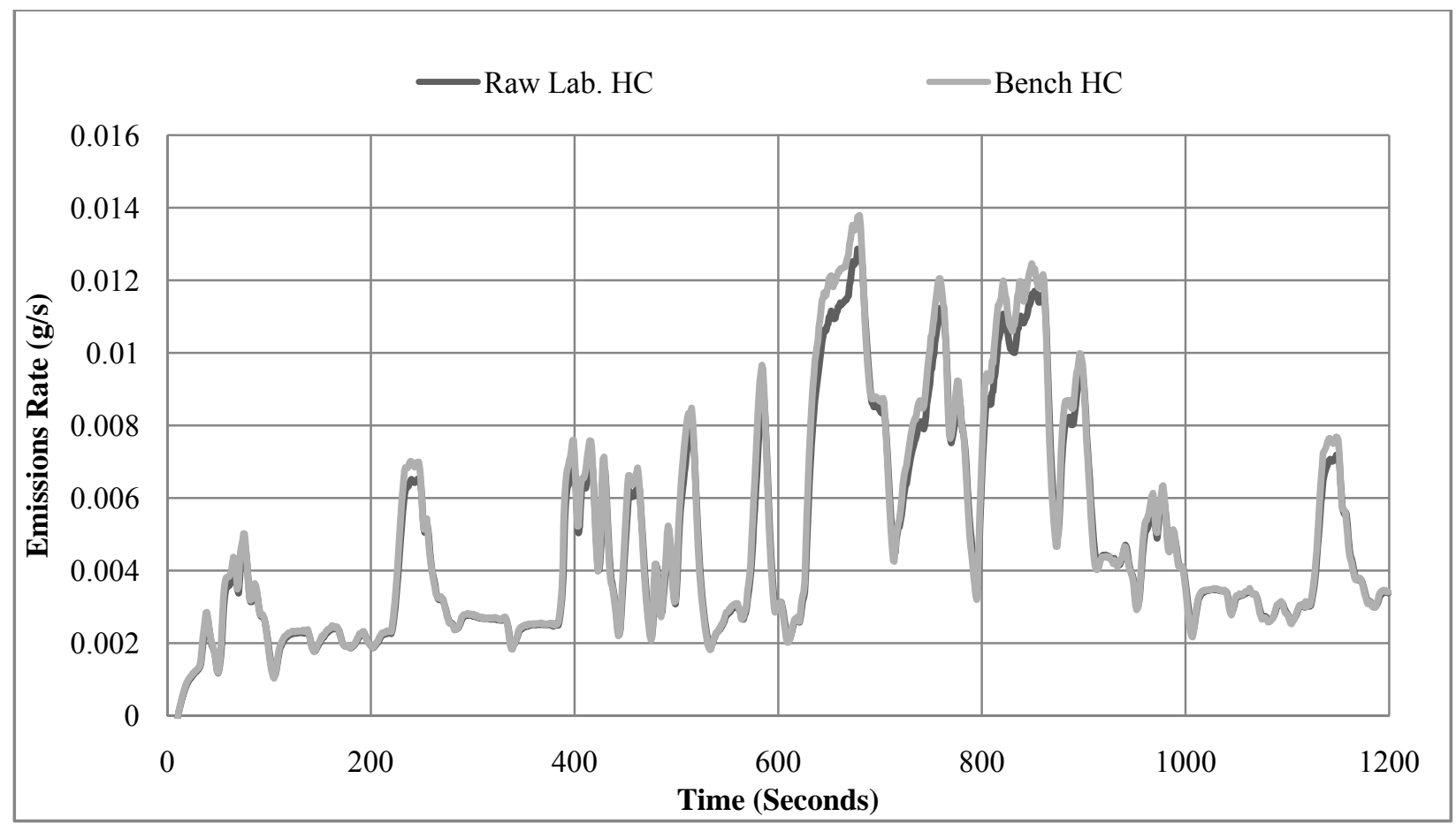

Figure 16: Hydrocarbon System Comparison, FTP One

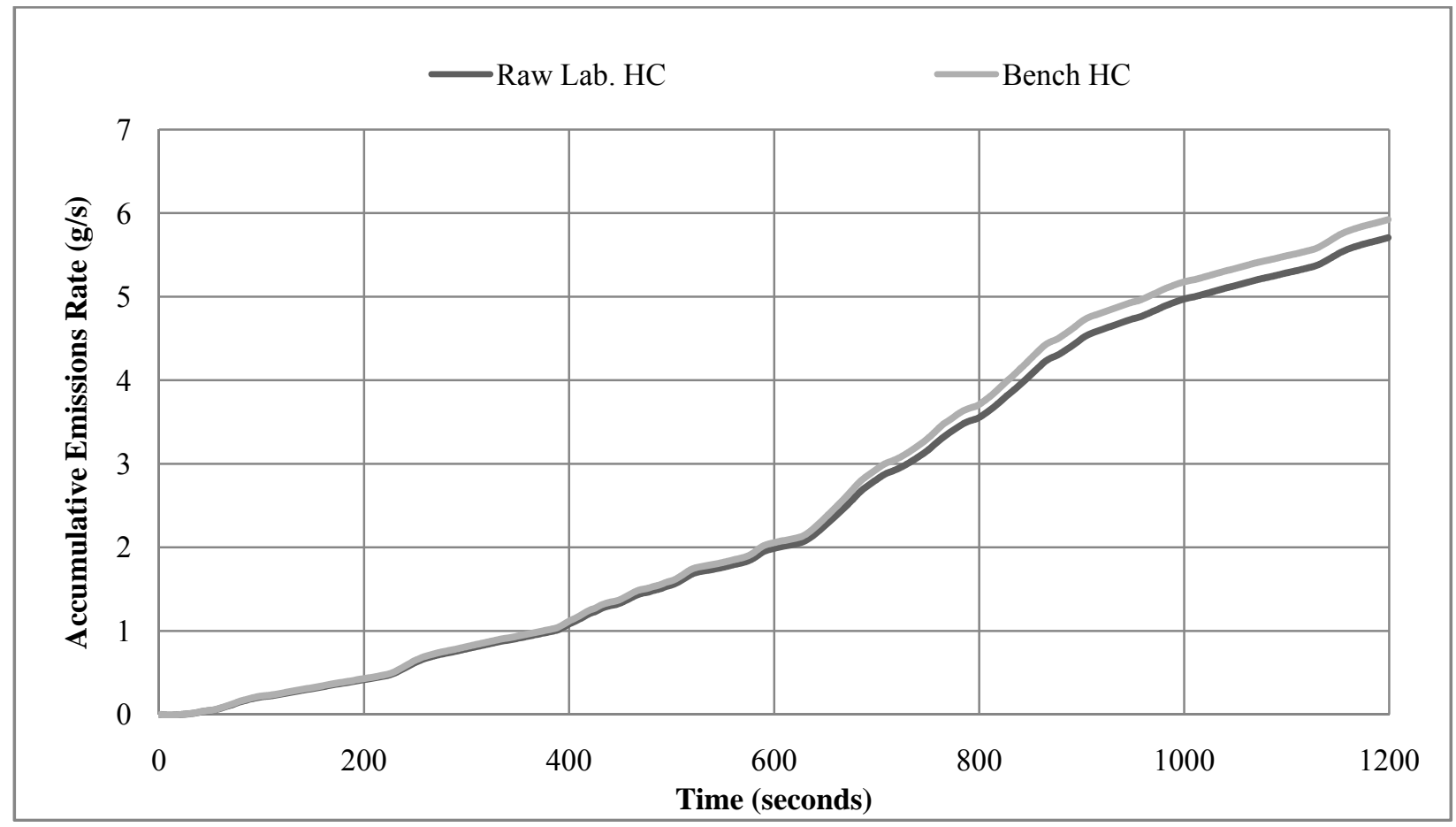

Figure 17: Hydrocarbon Summation, FTP One 
Three twenty minute FTPs were completed. The integrated final value was used to compare the EERL's HC bench results to the raw laboratory HC system results, and to make an assessment of whether or not the system was functioning properly. Table 15 shows the results of the three completed FTPs. The percent difference was found using equation

$$
\% \text { Difference }=\frac{\text { Bench } \sum H C(p p m)-\operatorname{RawLab} \sum H C(p p m)}{\text { Bench } \sum H C(p p m)} * 100
$$

\section{Equation 8}

Table 15: Hydrocarbon System Results

\begin{tabular}{|c|c|c|c|}
\hline Test & $\begin{array}{c}\text { Bench } \\
(\mathrm{g} / \mathrm{hr})\end{array}$ & $\begin{array}{c}\text { Raw Lab. } \\
(\mathrm{g} / \mathrm{hr})\end{array}$ & $\begin{array}{c}\text { Percent } \\
\text { Difference }\end{array}$ \\
\hline Run 1 & 17.8 & 17.1 & $3.7 \%$ \\
\hline Run 2 & 17.9 & 17.3 & $3.3 \%$ \\
\hline Run 3 & 17.6 & 17.1 & $3.3 \%$ \\
\hline \multicolumn{3}{|c|}{ Average Percent Difference } & $3.4 \%$ \\
\hline
\end{tabular}

Upon the completion of the testing it was decided that the hydrocarbon system designed for use in the raw laboratory measurement system was indeed verified versus the EERL's hydrocarbon measurement system. This assessment was made, based on the results of an integrated mass emission rate percent difference less that 5\%. The 5\% was developed as a means of assessing laboratory to laboratory comparisons. Upon the verification, the system was then implemented for testing programs taking place at the EERL. 


\subsection{Oxides of Nitrogen Analyzing System Verification}

Prior to testing the oxides of nitrogen sampling system a $\mathrm{NO}_{\mathrm{x}}$ efficiency test was performed on the system, verifying a $\mathrm{NO}_{\mathrm{x}}$ efficiency greater than $90 \%$. For this a $\mathrm{NO}_{\mathrm{x}}$ efficiency tester was used, determining a $\mathrm{NO}_{\mathrm{x}}$ conversion efficiency of $98 \%$. The $\mathrm{NO}_{\mathrm{x}}$ system was drift tested and leak checked as demonstrated by the values found in Table 16 and Table 17:

Table 16: NO $_{x}$ System Leak Check

\begin{tabular}{|c|c|c|}
\hline Initial Pressure (psig) & Final Line Pressure (psig) & Percent Difference \\
\hline 5.295 & 5.289 & $0.11 \%$ \\
\hline 5.283 & 5.276 & $0.13 \%$ \\
\hline
\end{tabular}

Table 17: NOx Zero and Span Drift Test

\begin{tabular}{|c|r|r|c|}
\cline { 2 - 4 } \multicolumn{1}{c|}{} & \multicolumn{1}{l|}{ Pre } & \multicolumn{1}{c|}{ Post } & Percent Difference \\
\hline Zero & 0.008 & 0.0000 & $0 \%$ \\
\hline Span & 221 & 221.200 & $-0.09 \%$ \\
\hline
\end{tabular}

Since locomotive testing relies on an external $\mathrm{NO}_{\mathrm{x}}$ converter the testing was performed with the flow passing through the external $\mathrm{NO}_{2}$ to $\mathrm{NO}$ converter prior to reaching the analyzer. The EERL's analyzer bench consisted of two $\mathrm{NO}_{\mathrm{x}}$ analyzers; an EcoPhysics CLD and a Rosemount 955 analyzer. The oxides of nitrogen system was then compared to each analyzer for the specific test sequence by connecting it to the full scale dilution tunnel via $1 / 4$ " Teflon heated line maintained at a temperature of $235^{\circ} \mathrm{F}$. The engine was run following a federal engine testing procedure. The engine used for this study was a rebuilt Detroit Diesel Series 60 diesel engine. 


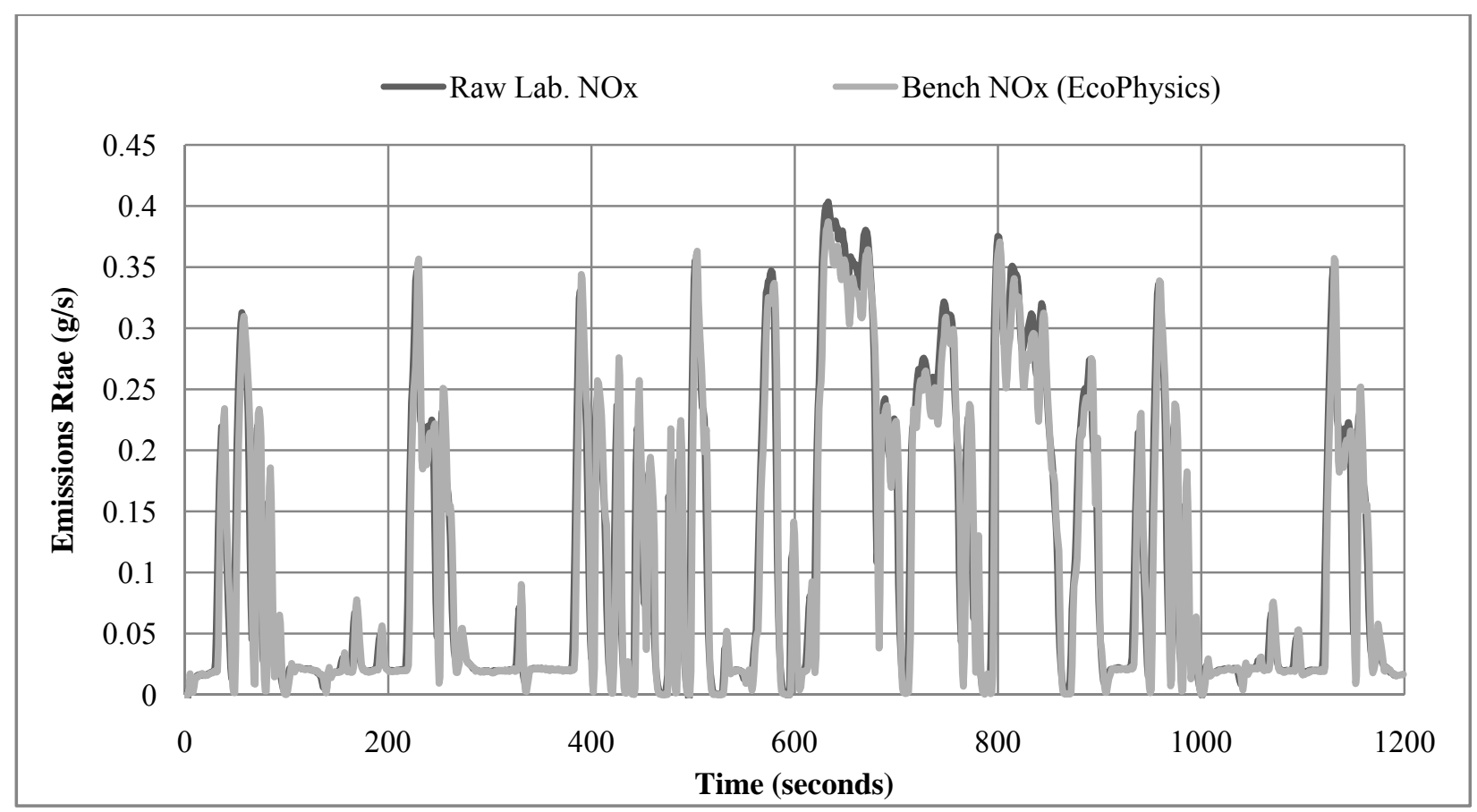

Figure 18: $\mathrm{NO}_{\mathrm{x}}$ System Comparison versus Bench EcoPhysics, FTP One

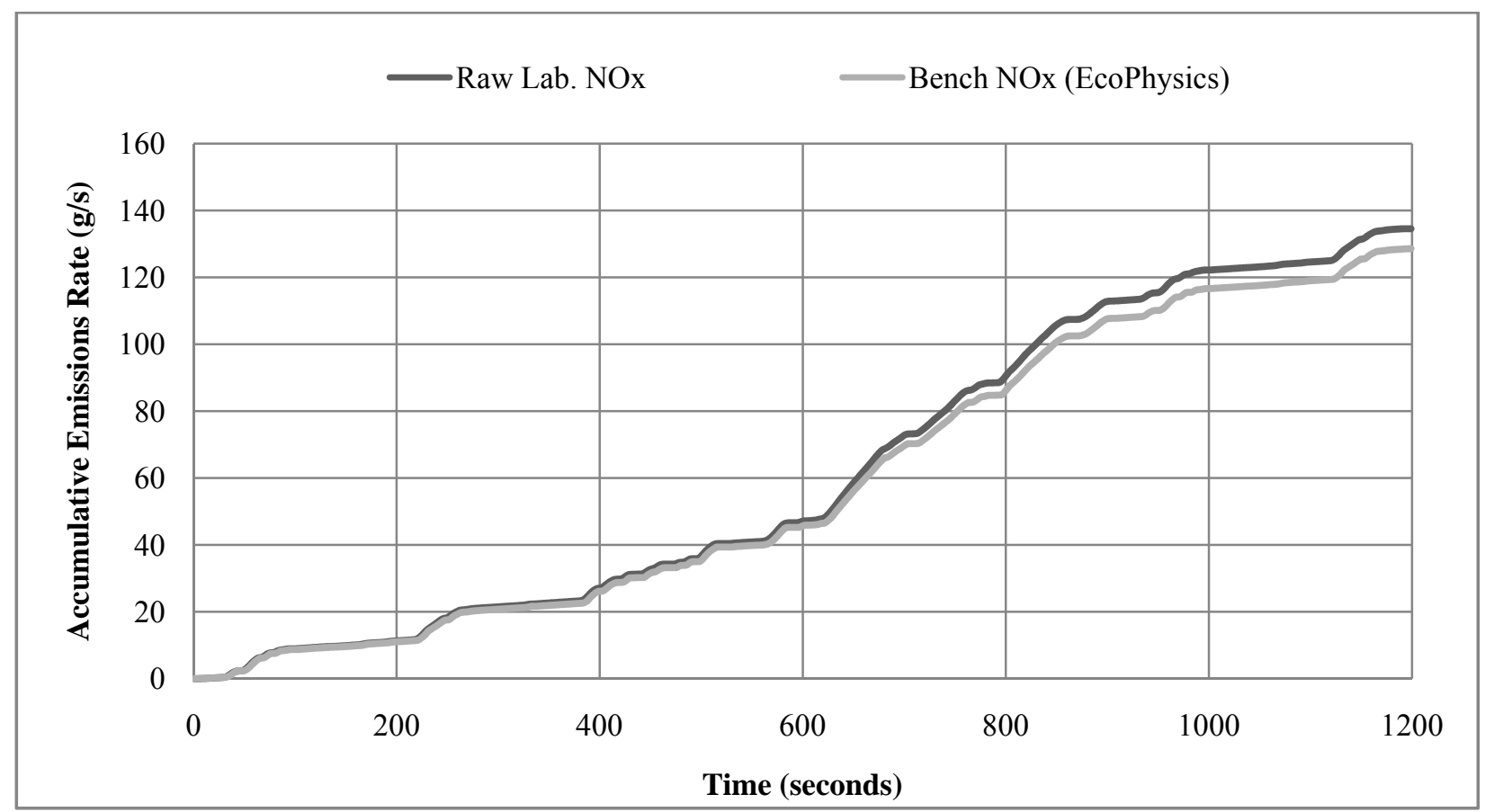

Figure 19: $\mathrm{NO}_{\mathrm{x}}$ Summation versus Bench Ecophysics, FTP One 
Three twenty minute FTPs were completed. The graphs showing the summation of the $\mathrm{NO}_{\mathrm{x}}$ represents the integrated $\mathrm{NO}_{\mathrm{x}}$ over the length of the test. This final value was then used to compare the EERL's $\mathrm{NO}_{\mathrm{x}}$ results to the raw laboratory's $\mathrm{NO}_{\mathrm{x}}$ results.

Table 18: $\mathrm{NO}_{\mathrm{x}}$ System Results

\begin{tabular}{|c|c|c|c|c|c|}
\hline Test & $\begin{array}{c}\text { Bench } \\
\text { EcoPhysics } \\
(\mathrm{g} / \mathrm{hr})\end{array}$ & $\begin{array}{l}\text { Bench } \\
\text { Rosemount } \\
(\mathrm{g} / \mathrm{hr})\end{array}$ & $\begin{array}{c}\text { Raw Lab. } \\
\text { (g/hr) }\end{array}$ & $\begin{array}{l}\text { EcoPhysics } \\
\text { (\%Difference) }\end{array}$ & $\begin{array}{c}\text { Rosemount } \\
\text { (\%Difference) }\end{array}$ \\
\hline Run 1 & 385.8 & 388.9 & 403.6 & $4.6 \%$ & $3.79 \%$ \\
\hline Run 2 & 394.85 & 390.9 & 405.7 & $2.76 \%$ & $3.8 \%$ \\
\hline Run 3 & 388.29 & 388.6 & 401.6 & $3.31 \%$ & $3.42 \%$ \\
\hline \multicolumn{4}{|c|}{ Average Percent Difference } & $3.57 \%$ & $3.67 \%$ \\
\hline
\end{tabular}

Post FTP completion deduced a verified $\mathrm{NO}_{\mathrm{x}}$ system based on the concurrence that verification relied on an integrated mass emissions rate; percent difference between the integrated mass emissions rate was less than $5 \%$. The system was able to handle the moisture presented in the exhaust stream, which was condensed in the M\&C chiller unit. Two analyzers in the EERL's bench system further assessed this verification. Upon its completion the system was integrated into testing programs located at the EERL for the emissions testing of heavy duty diesel engines. 


\section{6 $\mathrm{CO}_{2}$ Analyzing System Verification}

After leak checking and drift testing, the carbon dioxide analyzing system was connected to the full scale dilution tunnel via $1 / 4$ " Teflon heated line maintained at a temperature of $235^{\circ} \mathrm{F}$. The data for the leak check of the system is found in Table 19. The engine was run following a federal engine testing procedure or FTP. The engine used for this study was a Cummins ISM 370 diesel engine.

Table 19: $\mathrm{CO}_{2}$ System Leak Check

\begin{tabular}{|c|c|c|}
\hline Initial Pressure (psig) & Final Line Pressure (psig) & Percent Difference \\
\hline 5.622 & 5.612 & $0.18 \%$ \\
\hline 5.438 & 5.431 & $0.13 \%$ \\
\hline
\end{tabular}

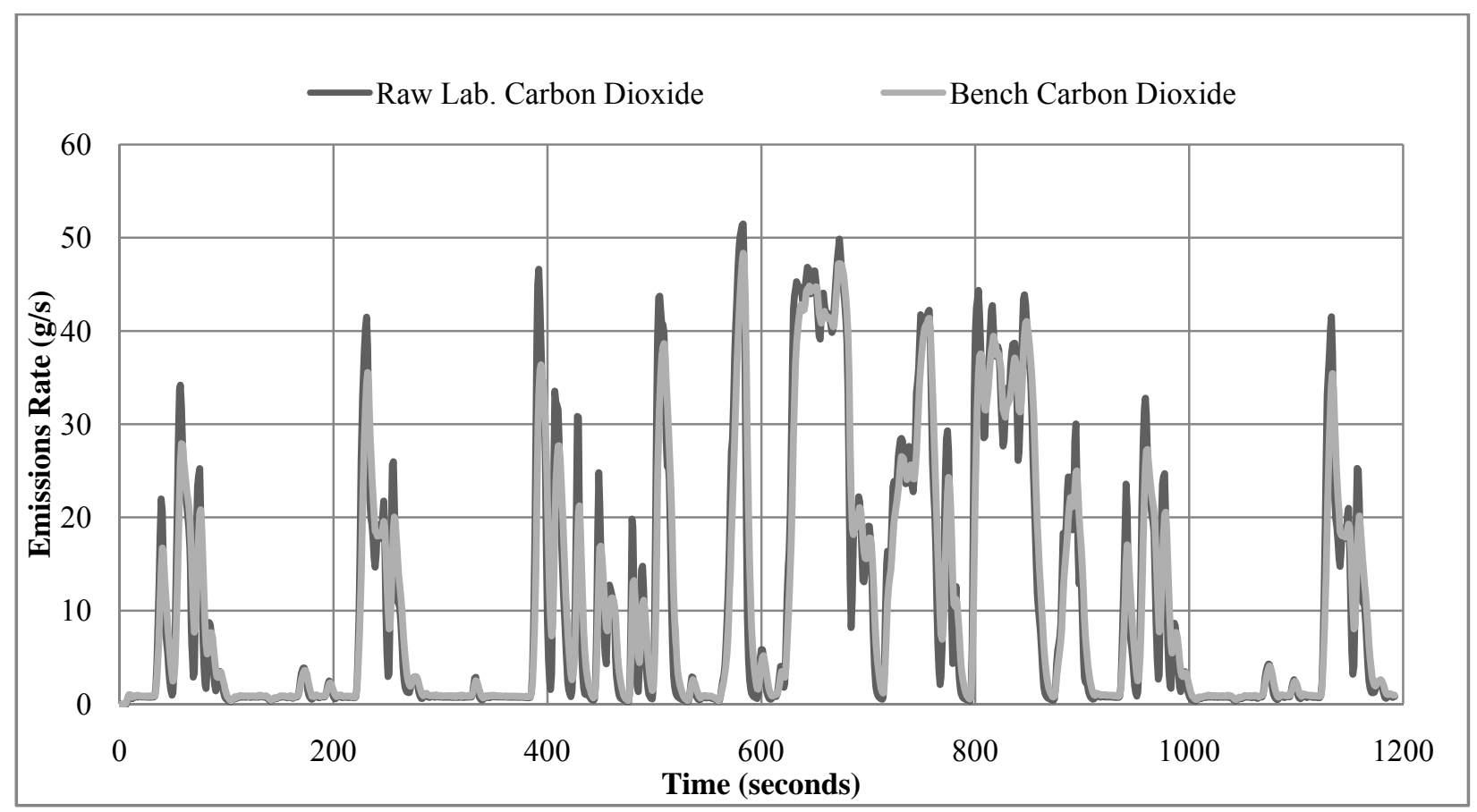

Figure 20: $\mathrm{CO}_{2}$ System Comparison, FTP One

Figure 36 illustrates the $\mathrm{CO}_{2}$ emissions rates during the 20 minute FTP test plan. 


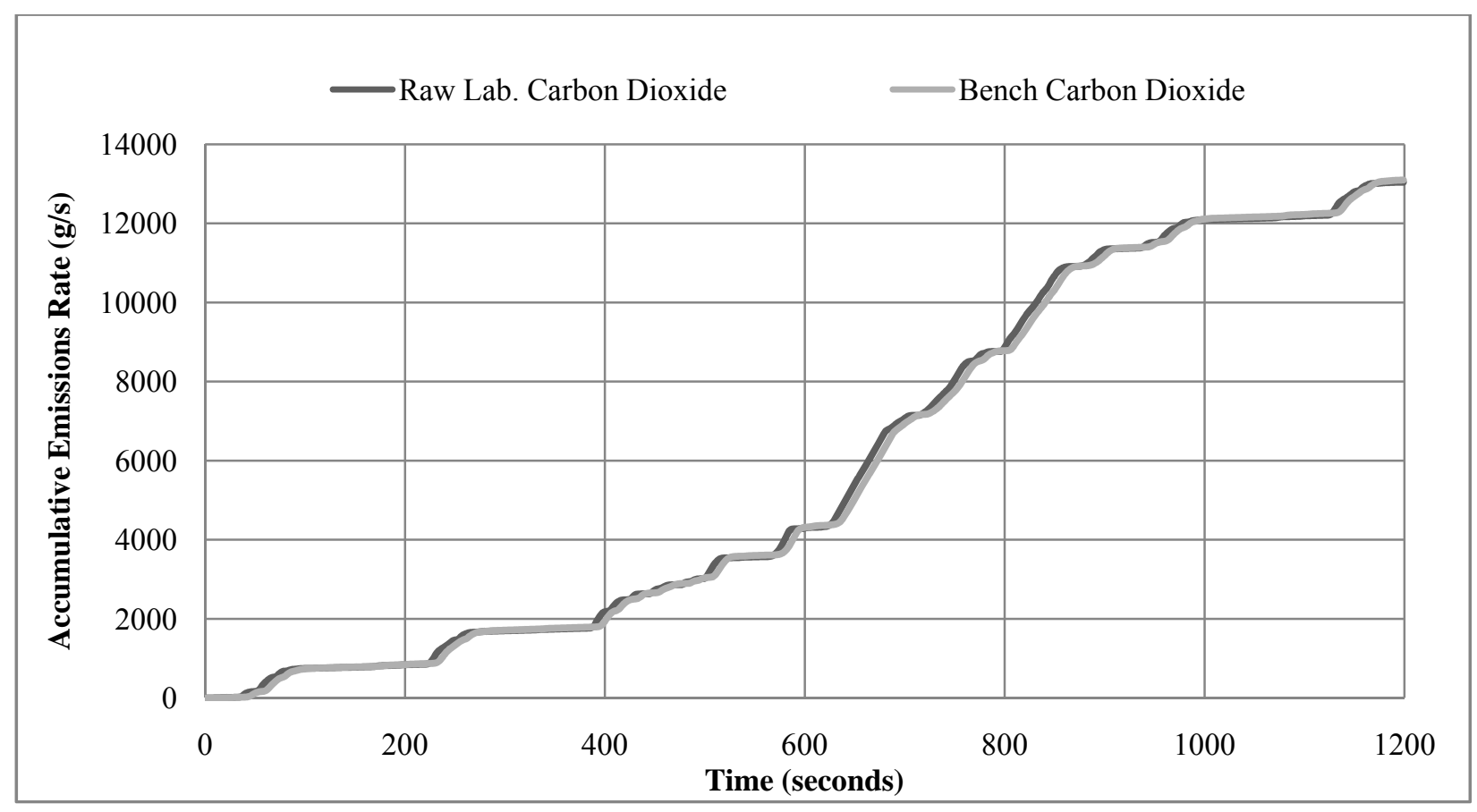

Figure 21: $\mathrm{CO}_{2}$ Summation, FTP One

Three twenty minute FTPs were completed with data collected. The graphs showing the cumulative $\mathrm{CO}_{2}$, represented the integrated $\mathrm{CO}_{2}$ over the duration of the FTP found in Figure 21. This value was used to determine the system's verification. Since the $\mathrm{CO}_{2}$ system fell well below the accepted laboratory percent difference of $5 \%$, the system was considered to be ready for in the field testing. The $\mathrm{CO}_{2}$ system was then included in other testing programs occurring at the EERL. Results from the FTPs are presented in Table 20.

Table 20: $\mathrm{CO}_{2}$ System Results

\begin{tabular}{|c|c|c|c|}
\hline Test & $\begin{array}{c}\text { Bench } \\
(\mathrm{g} / \mathrm{hr})\end{array}$ & $\begin{array}{c}\text { Raw Lab. } \\
(\mathrm{g} / \mathrm{hr})\end{array}$ & $\begin{array}{c}\text { Percent } \\
\text { Difference }\end{array}$ \\
\hline Run 1 & 39287.6 & 39117.3 & $0.43 \%$ \\
\hline Run 2 & 39195.3 & 39363.0 & $0.44 \%$ \\
\hline Run 3 & 39314.9 & 39361.0 & $0.12 \%$ \\
\hline \multicolumn{2}{|c|}{ Average Percent Difference } & $0.33 \%$ \\
\hline
\end{tabular}




\subsection{CO Analyzing System Verification}

Prior to $\mathrm{CO}$ comparison, the system was leak checked to verify the integrity of the internal piping systems. The lines were pressurized to $\sim 5.5 \mathrm{psig}$ and monitored for one minute. After one minute, if the reading did not vary by more than $0.5 \%$ the system was considered to pass the leak check. The results from the leak check are found in Table 21 below:

Table 21: CO System Leak Check

\begin{tabular}{|c|c|c|}
\hline Initial Pressure & Final Line Pressure & Percent Difference \\
\hline 5.622 & 5.612 & $0.18 \%$ \\
\hline 5.438 & 5.431 & $0.13 \%$ \\
\hline
\end{tabular}

The system was also drift checked to insure that analyzer stability requirements were met. The carbon monoxide analyzing system was connected to the EERL's full scale dilution tunnel via $1 / 4$ " Teflon heated line, maintained at a temperature of $235^{\circ} \mathrm{F}$. The temperature was sustained by using a PID temperature controller. This prevented the formation of water condensation which could lead to erroneous data and instrumentation damage. The engine was run following a federal engine testing procedure or FTP. The engine used for this study was a Cummins ISM 370 diesel engine. 


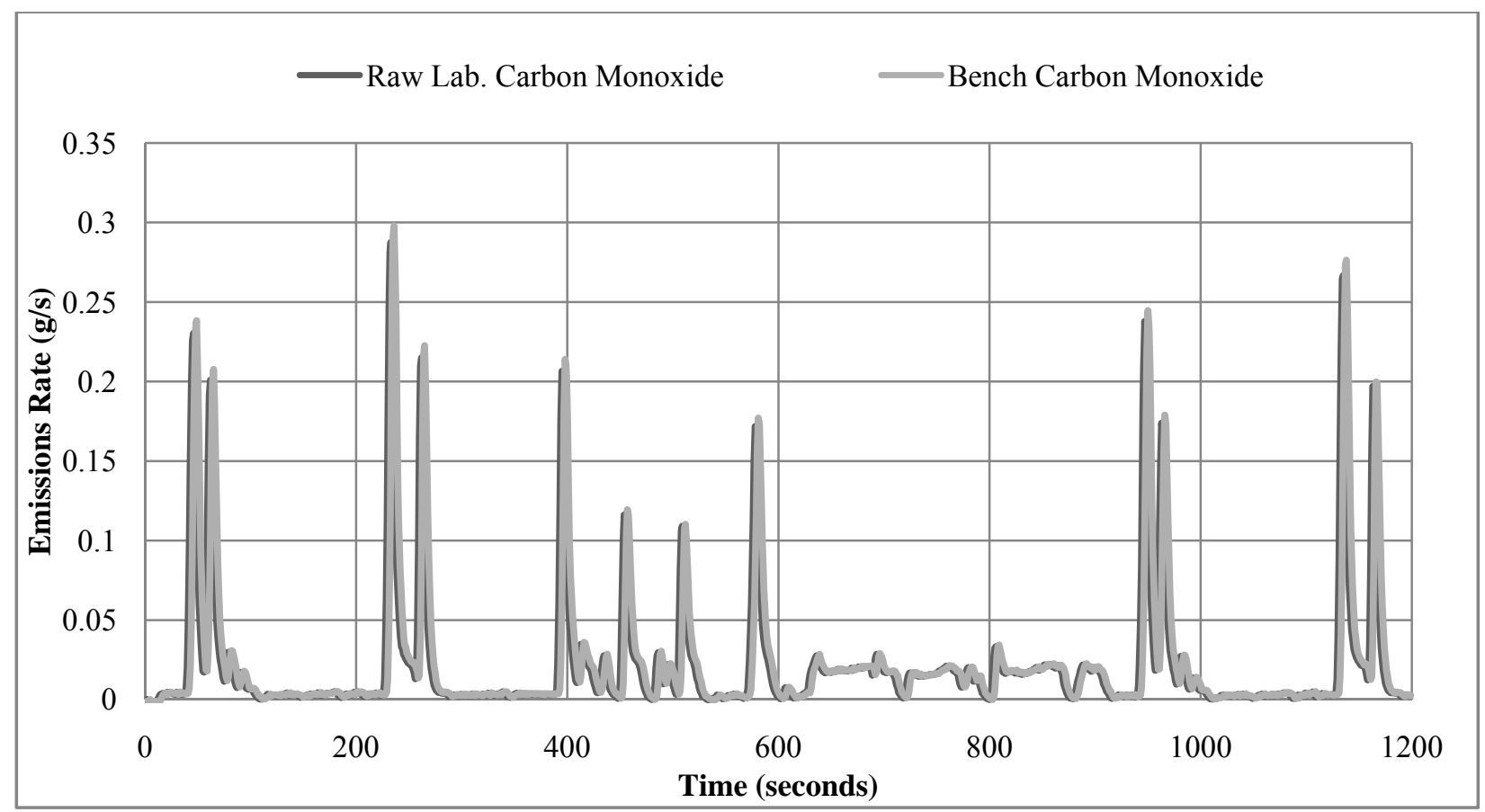

Figure 22: CO System Comparison FTP One

Figure 22 shows the carbon monoxide produced by the engine during the FTP. The data acquisition system, sampled at a frequency of $1 \mathrm{~Hz}$.

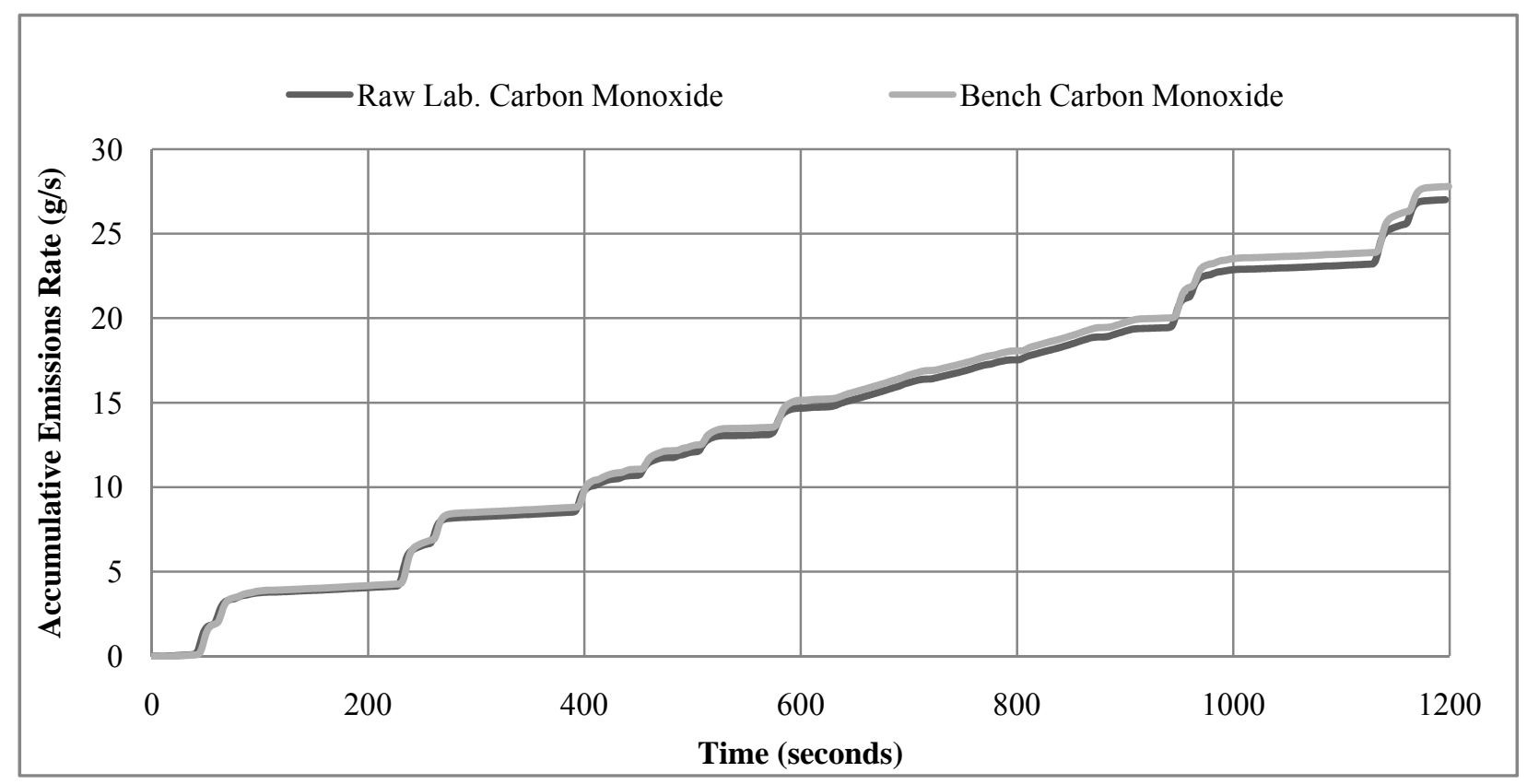

Figure 23: CO Summation, FTP One 
Three twenty minute FTPs were completed while collecting data. The graphs showing the accumulative $\mathrm{CO}$ mass emissions rate, represents the integrated $\mathrm{CO}$ over the duration of the test as shown in Figure 23. This final value was then used to compare the EERL's CO results to the raw laboratory $\mathrm{CO}$ system results.

Table 22: CO System Results

\begin{tabular}{|c|c|c|c|}
\hline Test & $\begin{array}{c}\text { Bench } \\
(\mathrm{g} / \mathrm{hr})\end{array}$ & $\begin{array}{c}\text { Raw Lab. } \\
(\mathrm{g} / \mathrm{hr})\end{array}$ & $\begin{array}{c}\text { Percent } \\
\text { Difference }\end{array}$ \\
\hline Run 1 & 83.4 & 81.0 & $2.8 \%$ \\
\hline Run 2 & 82.4 & 80.0 & $3.0 \%$ \\
\hline Run 3 & 83.7 & 81.2 & $3.0 \%$ \\
\hline \multicolumn{2}{|c|}{ Average Percent Difference } & $2.93 \%$ \\
\hline
\end{tabular}

The results proceeding the testing verified that the $\mathrm{CO}$ system was capable of measuring the exhaust constituents of a diesel engine within 5\% of the EERL's integrated CO mass emissions rate. This verification led to the conclusion that the $\mathrm{CO}$ system was ready to be put in operation for in the field use. 


\subsection{Gaseous Emissions Results Discussed}

Upon the completion of the testing of the individual analyzing systems versus the EERL's analytical system, it was found that the systems were functioning properly; accurately measuring the exhaust constituents produced by a diesel engine. The following table summarizes the averaged results of the FTP system comparisons.

\section{Table 23: Results Summary of Gaseous Emissions System Comparison}

\begin{tabular}{|c|c|}
\hline $\begin{array}{c}\text { Exhaust } \\
\text { Constituent }\end{array}$ & Percent Difference \\
\hline $\mathrm{HC}$ & $3.40 \%$ \\
\hline $\mathrm{NO}_{\mathrm{x}}$ & $3.62 \%$ \\
\hline $\mathrm{CO}_{2}$ & $0.33 \%$ \\
\hline $\mathrm{CO}$ & $2.93 \%$ \\
\hline
\end{tabular}

Currently the analyzer systems that make up the raw laboratory analyzing system are in use at the EERL as a measurement system for the EERL's 2007 full-scale dilution tunnel system. The next step prior to in the field testing would be to verify the system as a raw exhaust emissions measurement system, by analyzing a raw exhaust stream, comparing the obtained results to the dilute full-scale analytical system's results. To perform this action the systems would have to convert concentrations in grams per time and compare those numbers for each constituent to those acquired by the full-scale dilution tunnel system. Measuring raw will enhance confidence in the systems operation before in the field services.

Following Part 92, locomotive emissions testing requires a single stainless steel multiport sampling probe for raw gaseous emissions measurement. A heated line is then used, maintained at a temperature of $375^{\circ} \mathrm{F}$ to transport the sample to the individual sampling systems. A box was 
modified to contain a large heated filter, heated pump, heated lines, and heated manifold to draw a single sample from the locomotive exhaust plume and distribute the sample to the systems.

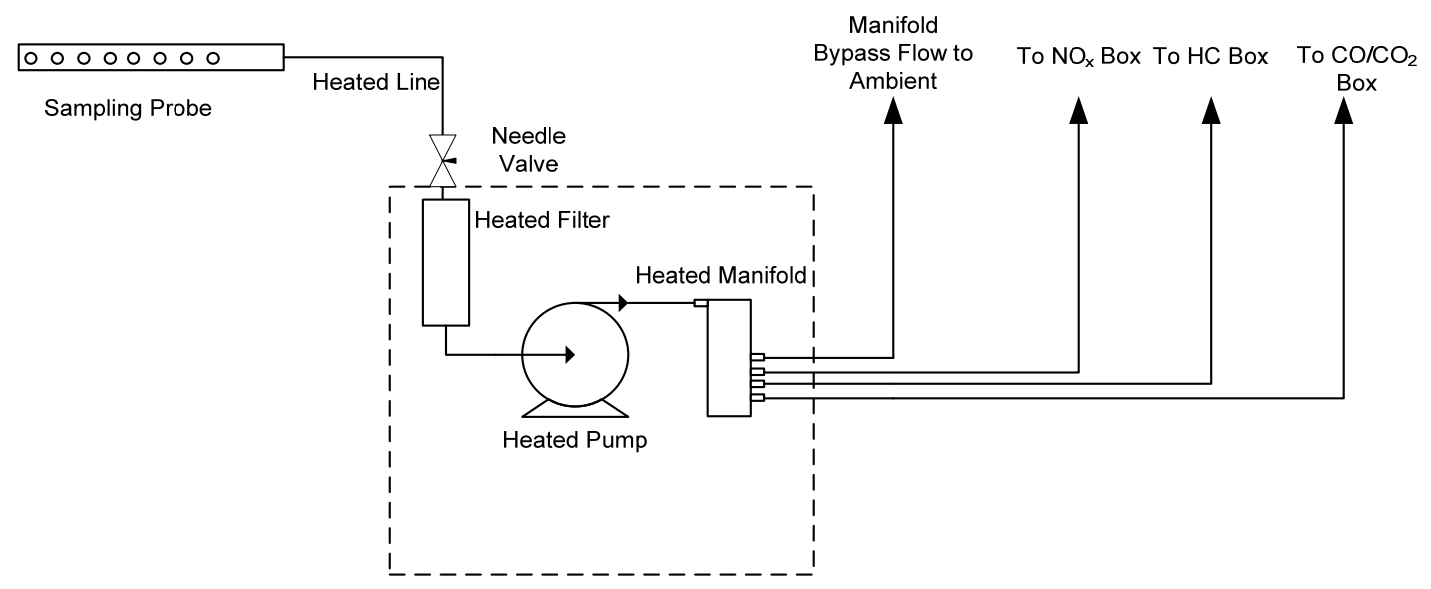

Figure 24: Raw Emissions Manifold System

Figure 24 illustrates the design schematic for the emissions manifold distribution system. A rack was designed to hold the system and create a single unit that would be operated as an emissions laboratory. The framework for the system could be carried to the test site as well as the individual sampling systems. Once on site the system could be assembled as a complete laboratory system. 


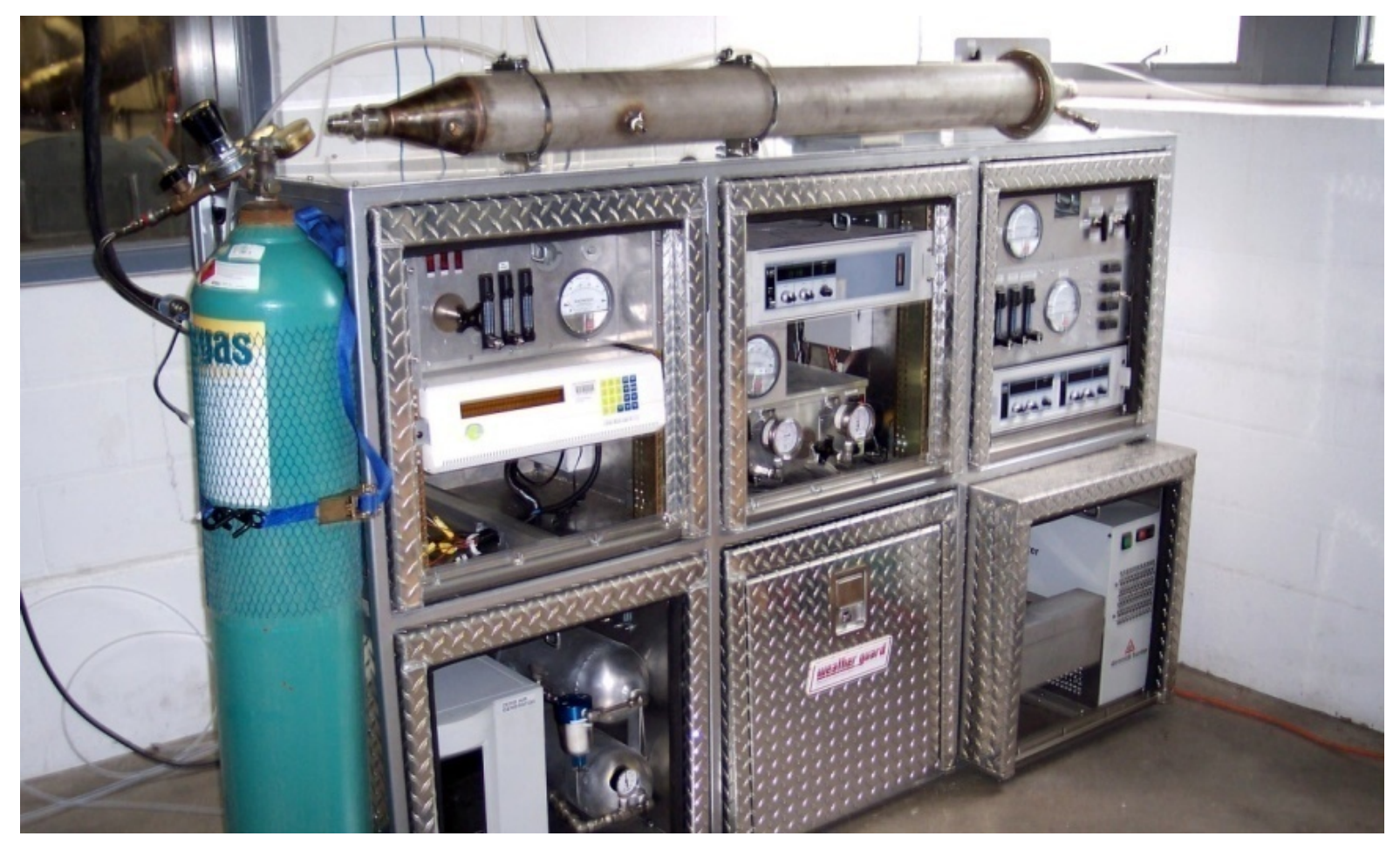

Figure 25: Photograph of the Raw Emissions Sampling System as a Unit

Figure 25 displays the emissions measurement equipment, assembled as a complete emissions measurement laboratory. Each system has an Ethernet port plug at the back of the unit that can transmit data to a centralized computer system. 


\section{Chapter 5 - Particulate Matter Measurement System Design}

\subsection{PM System Design Requirements}

Particulate Matter was measured gravimetrically by collecting it on fluorocarbon-coated glass fiber filters. In order to correctly measure the PM produced by an engine the exhaust sample was first diluted with air. This brought the temperature of the exhaust dilution air mixture to $125^{\circ} \mathrm{F}$ or lower. A temperature of $125^{\circ} \mathrm{F}$ or lower was required to ensure that the exhaust sample stream was sufficiently diluted. The temperature also prevented the loss of volatile organic compounds that can evaporate through the particulate filters at higher temperatures [12]. Many molecules of particulate matter form when coming into contact with the dilution air. For this operation, a dilution tunnel, of which the specifications are outlined in the CFR, Part 92 was developed. A schematic of the dilution tunnel system can be found in Figure 26:

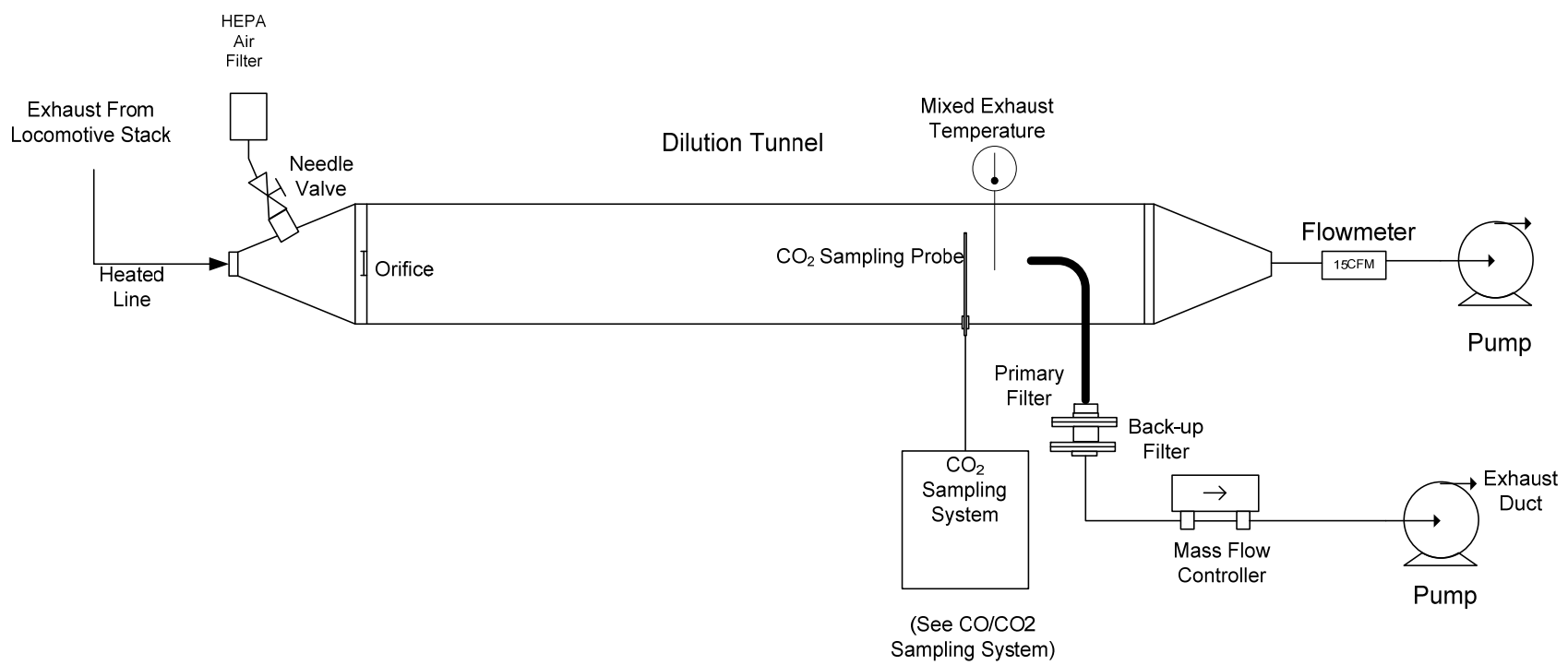

Figure 26: Partial Flow PM Dilution Tunnel System 
There were several design requirements that had to be met when developing the dilution tunnel system. The temperature of the sample stream prior to the sampling probe of the PM filters had to be at a temperature of $125^{\circ} \mathrm{F}$ or below. The dilution air used had to be at a temperature of 68 ${ }^{\circ} \mathrm{F}$ or higher. Third, the flow rate through the tunnel had to have a Reynolds number greater than 4000 to ensure turbulent flow.

Reynolds number is defined as [16]:

$$
\operatorname{Re}=\frac{V_{s} L}{v}
$$

\section{Equation 9}

Where:

$$
\begin{aligned}
& \mathrm{V}_{\mathrm{s}}=\text { average fluid velocity }(\mathrm{ft} / \mathrm{s}) \\
& \mathrm{L}=\text { pipe diameter }(\mathrm{ft}) \\
& v=\text { kinematic viscosity }\left(\mathrm{ft}^{2} / \mathrm{s}\right)
\end{aligned}
$$

Turbulent flow ensured that the stream was well mixed at the sampling region of the tunnel. The sampling region in the tunnel was located ten tunnel diameters downstream of the tunnel entrance to ensure ample distance was given to allow for the complete stream mixing. At the tunnel entrance a 1.25 inch mixing orifice was installed to further accelerate the mixing process. It was calculated that a flow rate of $15 \mathrm{CFM}$ at $125^{\circ} \mathrm{F}$ or $13.2 \mathrm{SCFM}$ needed to be achieved to ensure turbulent tunnel flow. The inside diameter of the dilution tunnel was 4.75 
inches. The CFR, Part 92 specified that the inside tunnel diameter must be greater than 4 inches. The tunnel was made of stainless steel which was electrically grounded. The stainless steel would not chemically react with the exhaust stream. A sample probe within the dilution tunnel, whose inside-diameter is 0.6 inches, was installed facing the entrance of the tunnel. Located fifteen inches from the tip of the dilute sampling probe was the primary filter holder. The CFR, Part 92 specified that a minimum sample probe of 0.5 inch inside diameter be installed and that the sample filters must be within 40 inches of the sampling probe tip.

\subsection{Particulate Matter Filter Flow Requirements}

The filter face velocity had to be maintained between $35 \mathrm{~cm} / \mathrm{s}$ and $80 \mathrm{~cm} / \mathrm{s}$. The filter used was a $70 \mathrm{~mm}$ filter with an effective stain area of $60 \mathrm{~mm}$. This produced an effective stain area of $28.27 \mathrm{~cm}^{2}$. To sustain the required filter face velocity the flow rate through the filters was maintained between 2.1 CFM and 4.79 CFM. To monitor and keep a constant flow rate through the filters, a mass flow controller was used. Mass flow controllers operate on the principles of heat transfer and the first law of thermodynamics [14]. Gas entered the mass flow controller main tube and separates into two streams: the sensor tube and laminar flow bypass stream. In the sensor tube two resistance thermal detector coils around the sensor tube transmitted a constant amount of heat into the gas stream. Heat traveled from the upstream coil to the downstream coil where a temperature difference was measured between the two. From these values an accurate mass flow rate was calculated [14]. This flow rate was recorded by monitoring the analog output signal produced by the mass flow controller. The mass flow controller used was a Sierra Instruments 0 - 4 SCFM mass flow controller that produced a 0 - 5 volt analog signal.

By collecting the data produced by the mass flow controller (MFC), the total volume of the sample passing through the filters was determined. The mass flow controller was calibrated 
using a NIST traceable laminar flow element (LFE) to develop a calibration curve used in the software to determine the sample volume pulled through the PM filters. Internally the LFE contains a matrix of small tubes that are sized to create steady laminar flow within the element. The pressure differential across the element was used to determine the actual flow rate of air through the element [14]. A second degree polynomial was then used to determine this flow rate by the following equation:

$$
Q=C \Delta P^{2}+B \Delta P
$$

Equation 10

Where:

$\mathrm{Q}=$ actual flow rate $(\mathrm{CFM})$

$\Delta \mathrm{P}=$ pressure drop across LFE (inches water)

$\mathrm{C} \& \mathrm{~B}=$ calibration coefficients provided by the manufacturer

Once the actual volumetric flow rate was determined the value was corrected to standard conditions to determine the total volume through the filters in standard cubic feet (SCF). The flow rate through the mass flow controller was varied over its full range of operation to develop a calibration curve that would reflect its operation. This curve was then used to assign a desired value of flow to be transferred through the filters during an emissions sampling test. Figure 27 illustrates the calibration curve developed for the mass flow controller. 


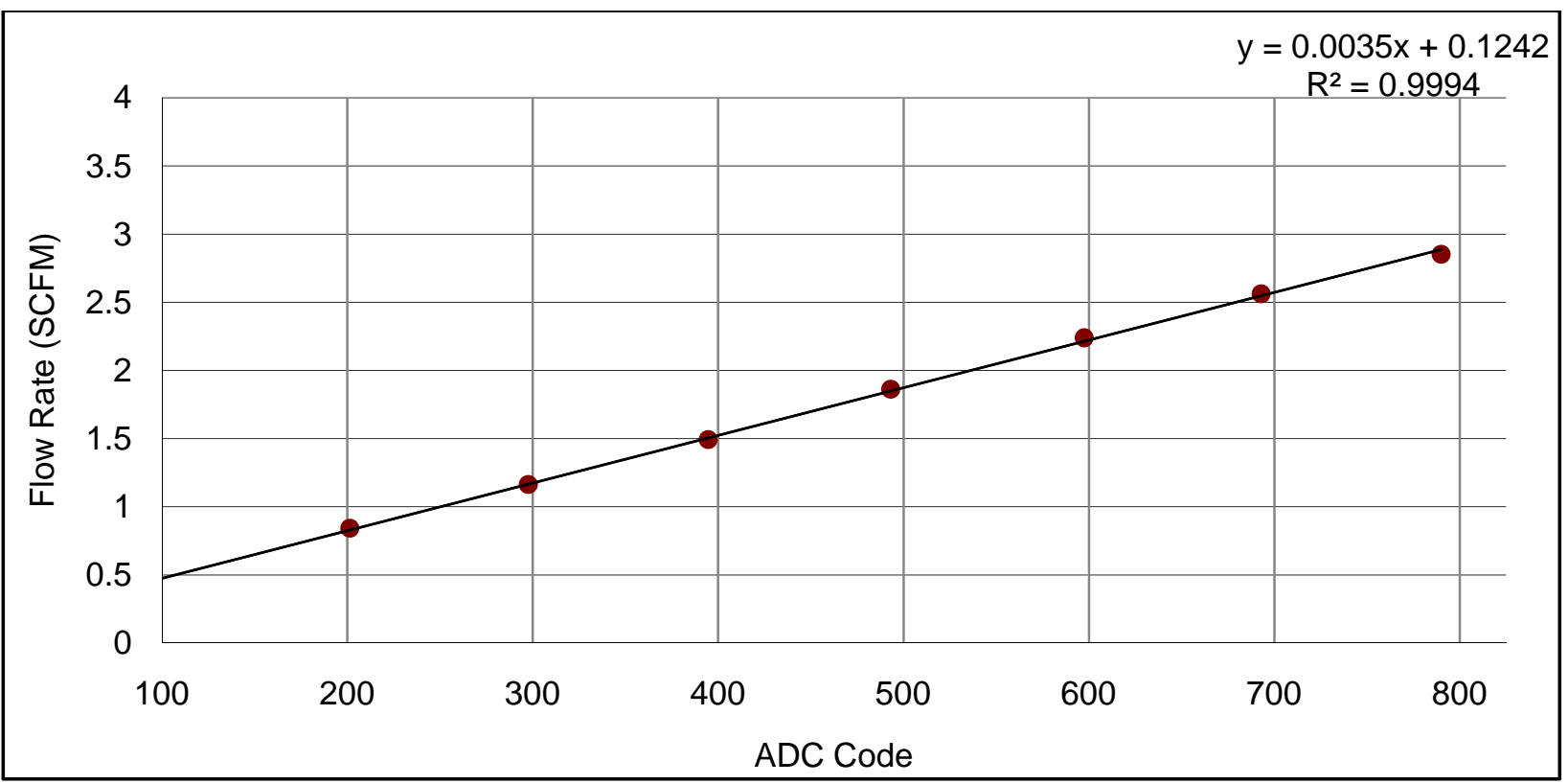

Figure 27: Mass Flow Controller Calibration Curve

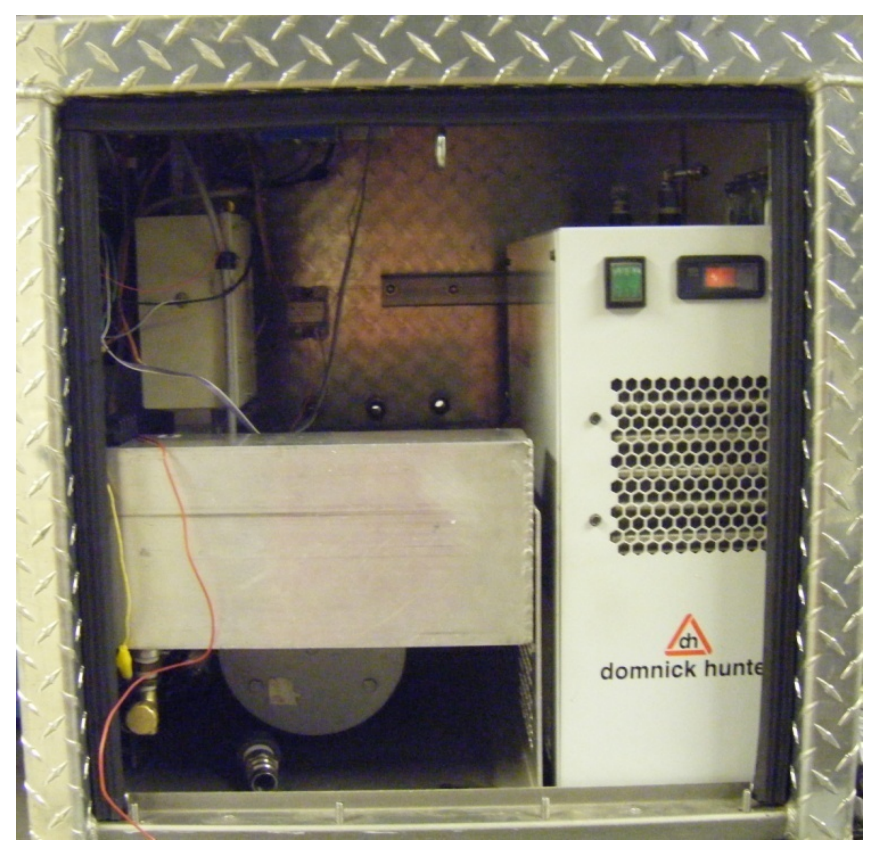

Figure 28: PM Mass Flow Controller System

Figure 28 shows a view of the developed system containing the mass flow controller used to draw a sample of exhaust through the PM filters at a controlled and measurable rate. The system contains a pump which is connected to a manifold. The manifold has ports, to which mass flow 
controllers can be connected. The manifold is on the vacuum side of the pump, thus allowing for the sample stream to be drawn through the mass flow controller. This gave the system the ability to provide flow for multiple mass flow controllers if need be in future testing programs.

\subsection{Raw and Dilute $\mathrm{CO}_{2}$ Measurement}

The partial flow dilution tunnel system design utilized the measurement of $\mathrm{CO}_{2}$ concentrations in the raw exhaust, as well as the concentrations in the partial flow tunnel system's dilute exhaust stream. The purpose of this measurement was to determine the ratio of raw exhaust versus dilution air in the partial flow dilution tunnel.

$$
D R=\frac{W C O_{2}-W C O_{2 D}}{W C O_{2 E}-W C O_{2 D}}
$$

Equation 11

Where, $\mathrm{WCO}_{2}$ was the raw $\mathrm{CO}_{2}$ concentration (\%), $\mathrm{WCO}_{2 \mathrm{E}}$ was the dilute $\mathrm{CO}_{2}$ concentration (\%) and $\mathrm{WCO}_{2 \mathrm{~d}}(\%)$ was the background $\mathrm{CO}_{2}$ concentration.

This value was used in the calculations to determine the PM mass emissions rate of the engine.

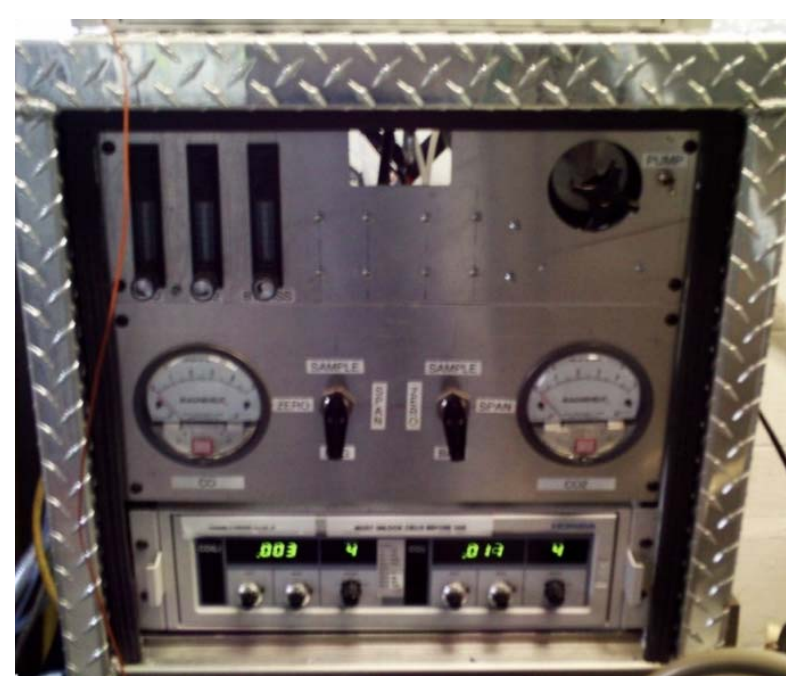

Figure 29: Dilute $\mathrm{CO}_{2}$ Sampling System 
Figure 29 is the dilute $\mathrm{CO}_{2}$ sampling system. The analyzer is a dual cell $\mathrm{CO} \& \mathrm{CO}_{2}$ AIA 220 Horiba Analyzer. The piping layout for this system is near identical to the raw $\mathrm{CO} / \mathrm{CO}_{2}$ system, pictured in Figure 13.

\subsection{Calculations Involved in Determining PM Mass Emission Rates}

Partial flow dilution tunnel systems operate on the principle of scaling a measured partial PM mass emissions rate to a total exhaust PM mass emissions rate. A partial sample is removed from the engine exhaust stream and diluted with air. The dilution ratio must be known to determine the amount of PM collected on the filters that is attributed to engine exhaust PM and the amount attributed from background PM concentrations found in the air. To assess this value, a background PM concentration is determined. $\mathrm{CO}_{2}$ concentrations were measured in the dilution

tunnel, and in the raw exhaust stream to determine a dilution factor. The dilution factor can be found in the following equation:

$$
D F=\frac{W C O_{2}-W C O_{2 D}}{W C O_{2 E}-W C O_{2 D}}-1
$$

Equation 12

Where:

$\mathrm{DF}=$ volumetric ratio of the raw exhaust to the diluted exhaust

$\mathrm{WCO}_{2}=$ carbon dioxide concentration in exhaust, percent (wet)

$\mathrm{CO}_{2 \mathrm{D}}=$ carbon dioxide concentration of dilution air as measured, percent (wet)

$\mathrm{CO}_{2 \mathrm{E}}=$ carbon dioxide concentration of the dilute exhaust, percent (wet) 
The dilution factor obtained can then be used to determine the amount of PM emitted by the engine, with the execution of the following equation [2]:

$$
M_{P M \text { Mode }}=(W V o l)\left(P M_{\text {conc }}\right)(1+D F)
$$

Equation 13

Where:

$\mathrm{M}_{\mathrm{PM} \text { Mode }}=$ Particulate Emissions (grams/hour) by mode or notch

$\mathrm{WVol}=$ Total Exhaust flow rate on a wet basis $\left(\mathrm{ft}^{3} /\right.$ hour $)$

Where:

$$
W V o l=\frac{\left(V_{m}\right)\left(W_{f}\right)}{\left(C M W_{f}\right)\left(\frac{W H C}{10^{6}}+\frac{W C O}{10^{6}}+\frac{W C O 2}{10^{6}}\right)}
$$

Equation 14

Where:

$\mathrm{V}_{\mathrm{m}}=$ Volume of one mole of gas at standard temperature and pressure $=0.8366 \mathrm{ft}^{3} / \mathrm{mole}$

$\mathrm{W}_{\mathrm{f}}=$ mass flow rate of the fuel consumed (grams/hour)

$\mathrm{CMW}_{\mathrm{f}}=$ Molecular Weight of the fuel per carbon atom $=(12.011+1.008 \alpha)$

$=13.825$ for No. 2 Diesel

$\alpha=$ hydrogen to carbon ratio of the fuel

$\mathrm{WHC}=$ raw $\mathrm{HC}$ concentration in the exhaust (wet basis ppm)

$\mathrm{WCO}=$ raw $\mathrm{CO}$ concentration in the exhaust (wet basis ppm) 
$\mathrm{WCO}_{2}=$ raw $\mathrm{CO}_{2}$ concentration in the exhaust (wet basis ppm)

$$
P M_{\text {conc }}=P M_{e}-P M_{d}\left(1-\frac{1}{D F}\right)
$$

\section{Equation 15}

Where:

$\mathrm{PM}_{\mathrm{conc}}=$ concentration of $\mathrm{PM}$ in the raw exhaust corrected for background (grams $\left./ \mathrm{ft}^{3}\right)$

$$
\begin{gathered}
P M_{e}=\frac{M_{P M e}}{V_{\text {sample }}} / 10^{3} \\
P M_{d}=\frac{M_{P M d}}{V_{\text {sample d }}} / 10^{3}
\end{gathered}
$$

Equation 16

Equation 17

Where:

$\mathrm{M}_{\mathrm{PMe}}=$ mass of PM deposited on the exhaust filter

$\mathrm{V}_{\text {sample }}=$ volume of sample removed from the dilution tunnel for the exhaust sample corrected to standard temperature and pressure

$\mathrm{M}_{\mathrm{PMd}}=$ mass of PM deposited on the background filter

$\mathrm{V}_{\text {sample } \mathrm{d}}=$ volume of sample removed from the dilution tunnel for the background sample corrected to standard temperature and pressure 
$\mathrm{CO}_{2}$ and $\mathrm{CO}$ concentrations were measured on a dry basis; meaning the water found in the exhaust stream was removed prior to measurement via peltier chiller unit. $\mathrm{CO}_{2}$ and $\mathrm{CO}$ must be then be converted to reflect a measured value on a wet concentration basis. This was accomplished utilizing the following equations $[2,19]$ :

$$
\operatorname{Conc}_{w e t}=\frac{\text { Conc }_{d r y}}{K_{w}}
$$

Equation 18

Where:

$$
\begin{gathered}
K_{w}=1+D_{\mathrm{H}_{2} \mathrm{O}} \\
\mathrm{DH}_{2} \mathrm{O}=\left[\propto *\left(\frac{\frac{C \mathrm{O}_{2 d r y}}{10^{2}}+\frac{C O_{d r y}}{10^{6}}}{2}\right)+Y * \text { DVOL }_{\text {Ratio }}\right] *\left[\frac{1}{1+\frac{C O_{d r y}}{C O_{2 d r y} * K * 10^{4}}}\right]
\end{gathered}
$$

Equation 19

$\mathrm{CO}_{2}$ dry $=$ dry $\mathrm{CO}_{2}$ concentration $(\%)$

$\mathrm{CO}_{\text {dry }}=$ dry $\mathrm{CO}$ concentration $(\mathrm{ppm})$

Where:

$$
Y=\frac{H * M W_{a i r}}{M W_{H_{2} O}}-\frac{P_{v}}{P_{B}-P_{v}}
$$

Equation 20

$\mathrm{P}_{\mathrm{v}}=$ partial pressure of the water vapor $(\mathrm{kPA})[17]$ 
$\mathrm{MW}_{\text {air }}=$ molecular weight of air $(\mathrm{amu})$

$\mathrm{MW}_{\mathrm{H} 20}=$ molecular weight of water $(\mathrm{amu})$

$\mathrm{P}_{\mathrm{B}}=$ barometric pressure $(\mathrm{kPa})$

Where:

$$
H=\frac{K_{H} * P_{v}}{P_{b}-P_{v}}
$$

Equation 21

$\mathrm{K}_{\mathrm{H}}=$ conversion factor $(0.622)$

$$
D V O L_{\text {ratio }}=1-\frac{C O_{2 d r y}}{10^{2}} * \frac{\propto}{4}-\frac{C O_{d r y}}{10^{6}} *\left(\frac{\propto}{4}+0.5\right)
$$

Equation 22

Once all $\mathrm{CO}_{2}$ concentrations were corrected to a wet basis the total exhaust flow rate of the engine per mode was determined. 


\section{Chapter 6 -Locomotive Engine Testing (PM System Comparison)}

\subsection{Introduction}

West Virginia University's Transportable Emissions Laboratory (Translab) was contracted to conduct emissions testing on remanufactured locomotive engines. WVU's transportable full scale dilution tunnel system was used to measure the exhaust constituents produced by these engines. Though the Translab is designed as a full-exhaust dilution tunnel system for heavy duty diesel engines; locomotive testing involves the sampling of a partial exhaust stream from the locomotive exhaust plume, diluting it and then measuring the exhaust and particulate concentrations. There are several calculations in Part 92 of the CFR to account for this sampling technique [2]. This testing provided a perfect opportunity for WVU to test their partial flow dilution tunnel system versus the Translab's PM system; an already trusted emissions measurement laboratory. Both systems sampled a portion of the exhaust flow, diluted it and measured the particulate matter concentrations. The differences in the calculations involved, and the results found in the study will therein be discussed.

\subsection{WVU's Transportable Emissions Laboratory}

WVU's Transportable Emissions Laboratory was designed to comply with Part 86 Subpart N of the Code of Federal Regulations, with the exception of controlled dilution air temperature and humidity [13]. The laboratory was normally used in conjunction with a chassis dynamometer to measure the exhaust constituents produced by heavy duty diesel engines. The dynamometer simulates on the road driving conditions of a heavy duty diesel vehicle throughout a designed test mode. During this operation, the driver follows a specific driving test cycle, with the total exhaust sample being routed into the full-scale dilution tunnel system. The laboratory uses state of the art analyzers and data acquisition computer systems to collect data during the 
test modes and then calculates the mass flow rates of exhaust constituents in grams per brake horsepower hour.

\subsubsection{Translab Compliance with Part 92}

Part 92 of the CFR specified the requirements for the locomotive exhaust gas and particulate matter emissions analytical sampling systems. Section E of 92.114 stated that locomotive emissions may be measured from a dilute exhaust stream prior to sampling. The system must comply with Title 40; Part 86 Subpart $N$ of the CFR with certain exceptions and additional requirements [2]. The system was not required to maintain proportional sampling techniques. The dilution of only a portion of the exhaust was allowed, provided that the total flow rate through the dilution tunnel system was measured and that the fraction of total exhaust was used to determine the mass emissions rates in grams/hour. Second, the ratio of the raw sample volume per dilute sample volume was used to determine the mass emissions rates from the measured fuel flow rates. This was the method employed to measure PM mass emissions rates in the newly developed partial flow dilution tunnel system (PFT). WVU's Translab measured the exhaust constituents from the fraction of the total exhaust diluted and circulated through the full-exhaust tunnel.

\subsubsection{Equations Used to Calculate the Translab PM (grams/ hr)}

Calculations determining the particulate matter mass emissions rates for both systems had their similarities and differences. The Translab chose to utilize equations involving the laboratory's critical flow venturi. PM mass emission rates $(\mathrm{g} / \mathrm{hr})$ for the Translab were found using the following equations [2]: 


$$
M_{P M \text { Mode }}=\frac{V_{\text {mix }} * P M_{\text {conc }}}{V_{f}}
$$

Equation 23

Where :

$\mathrm{V}_{\text {mix }}=$ Total diluted exhaust volumetric flow $\left(\mathrm{ft}^{3}\right)$

$$
P M_{\text {conc }}=P M_{e}-P M_{d}\left(1-\frac{1}{D F}\right)
$$

Equation 24

Where:

$$
P M_{e}=\frac{M_{P M e}}{V_{\text {sample }}} / 10^{3}
$$

Equation 25

And:

$$
P M_{d}=\frac{M_{P M d}}{V_{\text {sampled }}} / 10^{3}
$$

Equation 26

$$
D F=\frac{W C O_{2 r a w}-W C O_{2 b g}}{W C O_{2 \text { dilute }}-W C O_{2 b g}}-1
$$

Equation 27 
$\mathrm{WCO}_{2 \text { raw }}$ was the undiluted, raw concentration of $\mathrm{CO}_{2}$ measured directly out of the locomotive exhaust plume. $\mathrm{WCO}_{2 \text { dilute }}$ was the concentration of $\mathrm{CO}_{2}$ measured within the dilution tunnel. $\mathrm{WCO}_{2 \mathrm{bg}}$ was the background level of $\mathrm{CO}_{2}$ measured during testing.

$$
V_{f}=\frac{\frac{\left[\frac{C O_{2 \text { conc }}}{10^{6}}+\frac{C O_{\text {conc }}}{10^{6}}+\frac{H C_{\text {conc }}}{10^{6}}\right] V_{m i x} * C M W_{f}}{V_{m}}}{M_{f}}
$$

Equation 28

The fraction of exhaust circulated through the dilution tunnel is $\mathrm{V}_{\mathrm{f}} \cdot \mathrm{CO}_{2 \text { conc }}, \mathrm{CO}_{\text {conc }}$ and $\mathrm{HC}_{\text {conc }}$ and the concentrations of exhaust constituents measured within the dilution tunnel.

$\mathrm{CMW}_{\mathrm{f}}$ was the carbon molecular weight of the fuel, found by doing an analysis of the fuel used for testing, determining the hydrogen to carbon ratio of the fuel.

$\mathrm{V}_{\mathrm{m}}$ was the volume of one mole of gas at standard temperature and pressure.

$\mathrm{M}_{\mathrm{f}}$ was the mass of the fuel used during a test mode.

Upon the examination of the equations used by the Translab, it was noted that the $\mathrm{V}_{\text {mix }}$ used to determine the mass of PM emissions cancelled out in the calculation. Further investigation determined that the equations used to calculate PM emissions for the raw laboratory's PFT were equivalent to those used by the Translab. It was decided to calculate the PM emission rates of the two systems identically to aide in the comparison process. Both systems used the same raw exhaust sample concentration. The Translab's PM was calculated with both sets of equations as a means to check the results obtained. 


\subsection{Locomotive Engines Test Plan}

The objective of the study was to compare PM data from WVU's Translab to data collected by the partial flow dilution tunnel system. Testing took place on a water brake dynamometer system which was normally used to test remanufactured diesel locomotive engines' performance and functionality, prior to sale. The dynamometer measured the torque and speed of the engine, simulating normal operation for each notch of the test mode. These values then determined the horsepower produced.

A test plan was developed following the engine certification procedures outlined in Part 92, Table 3 of this document [2]. PM emissions data for each notch of the engine were measured for six minutes. The humidity and temperature of the ambient air were recorded in order to make a dry to wet conversion of the measured $\mathrm{CO}_{2}$ concentrations. $\mathrm{CO}_{2}$ was measured dry, after the water was removed by a chiller. The water volume removed from the sample was estimated to better represent the total volume analyzed by the NDIR. This allowed for an accurate measurement of the dilution ratio for each system.

\subsection{Equipment Setup and Procedures}

All procedures outlined in the CFR, Part 92 were strictly followed in this investigation [2]. The systems were set up in parallel to measure the PM production of a locomotive engine. Two baseline tests were completed for the engine. The engine was then modified and tested another two complete cycles. The values acquired by both systems were compared, developing an overall laboratory percent difference. This value determined the system verification, readying the partial flow dilution tunnel system for in the field testing of locomotive engines.

\subsubsection{PM Sampling Systems Setup}

Figure 34 provides an inside view of the exhaust sampling probes located in the exhaust stack plume. The probes were spaced to prevent any flow disturbances between systems. The top 
probe was used to transfer a sample to the Translab's dilution tunnel system, while the bottom probe was used to transfer a sample to the partial flow dilution tunnel. The probe met the specifications of the CFR Part 92 [2].

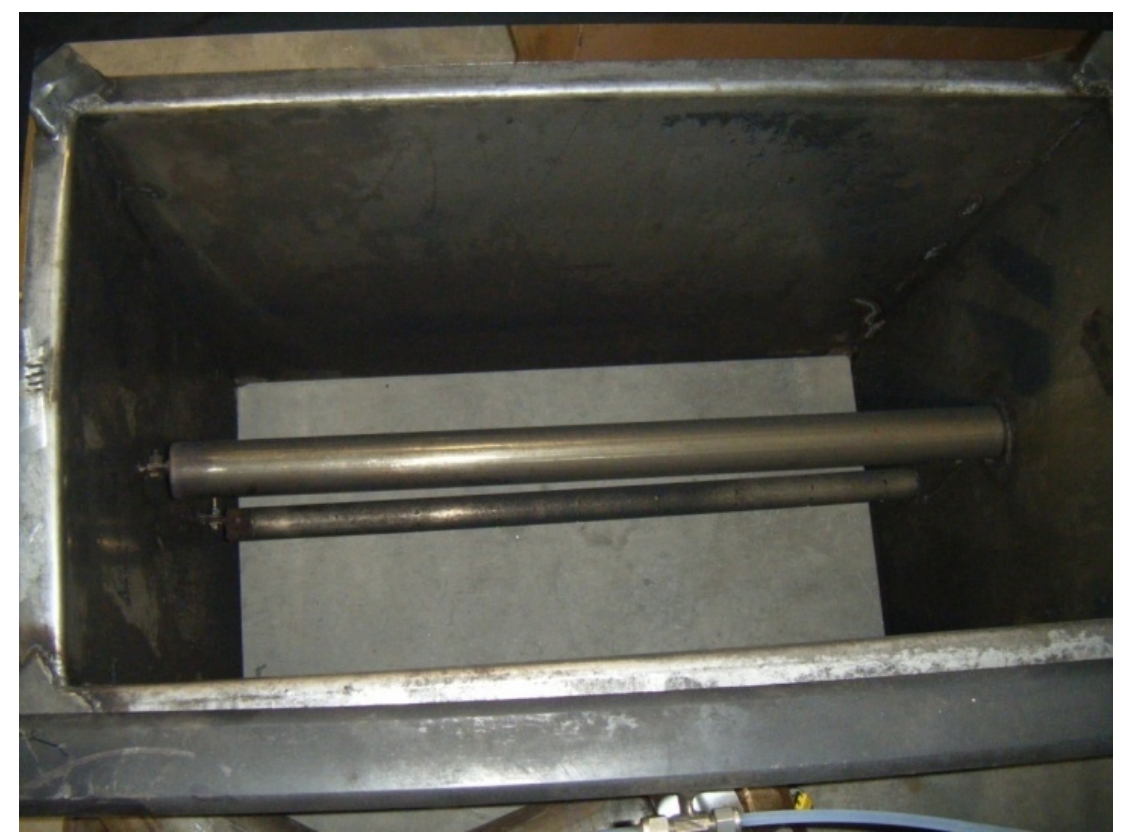

\section{Figure 30: Sampling Probes Located within the Locomotive Stack}

Holes in the probe were equally spaced across the exhaust duct facing in the opposite direction of the flow. This allowed a sample to be drawn from the plume that was representative of the entire span of the plume. A properly designed sampling probe was important. It ensured that the collected sample was representative of the total exhaust flow rate, as PM concentrations vary with the distance from the exhaust transfer tube wall [2]. Figure 33 represents the logic of the experiment. Both systems gathered data simultaneously. 


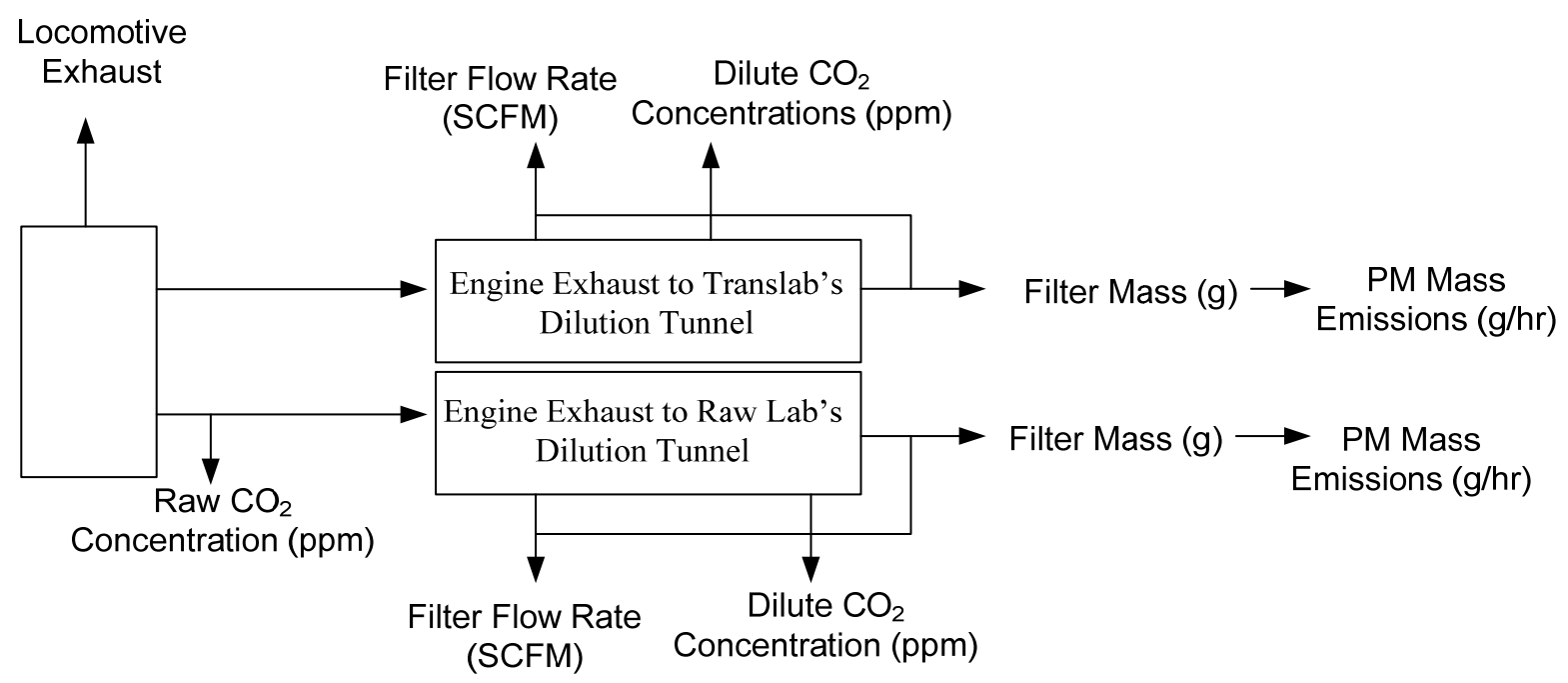

Figure 31: PM System Comparison Experimental Setup

The partial flow dilution tunnel system was mounted atop the Transportable Emissions Laboratory. The tunnel was attached to the locomotive stack adapter via electronically controlled heated line, maintained at a temperature of $385^{\circ} \mathrm{F}$. Two ladders placed aside of the Translab gave access to the dilution air valve and the particulate matter filter holder. The tunnel temperature was monitored during testing with a dilution air ratio adjusted to achieve a tunnel temperature below $125^{\circ} \mathrm{F}$. During a test the tunnel temperature was monitored visually to verify that the temperature did not exceed $125^{\circ} \mathrm{F}$. Prior to measuring the emissions for a particular mode the engine was allowed to stabilize while laboratory adjustments, such as zero and spanning the analyzers were made. This gave time to adjust the tunnel dilution ratio to a temperature safely below $125^{\circ} \mathrm{F}$. The particulate filters were noticeably loaded at a temperature between $115^{\circ} \mathrm{F}$ and $120^{\circ} \mathrm{F}$. 


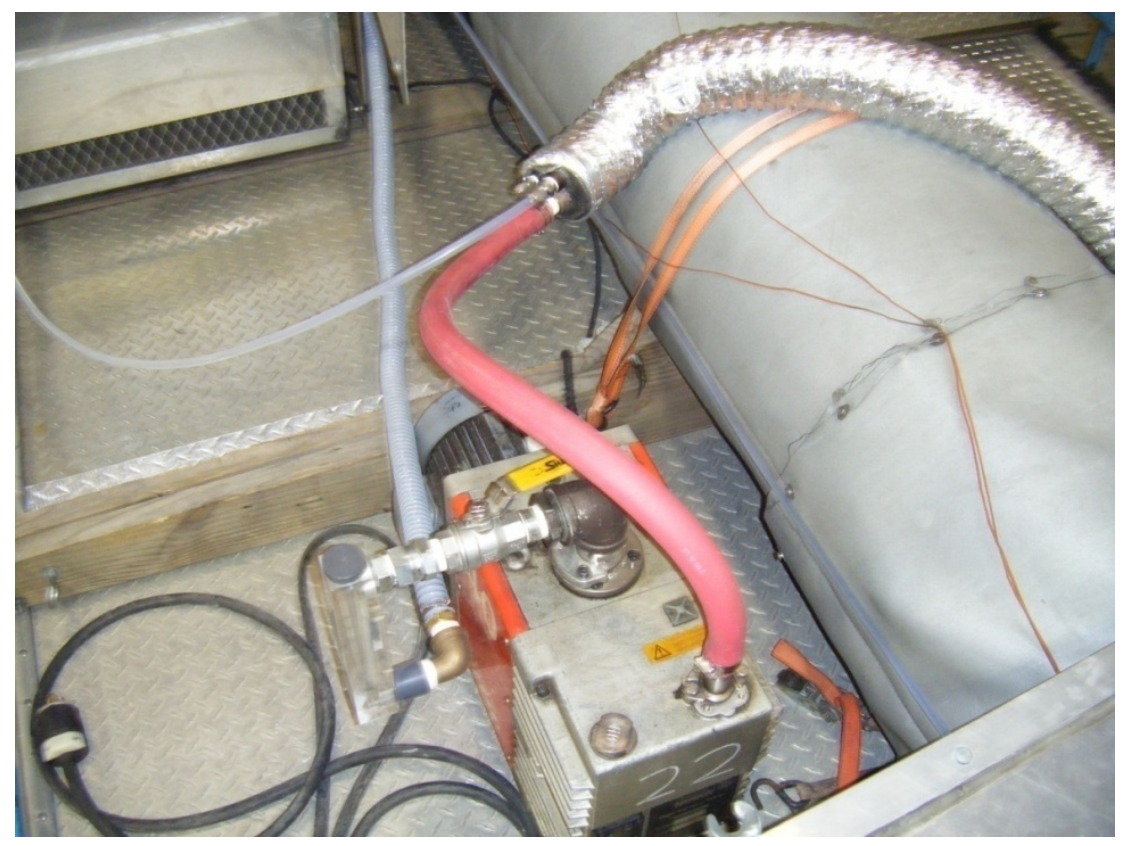

Figure 32: Partial Flow Dilution Tunnel Sample Pump and Exhaust Manifold atop the Translab

The total tunnel flow was maintained at $25 \mathrm{CFM}$ according to a Dwyer rotameter mounted at the entrance of the total tunnel flow pump pictured in Figure 35. This flow exceeded the requirements to sustain turbulent tunnel flow, ensuring complete exhaust and dilution air mixing. Engine exhaust was routed outside by a manifold system connected to a flexible duct. Connection points between the pump, tunnel and exhaust duct were minimized to maximize the flow rate provided by the high vacuum pump. The valve at the exit of the pump was throttled to provide a steady flow rate, free of pumping fluctuations. The pump was mounted atop the Translab with the rotameter visible from the ground allowing for the monitoring of the total tunnel flow. Prior to the rotameter a filter was installed at the tunnel exit to remove any PM that could soil the rotameter and the pump, causing damage over extended periods of use. 


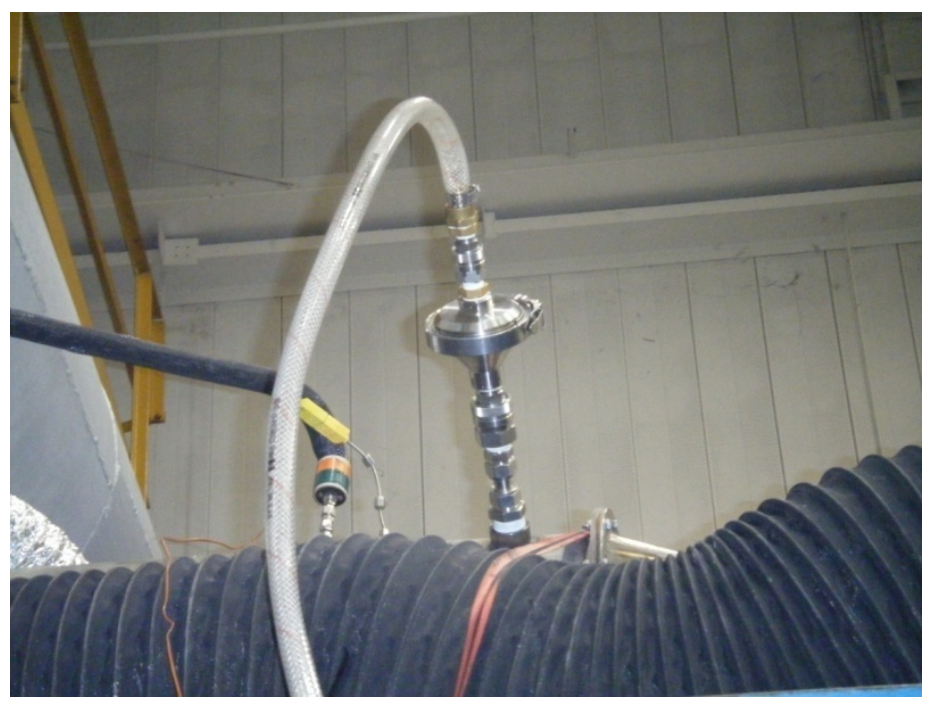

Figure 33: Particulate Matter Filter Holder

The filters used in the study were $70 \mathrm{~mm}$ T60A20 Teflo fluorocarbon-coated glass fiber filters. Filters were first conditioned in the CAFEE clean room, which kept the relative humidity and temperature of the room at $50 \%$ and $70^{\circ} \mathrm{F}$, respectively for one hour prior to weighing. The filters were placed in a glass Petri dish that remained unsealed to allow for humidity exchanges between the room and the filter. The covered Petri dish prevented any dust in the air from collecting on the filter's surface. The filters were weighed in pairs on a microbalance whose accuracy met the specifications mandated by the Code of Federal Regulations Part 92 [2]. Part 92 stated that the scale must have a precision (standard deviation) of no more than 20 micrograms and readability down to 10 micrograms or lower [2]. A reference filter was used as a system of checks and balances for the weighing process. The reference filter was weighed before and after the filter conditioning process to see if there had been any significant change in filter weight. The reference filter weight could not change more than $\pm 5 \%$ otherwise the particulate filters would have been discarded. The variance in the reference filter weight would be an indication that there had been a humidity exchange out of the specified tolerance ranges. 
The filters were placed in a stainless steel filter holder as shown in Figure 35. The exhaust/dilution air mixture was pulled through a mass flow controller which maintained a constant mass flow rate of 2.88 SCFM. The total volume of exhaust/dilution air mixture was recorded per notch setting, corrected to standard temperature and pressure. This value was then used to determine the total volume circulated through the filters for each notch. Once the mass of the loading on the filter was measured, this volume was used to determine the concentration of $\mathrm{PM}$ within the dilution tunnel in $\mathrm{g} / \mathrm{ft}^{3}$.

\subsubsection{Temporary Dilute $\mathrm{CO}_{2}$ for the Partial Flow System}

The system designed to measure dilute $\mathrm{CO}_{2}$ was in use on other projects, so a temporary system was developed. Prior to the locomotive testing, this system was verified versus an already valid system. To verify the system's accuracy, it was operated in parallel with a $\mathrm{CO}_{2}$ system located at the EERL. The analyzer used in the system was a California Analytical dual cell $\mathrm{CO} / \mathrm{CO}_{2}$ analyzer with a range of $0-5 \%$. The EERL was running FTP cycles on a 1992 Series 60 Detroit Diesel which gave a chance to verify the system. Prior to testing, the $\mathrm{CO}_{2}$ system was leak checked and drift tested showing a passing result.

\subsubsection{Results from Dilute $\mathrm{CO}_{2}$ System Verification}

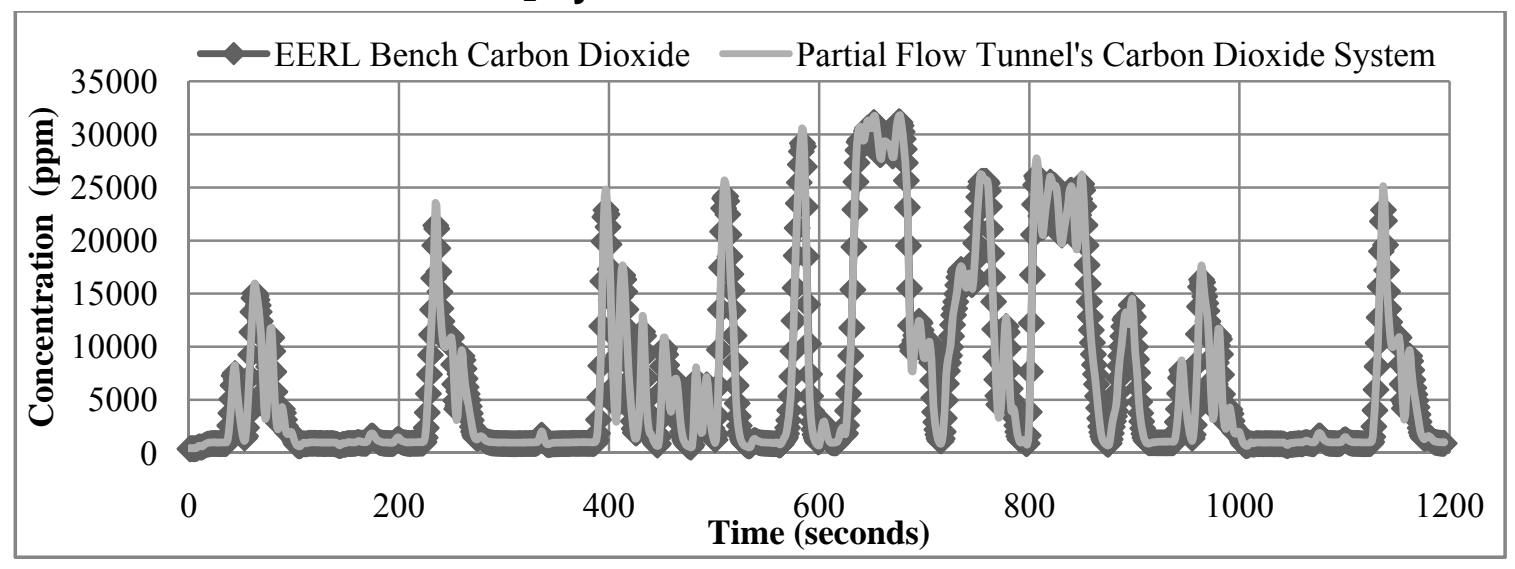

Figure 34: Temporary Dilute $\mathrm{CO}_{2}$ Verification 


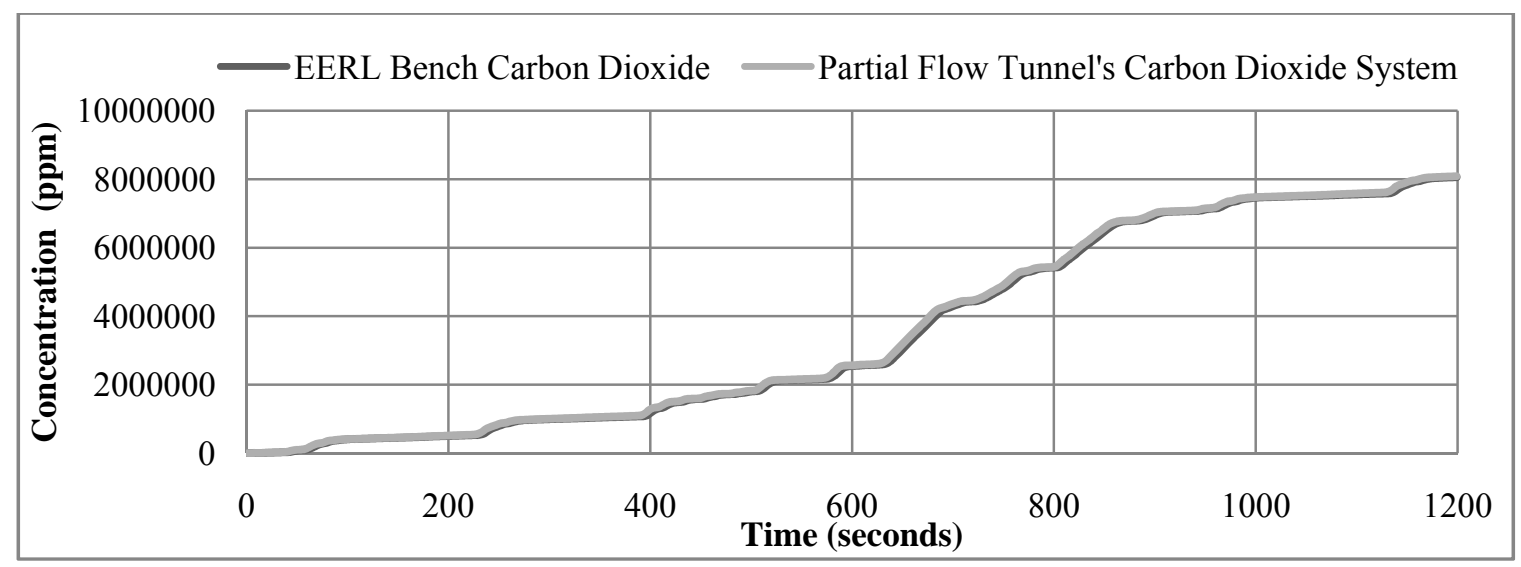

Figure 35: Integrated $\mathrm{CO}_{2}$ versus Time

Four runs were completed with results shown in Figure 34. Figure 35 displays the integrated concentrations for both systems in parts per million. The results of the four FTPs can be found in Table 24.

Table 24: Dilute $\mathrm{CO}_{2}$ System Verification Summary

\begin{tabular}{|r|c|c|c|}
\hline \multicolumn{1}{|c|}{ Run } & $\begin{array}{c}\text { EERL Integrated } \\
\mathrm{CO}_{2}(\mathrm{ppm})\end{array}$ & $\begin{array}{c}\mathrm{CO}_{2} \text { System Ongoing } \\
\text { Verification (ppm) }\end{array}$ & $\begin{array}{c}\text { Percent } \\
\text { Difference }\end{array}$ \\
\hline 1 & 8056387.41 & 8088402.74 & $0.40 \%$ \\
\hline 2 & 8037468.24 & 8035920.99 & $1.93 \%$ \\
\hline 3 & 8028000.71 & 8027051.50 & $1.18 \%$ \\
\hline 4 & 8016461.37 & 8018414.25 & $2.44 \%$ \\
\hline \multicolumn{2}{|r}{ Average Percentage Difference }
\end{tabular}

It was felt that the system would be a verified substitute for the original system designed to measure the dilute $\mathrm{CO}_{2}$ concentration of the PFT.

\subsubsection{Analyzer Calibrations}

The analyzers used in this study were calibrated using known concentrations of analytical gases. A gas divider was used to develop an eleven point calibration curve. The gases were diluted with nitrogen to achieve eleven points of calibration, equally spaced between $0-100 \%$. The bottles were named by the vender and re-verified using a standard reference material (SRM) 
bottle. Once the eleven points were collected, a third degree polynomial was fit through the points to develop a represented curve of gas ppm versus ADC. The analog signal ranging from 0 to 5 volts from the analyzer was used to determine the concentrations of $\mathrm{CO}_{2}(\mathrm{ppm})$ once conditioned with an analog input device. In this study a $12 \%$ bottle of $\mathrm{CO}_{2}$ was used to calibrate the raw $\mathrm{CO}_{2}$ sampling system and a $2 \%$ bottle of $\mathrm{CO}_{2}$ was used for the partial flow dilution tunnel system. Raw $\mathrm{CO}_{2}$ for notches 3 through idle were measured using a $6 \%$ calibration. Once the calibration curve was fit it was decided that a curve with a $\mathrm{R}^{2}$ value equal to or greater than 0.999 would be considered a satisfactory calibration curve. If the calibration resulted in a $\mathrm{R}^{2}$ value of less than 0.999 then the analyzer was recalibrated until this requirement was achieved. Calibrations are typically done for an analyzer when the span gas being used is changed from a previous gas.

\subsubsection{Fuel Measurement System}

A fuel measurement system that utilized a load cell to determine the weight of the fuel electronically was used to measure the fuel consumption, gravimetrically for each notch. The load cell was calibrated using NIST traceable calibration weights. The weight was varied over the entire range of operation to establish a ten point calibration curve. Fuel weight was recorded prior to and after a notch to determine the fuel consumption in pounds per hour for that notch. The mass of the fuel consumed was used to calculate the total exhaust flow rate for each notch. This value was then used to determine the PM emissions rates for each notch in conjunction with the tunnel's PM concentration multiplied by its dilution ratio. The return line from the engine ran through a chiller to cool the returned fuel stream. The fuel in this study was certified diesel fuel for locomotive engine emissions testing. The fuel was sent to a laboratory for analysis. This is where the hydrogen to carbon ratio of the fuel was determined which was used in the calculations to compute the total exhaust flow rate of the engine. 


\subsubsection{Test Sequence Alteration}

Based on previous years of testing and preference by WVU for ease of operation, the test sequence was chosen to run in reverse order starting with notch 8 , then proceeding downward until reaching idle. Each mode was run for 6 minutes; collecting both gaseous and PM exhaust emissions. Notch 8 was held for fifteen minutes, with PM samples collected for the first six minutes, while gaseous emissions were measured for the entire 15 minutes of operation. Background testing for PM was performed pre and post testing. The average PM for the background of the day was then computed. This number was used to subtract out the background's effects on PM filter weights. The background test mode was for 20 minutes, with the volume passing through the filter recorded. The 20 minutes allowed for a background level of PM to be accumulated on the filter, preventing weighing error.

\subsubsection{PM Sampling Test Timing}

To ensure both systems measured simultaneously, some relay wiring techniques were used to trigger both systems' PM filter pumps. The signal from the Translab's computer that triggered its PM pump to activate was wired in parallel with the partial flow dilution tunnel's PM pump relay. This bolstered system synchronicity. The partial flow dilution tunnel system was setup to continuously record the PM filter flow rate. Figure 36 depicts how test start times were determined. 


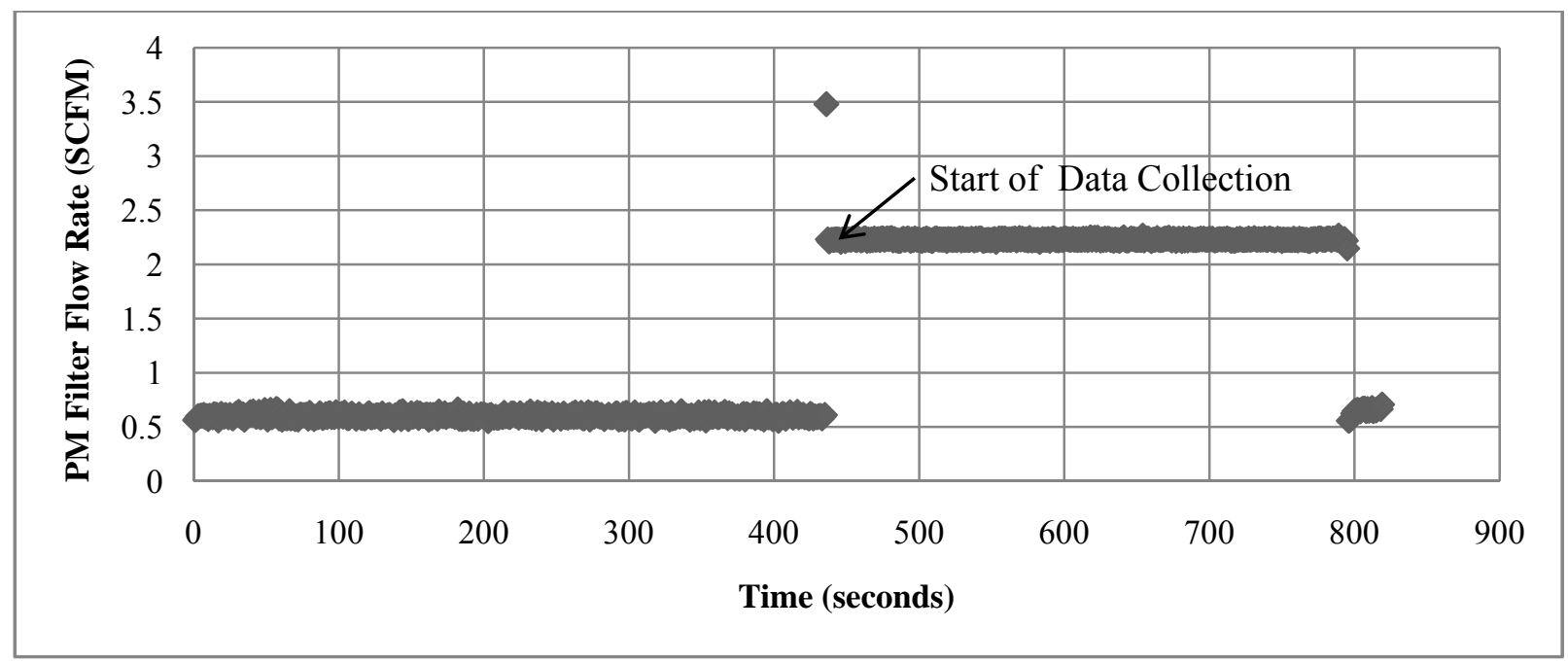

Figure 36: PM Filter Flow Rate Vs. Time: Illustration of the Timing between Both Systems

To ensure accurate PM filter loadings, the filter remained unconnected from the PM filter probe until the testing began. The filter holder remained capped to prevent any contamination from outside sources.

\subsubsection{Experimental Uncertainty}

A range of values measured, based on instrumentation precision and random error that represents the confidence level of a measured value was developed. To do so, a function of a known variables was analyzed. For the partial flow dilution tunnel system this function was:

$$
P M=W_{\text {vol }} * P M_{\text {conc }} *(D F+1)
$$

Equation 29

Each instrument had an uncertainty associated with its measurement. These uncertainties were taken into account in the following equation $[15,20]$.

$$
\text { Error }=\left|\Delta u_{1} \frac{\delta P M}{\partial u_{1}}\right|+\left|\Delta u_{2} \frac{\delta P M}{\partial u_{2}}\right|+\left|\Delta u_{3} \frac{\delta P M}{\partial u_{3}}\right|+. .+\left|\Delta u_{n} \frac{\delta P M}{\partial u_{n}}\right|
$$

Equation 30 
The $\Delta \mathrm{u}$ 's represent the instrumentation error associated with its particular instrumentation. Once the partial derivative for each variable is taken the instrument error applied can determine the overall system error by applying the following equation $[15,20]$.

$$
\text { Error }_{95 \% \text { confidence }}=\sqrt{\left(\Delta u_{1} \frac{\delta P M}{\partial u_{1}}\right)^{2}+\left(\Delta u_{2} \frac{\delta P M}{\partial u_{2}}\right)^{2}+. .+\left(\Delta u_{n} \frac{\delta P M}{\partial u_{n}}\right)^{2}}
$$

Equation 31

Table 25: Uncertainties Based on Equipment

\begin{tabular}{|l|c|}
\hline \multicolumn{1}{|c|}{ Equipment } & $\Delta \mathrm{u}$ \\
\hline Raw $\mathrm{CO}_{2}$ & $\pm 1 \%$ \\
\hline Dilute $\mathrm{CO}_{2}$ & $\pm 1 \%$ \\
\hline Mass Flow Controller & $\pm 1 \%$ \\
\hline Filter Weight & $\pm 4.30 \%$ \\
\hline
\end{tabular}

For the partial flow dilution tunnel system the error was found to be $\pm 5.12 \%$. The instrumentation errors, as well as weighing variability were used to develop this value. WVU had completed a study where filters were repeatedly weighed and the values recorded. The filters were kept in a closed Petri dish in WVU's clean room, preventing substantial humidity exchanges and particle deposition. The weighing process derived a standard deviation of 0.016 mg. The value obtained from this study was used in conjunction with the average filter weight to develop an error associated with the weighing process. These values were used to develop an error bar for the grams/bhp-hr comparison of each system. Since the Translab PM was computed identically, with instrumentation that had the same precision, the Translab's error bar was computed to be $\pm 5.12 \%$ as well. 


\subsection{Engine 1, Configuration 1}

The engine was operated in its OEM manufactured state for two consecutive tests to develop data corresponding to its baseline. The dilution tunnel that was to be used in conjunction with the raw gaseous emissions sampling laboratory is labeled the Partial Flow Dilution Tunnel (PFT) for these cases. The second baseline was completed immediately following the first, preventing the engine from cooling down. Prior to the first baseline the engine was given a substantial amount of time to reach a warm operating temperature. Data collected from a warmed engine best represented the emissions produced in its normal operation. The results are presented and then the differences discussed thereafter.

\subsubsection{Engine 1, Baseline- Run 1}

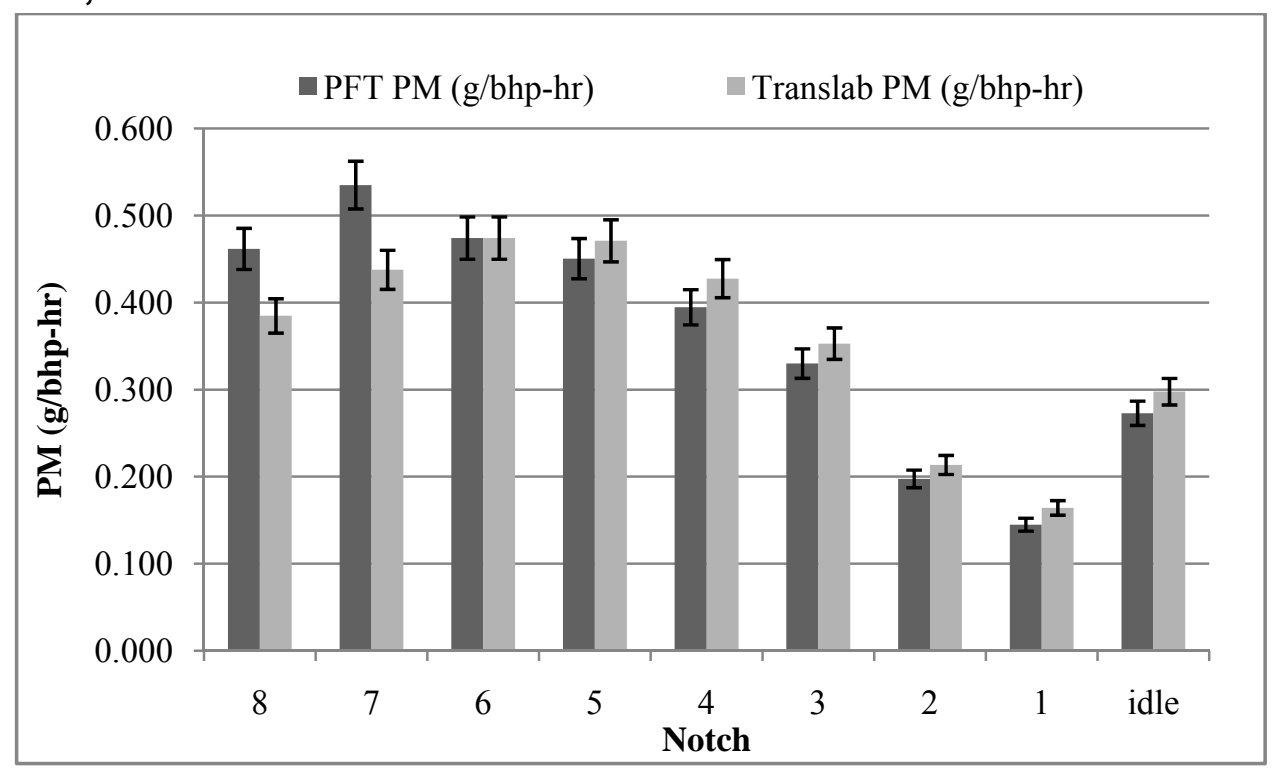

Figure 37: Engine 1, Configuration 1, Run 1 Result

Figure 37 shows the results for the first baseline for each notch setting. The locomotive was equipped with nine notches, notch 8 through idle. Each notch was tested for PM using different filters. The filters were placed in a glass Petri dish, inserted and sealed in shipping envelops after the mode completion. 
Table 26: Engine 1, Configuration 1, Run 1 Tabulated Results

\begin{tabular}{|c|c|c|c|}
\hline Notch & $\begin{array}{c}\text { PFT PM } \\
\text { (g/bhp-hr) }\end{array}$ & $\begin{array}{c}\text { Translab PM } \\
\text { (g/bhp-hr })\end{array}$ & Percent Difference \\
\hline 8 & 0.462 & 0.385 & $20.0 \%$ \\
\hline 7 & 0.535 & 0.438 & $22.22 \%$ \\
\hline 6 & 0.474 & 0.474 & $0.0 \%$ \\
\hline 5 & 0.451 & 0.471 & $4.35 \%$ \\
\hline 4 & 0.395 & 0.428 & $7.69 \%$ \\
\hline 3 & 0.330 & 0.353 & $6.49 \%$ \\
\hline 2 & 0.197 & 0.214 & $7.50 \%$ \\
\hline 1 & 0.145 & 0.164 & $11.76 \%$ \\
\hline Idle & 0.273 & 0.298 & $8.33 \%$ \\
\hline
\end{tabular}

The results produced by the first run showed a strong correlation of the data between notches six through idle. The average percent difference for this baseline run was $9.81 \%$. The results were tabulated in Table 25, with the percent difference for each notch shown. Notch 8 and notch 7 produced the greatest system differences in the PM calculations. Statistically, the rest of the notches fell within the experimental uncertainly of $5.12 \%$, graphically shown by the overlapping error bars. The Translab's PM results were calculated using the WVOL method, as well as the $V_{f}$ method to verify the calculations. To make an assessment as to why the two notches, 8 and 7, produced different results between the systems, the WVOL equation was analyzed. PM was calculated from the following equation:

$$
M_{P M \text { Mode }}=(W V o l)\left(P M_{\text {conc }}\right)(1+D F) / b H P
$$

Equation 32

Both systems utilized the same locomotive exhaust flow rate and brake horsepower, therefore eliminating the WVOL and bHP variables in the system variability. What was then left was the $\mathrm{PM}_{\text {conc, }}$, multiplied by the system's dilution ratio. This value obtained for each system can then be 
compared to determine the differences between the systems. The concentrations multiplied by the systems' dilution ratios, for each mode are tabulated in Table 26:

Table 27: Concentration Tabulated Results Baseline One (g/ft $\left.\mathbf{t}^{3}\right)$

\begin{tabular}{|c|c|c|c|}
\hline Notch & $\begin{array}{c}\text { PFT PM } \\
\left(\mathrm{g} / \mathrm{ft}^{3}\right)\end{array}$ & $\begin{array}{c}\text { Translab PM } \\
\left(\mathrm{g} / \mathrm{ft}^{3}\right)\end{array}$ & Difference \\
\hline 8 & 0.0030 & 0.0025 & 0.00050 \\
\hline 7 & 0.0033 & 0.0027 & 0.00060 \\
\hline 6 & 0.0022 & 0.0022 & 0.00000 \\
\hline 5 & 0.0022 & 0.0023 & -0.00010 \\
\hline 4 & 0.0012 & 0.0013 & -0.00010 \\
\hline 3 & 0.00072 & 0.00077 & -0.00005 \\
\hline 2 & 0.00037 & 0.0004 & -0.00003 \\
\hline 1 & 0.00015 & 0.00017 & -0.00002 \\
\hline idle & 0.00011 & 0.00012 & -0.00001 \\
\hline
\end{tabular}

It can be seen that for notch 8 the system variability is $+0.0005 \mathrm{~g} / \mathrm{ft}^{3}$. Notch 7 produced a system variability of $+0.0006 \mathrm{~g} / \mathrm{ft}^{3}$. A more in depth analysis for this system difference will be looked at following the data of the second baseline run. 
6.5.2 Engine 1, Baseline- Run 2

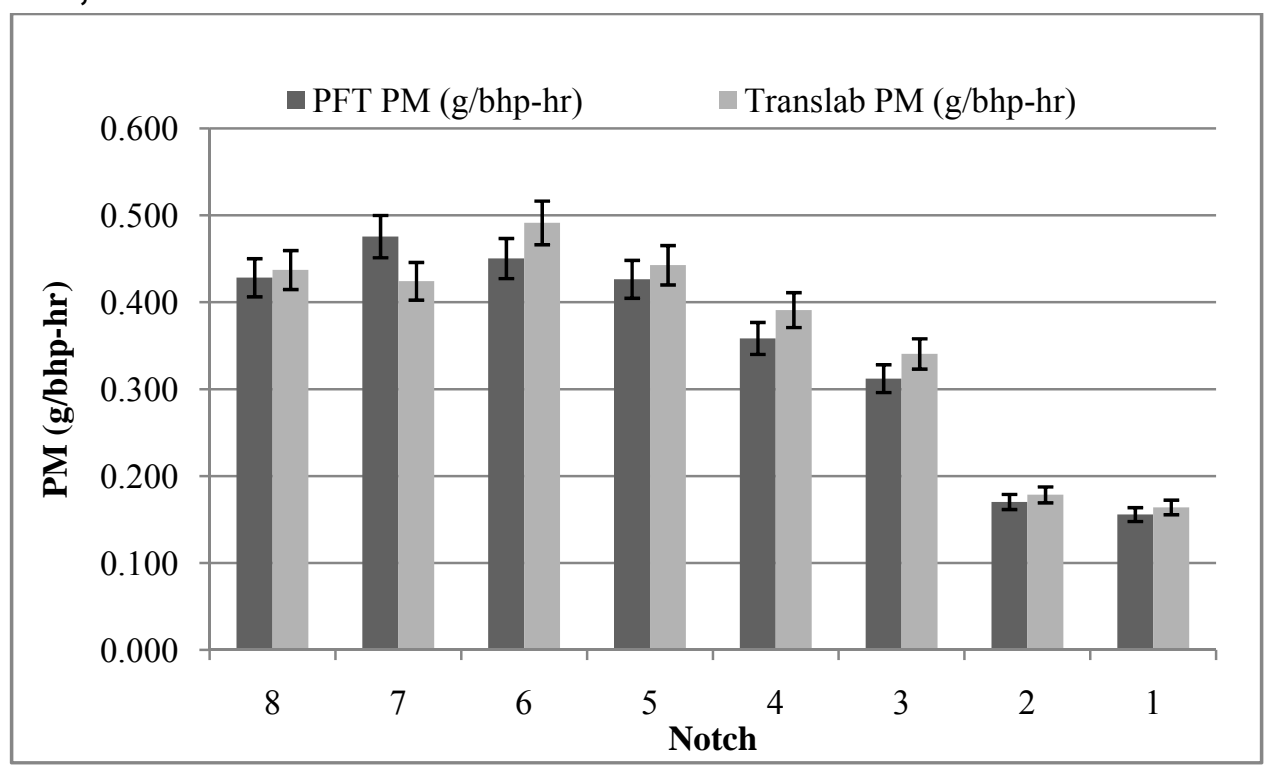

Figure 38: Engine 1, Configuration 1, Run 2 Results

Figure 38 has the results from the second baseline. The testing was stopped after the Translab's HC analyzer malfunctioned. This data provided the locomotive company with information regarding engine performance and emissions improvements between the baseline engine and the soon to be modified engine. It was felt that enough data had been collected from the baseline testing to continue on. Table 27 shows the results in tabulated form.

Table 28: Engine 1, Configuration 1, Run 2 Tabulated Results

\begin{tabular}{|c|c|c|c|}
\hline Notch & $\begin{array}{c}\text { PFT PM } \\
\text { (g/bhp-hr) }\end{array}$ & $\begin{array}{c}\text { Translab PM } \\
\text { (g/bhp-hr) }\end{array}$ & Percent Difference \\
\hline 8 & 0.428 & 0.437 & $2.03 \%$ \\
\hline 7 & 0.476 & 0.424 & $12.12 \%$ \\
\hline 6 & 0.450 & 0.491 & $8.33 \%$ \\
\hline 5 & 0.426 & 0.443 & $3.67 \%$ \\
\hline 4 & 0.358 & 0.391 & $8.33 \%$ \\
\hline 3 & 0.312 & 0.341 & $8.33 \%$ \\
\hline 2 & 0.170 & 0.178 & $4.62 \%$ \\
\hline 1 & 0.156 & 0.164 & $5.03 \%$ \\
\hline
\end{tabular}


The second baseline showed a strong correlation between all modes being tested. The average percent difference for this run was $6.56 \%$. Statistically the systems' error bars overlapped for all modes, with the exception of notch 7 as seen in Figure 39: Engine 1, Configuration 1, Run 2 Results. This mode was $1.4 \%$ out of the error bar tolerance. The percent difference for each mode is tabulated in Table 27. The actual difference between the modes as calculated by the $\mathrm{PM}_{\text {conc }}$ multiplied by the dilution factor for each mode was tabulated in Table 28.

Table 29: Concentration Tabulated Results, Baseline Engine: Run Two (g/ft $\left.{ }^{3}\right)$

\begin{tabular}{|c|c|c|c|}
\hline Notch & $\begin{array}{c}\text { PFT PM } \\
\left(\mathrm{g} / \mathrm{ft}^{3}\right)\end{array}$ & $\begin{array}{c}\text { Translab PM } \\
\left(\mathrm{g} / \mathrm{ft}^{3}\right)\end{array}$ & Difference \\
\hline 8 & 0.0029 & 0.00296 & -0.00006 \\
\hline 7 & 0.00296 & 0.00264 & 0.00032 \\
\hline 6 & 0.0022 & 0.0024 & -0.00020 \\
\hline 5 & 0.0021 & 0.00218 & -0.00008 \\
\hline 4 & 0.0011 & 0.0012 & -0.00010 \\
\hline 3 & 0.00066 & 0.00072 & -0.00006 \\
\hline 2 & 0.00031 & 0.000325 & -0.00002 \\
\hline 1 & 0.000151 & 0.000159 & -0.00001 \\
\hline
\end{tabular}

\subsubsection{Engine 1, Baseline: Overall Results Discussed}

The PFT and Translab were able to calculate PM emissions using Equation 31. Each system utilized the same raw $\mathrm{CO}_{2}$ concentration and total exhaust flow rate for the calculation. This left three variables that could have been responsible for the system differences: filter weight (mg), total filter volume (scf), and dilute $\mathrm{CO}_{2}$ concentration (ppm). Total filter volume for both systems remained relatively constant for all test modes, thus eliminating this variable as a culprit for the system differences. The total volume drawn through the filter was analyzed for each mode, and the variation in this volume was found to be $\pm 0.003 \mathrm{scf}$. Thus, the only variables left 
that could have caused system differences were the weighing of the filters, and the measurement of the dilute $\mathrm{CO}_{2}$ concentrations in the dilution tunnels.

A beneficial way to determine what caused the system difference was to look at a mode that was not within in the error bar limits for one test, but fell within those limits for a second test. Notch 8 for the baseline runs was a mode that fit this criterion. The results from the first baseline did not overlap for notch 8 , but did for the second baseline. Looking at the filter weight, dilute $\mathrm{CO}_{2}$ concentration, and the system dilution factor helped determine where there was a measurement difference. These values are tabulated in Table 29.

Table 30: System Variability-Results Analyzed

\begin{tabular}{|l|c|c|c|}
\cline { 2 - 4 } \multicolumn{1}{c|}{} & $\begin{array}{c}\text { Filter } \\
\text { Weight }(\mathrm{mg})\end{array}$ & Dilute $\mathrm{CO}_{2}(\mathrm{ppm})$ & DF \\
\hline PFT Run 1 & 7.5374 & 9325.4 & 6.1 \\
\hline PFT Run 2 & 6.6471 & 8967.4 & 6.6 \\
\hline Translab Run 1 & 4.5253 & 4749.69 & 13.67 \\
\hline Translab Run 2 & 5.3522 & 4778.9 & 13.67 \\
\hline
\end{tabular}

The dilution factor for the PFT system did not remain constant because the dilution ratio was adjusted manually with the hand valve located at the tunnel entrance. The filter weight changed due to this adjustment. Investigating the Translab's data, the dilution factor and the dilute $\mathrm{CO}_{2}$ concentration for that system remained constant for both runs. However, there was a variance in the weight of the filters between run 1 and run 2 for the Translab system. This difference was $0.8269 \mathrm{mg}$. It can then be concluded that the variance observed in this mode of testing was due to a weighing error. This error was possibly due to a combination of instrumentation and human error. The true cause of this error cannot be truly determined, though it does prove that the error 
was not associated with the physical design of the PFT system because everything was constant in the Translab system with the exception of the filter weight.

Another comparison that was made for the baseline results was comparing the overall computed system PM measurement in $\mathrm{g} / \mathrm{bhp}-\mathrm{hr}$ for each test, applying the weighting factors associated for each notch setting. The results from the baseline testing were averaged, and then the values were used to compute an overall PM brake specific mass emissions rate for the engine. As previously stated, the weighting factors for the engine were developed by the EPA to represent the percent of time a locomotive would be in each notch for its useful life. Notches that the locomotives were in more frequently were given a higher weighting factor. The factors used were from a line-haul locomotive that did not have a dynamic brake mode as specified by the EPA [3]. The weighting factors can be found in Table 30:

\section{Table 31: Locomotive Weighting Factors}

\begin{tabular}{|c|c|}
\hline Notch & Weighting Factor \\
\hline 8 & 0.505 \\
\hline 7 & 0.065 \\
\hline 6 & 0.065 \\
\hline 5 & 0.052 \\
\hline 4 & 0.044 \\
\hline 3 & 0.038 \\
\hline 2 & 0.039 \\
\hline 1 & 0.03 \\
\hline idle & 0.162 \\
\hline
\end{tabular}

Once the weighting factors for each notch setting were applied, Table 31 presented a laboratory percent difference of $4.8 \%$. 
Table 32: Overall PM: Engine 1 Baseline

\begin{tabular}{|l|c|}
\cline { 2 - 2 } \multicolumn{1}{c|}{} & $\begin{array}{c}\text { PM } \\
\text { (g/bhp-hr })\end{array}$ \\
\hline PFT & 0.44 \\
\hline Translab & 0.42 \\
\hline Percent difference & $4.8 \%$ \\
\hline
\end{tabular}

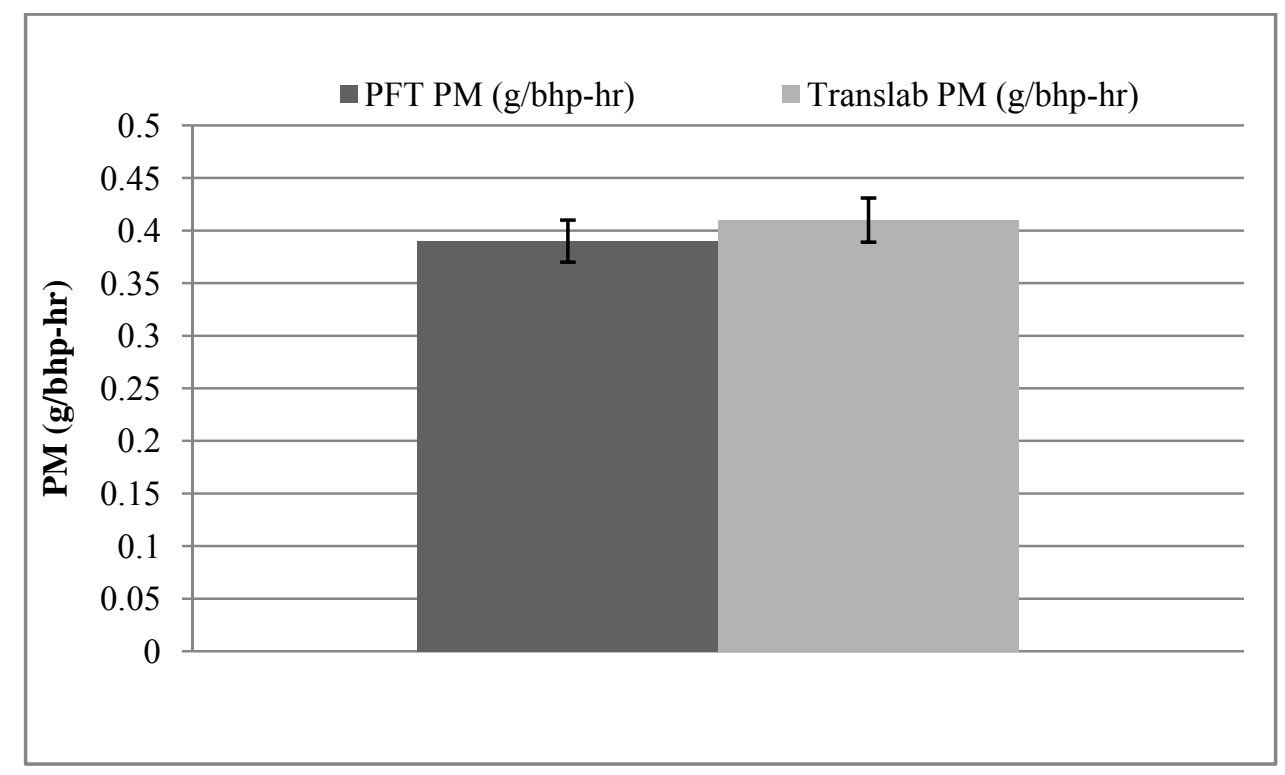

Figure 39: Brake Specific PM Mass Emissions, Baseline Run

Based on the baseline results, the partial flow dilution tunnel system functioned well. There was an observable measurement difference of two hundredths of a gram per brake horsepower hour between laboratories. Statistically the overall laboratory functionality was acceptable based on the $5.12 \%$ error bar developed shown in Figure 39. More testing would be completed to verify the systems functionality. 


\subsection{Engine 1, Configuration 2}

The engine that was used in the first set of data was modified and retested for emissions. The fuel injectors for the engine were replaced with aftermarket injectors. The intercoolers for the engine were also modified. Testing followed the same test plan as previously performed, with the addition of a dynamic brake, normal idle, and low idle test modes. The engine was tested two complete cycles and the numbers were used to develop a system comparison as done in the baseline testing. The weighting factors for each notch were utilized to develop a total system difference, of which was used to determine the PFT creditability as a PM measurement system. The modified engine was tested by WVU for the potential of receiving EPA certification. This gave WVU a second opportunity to collect more data for the newly developed PFT system.

\subsubsection{Engine 1, Configuration 2, Run 1 Results}

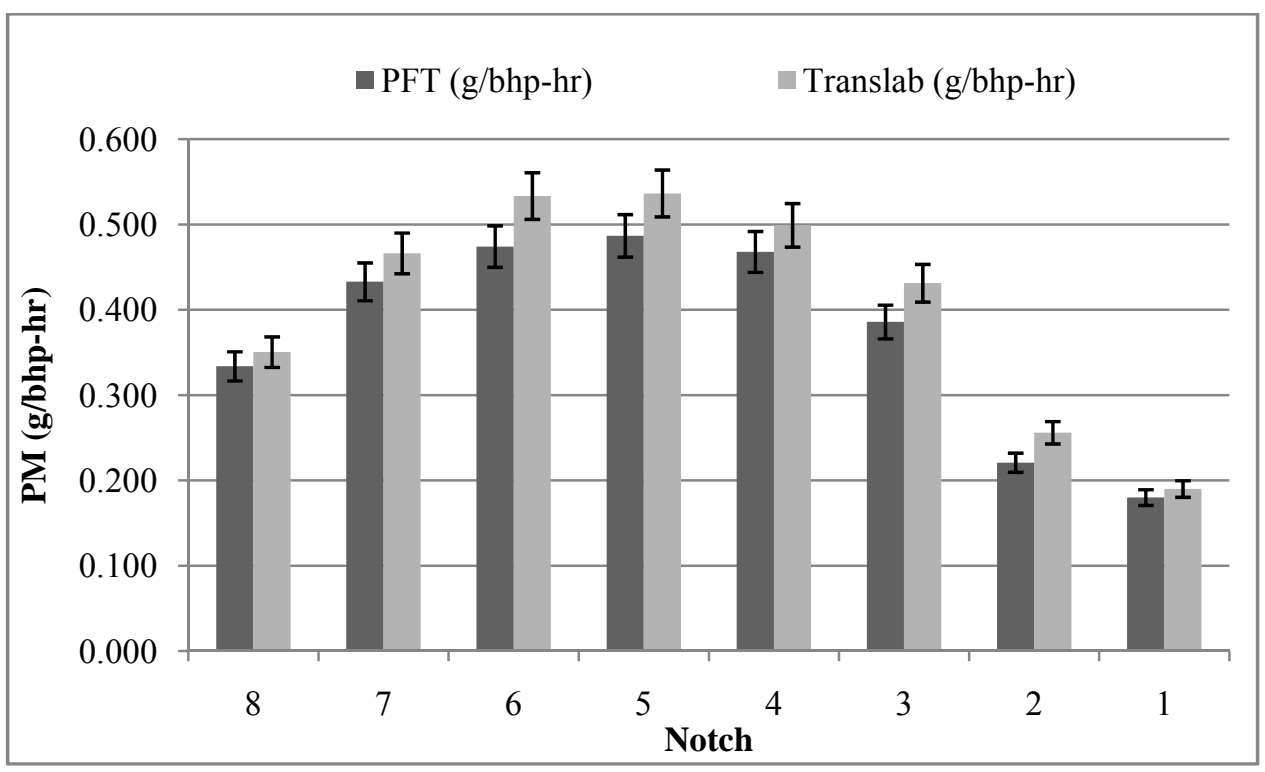

Figure 40: Engine 1, Configuration 2 Run 1 Results (Notch 8 - Notch 1) 


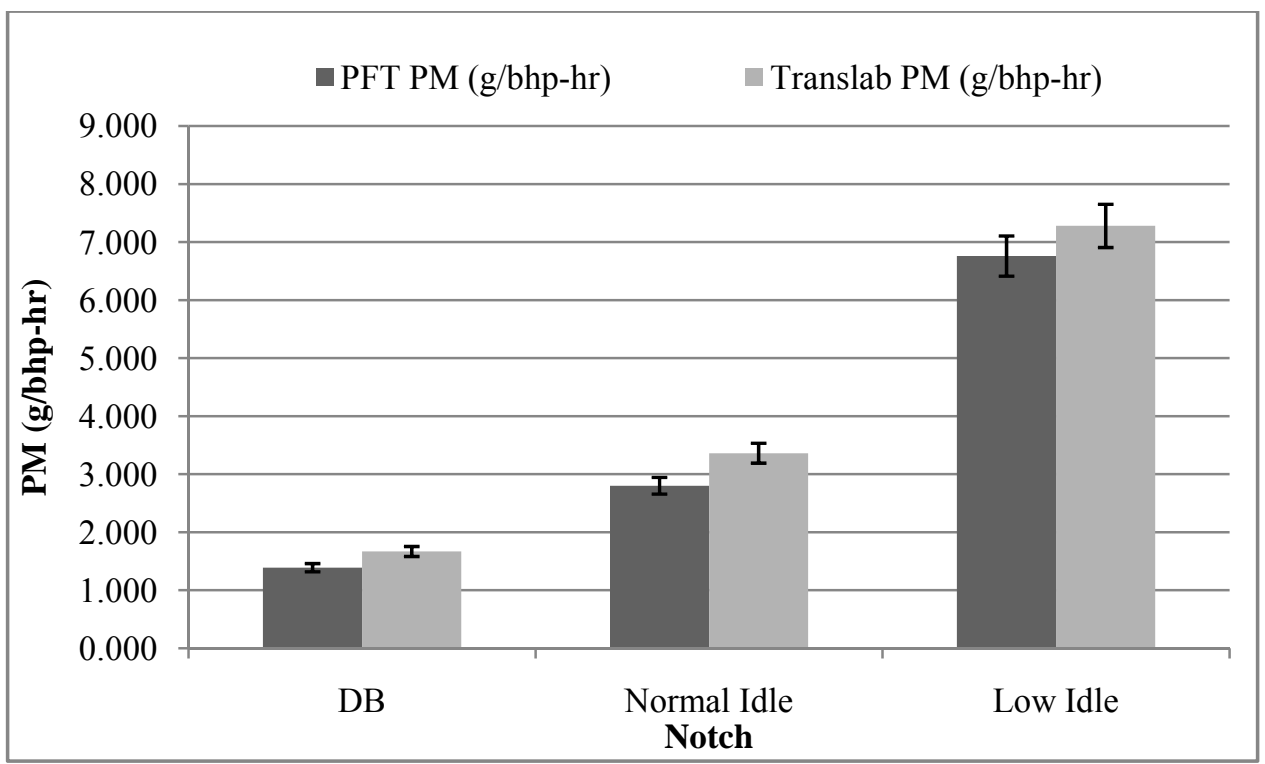

Figure 41: Engine 1, Configuration 2, Run 1 Results (Dynamic Brake - Low Idle)

Figure 40 and Figure 41 show the results for PM obtained from the first run of the modified engine. The dynamic brake, normal idle, and low idle modes are shown on a different bar graph to better show the values based on the scale. These notches have less power, therefore are divided by a much smaller number, resulting in higher brake specific PM values. Statistically, all modes, with the exception of notch 6 , notch 2 , dynamic brake and normal idle, are equivalent due to the overlapping error bars. The modes listed that have variation are just outside of the error bar range. These modes were analyzed to determine where there was a difference in the measured value between the systems and discussed in the results section. Table 32 shows the results from the testing in the tabulated form. 
Table 33: Engine 1, Configuration 2, Run 1 Tabulated Results

\begin{tabular}{|c|c|c|c|}
\hline Notch & $\begin{array}{c}\text { PFT PM } \\
\text { (g/bhp-hr) }\end{array}$ & $\begin{array}{c}\text { Translab PM } \\
\text { (g/bhp-hr })\end{array}$ & $\begin{array}{c}\text { Percent } \\
\text { Difference }\end{array}$ \\
\hline 8 & 0.334 & 0.350 & $4.76 \%$ \\
\hline 7 & 0.433 & 0.466 & $7.14 \%$ \\
\hline 6 & 0.474 & 0.533 & $11.11 \%$ \\
\hline 5 & 0.487 & 0.536 & $9.26 \%$ \\
\hline 4 & 0.468 & 0.499 & $6.25 \%$ \\
\hline 3 & 0.386 & 0.431 & $10.53 \%$ \\
\hline 2 & 0.221 & 0.256 & $13.73 \%$ \\
\hline 1 & 0.180 & 0.190 & $5.26 \%$ \\
\hline DB & 1.389 & 1.668 & $16.70 \%$ \\
\hline Normal Idle & 2.801 & 3.361 & $16.67 \%$ \\
\hline Low Idle & 6.759 & 7.279 & $7.14 \%$ \\
\hline
\end{tabular}

The average percent difference between the laboratories for the first engine modification run was $11.31 \%$. There was a variation in the percent differences for the laboratory throughout the testing. The normal idle mode shows the greatest error. The concentrations of these modes can be determined to analyze the actual differences between the systems; again considering each system utilized the same total exhaust flow rate and measured horsepower. The dilution ratio of each system multiplied by its $\mathrm{PM}_{\text {conc }}$ can be found in Table 33: Concentration Tabulated Results, Modified Engine: Run $1\left(\mathrm{~g} / \mathrm{ft}^{3}\right)$. It was felt that this number would give the best idea of the actual difference between the PFT system and the Translab system. 
Table 34: Concentration Tabulated Results, Modified Engine: Run 1 (g/ft $\left.\mathbf{t}^{3}\right)$

\begin{tabular}{|c|c|c|c|}
\hline Notch & PFT $\left(\mathrm{g} / \mathrm{ft}^{3}\right)$ & Translab $\left(\mathrm{g} / \mathrm{ft}^{3}\right)$ & Difference \\
\hline 8 & 0.0020 & 0.0021 & $1 \mathrm{E}-04$ \\
\hline 7 & 0.0026 & 0.0028 & 0.0002 \\
\hline 6 & 0.0024 & 0.0027 & 0.0003 \\
\hline 5 & 0.0025 & 0.0027 & 0.00025 \\
\hline 4 & 0.0015 & 0.0016 & 0.0001 \\
\hline 3 & 0.0009 & 0.0010 & 0.0001 \\
\hline 2 & 0.0004 & 0.0005 & 0.00007 \\
\hline 1 & 0.0002 & 0.0002 & 0.00001 \\
\hline DB & 0.0004 & 0.0004 & 0.000073 \\
\hline Normal Idle & 0.0001 & 0.0002 & -0.00003 \\
\hline Low Idle & 0.0001 & 0.0001 & 0.00001 \\
\hline
\end{tabular}

The tabulated concentration results as shown in Table 32 point out a notable attribute for the system difference. The notch with the highest percent difference, normal idle, shows one of the largest percent differences for the overall results, however due to the rounding, illustrates zero difference in the concentration. A mere 0.00003 grams per cubic foot produces a $16.67 \%$ difference in the final result. Dynamic brake was the same way, with a measured system difference of 0.000073 . The high error shown in the normal idle and dynamic brake modes can be concluded to be nothing more than a rounding issue. If the value obtained from the concentration table was used to calculate the PM emissions, there would have not been a difference in systems. From here it's concluded that the best way to analyze the systems was to use the numbers obtained and compare the overall system difference after the application of the weighting factors for each notch setting. The final number acquired was then used with the error bar analysis to see if each system produced results within the systematic error bar limits. 


\subsubsection{Engine 1, Configuration 2, Run 2 Results}

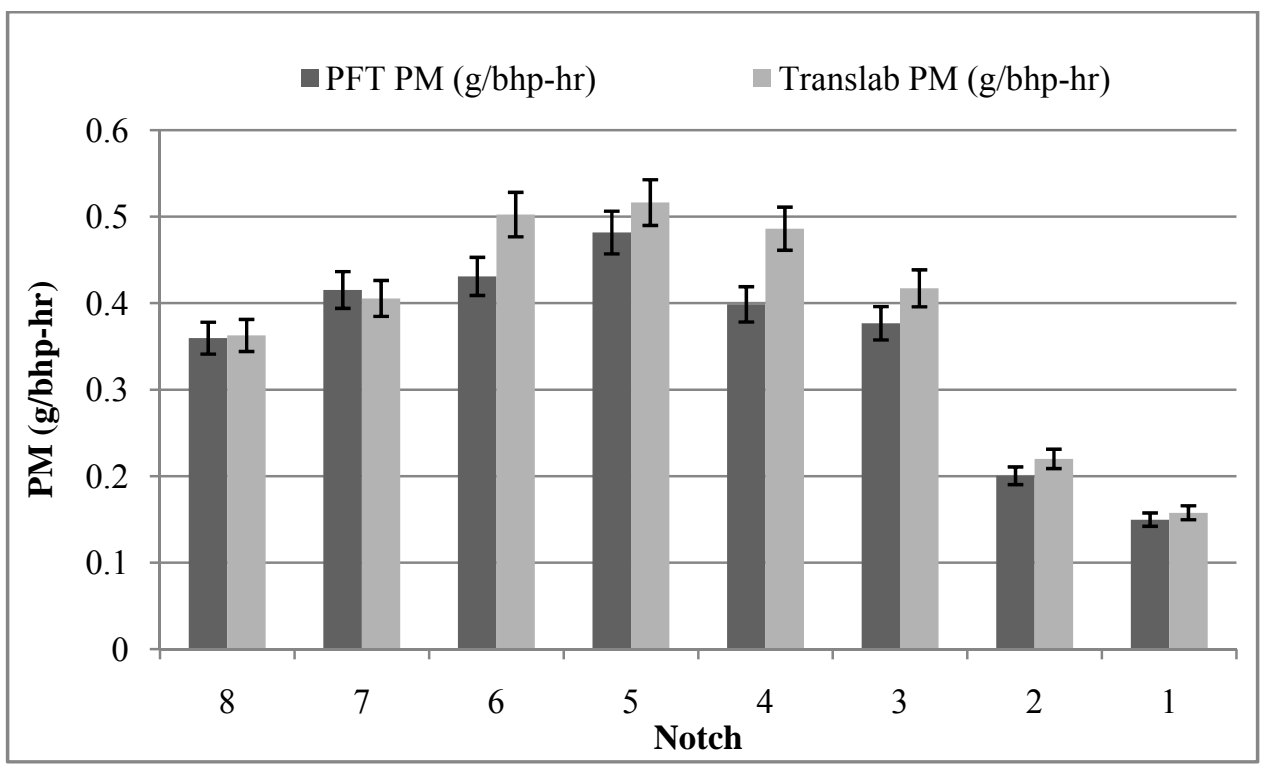

Figure 42: Engine 1, Configuration 2, Run 2 Results (Notch 8 - Notch 1)

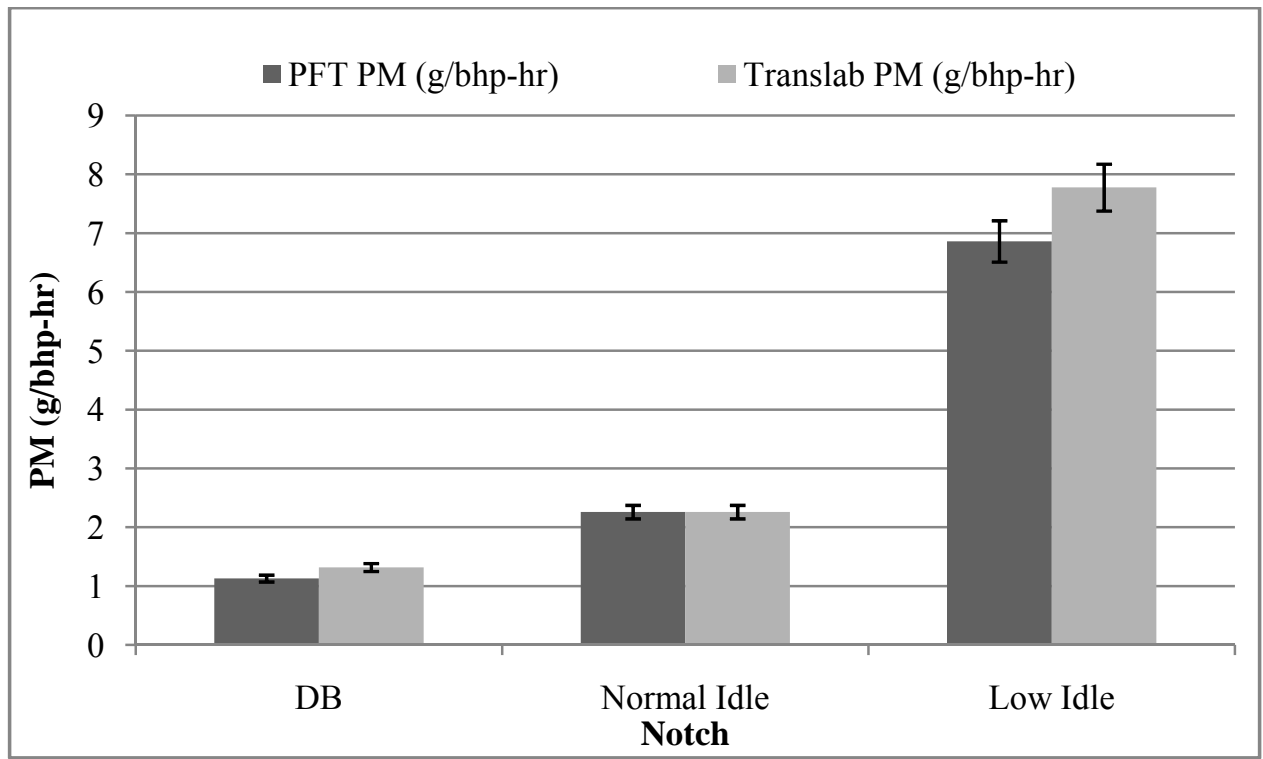

Figure 43: Engine 1, Configuration 2, Run 2 Results (Dynamic Brake - Low Idle)

Figure 42 and Figure 43 show the results from the second run of the modified engine. The majority of the modes have overlapping error bars, with the exception of notch 6 , notch 4 , dynamic brake, and low idle. 
Table 35: Engine 1, Configuration 2, Run 2 Tabulated Results

\begin{tabular}{|c|c|c|c|}
\hline Notch & $\begin{array}{c}\text { PFT PM } \\
\text { (g/bhp-hr) }\end{array}$ & $\begin{array}{c}\text { Translab PM } \\
\text { (g/bhp-hr) }\end{array}$ & $\begin{array}{c}\text { Percent } \\
\text { Difference }\end{array}$ \\
\hline 8 & 0.360 & 0.363 & $0.87 \%$ \\
\hline 7 & 0.415 & 0.405 & $2.40 \%$ \\
\hline 6 & 0.431 & 0.502 & $14.23 \%$ \\
\hline 5 & 0.482 & 0.516 & $6.72 \%$ \\
\hline 4 & 0.399 & 0.486 & $18.00 \%$ \\
\hline 3 & 0.377 & 0.417 & $9.68 \%$ \\
\hline 2 & 0.200 & 0.220 & $8.87 \%$ \\
\hline 1 & 0.150 & 0.158 & $5.06 \%$ \\
\hline DB & 1.129 & 1.317 & $14.29 \%$ \\
\hline Normal Idle & 2.259 & 2.259 & $0.00 \%$ \\
\hline Low Idle & 6.862 & 7.777 & $11.76 \%$ \\
\hline
\end{tabular}

The average percent difference between laboratories for the second engine modification run was $8.35 \%$. The lower modes of testing; dynamic brake, normal idle, and low idle are felt to have a difference due to rounding within the calculations. Table 35 illustrates the concentration difference between the systems.

Table 36: Concentration Tabulated Results, Modified Engine: Run 2 (g/ft $\left.\mathbf{t}^{3}\right)$

\begin{tabular}{|c|r|r|r|}
\hline Notch & PFT $\left(\mathrm{g} / \mathrm{ft}^{3}\right)$ & Translab $\left(\mathrm{g} / \mathrm{ft}^{3}\right)$ & Difference \\
\hline 8 & 0.0023 & 0.0023 & 0.00002 \\
\hline 7 & 0.0026 & 0.0025 & -0.00006 \\
\hline 6 & 0.0022 & 0.0026 & 0.00037 \\
\hline 5 & 0.0025 & 0.0027 & 0.00018 \\
\hline 4 & 0.0012 & 0.0015 & 0.00027 \\
\hline 3 & 0.0008 & 0.0009 & 0.00009 \\
\hline 2 & 0.0004 & 0.0004 & 0.00004 \\
\hline 1 & 0.0002 & 0.0002 & 0.00001 \\
\hline DB & 0.0003 & 0.0004 & 0.00006 \\
\hline Normal Idle & 0.0001 & 0.0001 & 0.00000 \\
\hline Low Idle & 0.0002 & 0.0002 & 0.00002 \\
\hline
\end{tabular}




\subsubsection{Engine 1, Configuration 2: Overall Results Discussed}

Most of the modes for the modified engine statistically agreed based on the overlapping of the developed error bars. However, there were several modes that fell outside of this developed error bar analysis. Notch 4 was a mode that produced a number between systems that was within the error bar tolerance for the first round of testing. This notch however, did not produce an overlapping error bar for the second round of testing. Looking at the data acquired the three variables of interest were analyzed for this notch: filter weight, dilute $\mathrm{CO}_{2}$ concentration and system dilution factor.

Table 37: System Variability-Results Analyzed, Configuration 2

\begin{tabular}{|l|c|c|c|}
\cline { 2 - 4 } \multicolumn{1}{c|}{} & $\begin{array}{c}\text { Filter Weight } \\
(\mathrm{mg})\end{array}$ & $\begin{array}{c}\text { Dilute } \mathrm{CO}_{2} \\
\text { Concentration }(\mathrm{ppm})\end{array}$ & $\mathrm{DF}$ \\
\hline PFT Run 1 & 3.4374 & 5029 & 6.36 \\
\hline PFT Run 2 & 3.0959 & 5033 & 6.17 \\
\hline Translab Run 1 & 2.4498 & 2635 & 14.7 \\
\hline Translab Run 2 & 2.4389 & 2703 & 13.75 \\
\hline
\end{tabular}

Based on this data, the PFT's second run's filter loading was lower than what it should have been to produce an equivalent result to the Translab's system. Solving for the required filter weight to achieve this value, results in a filter weight of $4.2131 \mathrm{mg}$. This does not prove that the PFT dilute tunnel $\mathrm{CO}_{2}$ concentration measurement was accurate. Solving to determine what the DF for the system would have had to been to achieve the $0.0015 \mathrm{~g} / \mathrm{ft}^{3}$ value, the measured DF would have had to been 8.5. Based on this difference it's felt that the weighing of the filter had the biggest impact on the overall results. An $8.5 \mathrm{DF}$ would have resulted in a $\mathrm{CO}_{2}$ concentration misreading of $27 \%$. Though there may have been some error associated with this reading, it's felt that the actual error would have not been this large to produce this kind of error. It was difficult to pinpoint the actual variation of the PM measurement. 
The modified engine mode of testing produced much more variation in PM measurement than the unmodified engine PM emissions measurement. It's felt that the lower modes of the engine operation caused this error due to the weighing of the filters. The overall picture was to present a laboratory system analysis based on the final PM number acquired by each system once the weighting factors for each notch had been applied. The modified engine test plan incorporated the dynamic brake, normal idle and low idle test modes, allowing for a PM value to be obtained for both the switch and line-haul locomotive scenarios. The final value ultimately best described the difference between laboratories. The weighting factors applied to each notch are found in Table 37.

Table 38: Weighting Factors for Locomotive Testing

\begin{tabular}{|c|c|c|}
\hline Notch & Line - haul Weighting Factor & Switch Weighting Factor \\
\hline 8 & 0.162 & 0.008 \\
\hline 7 & 0.03 & 0.002 \\
\hline 6 & 0.039 & 0.015 \\
\hline 5 & 0.038 & 0.036 \\
\hline 4 & 0.044 & 0.036 \\
\hline 3 & 0.052 & 0.058 \\
\hline 2 & 0.065 & 0.127 \\
\hline 1 & 0.065 & 0.124 \\
\hline DB & 0.125 & 0 \\
\hline Normal Idle & 0.19 & 0.299 \\
\hline Low Idle & 0.19 & 0.299 \\
\hline
\end{tabular}

The weighting factors were applied to each notch setting and the values were tabulated in Table 38 and Table 39.

Table 39: Modified Engine: Weighted PM (g/bhp-hr) for the Line Haul Duty Cycle

\begin{tabular}{|c|c|c|}
\hline $\begin{array}{c}\text { PFT PM: Line- Haul } \\
\text { (g/bhp-hr) }\end{array}$ & $\begin{array}{c}\text { Translab PM: Line-Haul } \\
\text { (g/bhp-hr) }\end{array}$ & $\begin{array}{c}\text { Percent } \\
\text { Difference }\end{array}$ \\
\hline 0.39 & 0.41 & $5.69 \%$ \\
\hline
\end{tabular}




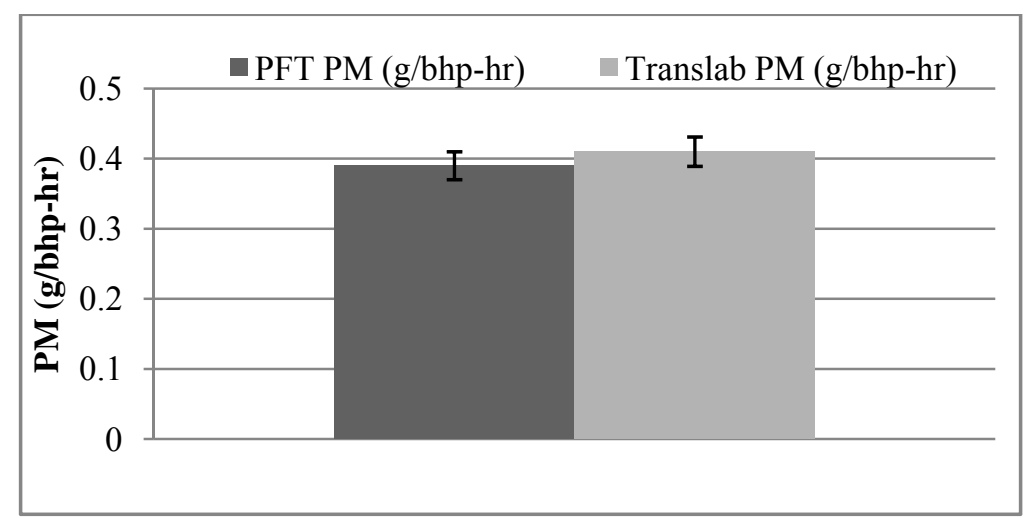

Figure 44: Modified Engine: Weighted PM (g/bhp-hr) for the Line Haul Duty Cycle It was noted that the error bar developed for the testing overlapped between the systems as seen in Figure 44 and Figure 45. This determined that the results obtained by the partial flow dilution tunnel system were equivalent to those measured by the Translab's PM system.

Table 40: Modified Engine: Weighted PM (g/bhp-hr) for the Switch Duty Cycle

\begin{tabular}{|c|c|c|}
\hline $\begin{array}{c}\text { PFT PM: Switch } \\
\text { (g/bhp-hr) }\end{array}$ & $\begin{array}{c}\text { Translab PM: Switch } \\
\text { (g/bhp-hr) }\end{array}$ & Percent Difference \\
\hline 0.41 & 0.45 & $8.20 \%$ \\
\hline
\end{tabular}

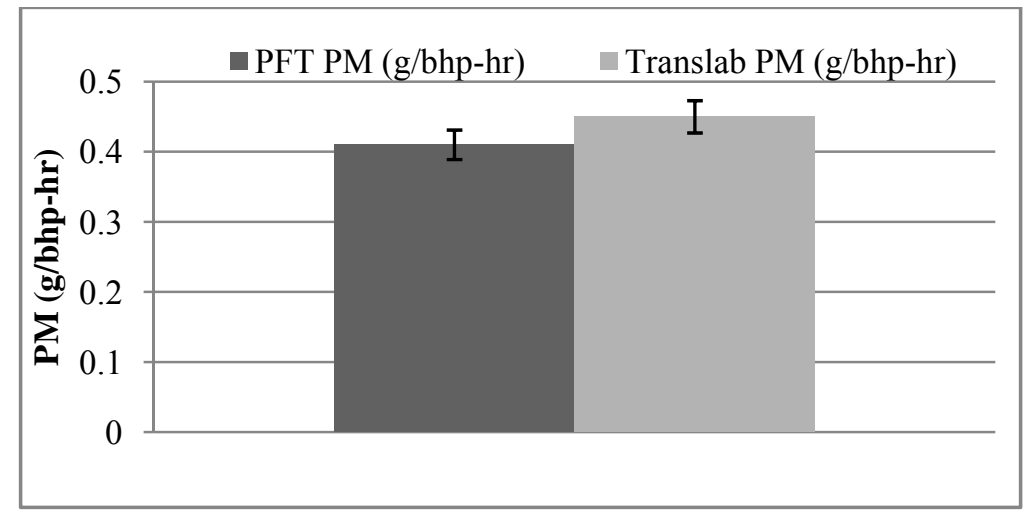

Figure 45: Modified Engine: Weighted PM (g/bhp-hr) for the Switch Duty Cycle 


\subsection{PM System Comparison Conclusion}

The testing gave a representation of the system as implemented for in the field testing of a locomotive engine. There was some variation of the results within the individual test modes, though the overall computed brake specific PM mass emissions rate for the PFT and the Translab produced equivalent results due to an overlapping error bar. It was felt that the individual error associated within the test modes was more of a rounding issue when determining the concentration of the PM from the dilution tunnel. The weighing of the filters seemed to possess the greatest influence on the overall difference associated with the measurement differences between systems. Ideally the system would have tested a single mode several times and that data compared statistically to prove that the systems produced the same PM result for each mode.

The final number was essentially the most important figure obtained by each system. This value was used to determine if a locomotive produced PM emissions levels lower than its regulated EPA established values. The variation of the PM measurement in the testing may have appeared to be large at first, but when looked at in depth, was realized that the percent difference for each mode may have not been the best way to represent a system difference. The overall value obtained by each system was then established to be the means for determining the system verification. Based on the results obtained, it was concluded that the PM system developed for the Part 92 compliant PM sampling system was ready for in the field testing locomotive engines due to the overlapping error bar for each complete engine test. Variation in data was not only found with the PFT system, but the Translab's system as well. The weighing of the filters seems to have the biggest impact on the system variation. 


\section{Chapter 7: Recommendations}

\subsection{Introduction}

Upon completion of the testing of the individual components of the equipment that will make up the raw gaseous emissions measurement system and partial flow dilution tunnel system, some insight of future work and recommendations have been generated. Towards the end of the project, the EPA established new criterion for future locomotive engine testing, passed in Title 40, Part 1033 that established the regulations for the future testing of locomotive engines [3]. This newly established legislation will be analyzed to help determine the future evolution of the system to remain EPA compliant. This will ensure that the system will be able to produce data that can be used for the certification of locomotive engines, providing substantial research opportunities for WVU in the future.

\section{2 Gaseous Emissions Recommendations}

The system was built to be compliant with Title 40- Part 92 of the Code of Federal Regulations. With recent regulation testing procedures updates an investigation to determine the revisions that need to be made to the raw gaseous emissions sampling system was made. Title 40, Part 1033 describes all of the equipment specifications to measure the gaseous and particulate emissions produced by a locomotive engine. It was felt that with an in depth analysis of the developed Part 92, compliant system that it may be able to meet the 1033 guidelines.

\subsubsection{Hydrocarbon System Requirements for 1033 Compliance}

Several requirements for the hydrocarbon analyzing system are outlined in Part 1065 Table 205 [10]. The system must have a 5 second rise time and fall time. The sampling frequency is set to $1 \mathrm{~Hz}$. The accuracy of the analyzer must be $2 \%$ of a point or $2 \%$ of a measured value. The repeatability of the analyzer must be $1 \%$ of a point or $1 \%$ of a measured value. The noise attributed to the system must be a maximum value of $1 \%$. The hydrocarbon 
system is required to pass linearity verification as outlined in 1065.307. Ten reference values including the zero and span of the analyzer should be selected. Each gas concentration is introduced to the analyzer's inlet port and measured a duration of 30 seconds at $1 \mathrm{~Hz}$. The arithmetical mean is used for each point to generate a mean and to calculate a least squares linear regression. Passing criteria is summarized in the following table:

Table 41: Analyzer Linearity Requirements

\begin{tabular}{|c|c|c|c|c|c|}
\hline $\begin{array}{c}\text { Measurement } \\
\text { System }\end{array}$ & $\begin{array}{c}\text { Frequency of } \\
\text { Verification }\end{array}$ & \multicolumn{3}{|c|}{ Linearity Criteria } \\
\hline \multirow{2}{*}{$\begin{array}{c}\text { Gas Analyzers for in } \\
\text { the Field Testing }\end{array}$} & $\begin{array}{c}35 \text { days Before in the } \\
\text { Field Testing }\end{array}$ & $\begin{array}{c}\text { \&verbarlm; } x_{\min }\left(a_{1}-1\right)+ \\
a_{0} \& \text { verbarlm; }\end{array}$ & a1 & see & $r^{2}$ \\
\cline { 2 - 6 } & $<$ & $<=1 \%$ & $.99-1.01$ & $<=1 \%$ & $>=0.998$ \\
\hline
\end{tabular}

It's currently felt that the possibility of the hydrocarbon system passing these checks is promising. The system needs to be tested prior to meeting 1033 compliance.

\subsection{2 $\mathrm{NO}_{\mathrm{x}}$ System Requirements for 1033 Compliance}

Several requirements for the $\mathrm{NO}_{\mathrm{x}}$ analyzing system are outlined in Part 1065 Table 205

[10]. The system must have a 5 second rise time and fall time. The sampling frequency is set to $1 \mathrm{~Hz}$. The accuracy of the analyzer must be $2 \%$ of a point or $2 \%$ of a measured value. The repeatability of the analyzer must be $1 \%$ of a point or $1 \%$ of a measured value. The noise attributed to the system must be a maximum value of $1 \%$. The $\mathrm{NO}_{\mathrm{x}}$ system must also pass the linearity verification as mentioned above and values found in Table 51 above. The system must also pass a CLD $\mathrm{H}_{2} \mathrm{O}$ and $\mathrm{CO}_{2}$ quench test which is outlined in 1065.370. $\mathrm{H}_{2} \mathrm{O}$ and $\mathrm{CO}_{2}$ can interfere with the response time of a $\mathrm{NO}_{\mathrm{x}}$ analyzer inhibiting certain reactions that the analyzer utilizes to measure $\mathrm{NO}_{\mathrm{x}}$. A CLD analyzer must have a combined $\mathrm{H}_{2} \mathrm{O}$ and $\mathrm{CO}_{2}$ quench of $\pm 2 \%$ or less, though strongly recommend a quench of $\pm 1 \%$ or less. The procedures for the $\mathrm{CO}_{2}$ and $\mathrm{H}_{2} \mathrm{O}$ 
quench verification can be found in 1065.370. Currently the $\mathrm{NO}_{\mathrm{x}}$ system has been quench tested and failed in its current configuration. The 2007 dilution tunnel located at the CAFEE utilizes the system with the sample bypassing the $\mathrm{NO}_{2}$ to $\mathrm{NO}$ converter and chiller. It was quench tested in this configuration. The system needs to be checked in the configuration it will be in during locomotive testing that includes the sample being routed through the $\mathrm{NO}_{2}$ to $\mathrm{NO}$ converter and then through a chiller. In this configuration the system may pass the water and $\mathrm{CO}_{2}$ interference test. If it does not then system modifications will have to be done which may lead to the purchase of another $\mathrm{NO}_{\mathrm{x}}$ analyzer that can pass these procedures.

Since the $\mathrm{NO}_{\mathrm{x}}$ system utilizes a $\mathrm{NO}_{2}-\mathrm{NO}$ converter upstream of the analyzer several

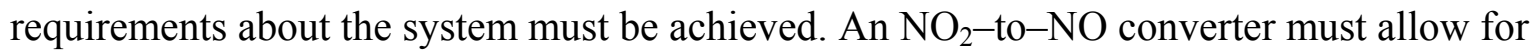
measuring at least $95 \%$ of the total $\mathrm{NO}_{2}$ at the maximum expected concentration of $\mathrm{NO}_{2}$. The current Horiba $\mathrm{NO}_{2}-\mathrm{NO}$ converter installed was able to meet those efficiencies. Procedures to calculate the efficiencies of the $\mathrm{NO}_{2}-\mathrm{NO}$ converter are found in 1065.378.

\subsubsection{CO/CO ${ }_{2}$ System Requirements for 1033 Compliance}

Several requirements for the $\mathrm{CO} / \mathrm{CO}_{2}$ analyzing system are outlined in part 1065 table 205. The system must have a 5 second rise time and fall time. The sampling frequency is set to 1 Hz. The accuracy of the analyzer must be $2 \%$ of a point or $2 \%$ of a measured value. The repeatability of the analyzer must be $1 \%$ of a point or $1 \%$ of a measured value. The noise attributed to the system must be a maximum value of $1 \%$. The $\mathrm{CO}_{2}$ system must pass a water interference test outlined in 1065.350. Water can interfere with an NDIR's measurement of $\mathrm{CO}_{2}$. $\mathrm{A} \mathrm{CO}_{2} \mathrm{NDIR}$ analyzer must have a water interference that is within $(0.0 \pm 0.4) \mathrm{mmol} / \mathrm{mol}$, though a lower interference that is within $(0.0 \pm 0.2) \mathrm{mmol} / \mathrm{mol}$ is recommended by the CFR, Part 1065 . 
The $\mathrm{CO}$ analyzing system must pass a $\mathrm{H}_{2} \mathrm{O}$ and $\mathrm{CO}_{2}$ interference check outlined in 1065.355. $\mathrm{H}_{2} \mathrm{O}$ and $\mathrm{CO}_{2}$ can positively interfere with an NDIR analyzer by causing a response similar to $\mathrm{CO}$.

The current $\mathrm{CO}_{2}$ and $\mathrm{CO}$ analyzer systems need to be checked to see if they can pass these quality assurance checks before being approved for 1033 compliance.

\subsection{Particulate Matter Sampling System Recommendations}

The addition of 1033 mandates lower PM emissions levels must be achieved. Therefore, newly developed legislation will be implemented to accurately test locomotive engines. What will have to be done to the Part 92 system to meet these demands will be discussed.

\subsubsection{Particulate Matter Sampling System, Title 40 Part 1033 Compliance}

Part 1033 of the CFR refers to the testing procedures and equipment requirements in section 1065. This section states that it is acceptable to use a partial flow dilution tunnel for the measurement of PM if certain guidelines are met. It expresses that for a discrete test mode, such as a locomotive notch, the dilution ratio for a partial flow dilution tunnel system must remain constant for that notch. It requires that the dilution ratio between modes be altered so that the dilution ratio in notch 8 meets the dilution ratio guidelines in 1065.140(e) (2) and that the dilution ratio for all other modes be higher than this ratio, by multiplying notch 8 's dilution ratio by the ratio of the notch 8 exhaust flow rate divided by the current mode exhaust flow rate [10]. Determination of the total exhaust flow rate can be found by doing a carbon balance with the locomotive fuel consumption for that mode of operation. As specified in 1065.140(e) (2) the minimum raw exhaust dilution ratio must be within a range of $5: 1-7: 1$ and at least $2: 1$ for the primary dilution stage [10]. 
The testing procedures for lower PM emissions measurements have also been updated. For certification of PM emissions at or above $0.05 \mathrm{~g} / \mathrm{bhp}-\mathrm{hr}$ a single pair of filters may be used per test mode. For emissions certifications below $0.05 \mathrm{~g} / \mathrm{bhp}-\mathrm{hr}$ a set of procedures have been developed collecting PM on a single filter for all test modes, varying the PM collection times based on the weighting factors for the specific line haul or switch weighting factors. For this the minimum sampling time in each mode is 400 seconds multiplied by the specific weighting factor. For example a weighting factor of .0030 would require a PM sampling time of 12 seconds for that mode. The section also specifies that a filter media be used of $47 \mathrm{~mm}$.

The dilution ratios of the tunnel are currently controlled by hand, adjusting a dilution air valve until the desired ratio is obtained. A possible alternative would be to replace the valve with a mass flow controller and create software to control this parameter. It's felt that a supplied conditioned compressed air stream may be a way to achieve these parameters. The dilution air stream would need to be conditioned in several ways. First of all the air would need to be HEPA filtered with a filter efficiency of $99.97 \%$. Second, the air would have to undergo a series of filters to remove any oil that may be in the air stream from the air compressor. The system may easily evolve into a 1033 compliant system. 


\section{Works Cited}

1. Locomotive Emissions Standards: Regulatory Support Document. Washington, DC: Environmental Protection Agency, 1998.

2. Code of Federal Regulations, Title 40 Part 92, United States Government Printing Office, Washington, DC 2007.

3. Code of Federal Regulations, Title 40 Part 1033, United States Government Printing Office, Washington, DC 2007.

4. Pulkrabek, Willard. Engineering Fundamentals of the Internal Combustion Engine. Upper Saddle River, NJ: Pearson Prentice Hall, 2004.

5. Clean-Diesel Breakthrough: Simultaneous Decrease in Emissions of Both Particulates and Oxides of Nitrogen During Combustion. Argonne National Laboratory. [Online] 1999. [Cited: July 12,2008] http://www.anl.gov/techtransfer/Awards/docs/cleandiesel.html.

6. Miller, C. Air Pollution Control Technologies. New York, New York: John Wiley and Sons, 2006.

7. Kittelson, D. B., Arnold, Megan and Watts, Winthrop Jr. Review of Diesel Particulate Matter Sampling. Minneapolis, MN: University of Minnesota, 1999.

8. Support Manual and Information AIA 220 Analyzer. Horiba Instruments Inc. 2006.

9. Locomotives, Non-road Engines, Equipment and Vehicles. US Environmental Protection Agency. [Online] [Cited: July 10, 2008.] http://www.epa.gov/oms/locomotv.htm.

10. Code of Federal Regulations, Title 40 Part 1065, United States Government Printing Office, Washington, DC 2008.

11. Zimmerman, Andrew. Evaluation of the Selective $\mathrm{NO}_{\mathrm{x}}$ Recirculation Technique Using Activated Carbon. Morgantown, WV 2007.

12. Khalek IA, Kittelson D.B., and Brear F. Influence of Dilution Conditions on Diesel Exhaust Particulate Size Distribution Measurements. 1999. SAE 1999-01-1142. 
13. Code of Federal Regulations, Title 40 Part 86 Subpart N, United States Government Printing Office, Washington, DC 2008.

14. Smart-Trak Series 100 Mass Flow Meters and Controllers: Instructional Manual. Monterey, CA: Sierra Instruments 2008.

15. Carder, Daniel. Performance Evaluation of Exhaust Aftertreatment Devices for Emissions Control on Diesel Engines Employed in Underground Coal Mines. Morgantown, WV 1999.

16. Young, Donald; Munson, Bruce; and Okiishi, Theodore. A Brief Introduction to Fluid Mechanics. New York, New York: John Wiley and Sons, 2001.

17. Moran, Michael; Shapiro, Howard. Fundamentals of Engineering Thermodynamics. New York, New York: John Wiley and Sons, 2004.

18. Regulatory Announcement: Final Emissions Standards for Locomotive Engines. Washington DC: Environmental Protection Agency, 1997.

19. Nuszkowski, John. Staten Island Ferry Emissions Reduction. Morgantown, WV 2005.

20. Beckwith, Thomas; Buck, N.; Marangoni, Roy. Mechanical Measurements. Reading, Massachusetts: Addison- Wesley Publishing Company, 1982. 


\section{APPENDIX A: Gaseous Emissions System Verification Data}

Hydrocarbon Verification: FTP ONE

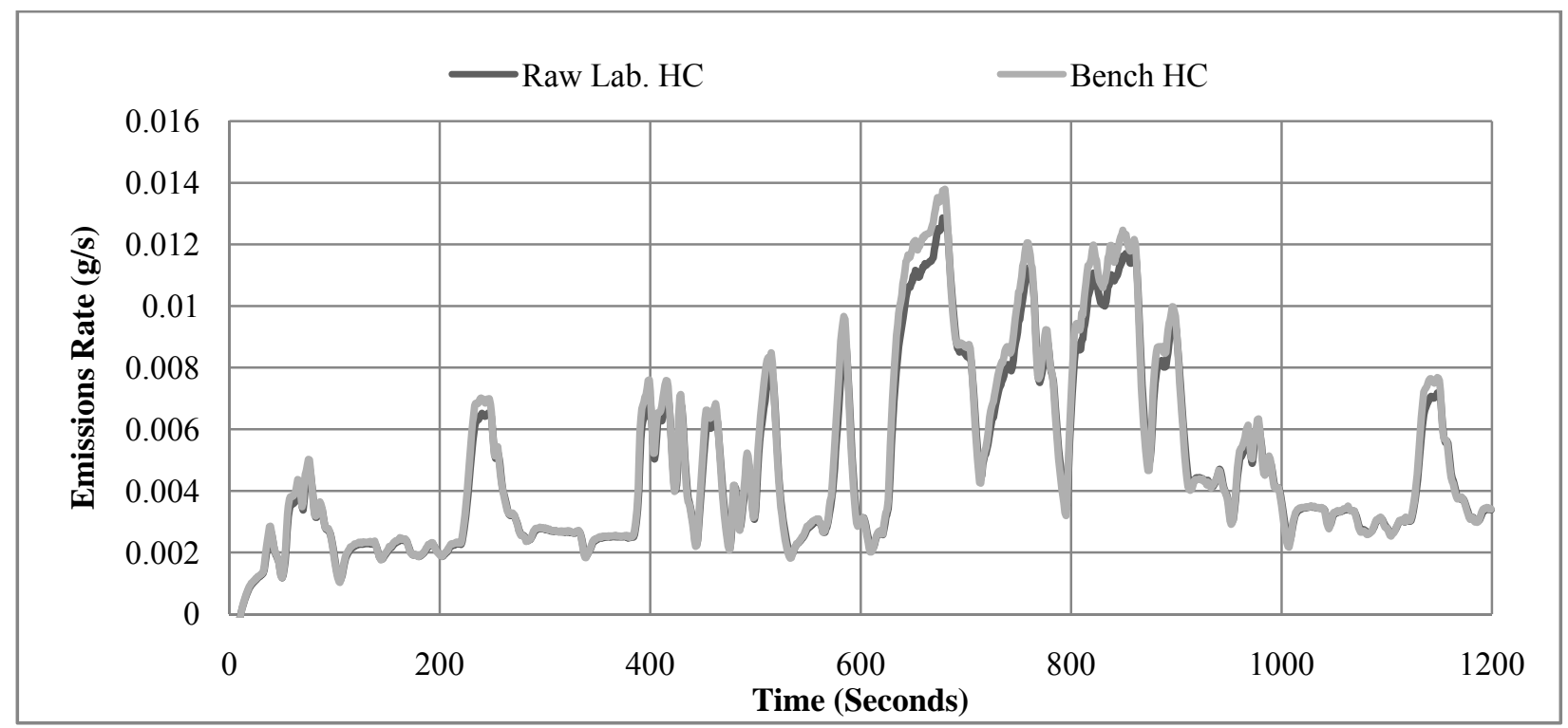

Figure 46: Hydrocarbon System Comparison, Run 1

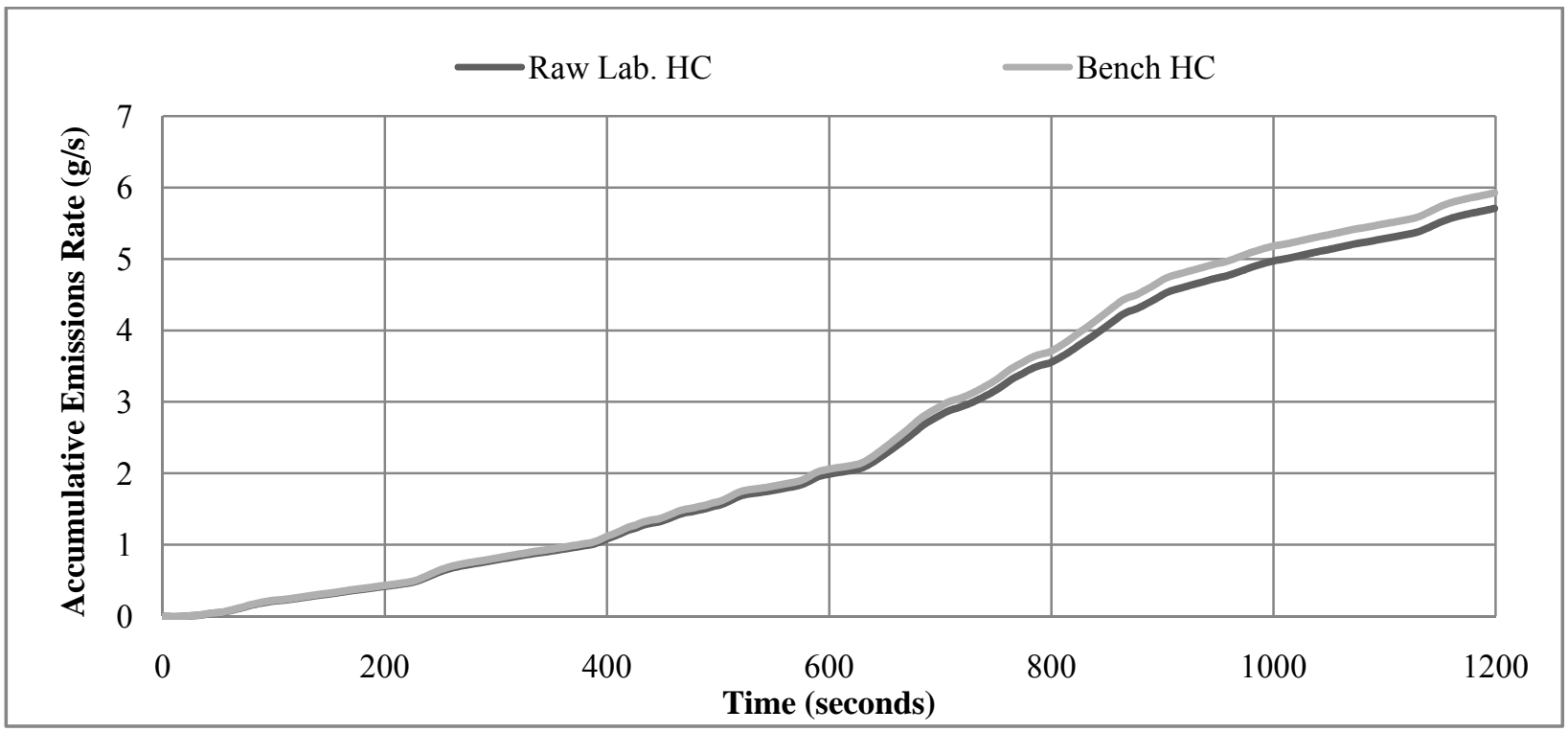

Figure 47: Hydrocarbon System Summation, Run 1 
Hydrocarbon Verification: FTP TWO

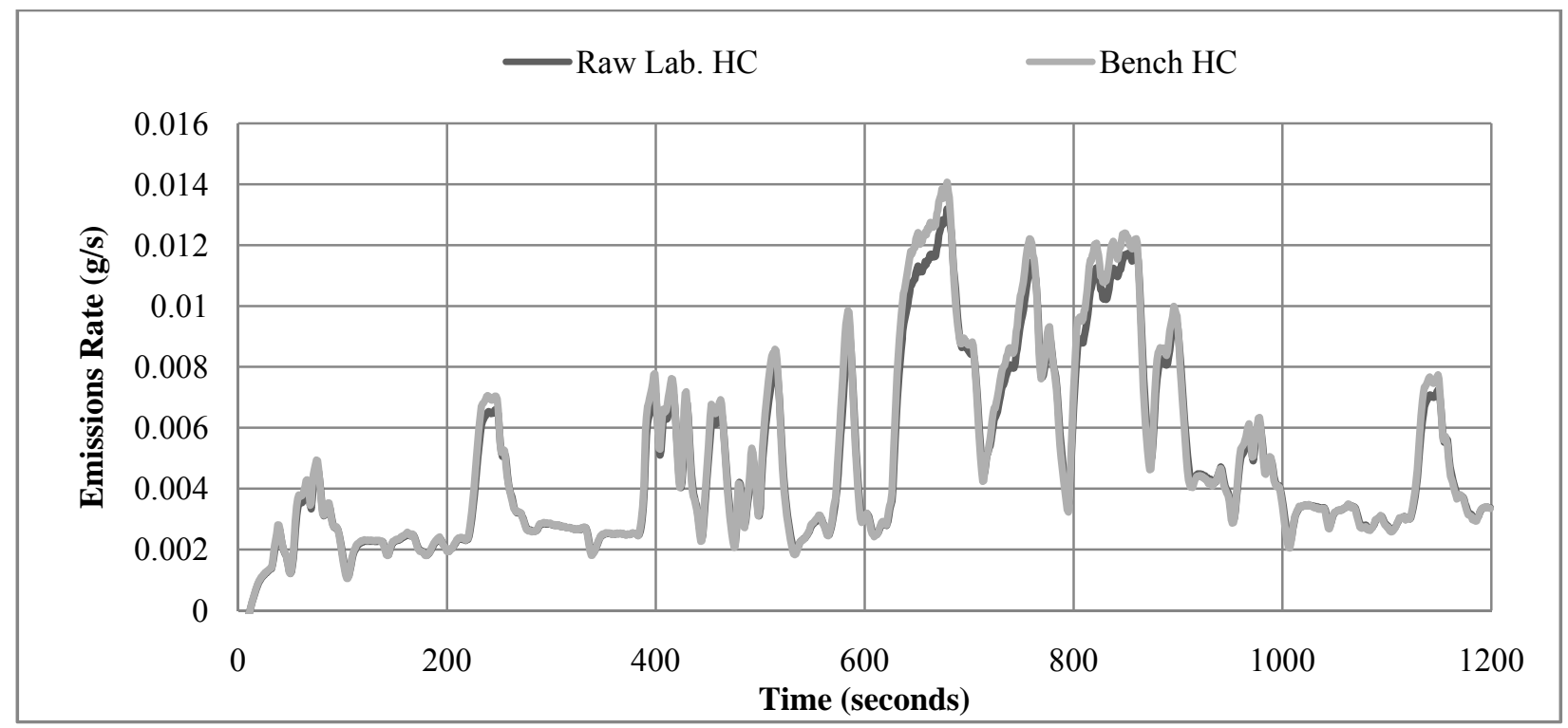

Figure 48: Hydrocarbon System Comparison, Run 2

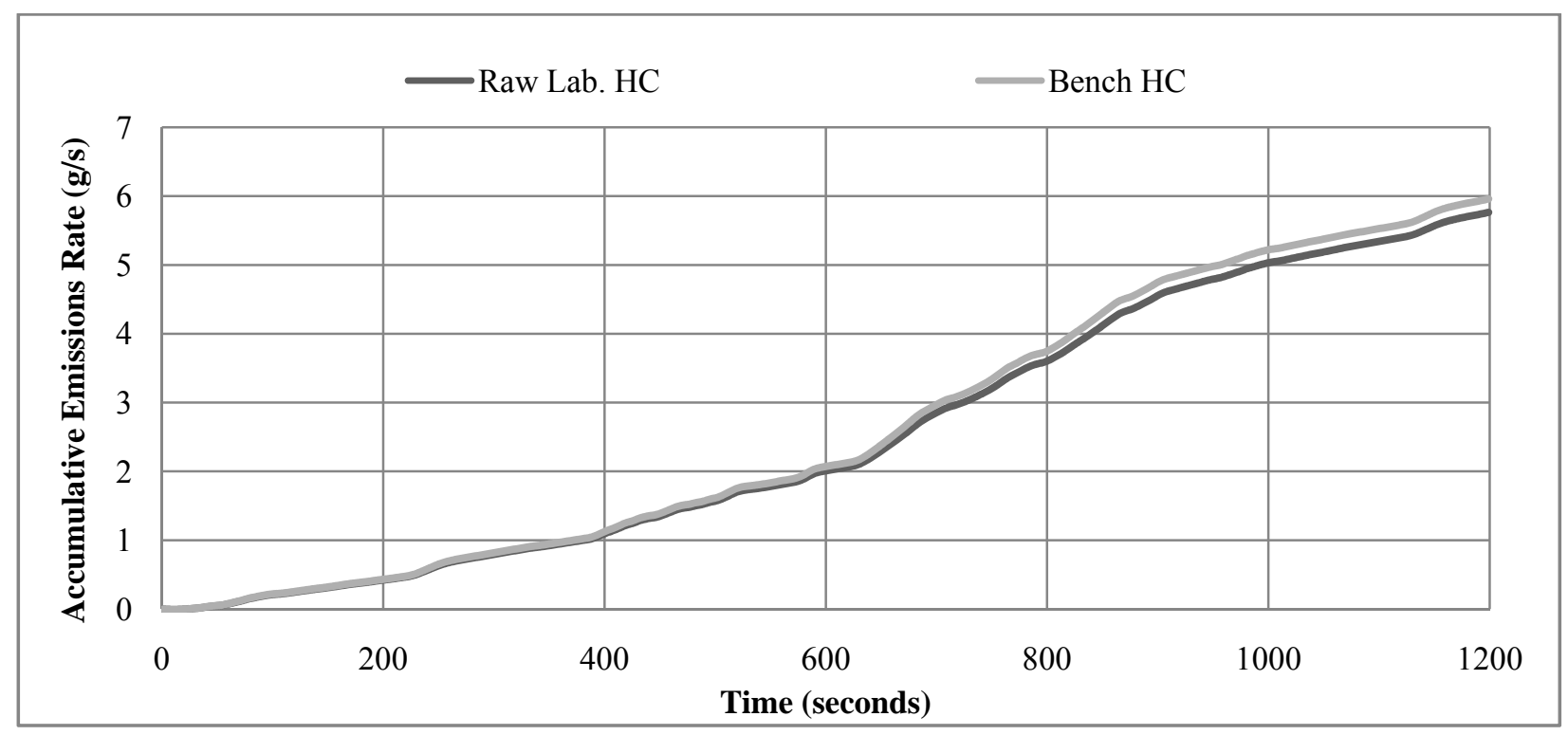

Figure 49: Hydrocarbon System Summation, Run 2 
Hydrocarbon Verification: FTP THREE

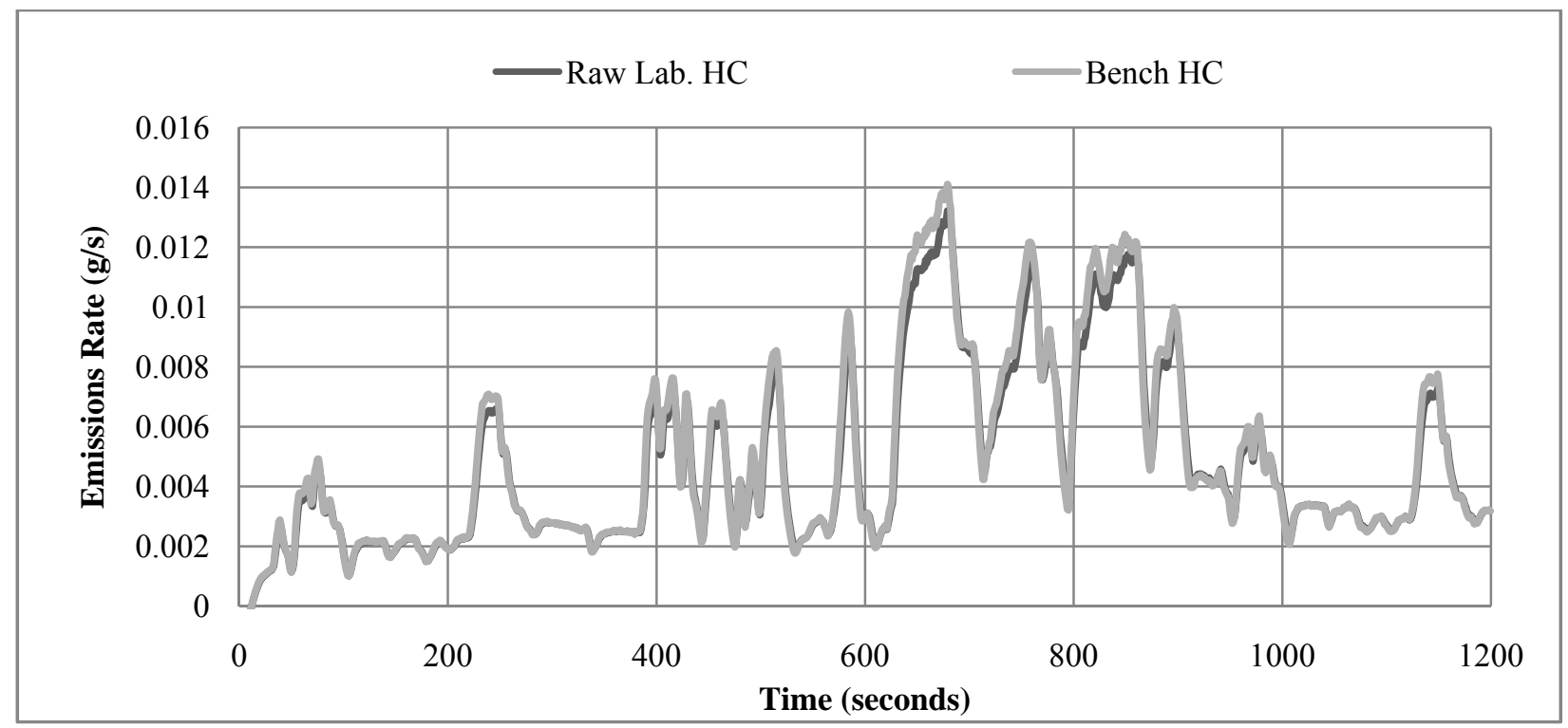

Figure 50: Hydrocarbon System Comparison, Run 3

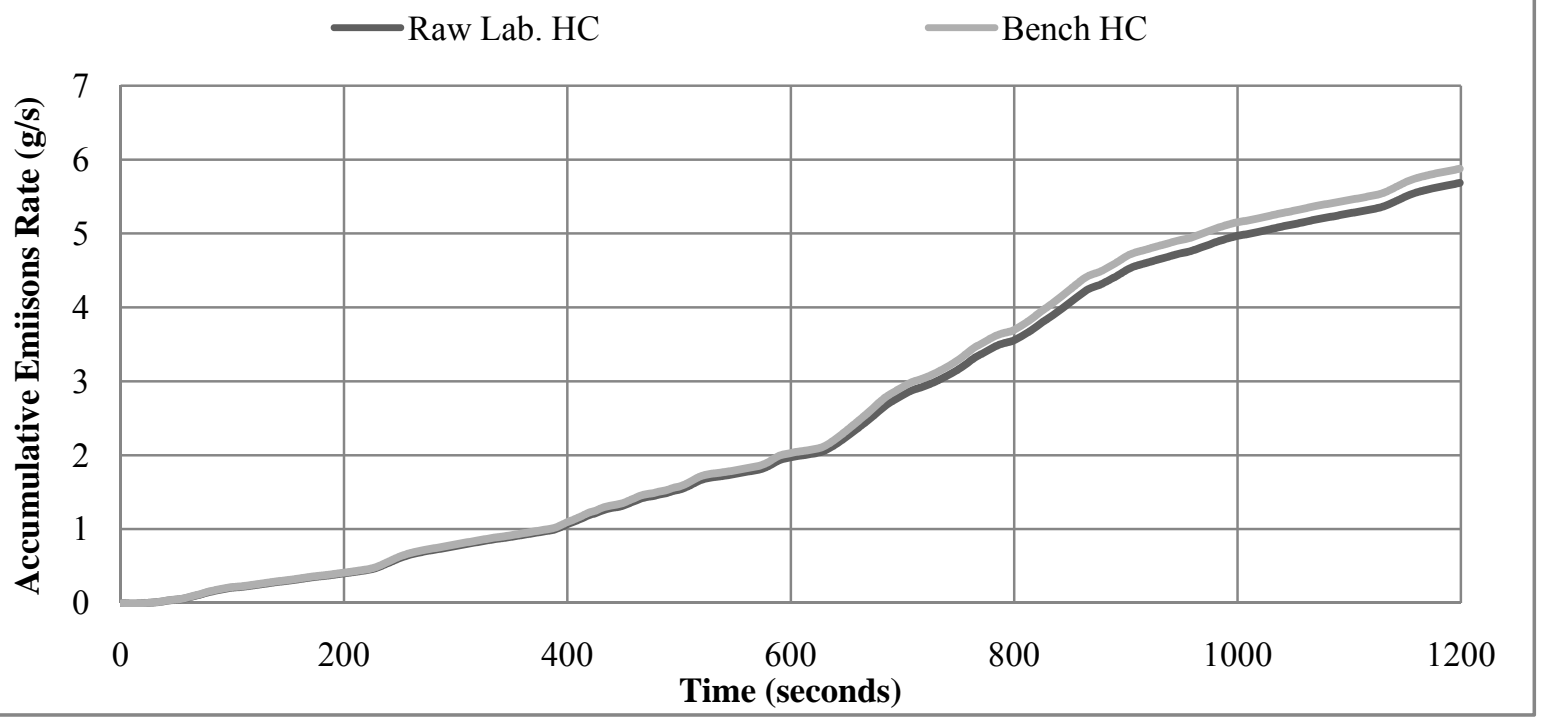

Figure 51: Hydrocarbon System Summation, Run 3 
$\mathrm{NO}_{\mathrm{x}}$ Verification: FTP ONE

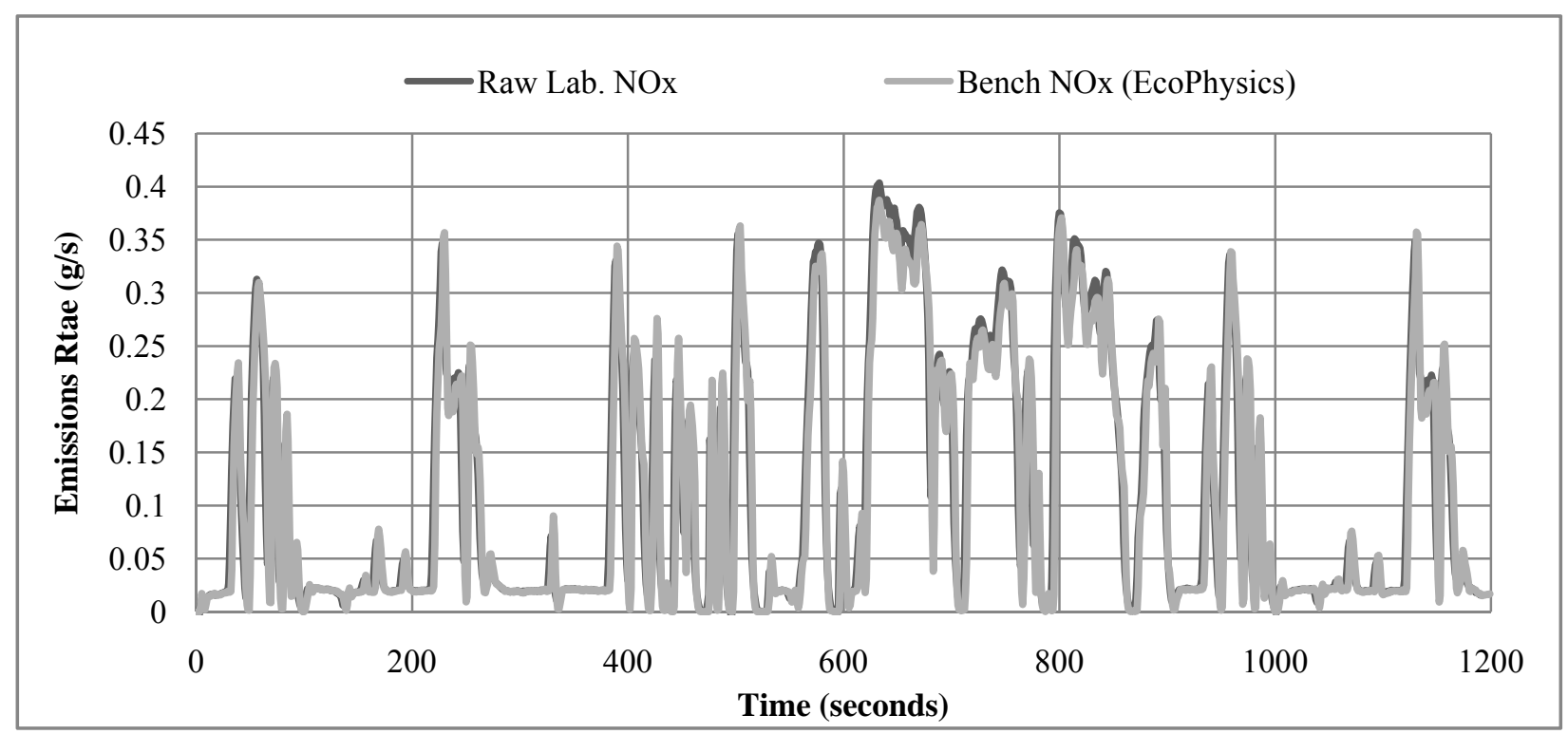

Figure 52: $\mathrm{NO}_{\mathrm{x}}$ System Comparison, Run 1

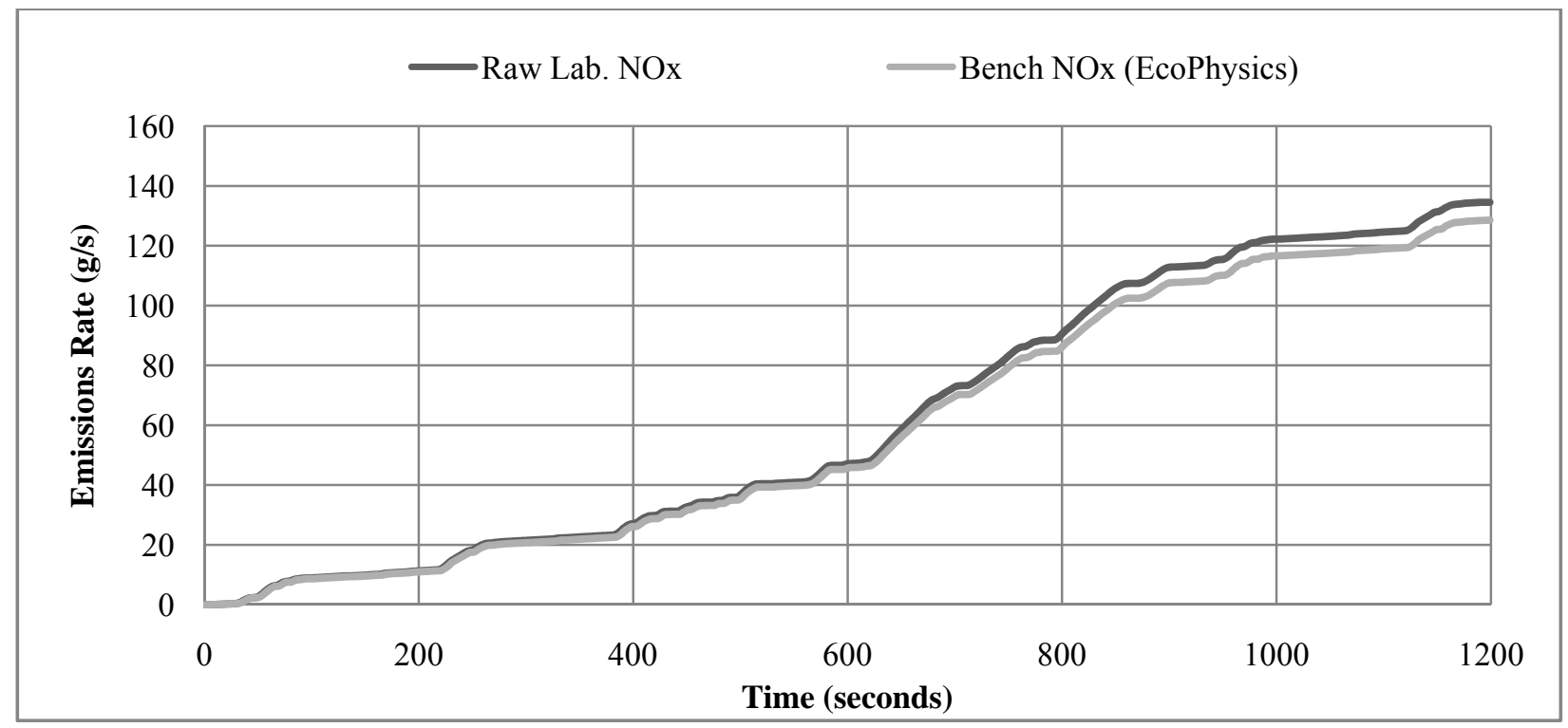

Figure 53: $\mathrm{NO}_{\mathrm{x}}$ System Summation, Run 1 


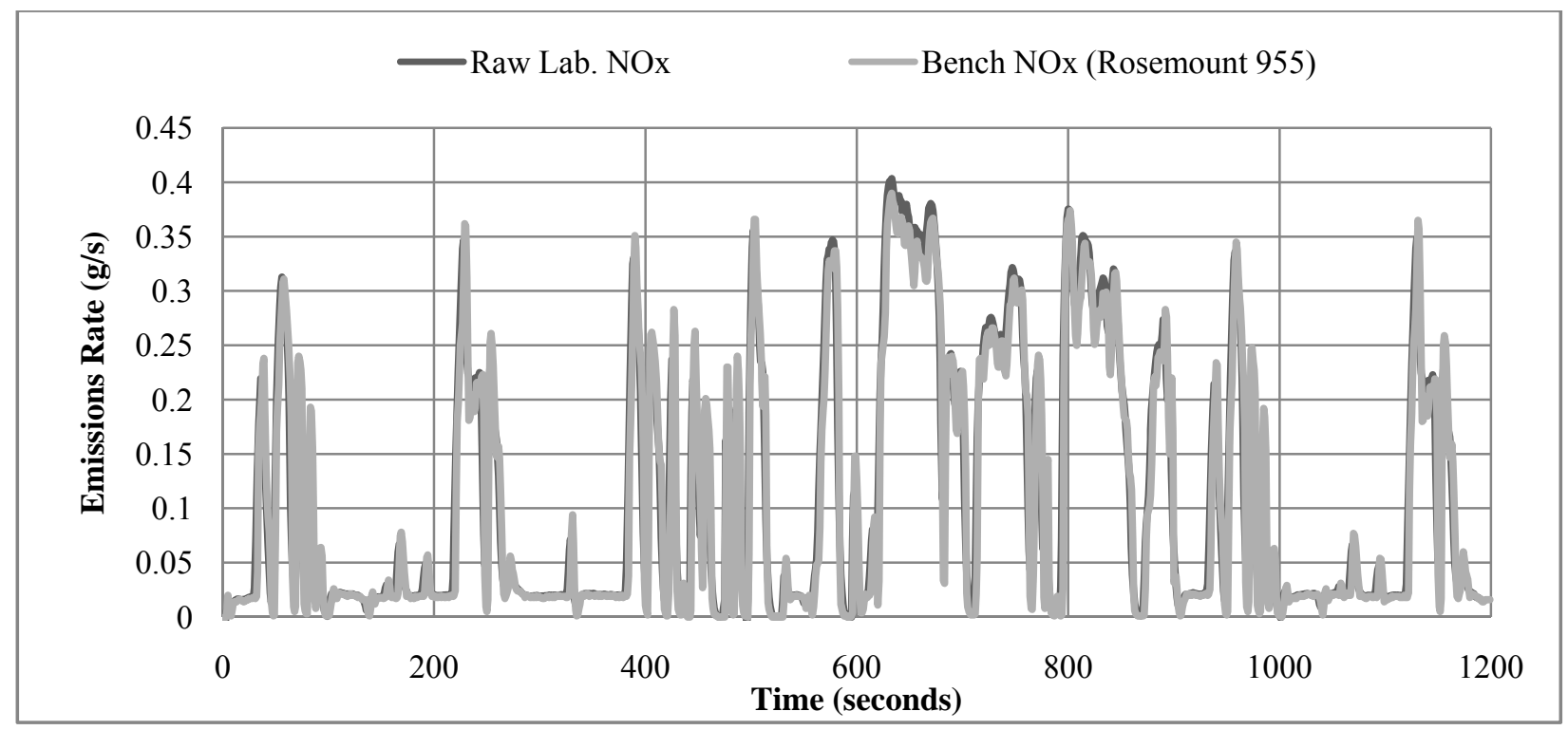

Figure 54: $\mathrm{NO}_{\mathrm{x}}$ System Comparison, Run 1

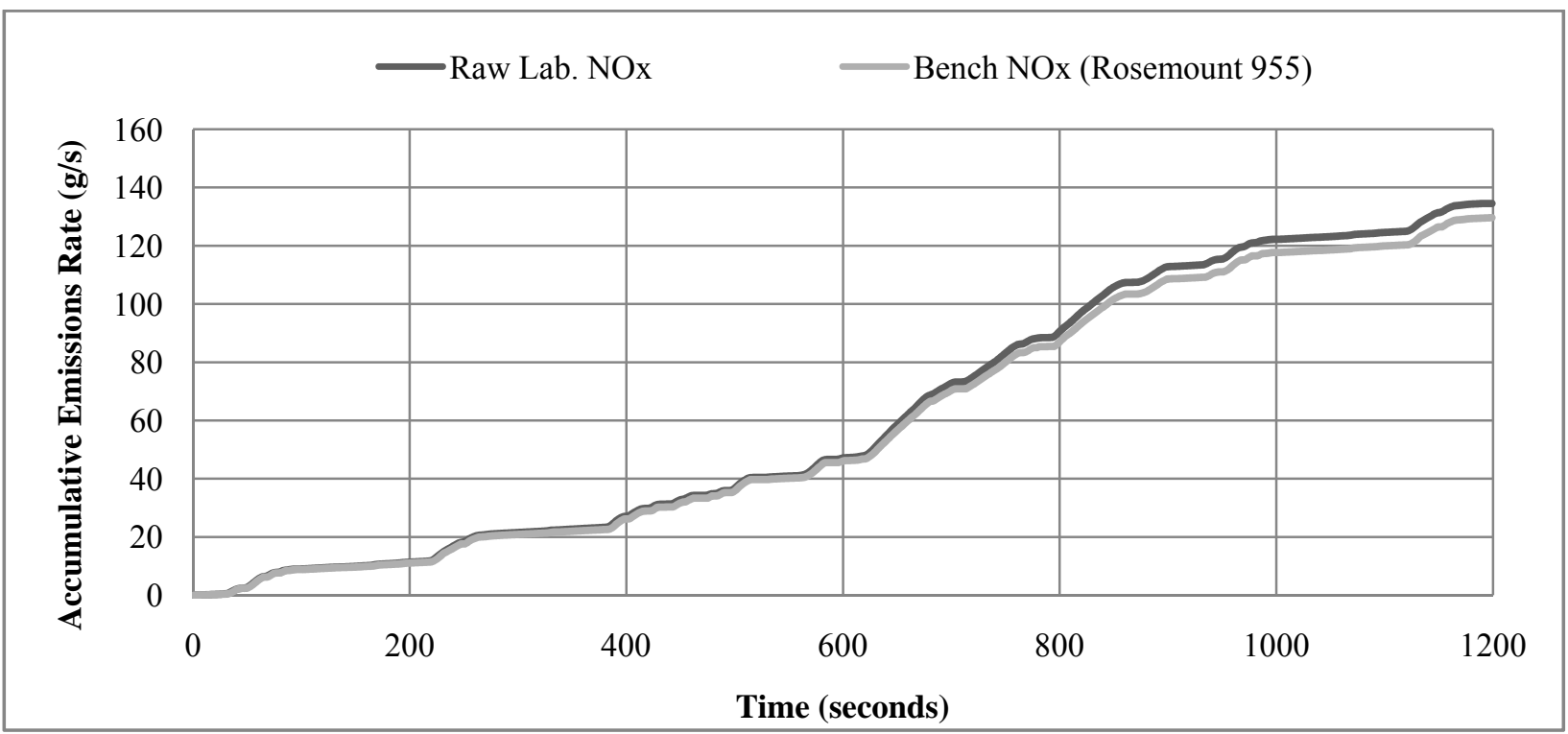

Figure 55: $\mathrm{NO}_{\mathrm{x}}$ System Summation, Run 1 
$\mathrm{NO}_{\mathrm{x}}$ Verification: FTP TWO

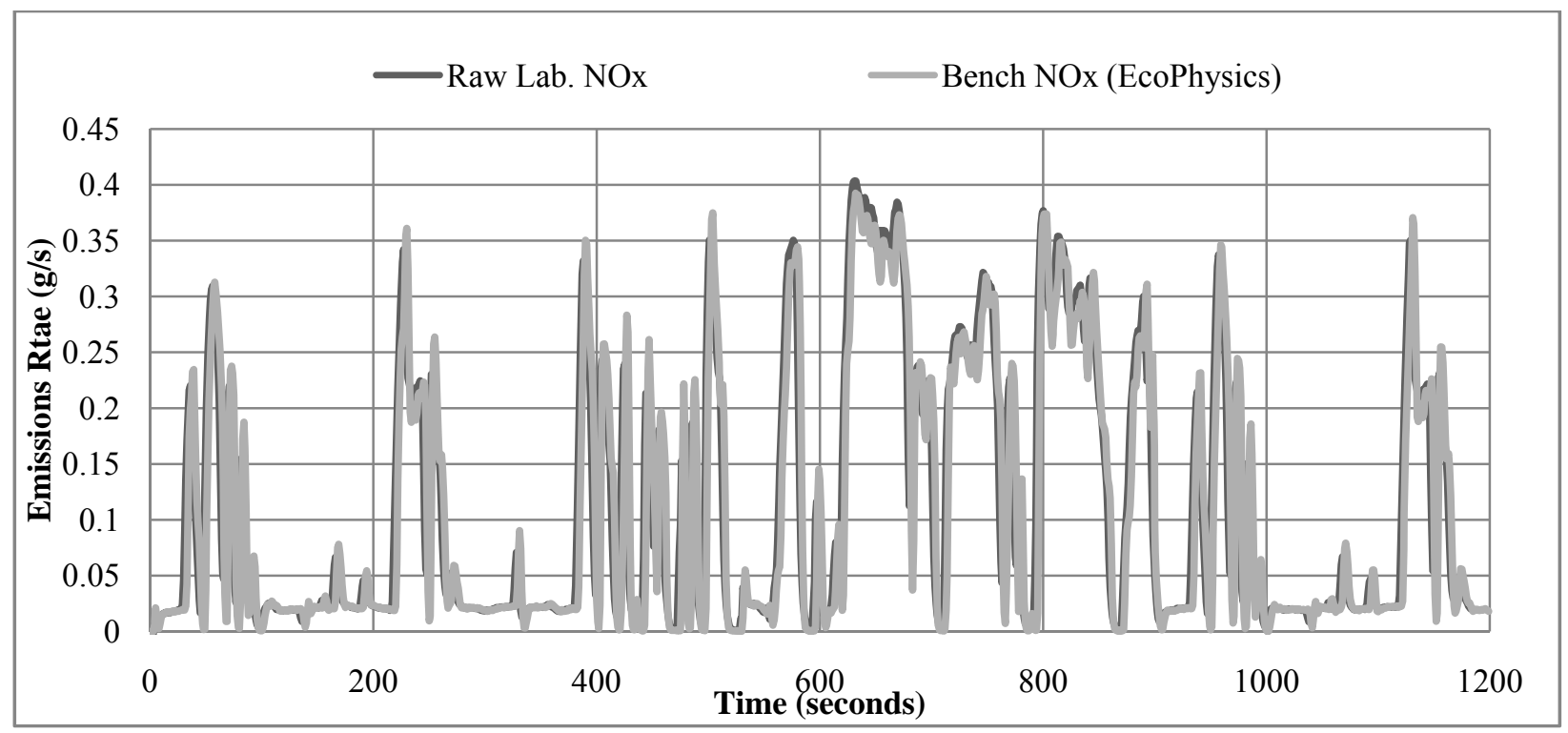

Figure 56: $\mathrm{NO}_{\mathrm{x}}$ System Comparison, Run 2

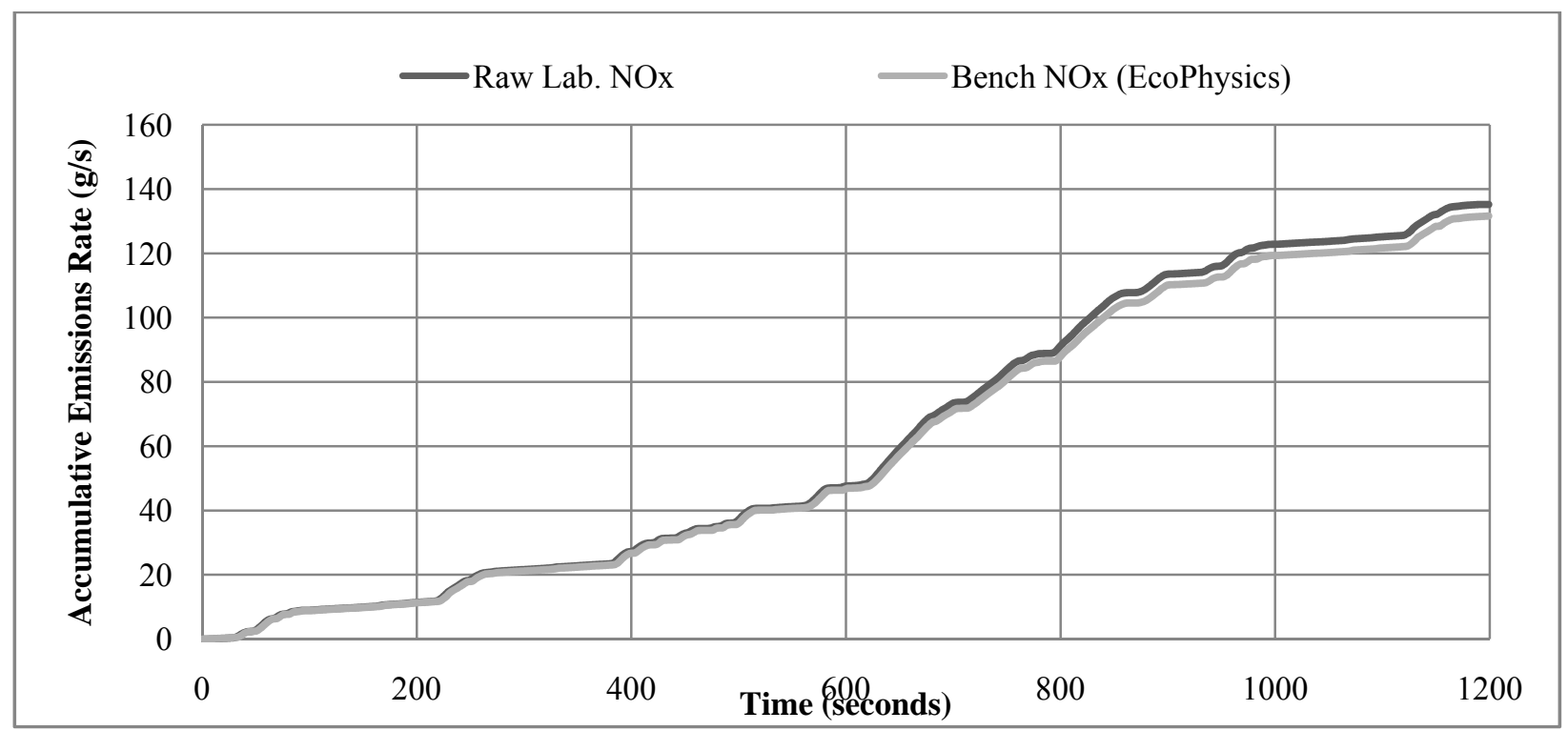

Figure 57: $\mathrm{NO}_{\mathrm{x}}$ System Summation, Run 2 


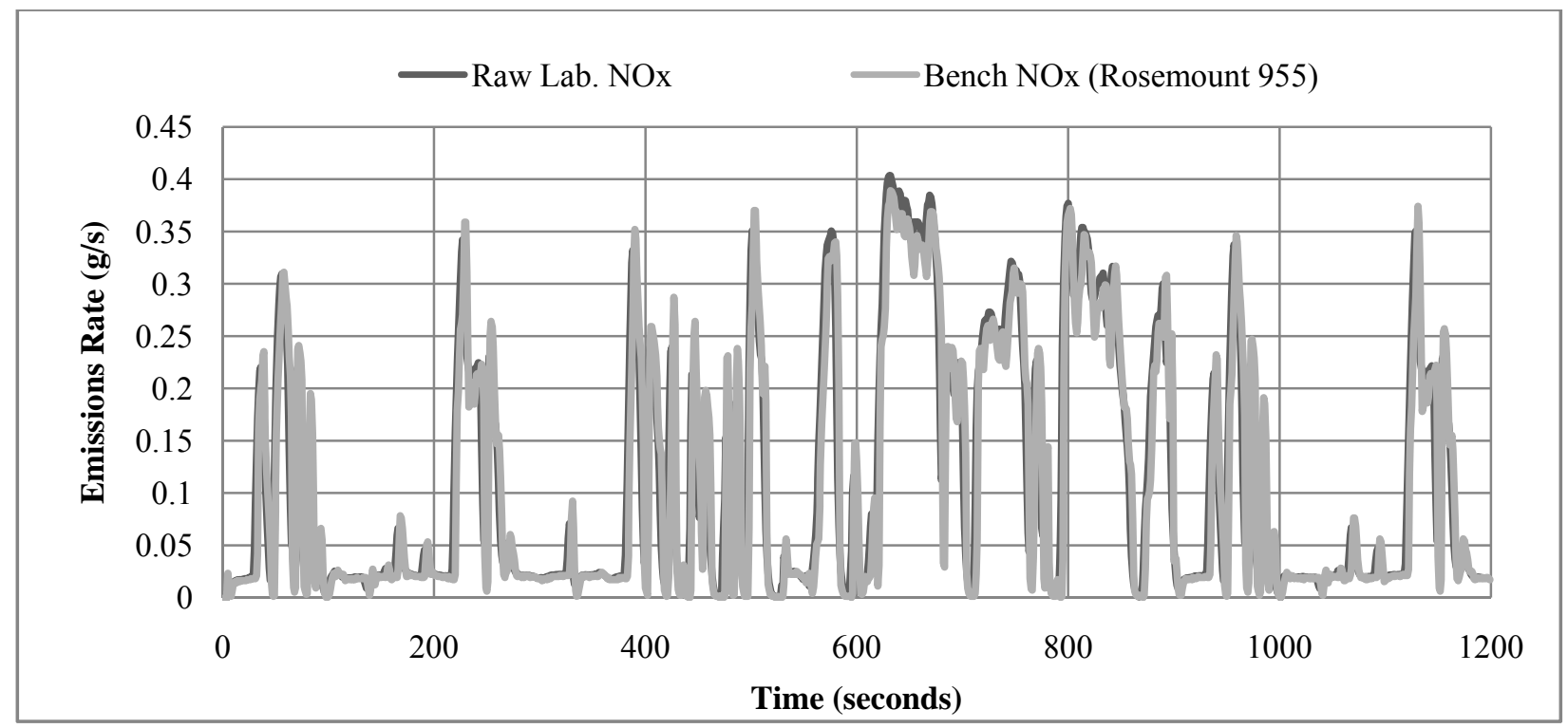

Figure 58: $\mathrm{NO}_{\mathrm{x}}$ System Comparison, Run 2

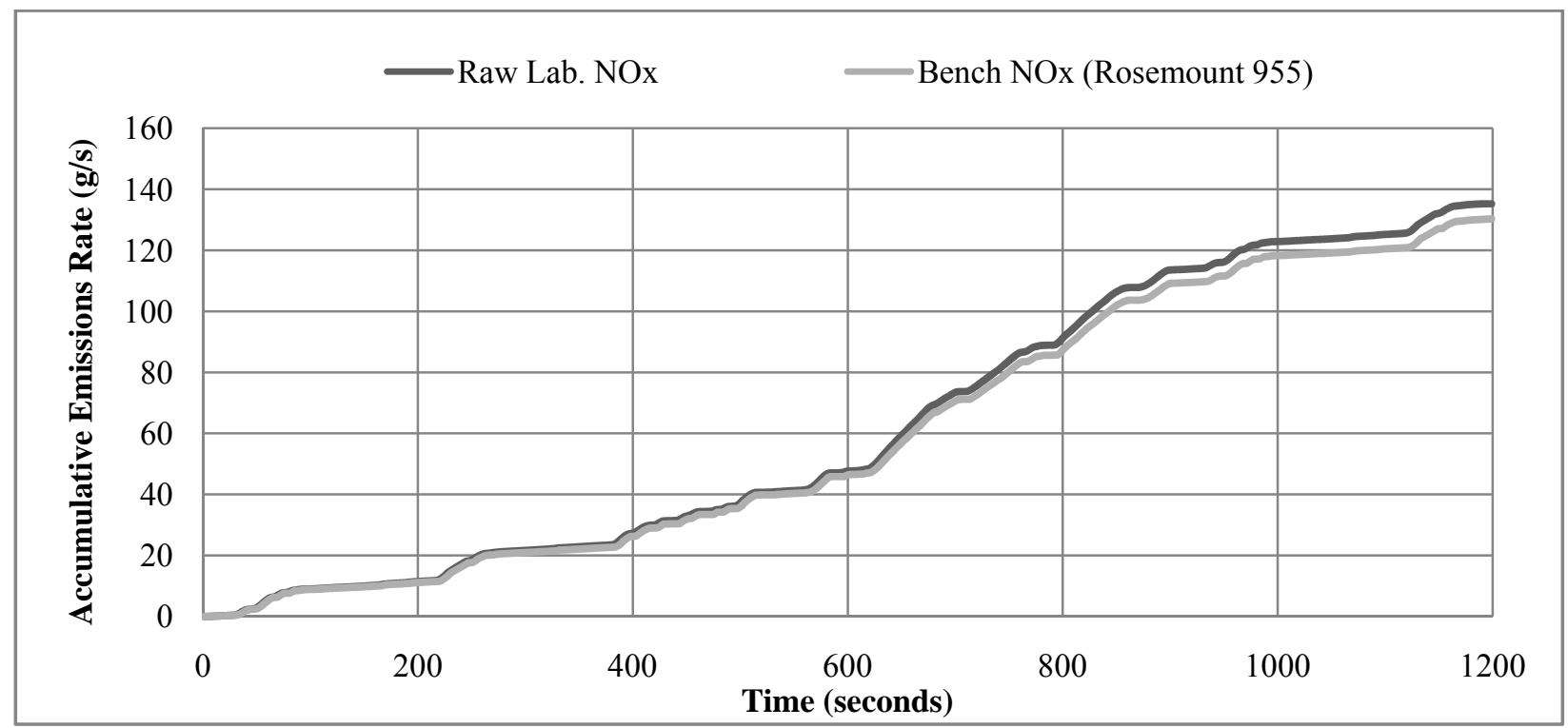

Figure 59: $\mathrm{NO}_{\mathrm{x}}$ System Summation, Run 2 
$\mathrm{NO}_{\mathrm{x}}$ Verification: FTP THREE

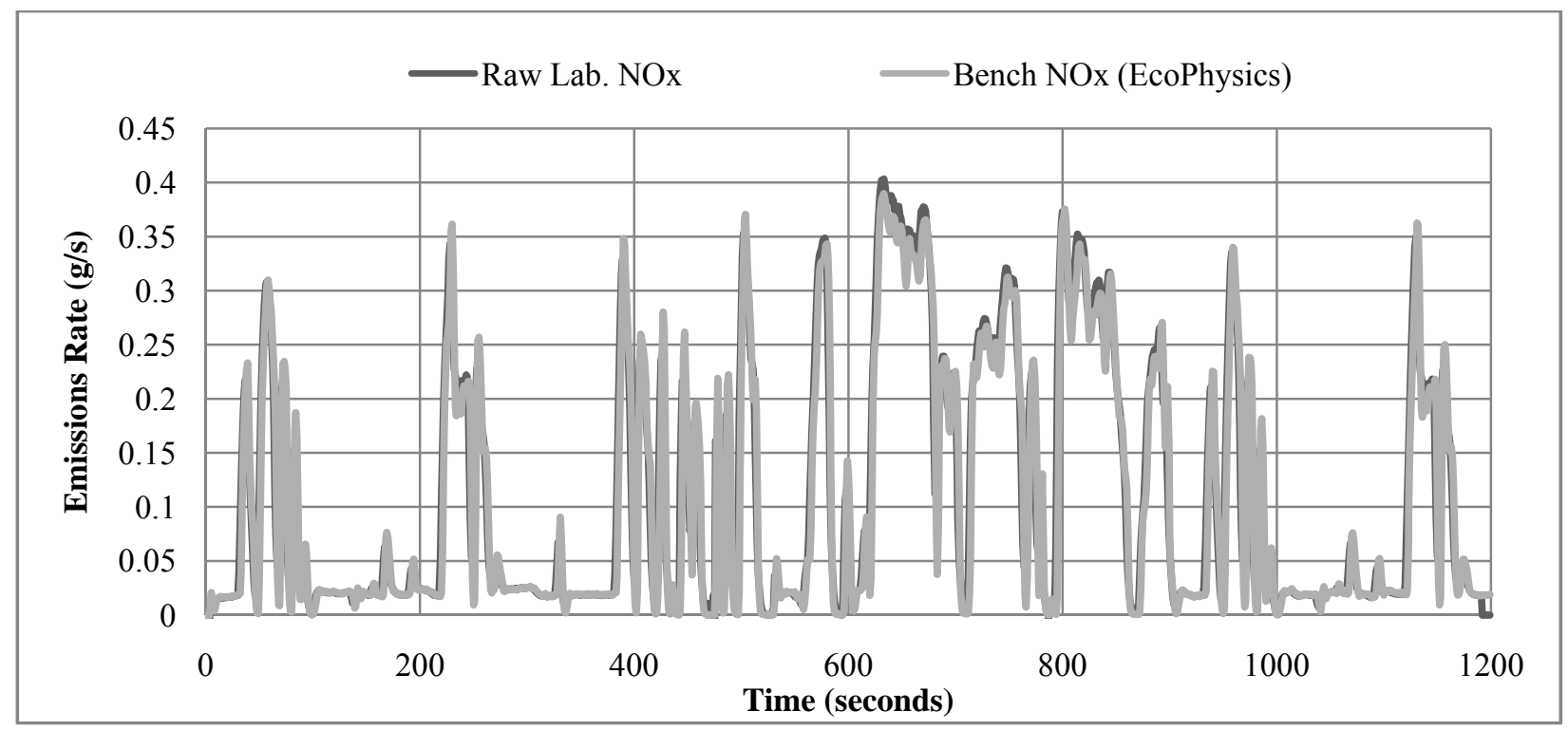

Figure 60: $\mathrm{NO}_{\mathrm{x}}$ System Comparison, Run 3

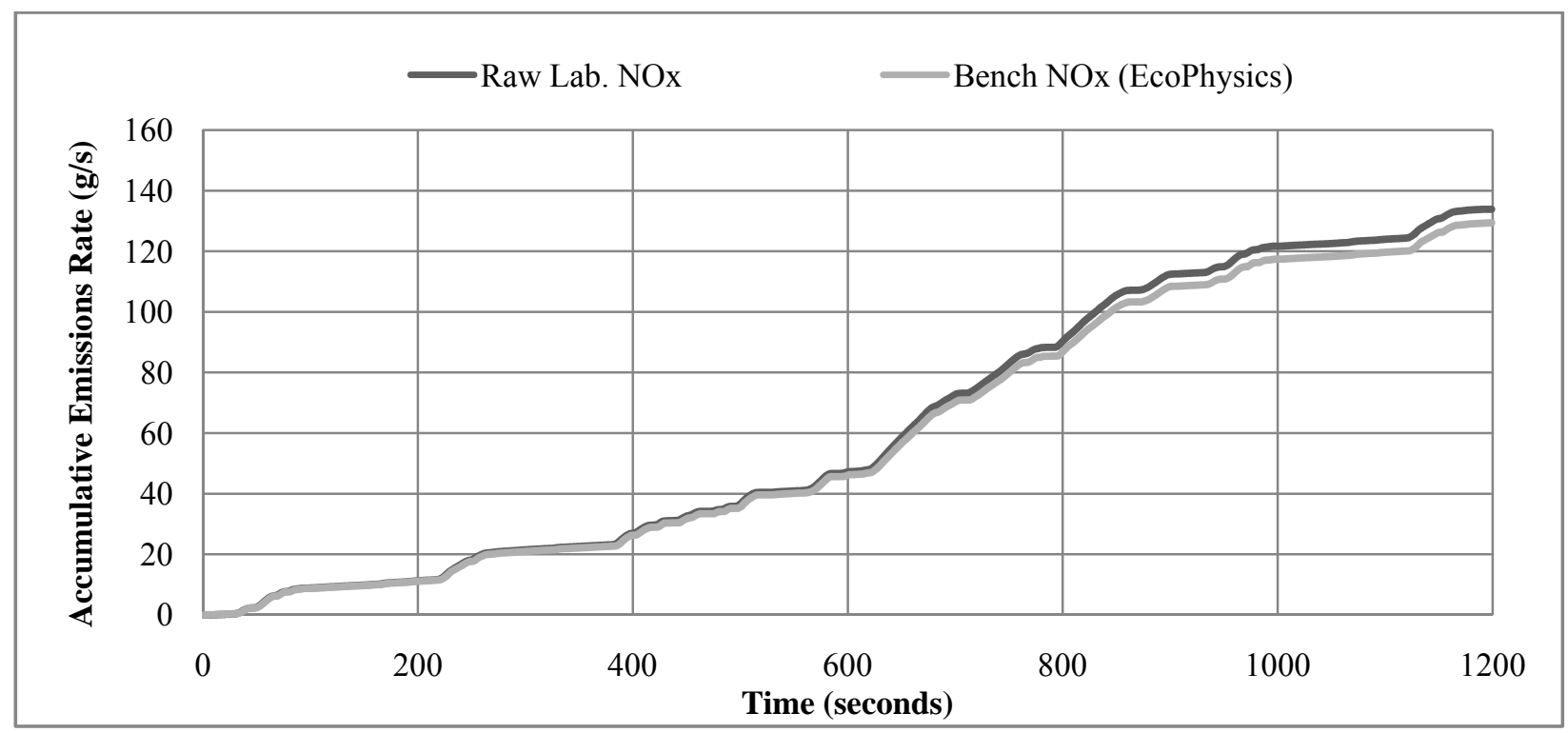

Figure 61: $\mathrm{NO}_{\mathrm{x}}$ System Summation, Run 3 


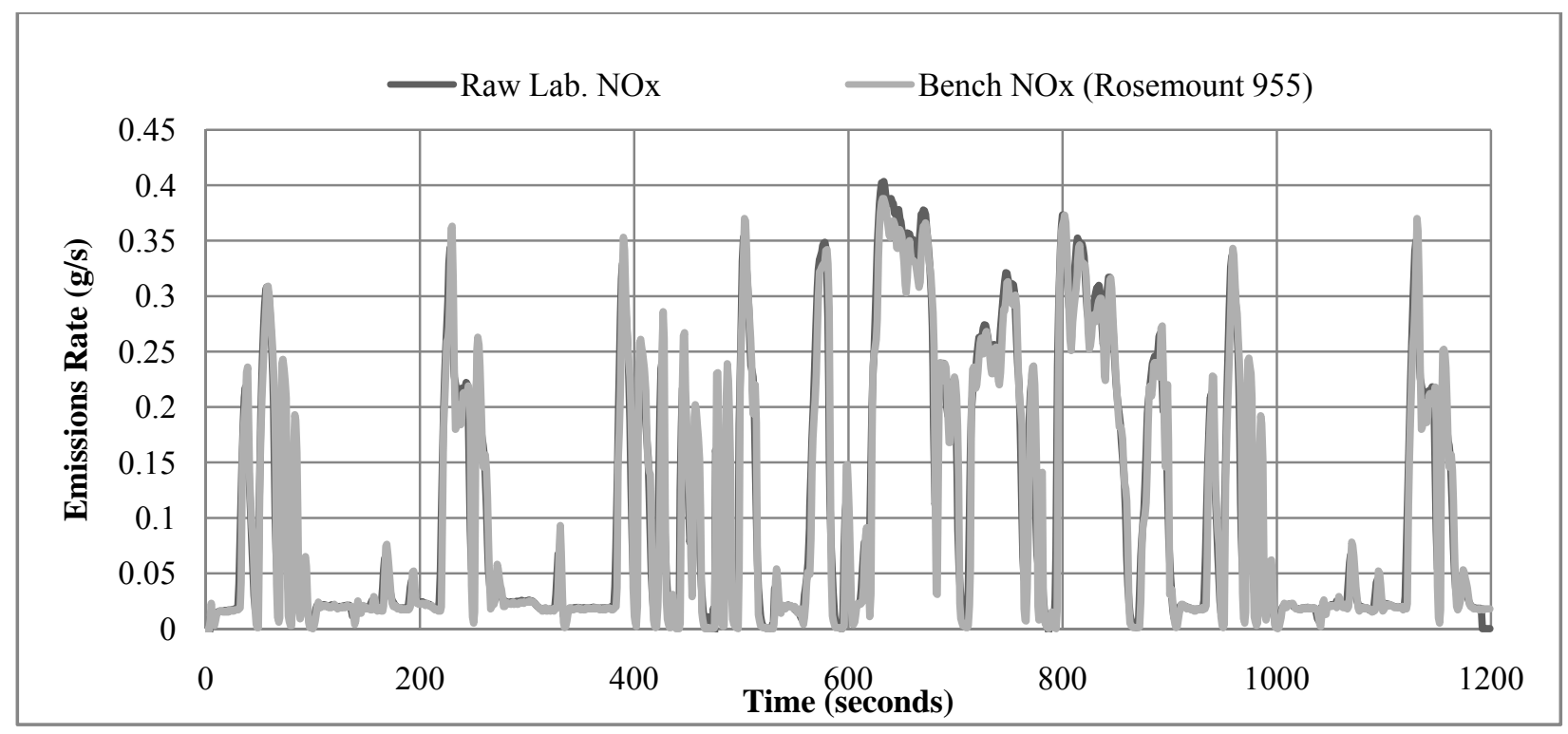

Figure 62: $\mathrm{NO}_{\mathrm{x}}$ System Comparison, Run 3

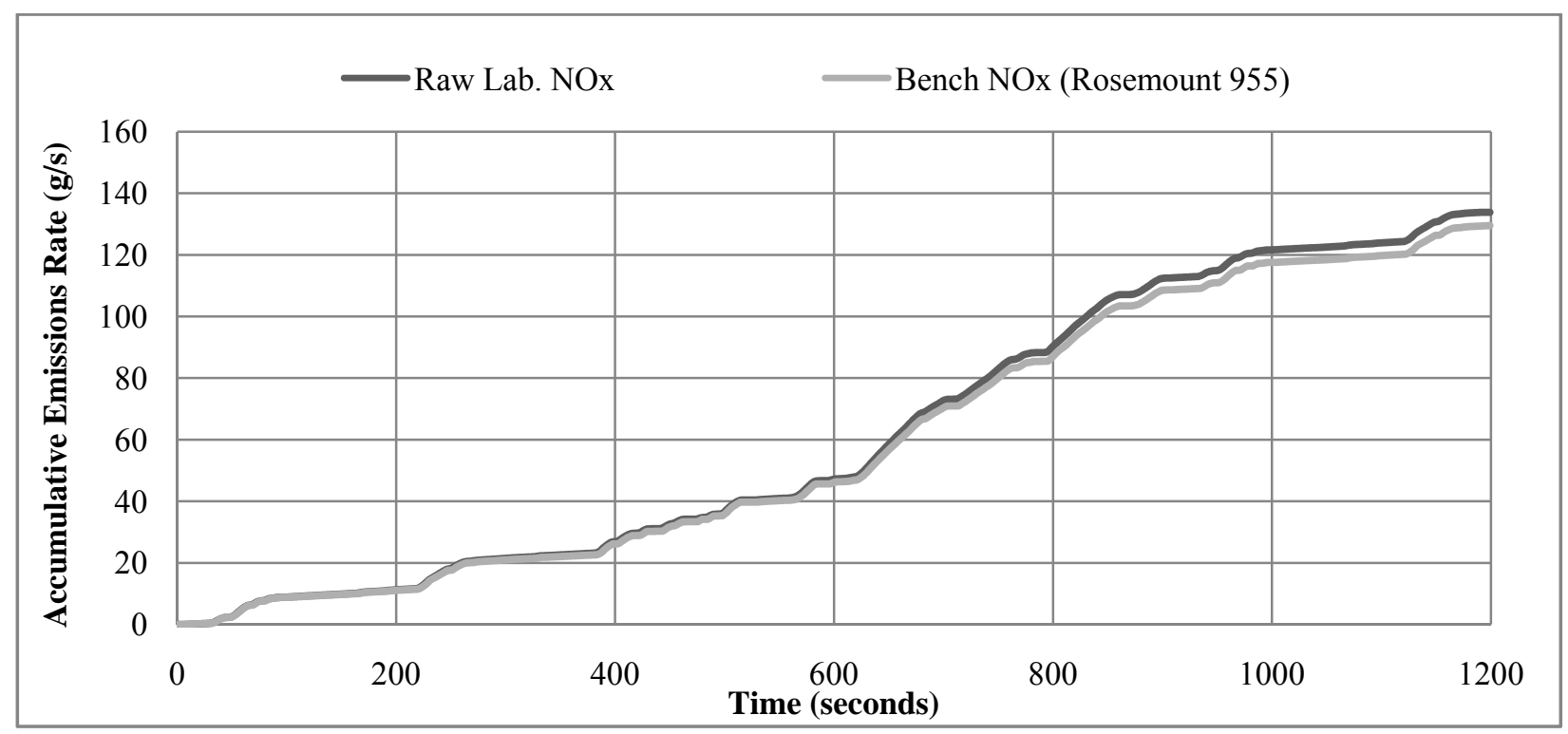

Figure 63: $\mathrm{NO}_{\mathrm{x}}$ System Summation, Run 3 
$\mathrm{CO}_{2}$ Verification: FTP One

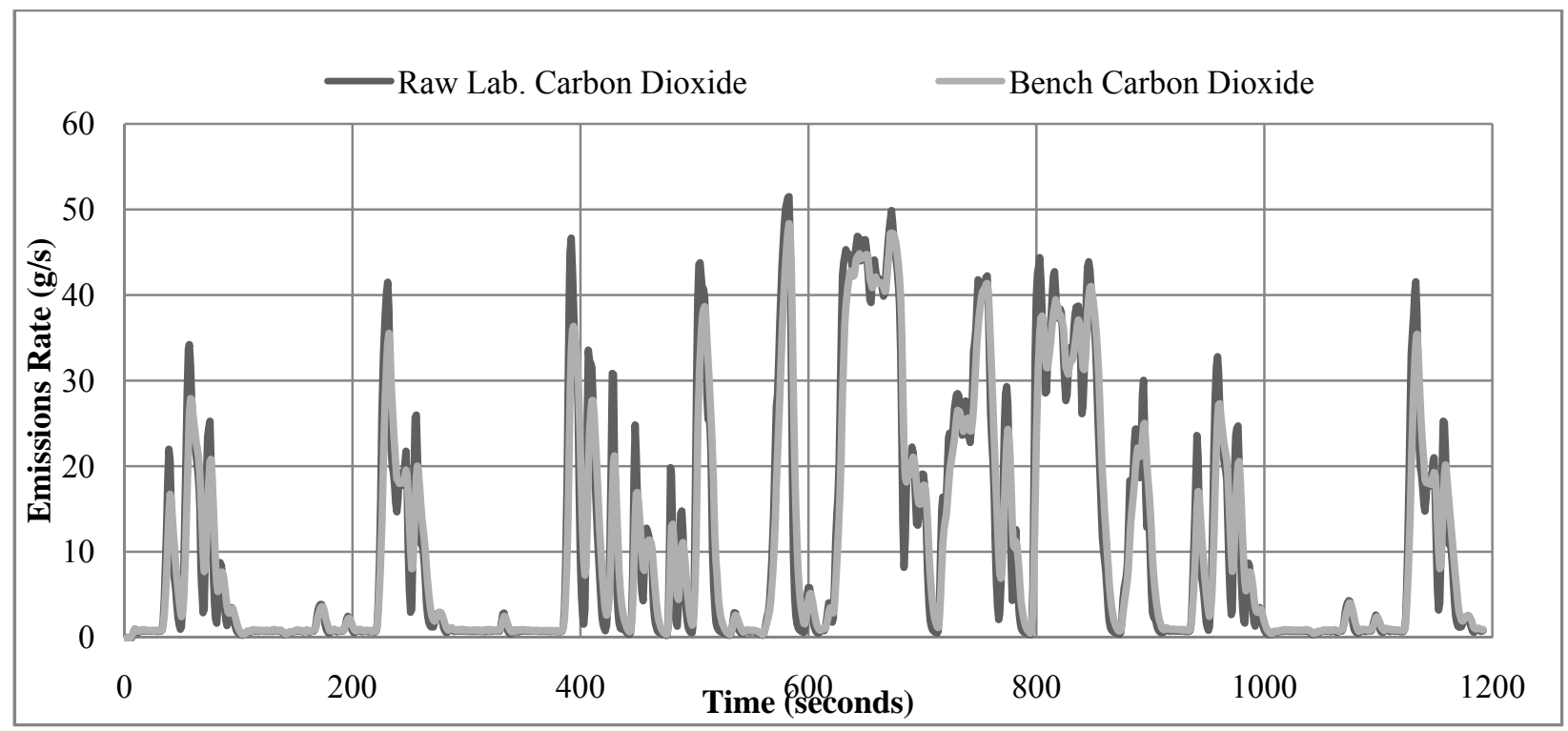

Figure 64: $\mathrm{CO}_{2}$ System Comparison, Run 1

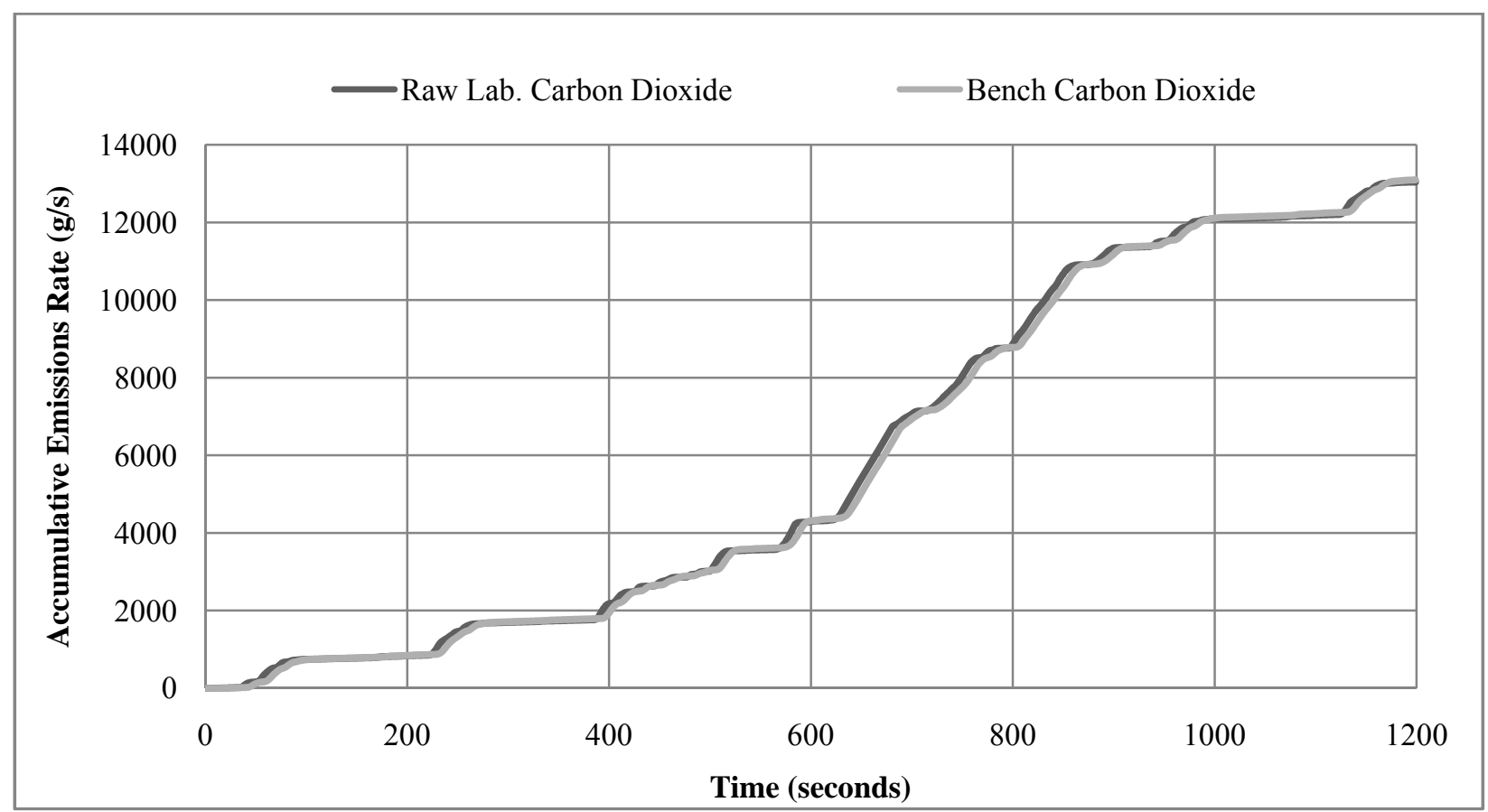

Figure 65: $\mathrm{CO}_{2}$ System Summation, Run 1 
$\mathrm{CO}_{2}$ Verification: FTP Two

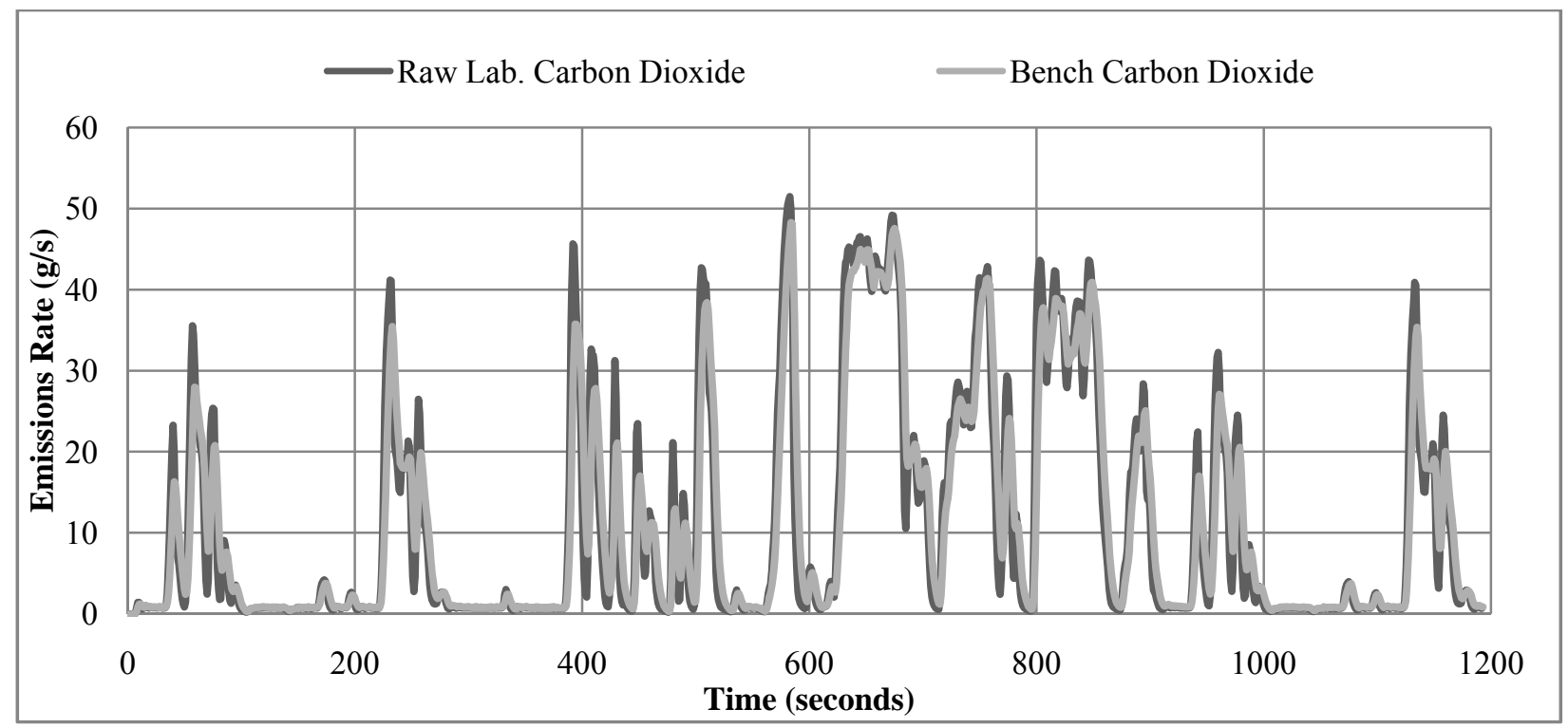

Figure 66: $\mathrm{CO}_{2}$ System Comparison, Run 2

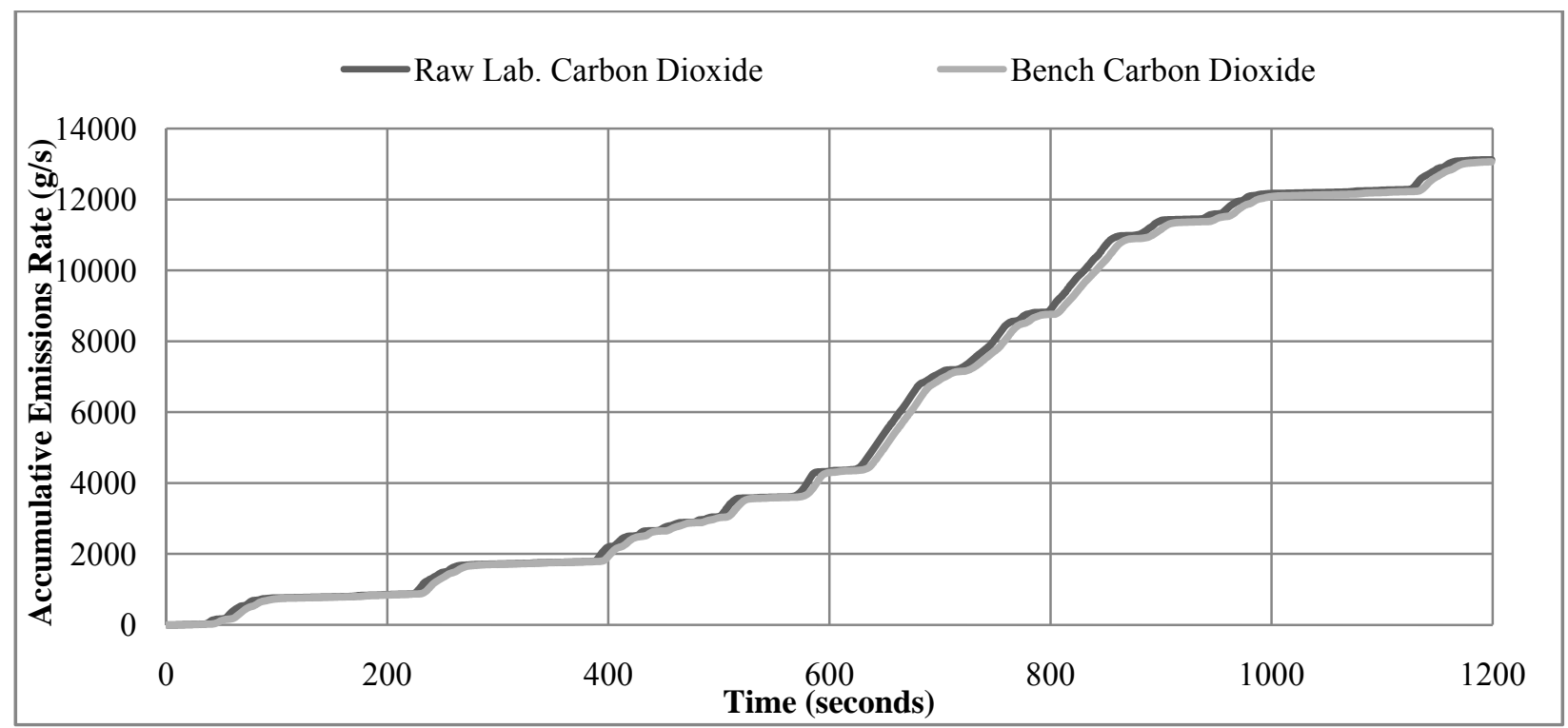

Figure 67: $\mathrm{CO}_{2}$ System Summation, Run 2 
$\mathrm{CO}_{2}$ Verification: FTP Three

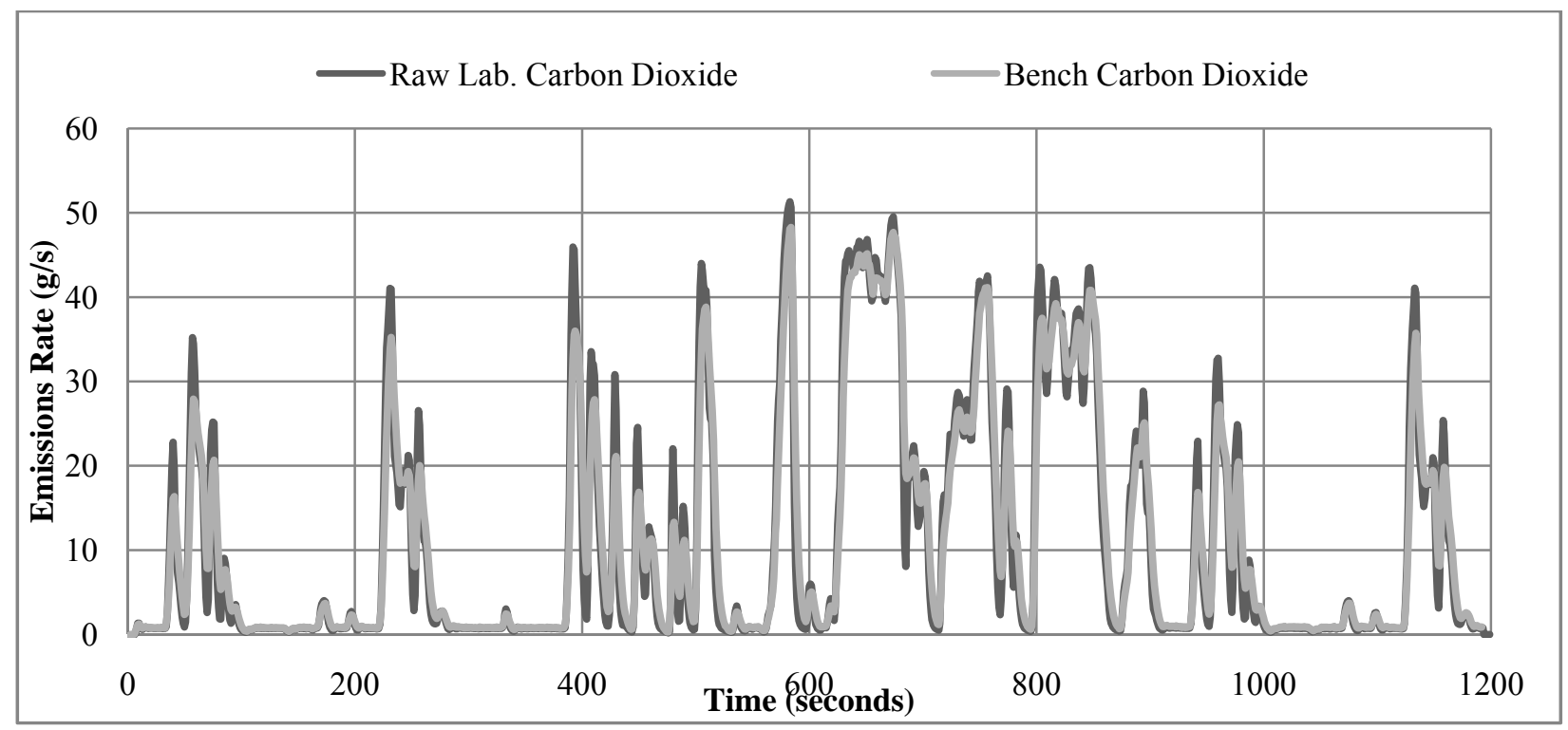

Figure 68: $\mathrm{CO}_{2}$ System Comparison, Run 3

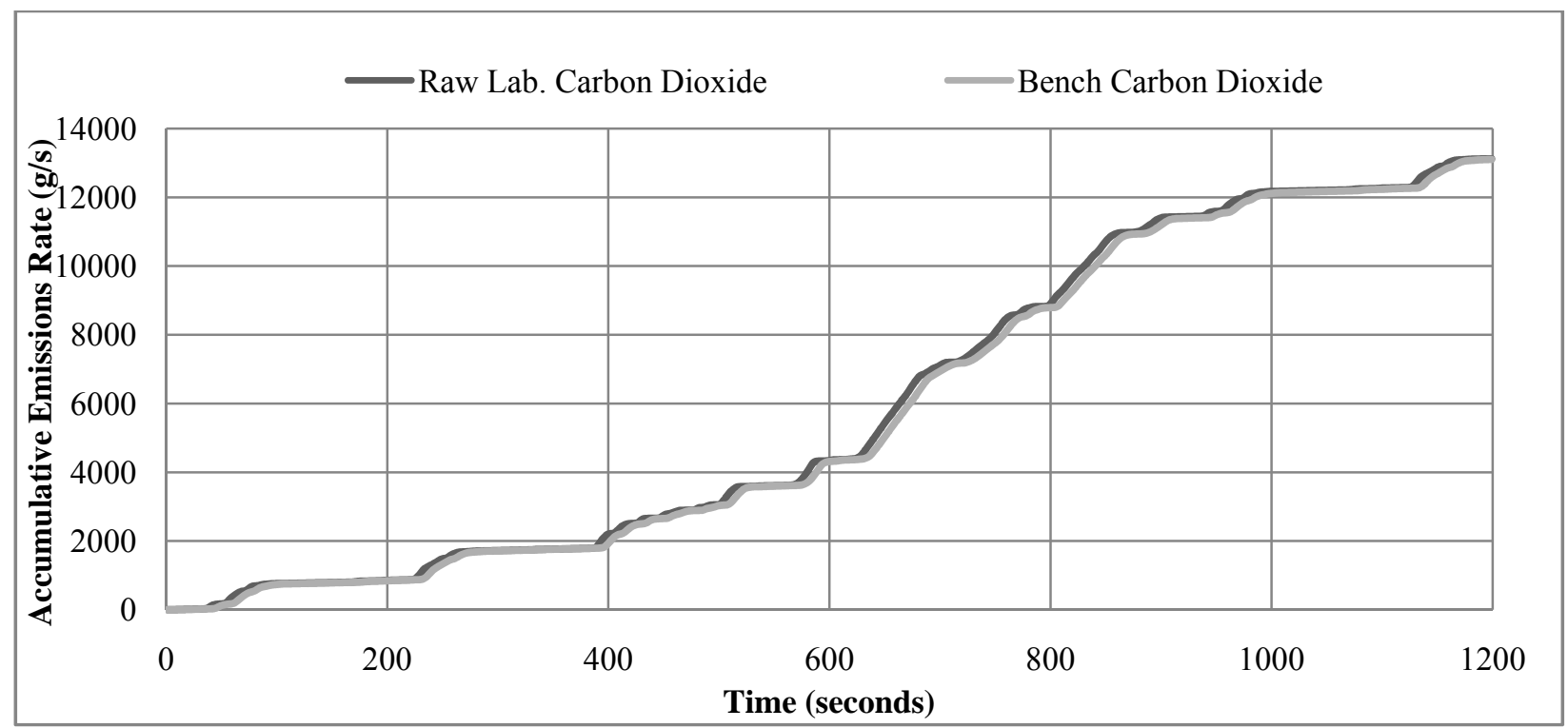

Figure 69: $\mathrm{CO}_{2}$ System Summation, Run 3 
CO Verification: FTP One

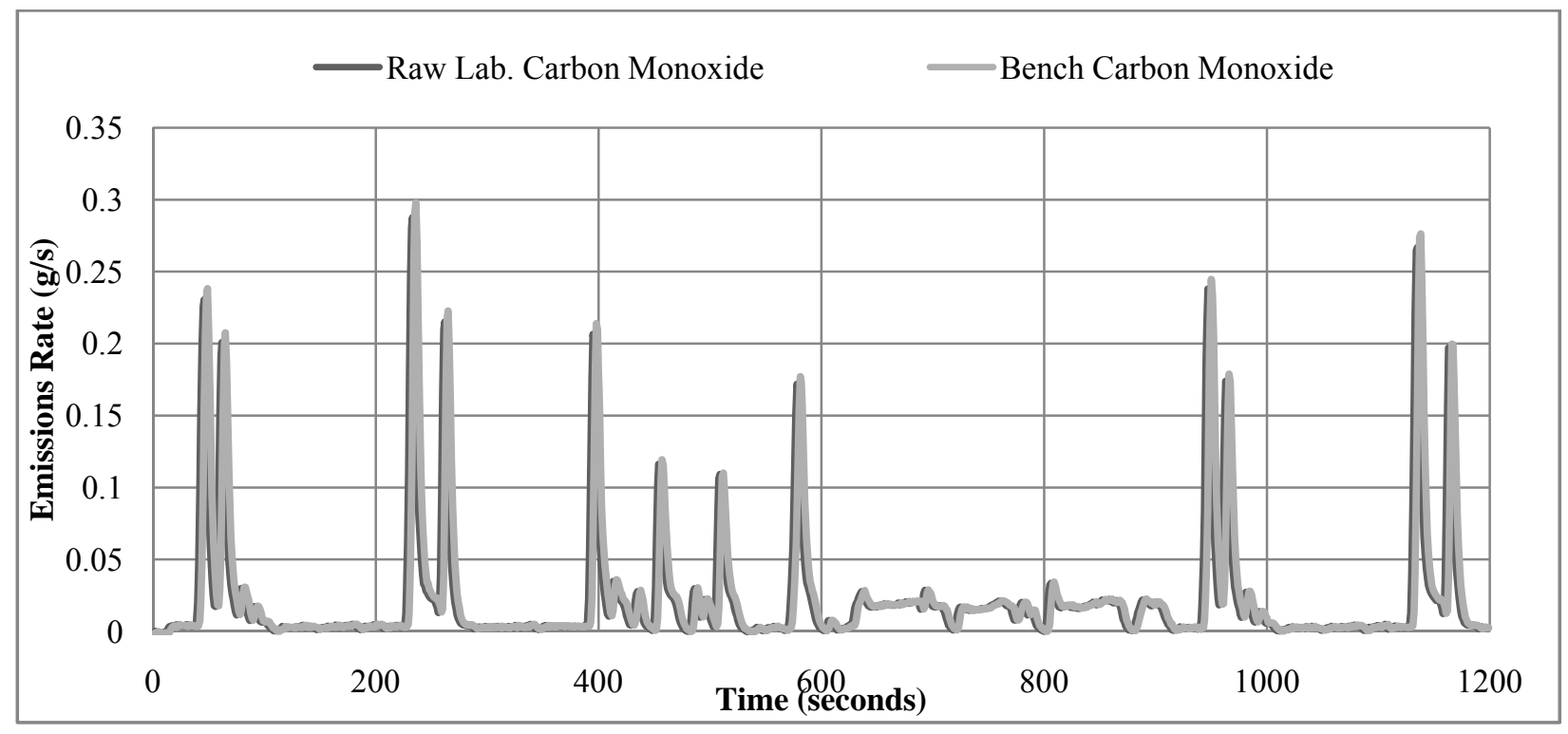

Figure 70: CO System Comparison, Run 1

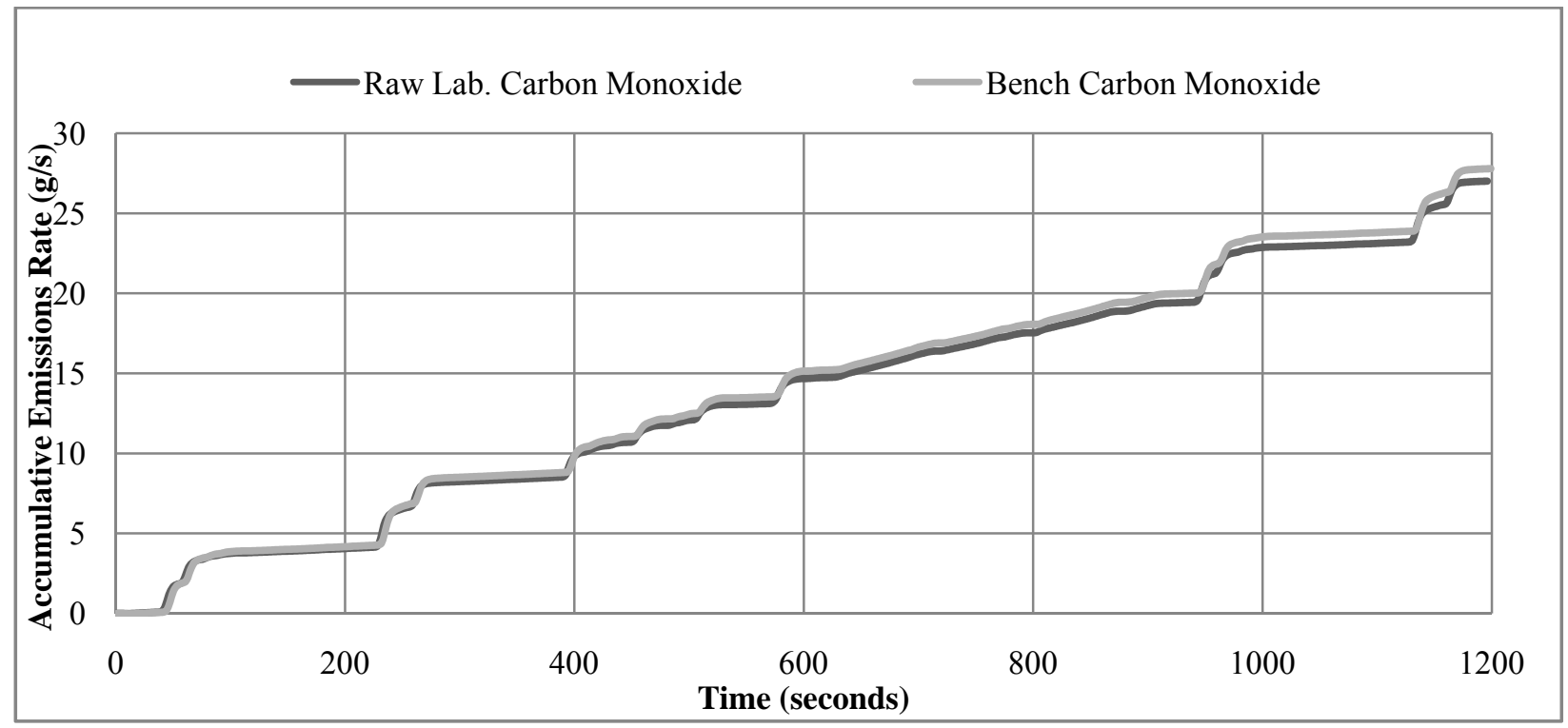

Figure 71: CO System Summation, Run 1 
CO Verification: FTP Two

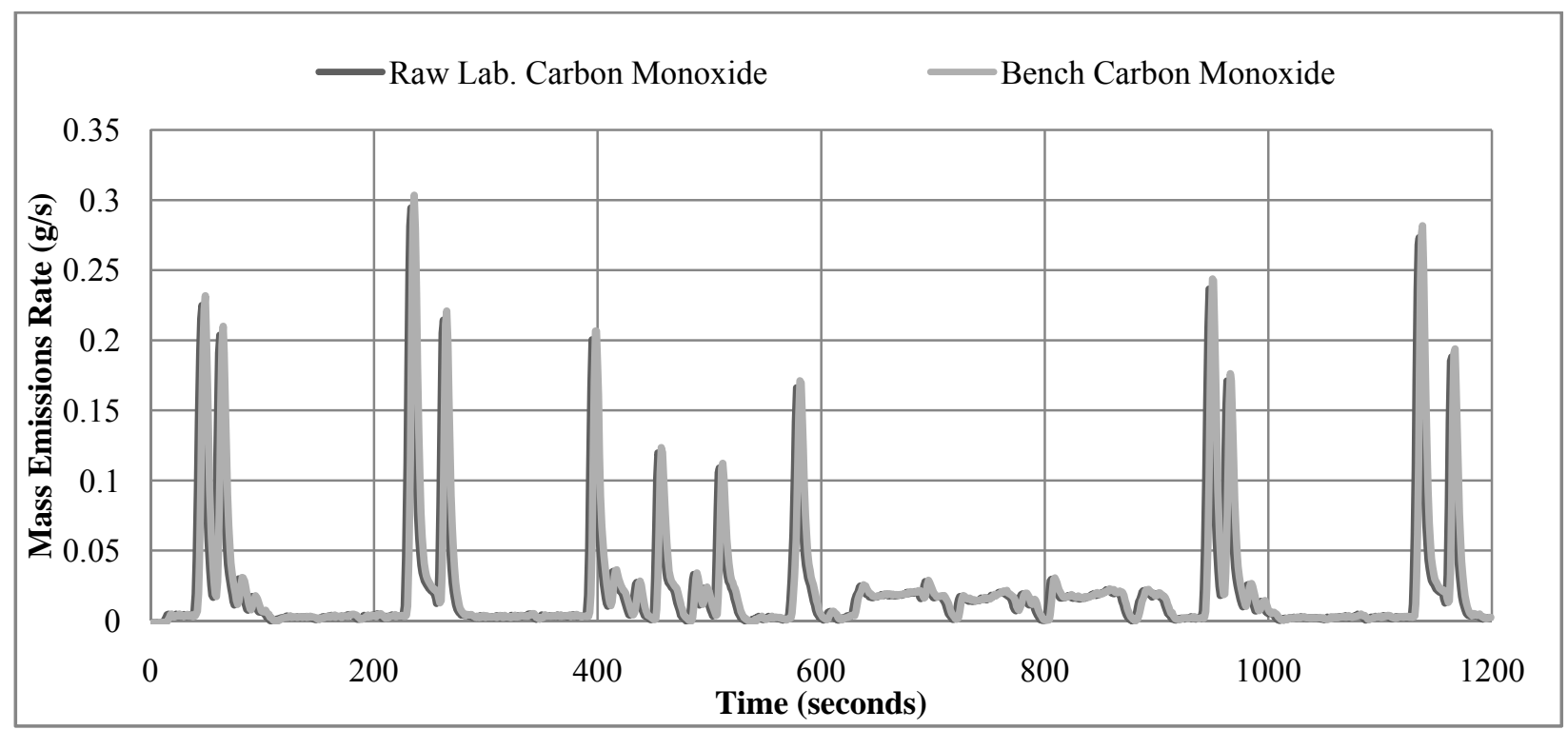

Figure 72: CO System Comparison, Run 2

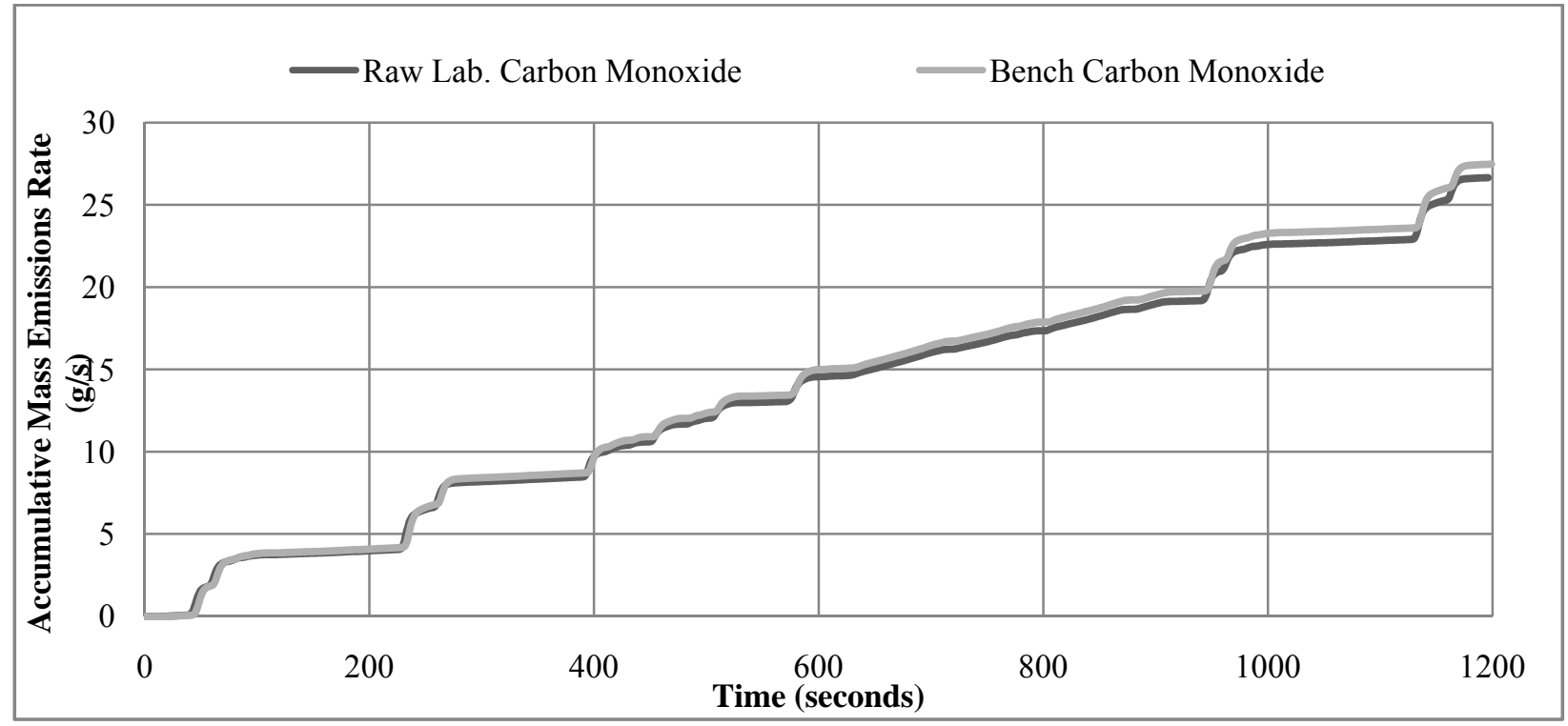

Figure 73: CO System Summation, Run 2 
CO Verification: FTP Three

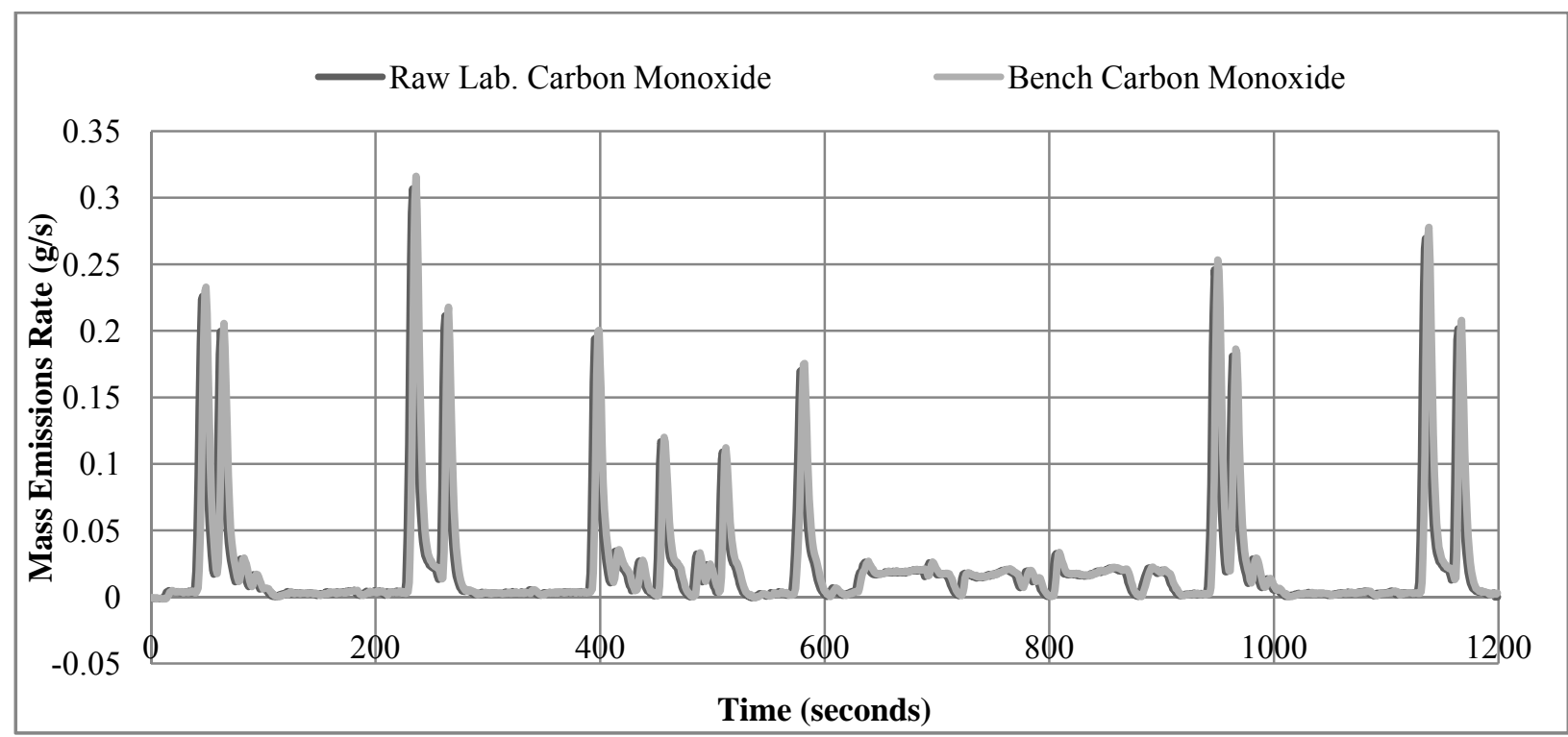

Figure 74: CO System Comparison, Run 3

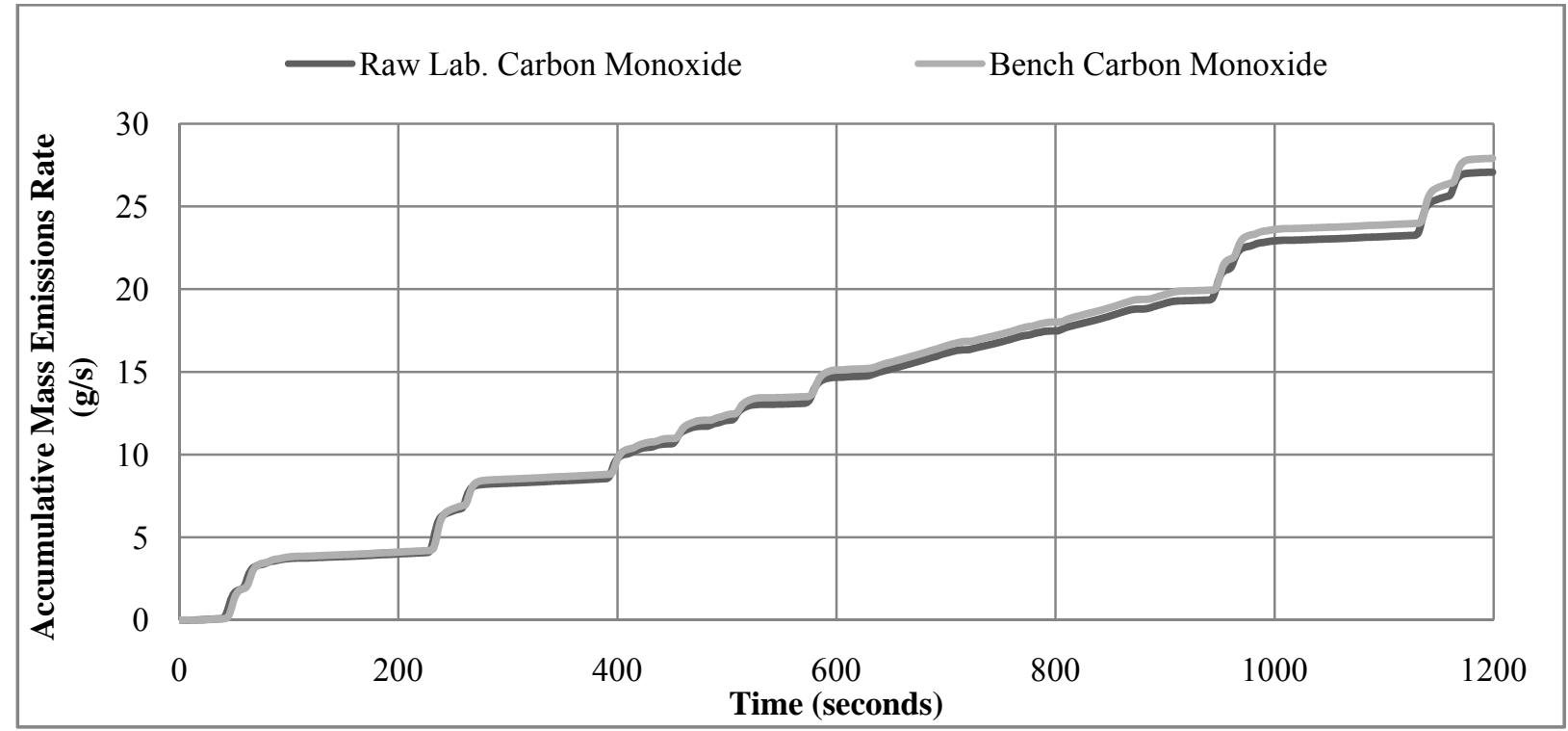

Figure 75: CO System Summation, Run 3 